\title{
Avances en la atención postaborto en América Latina y el Caribe: Investigando, aplicando y expandiendo
}

Deborah L. Billings

Ricardo Vernon

Follow this and additional works at: https://knowledgecommons.popcouncil.org/departments_sbsr-rh

Part of the Community-Based Research Commons, Gender and Sexuality Commons, International Public Health Commons, Maternal and Child Health Commons, Obstetrics and Gynecology Commons, Public Health Education and Promotion Commons, and the Women's Health Commons How does access to this work benefit you? Let us know!

\section{Recommended Citation}

Billings, Deborah L. and Ricardo Vernon (eds.). 2007. Avances en la atención postaborto en América Latina y el Caribe: Investigando, aplicando y expandiendo. Mexico City: Population Council and Ipas. 


\section{Avances en la atención posaborto en América Latina y el Caribe: Investigando, aplicando y expandiendo}

\section{Deborah L. Billings y Ricardo Vernon}

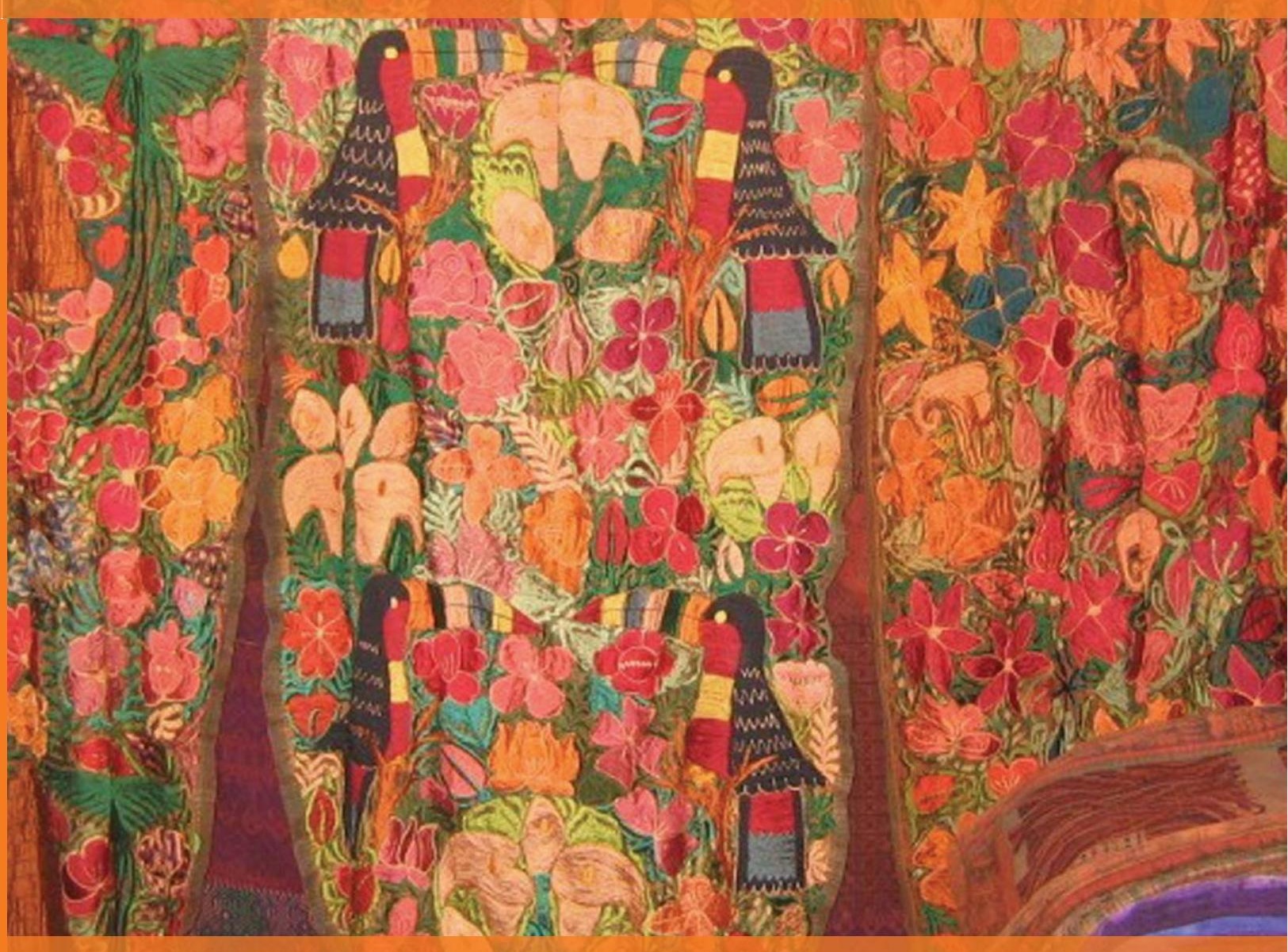


Avances en la atención posaborto en América Latina y el Caribe:

Investigando, aplicando y expandiendo 



\section{Avances en la atención posaborto en América Latina y el Caribe:}

Investigando, aplicando y expandiendo

Deborah L. Billings y Ricardo Vernon, editores, con la colaboración de Guillermina Herrera 
Avances en la atención posaborto en

América Latina y el Caribe:

Investigando, aplicando y expandiendo

D.R. (C) 2007 The Population Council, Inc.

ISBN: 978-968-9440-00-0

El Population Council hace investigación en todo el mundo para mejorar las políticas, programas y productos en tres áreas: VIH y SIDA; pobreza, género y juventud, y salud reproductiva.

Population Council

One Dag Hammarskjold Plaza

Nueva York, N.Y. 10017

E.U.A.

Tel. (212) 339-0500

www.popcouncil.org
Population Council

Escondida 110, Col. Villa Coyoacán

04000 México, D.F.

México

Tel. (52-55) 5999-8630

Ipas trabaja a nivel mundial para aumentar la capacidad de las mujeres de ejercer sus derechos sexuales y reproductivos y disminuir el número de muertes y lesiones relacionadas con el aborto. Nos esforzamos por ampliar la disponibilidad, calidad y sostenibilidad de los servicios de aborto y de otros servicios de salud reproductiva relacionados, e igualmente para mejorar el ambiente político para defender los derechos sexuales y reproductivos de las mujeres. En Ipas creemos que ninguna mujer debería verse obligada a arriesgar su vida o su salud por carecer de opciones seguras de salud reproductiva.

Ipas

P.O.Box 5027

Chapel Hill, N.C. 27514

E.U.A.

Tel. (919) 967-7052

www.ipas.org

Esta publicación fue posible gracias a los fondos proporcionados al Population Council por la Unión Europea a través del proyecto MEX/B7-6310/98/0578, a los recursos que Ipas facilitó, y a los fondos adicionales que proporcionaron dos donantes anónimos (a través del Programa de Salud Reproductiva del Population Council), que permitieron su impresión y distribución. Deborah L. Billings reconoce el apoyo de Ipas que le permitió dedicar tiempo a la elaboración de esta obra; igualmente, Ricardo Vernon agradece a la USAID su apoyo a través del Programa Fronteras de la Salud Reproductiva (Acuerdo de Cooperación HRN-A-00-98-00012-00) que hizo posible que dedicara tiempo para preparar este libro.

Cualquier parte de esta publicación puede reproducirse sin autorización previa siempre y cuando su distribución sea limitada y gratuita y se reconozca al Population Council como su fuente. El Population Council agradecerá recibir una copia de cualquier material en donde se use el texto.

Impreso en México.

\section{(2) Population Council}

Fotografia de portada: Ma. Antonieta Martin Diseño de portada: Christina Tse. 


\section{Contenido}

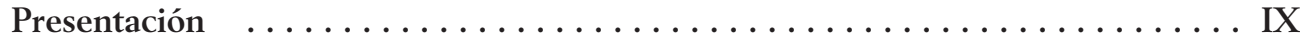

\section{SECCIÓN I PANORAMA GENERAL}

Capítulo 1. Elementos esenciales de la atención posaborto: un modelo ampliado y actualizado ..................... 3 Comisión Especial de Comunidad del Consorcio APA

Capítulo 2. Atención posaborto en América Latina: recomendaciones para políticas y servicios al cabo de un decenio de investigación operativa

Deborah L. Billings y Janie Benson

\section{SECCIÓN ॥ \\ EXPERIENCIAS DE PAÍSES}

Capítulo 3. La experiencia en Bolivia de la atención posaborto . . . . . . . . 27 Eliana del Pozo, Malena Morales, José del Barco y Carmen Cornejo

Capítulo 4. Calidad de la prestación del servicio en la atención posaborto en

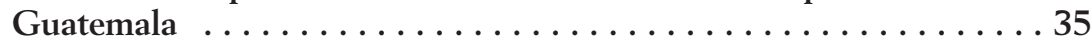
Edgar Kestler, Linda Valencia, Vinicio del Valle y Alejandro Silva

Capítulo 5. Atención posaborto en Honduras ................41 Ruth Maria Medina y Ricardo Vernon 
Capítulo 6. Atención posaborto: la experiencia de México en el mejoramiento de los servicios . ......................4 47

Deborah L. Billings, Deyanira González de León, Rubén Ramírez y M. Virginia Chambers

Capítulo 7. Vinculación de la atención posaborto y los servicios de anticoncepción en Nicaragua .................. 57

Estela Rivero-Fuentes, Ricardo Vernon, Freddy Solis, Adilia Gadea y Ana del Carmen Rojas

Capítulo 8. Calidad y acceso a la atención posaborto en Perú .......... 65 Janie Benson y Victor Huapaya

Capítulo 9. Calidad de la consejería durante la atención posaborto en República Dominicana ...................... 75 Estela Rivero-Fuentes, Marija Miric, Ricardo Vernon Gisela Quiterio y Maritza Molina

\section{SECCIÓN III PROVEEDORES Y COMPONENTES PROGRAMÁTICOS}

Capítulo 10. Función de la enfermera en la atención de mujeres en situación de aborto ............................ 85 Ma. Dolores Sotelo

Capítulo 11. Consejería en la atención a mujeres en situación de aborto . . . . 87 Ma. Dolores Sotelo, Nadine Gasman, Rubén Ramírez y Ma. Elena Collado

Capítulo 12. Observación de pares como una técnica de capacitación a proveedores en complicaciones hemorrágicas de la primera mitad del embarazo .................... José del Barco y Franz Calani

\section{SECCIÓN IV \\ ATENCIÓN CLÍNICA CON TECNOLOGÍAS DIVERSAS}

Capítulo 13. Métodos de evacuación endouterina en la atención posaborto . . . 101 Jeanine Herrick, Catherine Turner, Teresa McInerney y Laura Castleman

Capítulo 14. Manejo del dolor en la atención posaborto ............ 111 Daniel Grossman y Claudia Díaz Olavarrieta

Capítulo 15. Misoprostol en el tratamiento de aborto incompleto 


\section{SECCIÓN $V$ HOMBRES, JUVENTUD Y COMUNIDAD}

Capítulo 16. Participación de la pareja masculina en el proceso de atención posaborto

Deborah L. Billings y Eliana del Pozo

Capítulo 17. Guía técnica sobre APA amigable a la juventud 137

Consorcio Atención Postaborto

Capítulo 18. Adolescentes pacientes de atención posaborto en República Dominicana: sus necesidades y experiencias ............ 149

Brigida García Romero, Inés Escandón y José Figueroa

Capítulo 19. Percepciones comunitarias del aborto y de la atención a sus complicaciones 151 Fernando González, Ricardo Vernon, Claudia de la Quintana, Cecilia Cossío y José del Barco

Capítulo 20. Empoderamiento de la comunidad para mejorar la salud sexual y reproductiva y la atención posaborto en Bolivia .......... 161 Carmen Monasterios O, Rocío Lara Palma y Carolyn Curtis

Anexo

Organizaciones con trabajo en el tema de atención posaborto $\ldots \ldots \ldots \ldots \ldots 7$

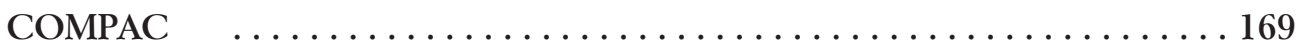

Índice 



\section{Presentación}

El aborto inducido está penado en casi todos los países de América Latina y el Caribe, salvo en circunstancias excepcionales. La Organización Mundial de la Salud (OMS) estima que en esta región cada año se practican alrededor de 3.7 millones de abortos en condiciones inseguras; es decir, alrededor de 29 abortos por cada 1000 mujeres en edad reproductiva, o casi un aborto por cada tres nacidos vivos, un nivel considerablemente más alto que el que se observa en otras regiones. Como consecuencia, en la región mueren cada año cerca de 3700 mujeres por abortos inseguros, y por cada muerte, muchas más mujeres sufren daños e incapacidades que requieren tratamientos médicos de urgencia. Cabe agregar que estas cifras muy probablemente subestiman la magnitud del problema de salud pública, pues tienden a excluir a las mujeres que no acuden a los servicios de salud y a una proporción importante de aquéllas cuya atención no queda registrada. Se sabe también que más de una décima parte de los embarazos terminan en abortos espontáneos, muchos de los cuales requieren ser atendidos para evitar secuelas importantes.

Desde hace muchos años, los sistemas de salud habían atendido las urgencias clínicas de las mujeres que llegaban a sus unidades con un aborto incompleto o complicado mediante el legrado uterino instrumental (LUI); sin embargo, en la Conferencia Internacional sobre la Población y el Desarrollo (CIPD, Cairo, 1994), numerosas organizaciones internacionales propugnaron porque se brindara a las mujeres un paquete integral de servicios de atención posaborto (APA), que incluyera información para ayudar a la mujer a atender sus necesidades de salud, servicios complementarios de anticoncepción y, cuando fuera posible, el uso de la aspiración manual endouterina (AMEU) como técnica de evacuación endouterina. Este llamado se hizo atendiendo a las experiencias que mostraban que de esta manera se lograría disminuir tanto las secuelas negativas para las mujeres como de manera considerable los costos de la atención a tal tipo de casos.

En esta obra tratamos de documentar el esfuerzo intelectual, financiero y gerencial que han hecho numerosas organizaciones e instituciones de América Latina y el Caribe para alcanzar el objetivo de mejorar la calidad y eficacia de los servicios de APA.

En la primera sección presentamos una descripción detallada de lo que hoy en día se entiende como el modelo completo de APA, que amplía el concepto agregando a los tres componentes originales antes mencionados los de la preparación de las comunidades para enfrentar el reto de los abortos inseguros y la atención a otras necesidades de 
salud reproductiva. En la misma sección ofrecemos el resumen de algunas investigaciones operativas alusivas hechas en nuestra región y que nos permiten distinguir claramente que los beneficios de reorganizar los servicios para prestarlos de forma integral incluyen un aumento en la proporción de mujeres que adoptan un método anticonceptivo, un trato más digno y respetuoso hacia ellas, mayor información a las pacientes para permitirles proteger su salud en los días siguientes al procedimiento y, con frecuencia, costos de atención más bajos por paciente, sobre todo cuando el servicio se presta de manera ambulatoria o se reduce el tiempo de la estancia hospitalaria, independientemente de la técnica quirúrgica empleada.

La segunda sección del volumen se refiere a las experiencias de siete países de la región en la implementación del modelo de APA. Estas experiencias muestran que en casi todos los países el proceso de introducir servicios integrales de APA tomó entre 5 y 15 años de arduo trabajo, que incluyó primero la sensibilización de los directivos y prestadores de servicios en torno al aborto como un problema importante de salud pública, y la implementación de investigaciones operativas o pruebas piloto del modelo de atención para que las instituciones pudieran observar en detalle los requerimientos para establecer los servicios y beneficios que podrían derivarse de ellos. En todos los casos, estas actividades llevaron a la aprobación de normas técnicas oficiales para la prestación de servicios de APA, un evento crítico que más tarde permitió expandir los servicios. Los artículos de experiencias nacionales permiten, asimismo, distinguir decisiones que los gerentes de los programas de salud tuvieron que tomar, y algunos retos especiales que los programas han tenido que enfrentar. Por ejemplo:

- Varios países desarrollaron los modelos de APA como un componente independiente, mientras que otros lo hicieron en el contexto de modelos de atención posevento obstétrico que prestan igualmente servicios integrales a las mujeres que tienen un parto o una cesárea en el hospital. En ambos casos los modelos son viables.

- A pesar de que la OMS y otras organizaciones, - como la Federación Internacional de Ginecología y Obstetricia (FIGO) - , recomiendan el uso de la AMEU, y considerando también los beneficios y ventajas comparativas que esta técnica tiene sobre el legrado, su adopción ha sido mucho más lenta y complicada de lo que podría suponerse. Algunos programas han implantado los modelos de APA sin cambiar la técnica de evacuación uterina, o bien la han introducido en una segunda etapa; mientras tanto, prácticamente todos los programas que usan la AMEU utilizan también de manera rutinaria el legrado.

- Los artículos apenas mencionan las dificultades de prestar el servicio de APA en contextos donde el aborto inducido es ilegal, lo que hace difícil distinguir a las mujeres que tuvieron un aborto inducido de las que tuvieron un aborto espontáneo y, por tanto, proporcionar la asesoría que cada tipo de mujer requiere.

- Los diagnósticos de servicios de APA que se han hecho recientemente en varios países muestran que, aunque es mucho lo que se ha avanzado, aún existe un gran número de oportunidades de mejoramiento que deberán aprovecharse en el futuro.

La tercera sección del libro se enfoca en los procesos de asesoría, y recuerda la importancia de ajustar el servicio a las circunstancias de las mujeres y a sus necesidades de información. Se revisa también la función crítica que las enfermeras tienen en la pres- 
tación de servicios integrales de APA, así como una experiencia de uso de la técnica de observación de pares (colegas prestadores de servicios que se observan entre sí en cuanto a la forma en que brindan los servicios) en los procesos de capacitación en APA del personal en hospitales.

La cuarta sección se enfoca en la atención clínica a pacientes de APA. Se analizan las técnicas de evacuación endouterina, así como las de manejo del dolor y del uso de misoprostol para atender a mujeres con abortos incompletos y en curso. Es posible que los dos últimos artículos resulten más novedosos para la mayoría de los lectores y que contribuyan más específicamente al mejoramiento de la calidad de los servicios. El primero analiza el concepto del dolor, la manera como se le puede medir y los diferentes métodos de control de dolor disponibles, incluyendo los no farmacológicos, así como las ventajas y desventajas de cada uno de ellos. Los dos siguientes presentan las indicaciones, contraindicaciones, efectos secundarios y modo de uso del misoprostol para atender a mujeres con abortos incompletos, lo que puede tener implicaciones en términos de la reducción de costos y de riesgos para las pacientes, y del aumento del confort y de la calidad de atención.

La última sección ofrece las reflexiones y experiencias de programas que han buscado adoptar los servicios de APA para atender a mujeres adolescentes y para incrementar la participación de los hombres y las comunidades en la prevención y atención de las consecuencias de abortos en curso y complicados.

Más allá de lo positivo que resultan estos avances, cabría señalar algunos de los retos pendientes que los programas aún deben enfrentar, como la vinculación de los servicios de APA con otros servicios de salud reproductiva, sostenimiento a largo plazo de los programas, fortalecimiento de las actividades de consejería a pacientes, inclusión de la APA en la currícula de capacitación previa al servicio de los estudiantes de medicina, enfermería y obstetricia, y la inclusión de instrumentos de AMEU en los sistemas de adquisiciones de las unidades de salud, que redundarían en un mejor acceso a, y calidad de la APA y, por tanto, en la reducción de la mortalidad y morbilidad derivadas de los abortos inseguros.

Esperamos que este volumen sea una aportación a la preparación de los directores, titulares y prestadores de servicios, y a la creación e implementación de políticas y programas basados en evidencia científica, y que redundarán en beneficio de las mujeres y de los propios servicios.

Finalmente, Ipas y el Population Council desean hacer patente su agradecimiento a todos los autores que contribuyeron con artículos a este volumen; a los dictaminadores que revisaron anónimamente los artículos y cuyas recomendaciones fueron fundamentales para mejorar la calidad de los textos presentados; y, sobre todo, a todos aquellos trabajadores de la salud que aportaron las experiencias que sirven de sustento a la totalidad del material incluido en este volumen. También agradecemos a Ana Langer y Raffaela Schiavon, quienes propusieron inicialmente la elaboración de este libro y recaudaron los primeros fondos para hacerlo posible. Resta sólo señalar que los editores asumen, desde luego, las deficiencias y limitaciones que puedan encontrarse en la obra.

Deborah L. Billings, $\mathrm{PhD}$ Ricardo Vernon, $\mathrm{PhD}$

México, D.F., 30 de julio de 2007 

Sección

Panorama general 



\section{Elementos esenciales de la atención posaborto: un modelo ampliado y actualizadoa}

Comisión Especial de Comunidad del Consorcio APA ${ }^{b}$

El Consorcio Atención Postaborto (APA) se complace en presentar estos "Elementos esenciales de la atención posaborto". Basado en un enfoque de atención continua, este modelo amplía el concepto original de atención posaborto que en 1991 articuló por

\section{CUADRO 1-1.}

Elementos esenciales de la atención posaborto

\begin{tabular}{|c|c|}
\hline $\begin{array}{l}\text { Alianzas entre comunidades } \\
\text { y proveedores de servicios }\end{array}$ & $\begin{array}{l}\text { Prevenir embarazos no deseados y abortos de alto riesgo } \\
\text { Movilizar recursos para ayudar a que las mujeres reciban atención } \\
\text { apropiada y tratamiento oportuno para complicaciones del } \\
\text { aborto } \\
\text { Asegurar que los servicios de salud reflejen y satisfagan las expec- } \\
\text { tativas de la comunidad y sus necesidades }\end{array}$ \\
\hline Orientación y consejería & $\begin{array}{l}\text { Identificar y responder a las necesidades de salud, emocionales } \\
\text { y fisicas, así como a otras preocupaciones de las mujeres }\end{array}$ \\
\hline Tratamiento & $\begin{array}{l}\text { Tratar abortos incompletos y de alto riesgo y las complicaciones } \\
\text { que son potencialmente una amenaza para la vida }\end{array}$ \\
\hline $\begin{array}{l}\text { Servicios de anticoncepción y } \\
\text { planificación familiar }\end{array}$ & $\begin{array}{l}\text { Ayudar a las mujeres a prevenir embarazos no deseados o } \\
\text { a practicar el espaciamiento de embarazos }\end{array}$ \\
\hline $\begin{array}{l}\text { Servicios de salud reproductiva y otros } \\
\text { servicios de salud }\end{array}$ & $\begin{array}{l}\text { Preferiblemente se proporcionan en el mismo lugar, o mediante } \\
\text { referencias a otros servicios accesibles dentro de la red de } \\
\text { proveedores de salud }\end{array}$ \\
\hline
\end{tabular}

a Versión editada de: http://www.pac-consortium.org/Newsletters/PACnewsletter0902SupSp.html PAC in Action, Núm. 2, suplemento 2, septiembre de 2002. Reproducido con autorización.

b Las organizaciones cuyos representantes participaron activamente en la Comisión Especial fueron: INTRAH, Ipas, Corporación JHPIEGO, Pacific Institute for Women's Health y Pathfinder International. 
primera vez Ipas ${ }^{1}$ y que fue publicado como un modelo por Ipas en $1994,{ }^{2}$ y por el Consorcio de APA en $1995 .^{3}$ Las lecciones aprendidas del modelo original y los compromisos con el Programa de Acción de la Conferencia Internacional sobre la Población y el Desarrollo (CIPD, 1994), inspiraron a la Comisión de Comunidad del Consorcio APA a desarrollar un modelo revisado que incluye cinco elementos de servicios de APA sostenibles y de alta calidad.

\section{RAZÓN FUNDAMENTAL DE CADA ELEMENTO ESENCIAL}

\section{Alianzas entre comunidades y proveedores de servicios}

Para lograr el acceso universal a los servicios de APA y a otros servicios de salud sexual y reproductiva que sean sostenibles y de alta calidad, los miembros de las comunidades, trabajadores de salud, los curanderos tradicionales y proveedores de servicios formalmente capacitados deben trabajar en alianza. Los componentes de esta alianza incluyen:

- Educación para aumentar la planificación familiar y el uso de anticonceptivos, prevenir embarazos no deseados y reducir abortos de alto riesgo.

- Participación en decisiones acerca de la disponibilidad, accesibilidad y costo de servicios.

- Promoción de servicios centrados en la cliente y basados en los derechos humanos que satisfagan las expectativas, prioridades y necesidades comunitarias.

- Educación sobre urgencias obstétricas y conducta adecuada para buscar atención médica.

- Movilización de recursos comunitarios, inclusive transporte, para asegurar que las mujeres que sufren de urgencias obstétricas reciban atención oportuna.

- Acceso a servicios para poblaciones especiales de mujeres, incluyendo adolescentes, mujeres con VIH/SIDA (virus de inmunodeficiencia humana y síndrome de inmunodeficiencia adquirida) o que han sufrido violencia, han experimentado la mutilación genital, mujeres que hacen pareja con mujeres, refugiadas, sexoservidoras y mujeres que están incapacitadas cognitiva y físicamente.

- Planificar para la sostenibilidad.

\section{Orientación y consejería}

La orientación efectiva para mujeres que están experimentando un aborto incompleto y posiblemente complicaciones, debe comenzar en el primer contacto entre la mujer y su proveedor de salud, y abordar en forma integral las necesidades emocionales y físicas, además de la planificación familiar y la anticoncepción. Los objetivos de la orientación son:

- Dar apoyo emocional durante la atención posaborto.

- Asegurar que las mujeres reciban información apropiada acerca de condiciones médicas, resultados de exámenes, opciones de tratamiento y manejo de dolor y visitas de seguimiento, y que entiendan cómo prevenir las complicaciones posprocedimiento, además de saber cuándo y dónde buscar atención si surgen complicaciones. 
- Ayudar a las mujeres a aclarar sus pensamientos acerca del embarazo, aborto incompleto, tratamiento, reanudación de la ovulación y futuro de su salud reproductiva.

- Habilitar a los proveedores de salud para que puedan responder mejor a otros factores que podrían tener un impacto sobre la atención de la cliente; por ejemplo, la violencia basada en género, las enfermedades de transmisión sexual (ETS) y el VIH.

\section{Tratamiento de abortos incompletos y de alto riesgo}

El tratamiento de urgencia ha sido el enfoque de muchas actividades de APA. Se redacta este elemento del modelo nuevamente porque se reconoce que el aborto incompleto y de alto riesgo no implica, necesariamente, complicaciones amenazantes para la vida, y por lo tanto, el tratamiento no es siempre una urgencia. Sin embargo, las complicaciones son potencialmente amenazantes para la vida sin la atención médica rápida y apropiada. El tratamiento de alta calidad incluye AMEU (aspiración manual endouterina) para la evacuación uterina, precauciones estándares de la prevención de infección, el manejo del dolor apropiado y las visitas de seguimiento.

\section{Servicios de anticoncepción y de planificación familiar}

A pesar del avance en el último decenio, hay un gran número de mujeres que desean demorar o evitar el embarazo, o practicar el espaciamiento del nacimiento, y no usan la anticoncepción. Asegurar que las mujeres tengan acceso a una gran variedad de métodos, inclusive la anticoncepción de emergencia, es una estrategia efectiva para prevenir los embarazos no deseados y abortos de alto riesgo, y ayuda a que las mujeres logren sus metas reproductivas. Además, si a las mujeres que no desean un embarazo o son aconsejadas por razones médicas contra un embarazo inmediato no se les ofrecen métodos anticonceptivos, quizás no vuelvan para su visita de seguimiento ni sigan una referencia para obtener un método anticonceptivo.

\section{Servicios de salud reproductiva y otros servicios de salud}

Un vínculo importante entre el nuevo elemento de orientación y este elemento es que la orientación efectiva debe contribuir a un aumento en el reconocimiento, acceso y uso de los servicios de reproducción y los otros servicios de salud que las mujeres necesitan. El modelo ampliado y actualizado fomenta que se proporcionen servicios de reproducción y otros servicios de salud apropiados, al tiempo que las mujeres reciben tratamiento para complicaciones de aborto, preferiblemente en el mismo lugar.

Cuando no es posible ni apropiado que el servicio de salud proporcione los servicios adicionales necesarios, el servicio debe mantener sistemas funcionales de referencia y de contrarreferencia y mecanismos de seguimiento, inclusive el mantenimiento de registros, para asegurar que las necesidades de las mujeres sean satisfechas. Los servicios ofrecidos pueden incluir: 
- Educación sobre la prevención de ETS/VIH, exámenes, diagnóstico y tratamiento.

- Detección, tratamiento y referencias para sobrevivientes de la violencia basada en el género.

- Diagnóstico de esterilidad, orientación, asesoría y tratamiento.

- Educación sobre nutrición e higiene.

- Examen de detección de cáncer y referencia.

¿Qué resultados se pueden esperar de los elementos esenciales del modelo de APA?

En las comunidades:

- Mayor conocimiento y aceptación de los servicios de APA.

- Aumento en la accesibilidad y uso de la APA y de otros servicios de salud.

- Búsqueda más oportuna de servicios de urgencia por parte de las mujeres que han sufrido complicaciones posaborto.

- Aumento en el uso de anticonceptivos, menos embarazos no deseados y menos abortos repetidos.

- Aumento en la satisfacción con los servicios de APA y otros servicios de salud.

En los servicios de salud pública:

- Servicios de APA que respondan a las necesidades, prioridades y expectativas comunitarias.

- Aumento en la calidad de los servicios de APA y otros servicios de salud.

- Mejor desempeño de los proveedores para satisfacer las necesidades de APA y de salud de las mujeres.

- Mejoramiento del mantenimiento de los registros.

- Mejoramiento de los sistemas de referencia y contrarreferencia.

\section{CONCLUSIÓN}

Ocho años después de que el modelo original de APA fue publicado por primera vez, los miembros del Consorcio APA apoyan una visión más amplia de APA de alta calidad. Al ampliar de un enfoque de tratamiento clínico a un enfoque más integral de salud pública, el modelo de "Elementos esenciales de la atención posaborto" responde más efectivamente a las necesidades y preocupaciones de las mujeres respecto de los servicios de salud sexual y reproductiva. Mientras los programas basados en el modelo son diseñados, implementados y evaluados, y la comprensión de servicios sostenibles de alta calidad de APA recibe más información, es probable que haya revisiones futuras del modelo.

\section{Referencias}

1. Ipas, Carrboro, NC: Strategy for the next decade. 1991.

2. Greenslade FC, McKay H, Wolf M y McLaurin K: Post-abortion care: A women's health initiative to combate unsafe abortion. En Ipas, Carrboro, NC: Advances in Abortion Care Series. 4(1), 1994.

3. Winkler J, Oliveras E, McIntosh N: Postabortion Care: A Reference Manual for Improving Qualityn of Care. PAC Consortium, 1995. 


\section{Atención posaborto en América Latina: recomendaciones para políticas y servicios al cabo de un decenio de investigación operativa ${ }^{a}$}

Deborah L. Billings ${ }^{b}$ y Janie Benson ${ }^{c}$

\section{INTRODUCCIÓN}

El aborto inseguro, definido como un procedimiento para terminar un embarazo no planeado y realizado por personas que carecen de las habilidades necesarias, o en un ambiente que carezca de los estándares médicos mínimos, o ambos, representa riesgos significativos para la salud y la vida de las mujeres. ${ }^{1}$ En toda la región de América Latina y el Caribe, las leyes sobre aborto lo restringen, mientras el aborto clandestino, a menudo inseguro, es común. Excepciones notables son las de Cuba y Guyana, donde el aborto es seguro para una amplia variedad de indicaciones. Se estima que en la región se practican alrededor de 3.7 millones de abortos cada año, con una tasa de 29 abortos por cada 1000 mujeres en edad reproductiva, o casi un aborto inseguro por cada tres nacidos vivos. ${ }^{1}$ La Organización Mundial de la Salud (OMS) ${ }^{2}$ estima que 15\% de los abortos inseguros ocurren a mujeres de 20 a 24 años, mientras que $56 \%$ sucede a mujeres entre los 25 y 49 años. En la región, casi 3700 mujeres mueren cada año a consecuencia de abortos inseguros. Por cada muerte, muchas más mujeres sufren daños e incapacidades que requieren tratamientos médicos de urgencia. La mayor parte de las cifras sobre mortalidad y morbilidad subestiman la realidad, pues tienden a excluir a las mujeres que no utilizan los servicios públicos de salud formales. Pero, además, muchos abortos no se registran ni siquiera en los servicios públicos de salud.

Con todo, la mortalidad y morbilidad que resultan del aborto inseguro pueden prevenirse. Enfoques médicos y quirúrgicos seguros para inducir el aborto son altamente eficaces y presentan poco riesgo para las mujeres. ${ }^{2-4}$ Sin embargo, en los lugares en donde las mujeres no pueden tener acceso a abortos inducidos seguros, la pronta aten-

\footnotetext{
$\bar{a}$ Reproducido con autorización de Health Policy and Planning, Vol. 20(3), 2005, pp. 158-166. Traducción de Guillermina Herrera.

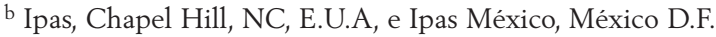

${ }^{c}$ Ipas, Chapel Hill, NC, EUA.
} 
ción posaborto (APA) puede, al menos, salvar sus vidas y permitirles oportunidades para prevenir embarazos no deseados en el futuro mediante asesoría y servicios anticonceptivos. En la Conferencia Internacional sobre la Población y el Desarrollo (CIPD) de 1994, los gobiernos avalaron la APA como una respuesta esencial al problema de salud pública que el aborto inseguro representa. Organizaciones de la sociedad civil y sistemas nacionales de salud de países en desarrollo introdujeron posteriormente un modelo de APA desarrollado por Ipas, una organización internacional de salud reproductiva; ello ocurrió, con frecuencia, a través de apoyos financieros importantes de agencias donantes como la Agencia de los Estados Unidos para el Desarrollo Internacional (USAID), el Departamento Británico para el Desarrollo Internacional (DFID) y varias fundaciones privadas. ${ }^{5,6}$ Los tres componentes principales del modelo son:

1. Tratamiento rápido de las complicaciones derivadas de abortos inseguros (o espontáneos) que amenazan potencialmente la vida utilizando aspiración manual endouterina (AMEU) u otros métodos preferidos.

2. Ofrecer asesoría y métodos anticonceptivos para ayudar a que las mujeres logren sus intenciones reproductivas y se evite la repetición de los abortos.

3. Ofrecer otros servicios de salud reproductiva que requieran las mujeres que experimenten complicaciones derivadas de abortos, en el lugar o mediante referencia.

Una revisión reciente del modelo APA hace explícitos dos elementos adicionales que rinden servicios de APA más eficaces para satisfacer las necesidades de las mujeres: la consejería general, para identificar y responder tanto a las necesidades emocionales y de salud física de las mujeres como a otras preocupaciones, y las alianzas entre comunidades y proveedores de servicios para contribuir a movilizar recursos para la APA y la prevención del aborto inseguro, y garantizar que los servicios de salud reflejen y satisfagan las expectativas y necesidades comunitarias. ${ }^{6}$

Durante los últimos diez años se han implantado elementos del modelo original en varios países del mundo, incluyendo la región de América Latina. En este texto se resumen los resultados de diez importantes proyectos de investigación operativa realizados en países de esta región durante el periodo de 1990-2002, principalmente, que utilizaron cuando menos dos elementos del modelo original de la APA (cuadro 2-1).

En general, los estudios demuestran que es posible lograr mejoras significativas en los servicios de APA en hospitales del sector público mientras, de modo simultáneo, se reduce el costo de provisión de esos servicios. La utilización de hallazgos de investigaciones bien realizadas para promover políticas eficaces y servicios costo-efectivos es urgente, en virtud de que el aborto inseguro continúa planteando riesgos importantes para la salud y la vida de las mujeres en toda América Latina, en especial de las mujeres pobres, adolescentes y otras poblaciones vulnerables. Por otra parte, la implementación posterior de la APA, de acuerdo con los hallazgos de estas investigaciones, ayudaría a que los gobiernos mejoraran el cumplimiento de los compromisos de la CIPD. Sería posible alcanzar un avance mayor si se consideraran los otros componentes de la APA, incluyendo vincular a las mujeres con otros servicios de salud reproductiva que pudieran necesitar y desarrollar alianzas eficaces entre las comunidades y los servicios de salud. 
CUADRO 2-1.

Estudios de intervenciones de base hospitalaria sobre APA en 10 hospitales seleccionados

de América Latina, por país, 1990-2002

\begin{tabular}{|c|c|c|c|}
\hline $\begin{array}{c}\text { País/Ubicación } \\
\text { del hospital } \\
\text { o filiación }{ }^{1}\end{array}$ & Año(s) & $\begin{array}{l}\text { Número } \\
\text { de lugares }\end{array}$ & Descripciōn \\
\hline $\begin{array}{l}\text { Bolivia/ } \\
\text { Ministerio de } \\
\text { Salud } l^{a}\end{array}$ & 1995 a 1997 & 3 & $\begin{array}{l}\text { Estudio de pre y posintervención. Midió la calidad de los servicios } \\
\text { mediante observaciones y entrevistas, lo mismo que la aceptación } \\
\text { de anticonceptivos posaborto a través de una revisión de los re- } \\
\text { gistros hospitalarios de clientes }\end{array}$ \\
\hline $\begin{array}{l}\text { Bolivia/ } \\
\text { Ministerio de } \\
\text { Salud } 2^{\text {b }}\end{array}$ & 1999 a 2001 & 3 & $\begin{array}{l}\text { Estudio pre y posintervención. Midió cambios en el suministro de } \\
\text { información y asesoría sobre procedimientos clínicos y anticoncep- } \\
\text { ción posaborto, tecnologías apropiadas y desempeño técnico, costo } \\
\text { de entrega de los servicios (atención ambulatoria de la AMEU, } \\
\text { AMEU en pacientes ingresadas y LUl en pacientes ingresadas), } \\
\text { gastos asumidos por la paciente y factores relacionados con la } \\
\text { sostenibildad de los servicios. Seguimiento a los tres meses poste- } \\
\text { riores al servicio con mujeres atendidas en una de las tres sedes } \\
\text { hospitalarias, y entrevistas con los compañeros de las mujeres, con } \\
\text { el consentimiento previo de ellas y ellos mismos en los tres sitios }\end{array}$ \\
\hline Centroamérica ${ }^{c}$ & 1996 & 4 & $\begin{array}{l}\text { Prueba aleatoria de dos técnicas para ofrecer anticoncepción } \\
\text { posaborto (asesoría individual comparada con sesiones informati- } \\
\text { vas en grupol, con seguimiento a tres meses de mujeres en El } \\
\text { Salvador, Guatemala, Honduras y Panamá }\end{array}$ \\
\hline Honduras $^{d}$ & 1999 a 2001 & 5 & $\begin{array}{l}\text { Estudio pre y posintervención. Midió cambios en el suministro de } \\
\text { información y asesoría sobre anticoncepción posaborto, aceptaciōn } \\
\text { anticonceptiva y necesidad no satisfecha de anticoncepción pos- } \\
\text { aborto. (Nota: este estudio midió, asimismo, cambios en los servi- } \\
\text { cios anticonceptivos posparto) }\end{array}$ \\
\hline $\begin{array}{l}\text { México/ } \\
\text { IMSS } 1^{e}\end{array}$ & 1991 & 5 & $\begin{array}{l}\text { Estudio posintervención sobre costos, uso de recursos y tiempo de } \\
\text { estancia de pacientes tratadas con AMEU en la atenciôn ambulato- } \\
\text { ria y con LUI en pacientes ingresadas }\end{array}$ \\
\hline $\begin{array}{l}\text { México/ } \\
\text { Oaxaca }^{f}\end{array}$ & 1995 a 1997 & 1 & $\begin{array}{l}\text { Estudio pre y posintervención. Midió cambios en la calidad de la } \\
\text { atención, uso de la AMEU, prevención de infecciones, manejo del } \\
\text { dolor, asesoría anticonceptiva posaborto y aceptación de anticon- } \\
\text { ceptivos, costo, uso de los recursos y tiempo de estancia en relación } \\
\text { con entrega de los servicios (atención ambulatoria de AMEU y de } \\
\text { LUl en pacientes ingresadas) }\end{array}$ \\
\hline $\begin{array}{l}\text { México/ } \\
\text { IMSS } 2^{g}\end{array}$ & 1997 a 1998 & 6 & $\begin{array}{l}\text { Estudio de comparación de un grupo estático. Evaluó seguridad y } \\
\text { eficacia de la técnica clínica, información y asesoría, manejo del } \\
\text { dolor, asesoría en anticoncepción posaborto y aceptación de anti- } \\
\text { conceptivos, costo, uso de recursos y tiempo de estancia en relación } \\
\text { con la entrega de servicios (AMEU y atención ambulatoria de LUII, } \\
\text { con seguimiento a seis meses de mujeres atendidas en seis sitios } \\
\text { hospitalarios }\end{array}$ \\
\hline
\end{tabular}


$10 \quad$\begin{tabular}{l|l} 
Capítulo 2 \\
Avances en la atención posaborto en América Latina y el Caribe . . .
\end{tabular}

CUADRO 2-1. (continuación)

Estudios de intervenciones de base hospitalaria sobre APA en 10 hospitales seleccionados

de América Latina, por país, 1990-2001

\begin{tabular}{|c|c|c|c|}
\hline $\begin{array}{c}\text { País/Ubicación } \\
\text { del hospital } \\
\text { o filiación }{ }^{1}\end{array}$ & Año(s) & $\begin{array}{l}\text { Número } \\
\text { de lugares }\end{array}$ & Descripción \\
\hline $\begin{array}{l}\text { Perú/ } \\
\text { Callaolh }^{h}\end{array}$ & 1996 a 1998 & 1 & $\begin{array}{l}\text { Estudio pre y posintervención. Midió cambios en la calidad de la } \\
\text { atención, uso de AMEU, prevención de infecciones, manejo del } \\
\text { dolor, asesoría anticonceptiva posaborto y aceptación de anticon- } \\
\text { ceptivos, costo, uso de recursos y tiempo de estancia en relación } \\
\text { con la entrega de servicios (atención ambulatoria de AMEU y de LUI } \\
\text { en pacientes ingresadas), lo mismo que gastos asumidos por las } \\
\text { pacientes }\end{array}$ \\
\hline $\begin{array}{l}\text { Perú/ } \\
\text { Callao2i }\end{array}$ & 2000 a 2002 & 1 & $\begin{array}{l}\text { Tercera etapa del estudio Perú/Callao } 1996 \text { a 1998, en el cual un } \\
\text { segundo periodo de seguimiento documentó la continuación de } \\
\text { mejoras en el mediano plazo en relación con la atención clínica, } \\
\text { servicios anticonceptivos posaborto, costo, duración de la estancia y } \\
\text { factores relacionados con la sostenibilidad de los servicios }\end{array}$ \\
\hline $\begin{array}{l}\text { Perú/ } \\
\text { Limai }\end{array}$ & 1996 & 1 & $\begin{array}{l}\text { Prueba aleatoria de tres técnicas clínicas (LUI, AMEU y aspiración } \\
\text { eléctrica) para el tratamiento del aborto incompleto. Estudio de } \\
\text { costo posintervención, uso de recursos y duración de la estancia } \\
\text { para uso de la AMEU y la aspiración eléctrica en atención ambula- } \\
\text { toria y LUI en pacientes ingresadas. Midió también las mejoras en } \\
\text { la asesoría anticonceptiva posaborto y la aceptación anticonceptiva } \\
\text { previa al egreso del hospital y en las visitas de seguimiento a los } \\
\text { hogares }\end{array}$ \\
\hline
\end{tabular}

${ }^{1}$ En los paises en donde se realizó más de un estudio, se indica la ubicación del hospital del estudio o el sistema de salud.

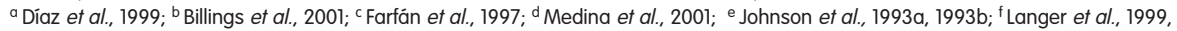

Langer et al., 2002, Brambila et al., 1999; ' Fuentes Velásquez et al., 1998 y Billings et al., 2003; ${ }^{\mathrm{h}}$ Benson et al., 1998; 'Benson y

Huapaya, 2002; i Távara Orozco y Ramírez Jiménez, 1996.

\section{SELECCIÓN DEL ESTUDIO Y ORIENTACIONES METODOLÓGICAS}

El cuadro 2-1 resume los métodos y hallazgos de los estudios de APA claves que se seleccionaron para este análisis. En todos los casos se trató de investigaciones operativas; esto es, estudios diseñados a fin de medir la eficacia de una intervención para lograr resultados en la entrega de los servicios. ${ }^{7}$ Con el objetivo de ofrecer a proveedores de servicios, gerentes y diseñadores de políticas recomendaciones bien fundamentadas, la inclusión de los estudios obedeció a los siguientes criterios de selección:

- Intervenciones de capacitación y entrega de servicios de APA implementadas en hospitales del sector público que ofrecían tratamiento de complicaciones deriva- 
das de abortos. Los insumos para las intervenciones de APA incorporaban, típicamente, algunos o todos los elementos siguientes: a) construcción de consensos entre diseñadores de políticas, gerentes y proveedores; $\mathrm{b}$ ) talleres para gerentes $\mathbf{y}$ personal de los servicios a fin de orientarlos sobre los nuevos servicios de APA; c) reorganización física de los servicios para hacerlos más eficientes y costo-eficaces; d) capacitación sobre APA en el servicio para proveedores de atención a la salud, incluyendo el uso de aspiración manual endouterina (AMEU) para la evacuación uterina del aborto incompleto, prevención de infecciones, manejo del dolor, interacciones paciente-proveedor y mensajería anticonceptiva posaborto y provisión de métodos; y e) entrega de servicios, incluyendo los procedimientos de AMEU, asesoría y servicios anticonceptivos.

- Una metodología de evaluación sólida, utilizando más a menudo medidas pre y posintervención a fin de evaluar resultados definidos de la intervención.

- Hallazgos divulgados a través de un documento revisado por pares, ya sea que fuere un informe final de proyecto, un capítulo de libro o una revista profesional.

Hasta donde las autoras conocen, el presente análisis abarca toda la investigación operativa en APA realizada en América Latina que satisface los criterios anteriores para ser incluida.

En términos generales, los diseños de los estudios fueron no o quasi experimentales; la mayor parte empleó muestras no aleatorias de conveniencia de proveedores o pacientes, aunque un estudio asignó de manera aleatoria a pacientes a uno de dos modelos diferentes de asesoría en planificación familiar, ${ }^{8}$ y otro las asignó del mismo modo a uno de tres grupos de técnicas de evacuación uterina. ${ }^{9}$ Casi todos los proyectos se diseñaron como estudios pre y posintervención, aunque en un caso se trató de una comparación posintervención de tres modelos de entrega de servicios de APA. ${ }^{10}$ Diversos factores contribuyeron al uso de diseños no o quasi- experimentales. La adopción del modelo de APA empleando AMEU requiere, en general, de la reorganización de los servicios y de que las pacientes ingresadas pasen a ser pacientes externas o ambulatorias. La asignación aleatoria de las mujeres al tratamiento, ya sea como pacientes ingresadas en una sala de operaciones o como pacientes externas en una sala de procedimientos, hubiera sido irrealizable en el escenario de una clínica de urgencias. Se ha documentado, además, que el tratamiento con AMEU a mujeres que sufren abortos incompletos es más seguro que el legrado uterino instrumental (LUI). ${ }^{11}$ Consideraciones éticas pueden impedir el tratamiento de pacientes con LUI una vez que los proveedores han sido entrenados en el uso de la AMEU.

Para la recolección de datos se emplearon, en términos generales, entrevistas estructuradas y semiestructuradas con pacientes, proveedores y/o diseñadores de políticas, bitácoras y análisis de registros de casos, lo mismo que listas de cotejo de observaciones. En los estudios participaron proveedores de atención a la salud y otro personal de las unidades, lo mismo que mujeres que habían acudido a los hospitales para tratarse un aborto incompleto debido a un aborto espontáneo o inducido. Los tamaños de las muestras se determinaron más por el número de pacientes atendidas y los presupuestos para las investigaciones que por consideraciones de tipo estadístico. En los estudios, el número de unidades hospitalarias osciló entre uno y seis. Se mencionan los valores de significación estadística en los casos en que fueron incluidos en el informe original o el artículo revisado.

Los estudios de costos y uso de recursos (tiempo-movimiento) solían incorporar metodologías de evaluación rápida; esto es, observaciones de pequeños números de 
pacientes —desde su ingreso hasta el egreso o salida del hospital—, y datos recolectados sobre uso del equipo médico y los suministros, gastos generales (overheads) y tiempo que el personal invirtió para brindar la atención. ${ }^{9}, 12-16$ En otros textos se han descrito las metodologías de costos y uso de los recursos. ${ }^{17}$ Dado el pequeño tamaño de las muestras incluidas en los estudios de costos, no se realizaron pruebas de significación estadística.

Varios de los estudios incluyeron evaluaciones de los servicios pre y posintervención dentro de la misma unidad; $13,15,16,18-20$ cuatro estudios siguieron a las pacientes en el transcurso de un cierto tiempo. ${ }^{8,9,14,16}$ Un estudio se abocó específicamente a factores relacionados con la sostenibilidad de los servicios en el mediano plazo, documentando su implementación y calidad durante aproximadamente tres años a partir de la intervención original. ${ }^{21}$

En virtud de que el aborto está legalmente restringido en todos los países en donde las investigaciones se efectuaron, era probable que muchas de las participantes en el estudio estuvieran renuentes a revelar sus nombres. De ahí que la mayoría de los investigadores confiaran en el consentimiento informado verbal al reclutar a pacientes y proveedores para los estudios, en vez de solicitarles la firma de formatos de ese consentimiento. En tales casos, los entrevistadores firmaron formatos de consentimiento verificando que los procedimientos éticos se habían observado.

\section{RESULTADOS Y DISCUSIÓN}

En las siguientes secciones se resumen los hallazgos más destacados de los estudios seleccionados en cuatro áreas clave: 1) prácticas clínicas, incluyendo tecnologías y medicamentos empleados; 2) servicios anticonceptivos posaborto; 3) calidad de las interacciones paciente-proveedor, según lo indicaba la información y asesoría sobre el diagnóstico, tratamiento y atención de seguimiento; y 4) costos, uso de los recursos y duración promedio de la estancia en la unidad, lo mismo que organización de los servicios. Es significativo que los estudios hayan reportado de manera consistente resultados similares en estas cuatro áreas, lo cual sugiere que ofrecen una orientación confiable para desarrollar servicios y políticas eficaces de APA en toda la región.

\section{PRÁCTICAS CLÍNICAS}

En la mayor parte de los hospitales de América Latina, el tratamiento de mujeres que presentan abortos incompletos implica el uso de LUI para la evacuación uterina, que se acompaña de anestesia general o sedación fuerte. Los protocolos clínicos requieren a menudo que el procedimiento de evacuación se realice en una sala de operaciones, seguido por una estancia de una noche en el centro hospitalario, lo que hace necesaria la admisión de la paciente. Además, las mujeres suelen esperar muchas horas a partir de su llegada al hospital hasta que reciben atención clínica.

Varios estudios aprovecharon la intervención de la capacitación y la introducción de la AMEU como momentos de oportunidad, durante los cuales los servicios se reorganizaron simultáneamente. En Perú-Callaol, México-Oaxaca y Bolivia MS2 (en dos de los tres sitios de los estudios), el procedimiento de evacuación uterina se trasladó de la sala de 
operaciones a un área ambulatoria de atención ginecoobstétrica, ${ }^{13,16,19}$ un hecho que resultó en la reducción de costos y del tiempo promedio de estancia de la paciente (véase Costos, uso de los recursos y duración promedio de la estancia, en párrafos siguientes).

El uso del procedimiento de AMEU fue una característica central de las nuevas prácticas clínicas asociadas con las intervenciones de la APA en todos los estudios. Se ha demostrado que la AMEU es una alternativa más segura y eficaz que el LUI para la evacuación uterina del aborto incompleto equivalente a 12 semanas o menos de gestación. 11, 22, 23 La OMS sostiene que "los servicios de aspiración manual deberían estar ampliamente disponibles para tratar a las mujeres que presentan complicaciones derivadas de un aborto incompleto e inseguro", y recomienda que los servicios de dilatación y legrado o LUI sean reemplazados por la aspiración para "mejorar la seguridad y calidad de la atención". 1

El tratamiento con la AMEU puede administrarse en una variedad de escenarios ambulatorios, incluyendo salas de procedimientos o de urgencia, o áreas de consulta externa. La APA suministrada en consulta externa resulta a menudo en el inicio más rápido del tratamiento y en estancias posprocedimiento reducidas (véase Costos, uso de los recursos y duración promedio de la estancia, en párrafos siguientes). El manejo del dolor incluye opciones como sedación ligera y/o bloqueo paracervical, en combinación con apoyo tranquilizador a la mujer, ofreciendo ventajas en términos de seguridad para la paciente al compararse con niveles más elevados de anestesia utilizados a menudo con el LUI. ${ }^{24}$ Es interesante observar que una prueba clínica aleatoria que Gómez et al. realizaron en República Dominicana, ${ }^{25}$ no mostró diferencias significativas en la experiencia de dolor de las mujeres durante el procedimiento cuando se usaba bloqueo paracervical con apoyo psicológico, en comparación con ofrecer meramente apoyo psicológico, quizás porque la mayoría de las mujeres que padecen complicaciones derivadas de un aborto ya tienen el cérvix dilatado cuando llegan al hospital, con lo cual el efecto del bloqueo paracervical es mínimo para mitigar otras fuentes de dolor, como el calambre uterino.

La mayor parte de los estudios de investigación operativa sobre APA que se analizan en este trabajo documentaron el impacto de cambios en las prácticas clínicas; esto es, la implementación de nuevos protocolos por parte del personal de la unidad para tratar a mujeres que acudían con abortos incompletos. Lo anterior incluye un cambio en la tecnología de evacuación empleada, casi siempre del LUI a la AMEU —aunque en un estudio se usó también la aspiración eléctrica-, 9 lo mismo que la técnica de manejo del dolor y la organización de servicios clínicos. Es importante observar que ningún estudio examinó el uso de medicamentos para la evacuación uterina, como pudieran ser metrotexato y misoprostol, mifepristona y misoprostol, o misoprostol solo.

En los estudios México-Oaxaca y Perú-Callaol, se utilizó el LUI para tratar a todas las mujeres con complicaciones de aborto antes de la intervención de la APA. Una vez realizada la capacitación a los proveedores, la supervisión del personal y la asistencia técnica, el uso de la AMEU se incrementó de forma notable a 78\% y casi 90\% de las pacientes, respectivamente, ${ }^{13,19,27}$ Una revisión de los registros hospitalarios del estudio Perú-Callao en el 2000, casi tres años después de la intervención original, mostró que, en promedio, 99\% de todas las mujeres elegibles continuaban siendo tratadas con AMEU, demostrando la factibilidad del sostenimiento del servicio. ${ }^{21}$

En los sitios de los estudios, antes de las intervenciones, los protocolos para el manejo del dolor solían exigir alguna forma de sedación fuerte o anestesia general, a ser admi- 
nistrada inmediatamente antes de la evacuación uterina para que la mujer no estuviera totalmente consciente durante el procedimiento. En contraste, el manejo del dolor propuesto en las intervenciones y utilizado en los estudios consistía, casi siempre, en una sedación ligera y una interacción de apoyo entre el personal de salud y las mujeres, planteando así menos riesgos para la salud mientras se practicaba un manejo adecuado del dolor. Tal y como lo señalan Margolis et al.,26 "el objetivo del manejo del dolor es asegurar que la mujer experimente el mínimo de ansiedad y molestia, y también que los riesgos para su salud sean los menos". En algunos estudios, como el de México-Oaxacaa ${ }^{27}$ y México- IMSS2,14 se plantean sugerencias para el manejo del dolor previo y subsecuente al procedimiento utilizando analgésicos; en el caso de Oaxaca se pusieron a prueba en el proyecto. Considerando todos los estudios, las mejoras más significativas en el manejo del dolor durante la evacuación uterina fueron las reportadas por el proyecto México-Oaxaca, en donde el uso de anestesia general descendió de 91 a 30\% de los procedimientos, mientras el uso del bloqueo paracervical se incrementó de 1 a $59 \%$ al compararse los datos pre y posintervención. ${ }^{19}$

\section{SERVICIOS ANTICONCEPTIVOS POSABORTO}

La provisión de servicios anticonceptivos posaborto es uno de los tres componentes centrales del modelo de APA que debería suministrarse a todas las mujeres que accedan a los servicios de salud con complicaciones derivadas de un aborto. ${ }^{5}$ Los proveedores deberían preguntar a las mujeres si desean embarazarse pronto nuevamente y hacer el seguimiento con una asesoría diseñada de acuerdo con los planes futuros de la mujer para embarazarse. Las mujeres pueden entonces tomar decisiones absolutamente informadas sobre aceptar o continuar con los anticonceptivos. Sin importar la causa que dio lugar al aborto, las mujeres no deberían volver a sus casas si no han comprendido completamente su rápido regreso a la fecundidad y los beneficios, riesgos y efectos secundarios de una variedad de métodos anticonceptivos. Es común que las mujeres no regresen a sus citas de referencia. Por ello, a aquéllas que no deseen embarazarse en el corto o mediano plazo se les debe ofrecer un método antes de ser dadas de alta en la unidad en donde fueron atendidas por un aborto incompleto. La importancia de los servicios anticonceptivos posaborto brindados en los espacios hospitalarios quedó demostrada en estudios de base hospitalaria realizados en Kenya ${ }^{28}$ y Zimbabwe; ${ }^{29}$ en este último país se evidenció que tales servicios pueden reducir embarazos subsecuentes no planeados y abortos repetidos hasta por un año después del tratamiento posaborto.

Antes de cualquier intervención de capacitación, unidades de Bolivia, El Salvador, Guatemala, Honduras, Panamá y Perú no solían incluir la asesoría anticonceptiva ni el suministro de métodos como parte de los servicios que normalmente ofrecían a pacientes después del tratamiento de abortos incompletos; tampoco ofrecían referencias para tales servicios. $8,13,16,18,19,26$ Las razones de la falta de vínculos incluían la separación física y administrativa entre el espacio o área en donde se ofrecen los servicios de urgencia y las clínicas de planificación familiar del lugar, el acceso limitado a métodos anticonceptivos del personal que no trabaja en la clínica de planificación familiar, y conocimientos mínimos del personal sobre anticoncepción posaborto.

Durante el periodo posintervención, las obstetrices del proyecto Perú-Callaol ofrecieron asesoría anticonceptiva a pacientes posaborto. ${ }^{13}$ Las obstetrices, conocidas también como matronas en algunos países de América Latina, son parteras con entrenamiento 
universitario que han cursado programas de capacitación práctica y teórica durante cinco años; en algunos países, es sobre ellas que descansa la carga de proveer los servicios de salud reproductiva. En los proyectos México-Oaxaca, México- IMSS2 y Centroamérica, 8, 14, 19 los médicos que atendieron a las mujeres por abortos incompletos y los trabajadores sociales integraban el cuadro principal de proveedores que ofrecían los servicios anticonceptivos, incluyendo la consejería. En Bolivia, las enfermeras eran las principales proveedoras de la planificación familiar posaborto. ${ }^{16,18}$ En general, los proveedores de servicios de salud que incluyeron la asesoría anticonceptiva en el repertorio de servicios ofrecidos a las mujeres, encontraron que no habían invertido tiempo extra en razón de sus interacciones con las pacientes y que la estancia hospitalaria tampoco se había prolongado. En vez de ello, emplearon su tiempo de manera más eficaz para ofrecer un servicio importante. ${ }^{13-15}$

Cuando los servicios de tratamiento clínico se vincularon con la asesoría anticonceptiva posaborto y la provisión de métodos, se ofreció a las pacientes una variedad de métodos significativamente mayor, recibieron información sobre ellos y, de hecho, antes de dejar el hospital se les suministró también un método anticonceptivo (cuadro 2-2). Los vínculos ocurrieron cuando se colocaron métodos directamente en las áreas en donde las pacientes se trataban y recuperaban, y cuando distintos proveedores de servicios de salud se capacitaron para dar asesoría y métodos.

Por ejemplo, en la fase de preintervención, 30\% de las pacientes del estudio MéxicoOaxaca recibieron un método antes de salir del hospital; esta cifra se incrementó a 60\% en la posintervención $(\mathrm{p}<0.05) .{ }^{19}$ De modo similar, en el estudio Perú-Callaol, la aceptación de un método pre y posintervención se incrementó de 2 a $59 \%$ de las pacientes $(\mathrm{p}<0.05) .{ }^{13}$ En el año 2000, durante el seguimiento del estudio Perú-Callao2, ${ }^{21}$ el suministro de información sobre planificación familiar y métodos se incrementó de forma constante en la medida en que los servicios se volvieron una rutina. Casi tres cuartas partes de las pacientes entrevistadas durante el seguimiento señalaron que habían recibido información sobre el riesgo de un embarazo inmediato, y cerca de $90 \%$ recibió

\section{CUADRO 2-2.}

Porcentaje de pacientes posaborto que recibieron un método anticonceptivo antes de egresar de la unidad

\begin{tabular}{|c|c|c|}
\hline Ubicación del estudio & $\begin{array}{l}\text { Preintervención \% } \\
\text { (n) }\end{array}$ & $\begin{array}{c}\text { Posintervención \% } \\
(\mathrm{n})^{1}\end{array}$ \\
\hline México-Oaxaca & $29.5(136)$ & $59.7^{1}(207)$ \\
\hline $\begin{array}{l}\text { Perú-Callaol } \\
\text { (pre=1996; pos=1997) }\end{array}$ & $2.0(99)$ & $58.8^{1}(99)$ \\
\hline Perú-Callao2 (Pos=2000) & n.d. & $87.0^{2}$ (119) \\
\hline \multirow[t]{2}{*}{ Honduras } & $13.0(24)$ & $54.0^{1}(71)$ \\
\hline & LUI estándar & AMEU-APA \\
\hline México-IMSS2 & $36.5(282)$ & $63.3^{1}(251)$ \\
\hline \multicolumn{3}{|c|}{$\begin{array}{l}{ }^{1} p<0.05 \\
2 \text { Los resultados provienen de datos recolectados durante el período de seguimiento en el } 2000 \text {. } \\
\text { La diferencia entre los resultados posintervención de } 1997 \text { y los de } 2000 \text { son significativos: } p<0.05 \text {. } \\
\text { n.d. = no existen datos }\end{array}$} \\
\hline
\end{tabular}


información de planificación familiar y obtuvo un método $(\mathrm{p}<0.05)$. En Honduras, ${ }^{20}$ la provisión de servicios anticonceptivos posaborto mejoró de manera significativa, mientras la necesidad no satisfecha de anticonceptivos descendió de 48 a $21 \%$ en todas las mujeres atendidas ( $\mathrm{p}<0.05)$. Enfatizando la importancia de la asesoría anticonceptiva, $37 \%$ de los clientes a quienes se dio información mínima sobre planificación familiar en el estudio México-IMSS2 (LUI estándar), recibieron un método, en comparación con 63\% que fueron asesoradas de manera más estricta (AMEU, APA) $(\mathrm{p}<0.05) .{ }^{10}$

\section{INTERACCIONES PACIENTE-PROVEEDOR}

En sus interacciones con mujeres que sufren complicaciones derivadas de un aborto, los proveedores de servicios de salud deben asegurarse de que las mujeres reciben información precisa sobre sus condiciones de salud, tratamiento clínico empleado para completar el aborto, complicaciones posibles posteriores al procedimiento, higiene, regreso a las actividades de rutina, reanudación de la fecundidad y opciones de planificación familiar. La consejería debería brindar a las mujeres información sobre sus condiciones clínicas que les permita sentirse respetadas y apoyadas, y ofrecerles la oportunidad de plantear sus preguntas y tomar decisiones. ${ }^{30}$

Antes de que la APA se introdujera como un enfoque integral, muchas mujeres llegaban a las unidades de salud con complicaciones derivadas de abortos; ahí, los proveedores de servicios de salud las regañaban por haber abortado. ${ }^{18,31,32}$ En general, los proveedores y administradores solían suponer que todas las mujeres se habían inducido el aborto.

Con el propósito de mejorar la consejería, se pusieron en marcha intervenciones de capacitación en cinco de los estudios revisados, con resultados diversos. ${ }^{8}, 13,16,18,19$ En un sexto estudio (México- IMSS2), los modelos de atención existentes que incorporaban la asesoría, se compararon con un modelo estándar de atención que sólo presentaba la información a las mujeres. ${ }^{10}$ Los otros tres estudios no medían específicamente la mejoría de la consejería general; más bien se orientaban a los servicios de planificación familiar, aunque un estudio documentó los costos de entrega de los servicios de APA bajo diferentes modelos.

En el estudio México-Oaxaca, 19, 27 la capacitación del personal hospitalario, en particular la de enfermeras y trabajadores sociales, tuvo un efecto positivo importante sobre las comunicaciones interpersonales entre las pacientes posaborto y el personal médico. Aunque durante la fase de línea basal prácticamente ninguna mujer recibió información sobre recuperación posterior al procedimiento, problemas potenciales y dónde buscar atención en caso de presentarse problemas, a la mitad de todas las mujeres se les informó sobre posibles complicaciones y dónde acudir en busca de ayuda después de la intervención. Además, el porcentaje de mujeres que recibieron información sobre sus condiciones de salud antes de ingresar a la sala de procedimientos se incrementó de 68 a $87 \%$ $(\mathrm{p}<0.05)$; igual ocurrió con el porcentaje de mujeres que sabían el nombre del médico que llevaría a cabo el procedimiento (pre: 17\%; pos: 74\%; $p<0.05$ ). Los proveedores notaron un cambio en sus propias actitudes después de haber participado en los talleres sobre relaciones interpersonales. Tal y como lo expresó uno de ellos: "Podemos hacerlo si nos tranquilizamos, porque nuestra excusa ha sido siempre la falta de tiempo. Es posible charlar con la paciente y darle información en sólo un par de minutos, mientras nos preparamos para realizar el procedimiento". ${ }^{19}$ 
En una entrevista previa al egreso se pidió a las mujeres del estudio Perú-Callaol evaluar la información y asesoría que habían recibido. ${ }^{13}$ Los resultados fueron, de alguna manera, mixtos en la fase de posintervención, dado que un porcentaje significativamente mayor de mujeres recordó haber recibido información sobre el momento en que debían retomar sus actividades diarias y cuándo regresaría su periodo menstrual después de la intervención $(\mathrm{p}<0.05)$. Pero pocas de ellas recordaron que se les hubiera mencionado la necesidad de la higiene personal, los signos de posibles complicaciones posteriores al procedimiento y la necesidad de retrasar las relaciones sexuales $(\mathrm{p}<0.05)$. Al preguntar a los supervisores las razones por las cuales la información ofrecida a las mujeres tratadas durante el periodo posterior a la intervención habría disminuido, ellos mismos especularon que el personal percibía a las pacientes posaborto, que se clasificaban como ambulatorias, con menor necesidad de información integral, en contraste con las pacientes hospitalizadas, a quienes se consideraba más "enfermas" y, por ende, con mayor necesidad de atención. ${ }^{13}$

Durante el segundo periodo de seguimiento (Perú-Callao2), ${ }^{21}$ se mantuvieron algunas mejoras, mientras que otros aspectos de la atención continuaron siendo un desafío. Durante el seguimiento, cerca de dos tercios de los clientes posaborto (62\%) indicaron que se les había informado sobre el tratamiento que requerían —una mejora significativa respecto de las proporciones previas a la intervención $(10 \%, \mathrm{p}<0.05)$. A pesar de ello, menos de un tercio de los clientes entrevistadas en el seguimiento se dieron cuenta de que habían recibido información sobre los signos de alarma más importantes, como dolor agudo y sangrado.

En los servicios de APA del proyecto México- IMSS2, donde se ofreció asesoría de manera regular (modelos AMEU, APA y LUI), las mujeres atendidas informaron haberse sentido más confiadas en el personal del hospital, del cual percibieron que había identificado sus preocupaciones; les pareció que ese personal les había ayudado a abordar sus preocupaciones, en comparación con mujeres tratadas en el modelo estándar de atención del LUI, en donde la información brindada fue mínima. Las mujeres tratadas según el modelo de APA recibieron también más información sobre su condición de salud en comparación con las pacientes atendidas en el modelo de atención estándar del LUI. Una proporción significativamente mayor de las mujeres tratadas con AMEU recibieron información sobre el procedimiento de evacuación uterina, al compararse con quienes fueron tratadas con el LUI (53\% estaba suficientemente informada, en comparación con 10 y $3 \%$ para APA, LUI y LUI estándar, respectivamente; $\mathrm{p}<0.05)$. Lo que fue decepcionante fue la baja proporción de mujeres ( 2 a $41 \%$ en los tres modelos) que, en general, recibieron información sobre posibles complicaciones posteriores al procedimiento y el regreso a sus actividades normales. A pesar de las bajas cifras, los modelos de APA que incluyeron asesoría fueron evaluados positivamente por las mujeres, en términos generales, al compararse con el modelo estándar del LUI, que no incluía la asesoría como parte del paquete estándar de servicios. ${ }^{10}$

\section{COSTOS, USO DE LOS RECURSOS Y DURACIÓN PROMEDIO DE LA ESTANCIA}

Los estudios de costos generan estimados de costos de oportunidad, en donde los cambios en los costos pueden interpretarse como recursos que se liberan para usarse en otros servicios. En circunstancias óptimas, las unidades de atención a la salud deben 
ofrecer servicios de APA seguros y eficaces, al tiempo que minimizan sus propios costos y también los que corren a cargo de la paciente. Los investigadores han reportado que el tratamiento de mujeres con abortos incompletos puede absorber más de $50 \%$ de los presupuestos obstétricos y ginecológicos de las unidades y, asimismo, que el alto costo de los servicios puede ser una barrera para obtener los servicios clínicos. ${ }^{12}$

Datos de cuatro estudios, que aparecen en los cuadros $2-3$ y $2-4$, muestran estimados de la estancia hospitalaria promedio (EHP) y el promedio del costo total por paciente por servicios de APA. ${ }^{13}, 15,16,21,33$ En general, los resultados de estos estudios muestran que si el cambio a la práctica de la AMEU ocurre de forma paralela a la reorganización de los servicios a una base de atención externa, existe una tendencia a que la estancia hospitalaria promedio y los costos de tratamiento de la unidad se reduzcan de manera importante. ${ }^{34}$ Las prolongadas esperas antes y después del tratamiento suelen ser una fuente importante de insatisfacción de las pacientes en APA.

Aunque la mayor parte de los estudios informaron marcados descensos en la estancia hospitalaria promedio y los costos cuando se empleaba la AMEU para tratar abortos incompletos en unidades ambulatorias, en algunos casos hubo resultados distintos. En 1993, un estudio hecho en Ecuador mostró que las unidades que cambiaron a la AMEU mientras continuaban tratando a las pacientes posaborto con anestesia general en una sala de operaciones tenían, de hecho, costos y EHP similares al compararse con unidades que continuaban usando el LUI bajo las mismas condiciones. ${ }^{12}$ Esta información refuerza la conclusión de que la reorganización de los servicios es crítica para brindar servicios eficaces. Alternativamente, el estudio México- IMSS2 encontró que cuando se realizaba el LUI a pacientes externas, el cambio a la AMEU practicada en servicios para pacientes externas no generaba ahorros adicionales en comparación con pacientes del LUI. ${ }^{14}$ De modo similar, en el estudio Perú-Lima, la estancia hospitalaria promedio entre el LUI y la AMEU, ofrecidos ambos a pacientes externas, era comparable: entre 6.6 y 6.0 horas, respectivamente. El costo por paciente tratada era casi idéntico. ${ }^{9}$

Uno de los defectos de muchos estudios de costos sobre APA ha sido el estrecho enfoque sobre los costos para la unidad. Dichos costos son, ciertamente, un componente

\section{CUADRO 2-3.}

Estancia hospitalaria promedio, en horas, comparando servicios de APA a pacientes ingresadas suministrados con LUI, con servicios de APA ambulatorios, con AMEU, en cuatro hospitales

\begin{tabular}{|c|c|c|c|}
\hline \multirow[t]{2}{*}{ Hospital } & \multicolumn{3}{|c|}{ Estancia hospitalaria promedio (horas) } \\
\hline & $\begin{array}{c}\text { Servicios de LUI } \\
\text { a pacientes ingresadas }\end{array}$ & $\begin{array}{c}\text { Servicios de AMEU } \\
\text { ambulatorios }\end{array}$ & $\begin{array}{c}\text { Diferencia } \\
\text { (\% disminución) }\end{array}$ \\
\hline Bolivia/MS $2^{\mathrm{a}}$ & 34.0 & 10.7 & $-68.5 \%$ \\
\hline México/IMSS $1^{b}$ & 19.7 & 11.4 & $-42.1 \%$ \\
\hline México/Oaxaca ${ }^{c}$ & 27.0 & 17.4 & $-35.6 \%$ \\
\hline $\begin{array}{l}\text { Perú/Callaol y } \\
\text { Perú/Callao2d }^{\text {d }}\end{array}$ & 33.3 & $\begin{array}{l}6.4(1997) \\
6.7(2000)\end{array}$ & $\begin{array}{l}-80.8 \% \\
-79.9 \%\end{array}$ \\
\hline \multicolumn{4}{|c|}{$\begin{array}{l}\text { a Billings et al., } 2001 \text { (Nota: los resultados son únicamente de La Paz); b Johnson et al., 1993b; ' Brambila, et al., 1999; ' Benson et al., } 1998 \\
\text { Benson y Huapaya, } 2002 .\end{array}$} \\
\hline
\end{tabular}


CUADRO 2-4.

Costo promedio de la atención por paciente en APA: servicios de APA con LUl a pacientes ingresadas en comparación con los servicios de APA ambulatorios, brindados con AMEU, en cuatro hospitales (doláres EUA)

\begin{tabular}{|c|c|c|c|}
\hline \multirow[t]{2}{*}{ Hospital } & \multicolumn{3}{|c|}{ Estancia hospitalaria promedio (horas) } \\
\hline & $\begin{array}{c}\text { Servicios de LUI } \\
\text { a pacientes ingresadas }\end{array}$ & $\begin{array}{c}\text { Servicios de AMEU } \\
\text { ambulatorios }\end{array}$ & $\begin{array}{c}\text { Diferencia } \\
\text { (\% disminución) }\end{array}$ \\
\hline Bolivia/MS a & 65.65 & 24.92 & $-62.0 \%$ \\
\hline México/IMSSI ${ }^{b}$ & 150.58 & 65.73 & $-56.3 \%$ \\
\hline México/Oaxacac & $264.47^{1}$ & $180.22^{1}$ & $-31.9 \%$ \\
\hline $\begin{array}{l}\text { PerúCallaol y } \\
\text { Perú/Callao2 }^{\text {d }}\end{array}$ & 118.72 & $\begin{array}{l}45.14(1997) \\
33.45(2000)\end{array}$ & $\begin{array}{l}-62.0 \% \\
-72.0 \%\end{array}$ \\
\hline
\end{tabular}

${ }^{1}$ Costos de capacitación en AMEU incluidos en el estimado de pacientes externas; mientras tanto, en el estimado de pacientes ingresadas con servicio de LUI no se incluyen costos de capacitación.

a Billings et al., 2001; b Johnson et al., 1993b; ' Brambila y et al., 1999; d Benson et al., 1998; Benson y Huapaya, 2002

clave de los servicios sostenibles; pero las tarifas para las pacientes y otros gastos que ellas mismas asumen juegan, quizá, un papel importante para que se inclinen a buscar servicios profesionales de APA cuando los requieren. Considerando que la reorganización de los servicios puede reducir de manera importante los costos de oportunidad para las unidades, en algunos casos los administradores han trasladado estos ahorros a las pacientes reduciéndoles las tarifas. En el estudio Perú-Callaol, cuando se presentó a la directora del hospital la información probatoria del alto costo de los tratamientos con el LUI (un promedio de 119 dólares (EUA) por paciente) y el potencial para reducciones sustanciales con la AMEU practicada a pacientes ambulatorias, dicha funcionaria redujo a la mitad las tarifas para pacientes ambulatorias (de casi 32 a 16 dólares [EUA]) ${ }^{13}$ En términos generales, los gastos que se asumieron individualmente (incluyendo admisión, tarifas por el tratamiento, medicamentos y algunos suministros), disminuyeron de 52.98 a 37.40 dólares (EUA) después de la intervención. Cuando se realizó el seguimiento, en el 2000, el costo promedio para las pacientes era de 32.75 dólares (EUA). En el mismo seguimiento del 2000, el hospital estaba recuperando casi 98\% del costo total de provisión de los servicios de AMEU, en comparación con menos de la $\operatorname{mitad}(45 \%)$ antes de la intervención. ${ }^{21}$

\section{CONCLUSIÓN}

Los resultados de los estudios que se han resumido en este capítulo demuestran que las intervenciones piloto de APA que se efectuaron en varios países de América Latina en el periodo de 1990-2002, condujeron a mejoras significativas en la calidad de los servicios y a reducciones en los costos. Específicamente y en forma colectiva, los estudios muestran evidencia convincente de que:

- La adopción de la AMEU, una alternativa al LUI que es segura y eficaz para el tratamiento de mujeres con abortos incompletos, realizada por proveedores capacitados, es factible y deseable. 
- La reorganización de la APA como servicio ambulatorio, más que los cambios en la técnica clínica por sí sola, es clave para reducir la estancia hospitalaria promedio y los costos para la unidad. Además del cambio en la organización de los servicios, la capacitación integral de los proveedores y el apoyo y supervisión de la gerencia son igualmente esenciales para mejorar la calidad de los servicios. Con todo, la adopción de tecnologías nuevas como la AMEU facilita cambios concurrentes, como efectuar el tratamiento de abortos incompletos como servicio ambulatorio. ${ }^{10}$

- Existen alternativas de alta calidad para el manejo efectivo del dolor cuando se recurre a la AMEU, distintas a la sedación fuerte; pero los proveedores de servicios de salud —-médicos y enfermeras - deben estar dispuestos a interactuar brindando apoyo y tranquilizando a las mujeres antes, durante y después del procedimiento de evacuación uterina. Las necesidades que las mujeres tengan de medicamentos para el dolor deben satisfacerse desde que llegan a la unidad de atención a la salud y durante toda su estancia.

- En casi todos los estudios, las pacientes posaborto aceptaron la anticoncepción en tasas más altas que cuando no se ofrecían los servicios de APA. Para asegurar que las pacientes que deseaban prevenir o retrasar un embarazo salieran del hospital con información y un método, fue vital vincular de modo sistemático la anticoncepción con el tratamiento posaborto, colocando los anticonceptivos en la misma ubicación física.

- La consejería a pacientes siguió siendo un punto débil en los diversos estudios que examinaron este resultado, lo cual sugiere la necesidad de una mayor y más significativa capacitación y supervisión de los proveedores para fortalecer tal componente de la atención. Ésta es una de las razones principales para expandir el modelo original de APA a otro que explícitamente incluya el componente de consejería.

Los hallazgos de esta revisión señalan la necesidad de que los proveedores de atención a la salud, los administradores y quienes formulan políticas, busquen maneras sencillas y costo-efectivas para mejorar las prácticas y políticas relacionadas con el tratamiento de mujeres que buscan atención por complicaciones derivadas de un aborto. Señalan, igualmente, la necesidad de una serie de pasos en el nivel de los sistemas de salud para aumentar a escala estas promisorias intervenciones piloto y asegurar su sostenibilidad; esto es, la inclusión de la APA en la currícula de capacitación previa al servicio, de estudiantes de medicina, enfermería y partería, y la inclusión de instrumentos de AMEU en los sistemas de adquisiciones de las unidades de salud. La mejoría en el acceso y la calidad de la APA, implementada como se realizó en estos estudios de investigación operativa, si se toman a escala, contribuirán sin duda a reducir la mortalidad y morbilidad causadas por abortos inseguros.

Es notable, sin embargo, que ninguno de los estudios que se resumen en este documento haya explorado maneras de implementar el tercer elemento del modelo original de la APA — vincular a las mujeres con servicios de salud reproductiva y otros. Las estrategias para vincular a las comunidades con otros servicios estuvieron notablemente ausentes. Además, mientras que los estudios apuntan a beneficios a través de una APA mejorada, es importante reconocer que la APA es una medida de prevención secundaria que se ofrece después de que las complicaciones derivadas de un aborto se han presentado. Para prevenir el aborto inseguro deben ocurrir mejoras en la planificación familiar 
y en los abortos legales y electivos. Los servicios anticonceptivos deberían estar accesibles para todas las mujeres y parejas, incluyendo a las mujeres y varones adolescentes sexualmente activos. La anticoncepción de urgencia sirve como un importante respaldo en situaciones de relaciones sexuales no protegidas, incluyendo la violación. La provisión de servicios de aborto seguro y legal, que estén ampliamente disponibles para mujeres que los requieren, podría eliminar la incidencia de complicaciones de aborto y, en consecuencia, la necesidad de la APA, salvando la vida de las mujeres y reduciendo drásticamente los de por sí sobrecargados costos de los sistemas de salud.

\section{AGRADECIMIENTOS}

Los proyectos revisados en este artículo no hubieran sido posibles sin los esfuerzos incansables de profesionales de la salud, administradores, funcionarios, investigadores y agencias donantes, que son demasiado numerosos para que podamos extender nuestro agradecimiento en forma individual. Las autoras quisieran agradecer de forma especial a los siguientes revisores y evaluadores: Marian Abernathy, Tania Connaughton-Espino, Barbara Crane, James Foreit, Forrest Greenslade, Roxanne Henderson, Ronnie Johnson, Ricardo Pérez-Cuevas y Ricardo Vernon; lo mismo que a los co-autores adicionales del manuscrito de un análisis previo, Timothy Kina y Alison Friedman, por su colaboración para cotejar información básica de los estudios para los cuadros. La mayor parte de los estudios que se citan en este texto fueron financiados por el proyecto INOPAL III (Investigación Operativa y Asistencia Técnica en Planificación Familiar y Salud Reproductiva en América Latina y el Caribe) del Population Council, financiado por la Oficina de Población de la Agencia de los Estados Unidos para el Desarrollo Internacional (USAID). Una versión previa de este texto formó parte del Informe Final de INOPAL III, publicado en 1998 con el título Investigación Operativa en Salud Reproductiva, 1995-1998, Population Council, Nueva York.

\section{Referencias}

1. World Health Organization: Safe Abortion: Technical and Policy Guidance for Health Systems. Ginebra, 2003.

2. World Health Organization: Unsafe abortion. Global and regional estimates of the incidence of unsafe abortion and associated mortality in 2000, 4th edition. Ginebra, 2004 Disponible en: http://www.who.int/reproductive-health/unsafe_abortion/ [Acceso el 20 de mayo de 2004].

3. Grimes DA: Medical abortion in early pregnancy: a review of the evidence. En: Obstetetrics and Gynecology, 89, 1997:790-796.

4. Dudley S: Safety of abortion. Washington, D.C. National Abortion Federation, 2002. Disponible en: http://www.prochoice.org/ [Acceso el 23 de septiembre, 2002].

5. Greenslade FC, McKay H, Wolf M, McLaurin K: Post-abortion care: A women's health initiative to combat unsafe abortion. En: Advances in Abortion Care \# 26 4, 1994:1-4.

6. Corbett MR, Turner KL: Essential elements of postabortion care: Origins, evolution and future direction. En: International Family Planning Perspectives 29(3), 2003:106-111.

7. Fisher AA, Laing JE, Stoeckel JE, Townsend JW: Handbook for family planning operations research design, 2nd edition. Nueva York: Population Council, 1991.

8. Farfán O, Kestler JE, Abrego de Aguilar MM et al.: Información y asesoría en planificación familiar post-aborto. Experiencia en cuatro hospitales de Centroamérica. En: Revista Centroamericana de Ginecología y Obstetricia, 1997;7: 46-56.

9. Távara O L, Ramírez J Y: Atención del aborto incompleto no complicado. Lima: INPPARES, IPPF y Fundación Bergstrom, 1996. 
10. Billings DL, Fuentes V J, Pérez-Cuevas R: Comparing the Quality of Three Models of Postabortion Care Models in Public Hospitals in Mexico City. En: International Family Planning Perspectives, 29(3), 2003:112-120.

11. Forna F, Gülmezoglu AM. Surgical procedures to evacuate incomplete abortion (Cochrane Review). En: The Cochrane Library, Issue 4. Update Software. Oxford, 2001.

12. Johnson BR, Benson J, Bradley J, et al.: Costs of alternative treatments for incomplete abortion. World Bank Working Paper. Washington, DC: The World Bank, 1993.

13. Benson J, Huapaya V, Abernathy M, King TDN: Improving quality and lowering costs in an integrated postabortion care model in Peru: Informe final. Ipas, Population Council, Carrboro, NC, 1998.

14. Fuentes VJ, Billings DL, Cardona Pérez JA, Otero Flores JB: Una comparación de tres modelos de atención post-aborto en México. Documento de Trabajo No.14. México, D.F.: Population Council, 1998.

15. Brambila C, Langer A, Garcia-Barrios C, Heimburger A: Estimating costs of postabortion services at Dr. Aurelio Valdivieso General Hospital, Oaxaca, Mexico. En: Huntington D, PietPelon NJ (eds.) Postabortion Care: Lessons from Operations Research. Nueva York: Population Council, 1999.

16. Billings DL, Del Pozo E, Arévalo H: Testing a model for the delivery of postabortion care in the Bolivian public health system: Informe final. Ipas, Population Council, Carrboro, NC, 2001.

17. King TD, Abernathy M, Hord C, Nicholson LA, Benson J, Johnson BR, DATAPAC Cost and Resource Use Technical Working Group: A guide to assessing resource use in the provision of postabortion care: The DATAPAC Core Questionnaire Series (Module 3). Ipas, Carrboro, NC, 1998.

18. Diaz J, Loayza M, de Yépez YT, et al.: Improving the quality of services and contraceptive acceptance in the postabortion period in three public-sector hospitals in Bolivia. En: Huntington D, Piet-Pelon NJ (eds.) Postabortion Care: Lessons from Operations Research. Nueva York: Population Council, 1999.

19. Langer A, Garcia-Barrios C, Heimburger A et al.: Improving postabortion care with limited resources in a public hospital in Oaxaca, Mexico. En: Huntington D, Piet-Pelon NJ (eds.) Postabortion Care: Lessons from Operations Research. Nueva York: Population Council, 1999.

20. Medina R, Vernon R, Mendoza I, Aguilar C: Expansion of postpartum/postabortion contraception in Honduras. Informe final. Nueva York: Population Council, 2001.

21. Benson J, Huapaya V: Sustainability of postabortion care in Peru: Informe final. Ipas, Population Council, Carrboro, NC, 2002.

22. Baird TL, Gringle RE, Greenslade FC: MVA in the treatment of incomplete abortion: Clinical and programmatic experience. Ipas, Carrboro, NC, 1995.

23. Baird TL, Flinn SK: Manual vacuum aspiration: Expanding women's access to safe abortion services. Ipas, Chapel Hill, NC, 2001

24. Castleman L, Mann C: Manual vacuum aspiration for uterine evacuation: Pain management. Ipas, Chapel Hill, NC, 2002.

25. Gómez PI, Gaitán H, Nova C, Paradas A: Paracervical block in incomplete abortion using manual vacuum aspiration: Randomized clinical trial. En: Obstetrics and Gynecology 103, 2004:943-51.

26. Margolis A, Leonard AH, Yordy L: Pain control for treatment of incomplete abortion with MVS. En: Advances in Abortion Care 3, 1993:1-8.

27. Langer A, Heimburger A, García-Barrios C, Winikoff B: Improving postabortion care in a public hospital in Mexico. En: Haberland N, Measham D (eds.) Responding to Cairo: Case studies of changing practice in reproductive health and family planning. Nueva York: Population Council, 2002.

28. Solo J, Billings DL, Aloo-Obunga C et al.: Creating linkages between incomplete abortion treatment and family planning services in Kenya. En: Studies in Family Planning 30(1), 1999:17-27. 
29. Johnson B, Ndhlovu S, Farr S, Chipato T: Reducing unplanned pregnancy and abortion in Zimbabwe through postabortion contraception. En: Studies in Family Planning 33(2), 2002:195-202.

30. Lettenmaier C, Gallen ME: Why counseling counts. En: Population Reports Series J, No. 36, 1990

31. Rance S: Necesidad de información sobre el aborto. En: J\&G Revista de Epidemiología Comunitaria 4, 1990.

32. Gárate MR, Aliaga E, Huapaya V, et al.: A qualitative assessment of postabortion care in a Peruvian hospital. Ponencia presentada en la Reunión Anual de la American Public Health Association, Indianapolis, noviembre 1997:9-13.

33. Johnson BR, Benson J, Bradley J, Rábago Ordoñez A: Costs and resource utilization for the treatment of incomplete abortion in Kenya and Mexico. En: Social Science and Medicine 36, 1993:1443-1453.

34. King TDN, Benson J, Stein K: Comparing the cost of postabortion care in Africa and Latin America: The DATAPAC Project. Ponencia presentada en la Reunión Global sobre Atención Posaborto: Avances y Retos en Investigación Operativa, Nueva York, enero 1998:19-21. 

Sección

Experiencias de países 



\title{
La experiencia en Bolivia de la atención posaborto
}

\author{
Eliana del Pozo, ${ }^{a}$ Malena Morales, ${ }^{a}$ \\ José del Barco ${ }^{b}$ Carmen Cornejo ${ }^{b}$
}

\section{INTRODUCCIÓN}

En Bolivia, la tasa de mortalidad ha descendido significativamente entre los años 1994 y 2003, de 390 a 230 por 100000 nacidos vivos. ${ }^{1}$ Este dato refleja el número de mujeres fallecidas por causas relacionadas con el embarazo, parto y puerperio en los últimos cinco años. Pese al descenso, Bolivia continúa siendo el país con más alta mortalidad materna en América Latina: en la encuesta poscensal del 2000, se registraron 627 muertes por estas causas, y de ellas, $9.2 \%$ correspondió a hemorragias de la primera mitad del embarazo (HPME), es decir, a complicaciones del aborto inseguro. Aunque no existen cifras definitivas, se calcula que $35 \%$ de las muertes maternas se deben a esta última causa. $^{2}$

En el país, una mujer queda embarazada cada dos minutos; seis de cada diez no tenían la intención de concebir en el momento que lo hicieron, y hubieran preferido retrasar sus embarazos o simplemente evitarlos. Muchas de esas mujeres recurrirán al aborto en condiciones de alto riesgo, tanto así que algunas investigaciones afirman que día a día ocurren alrededor de 115 abortos, y que 600 de cada 1000 mujeres han abortado alguna vez durante su vida reproductiva. ${ }^{3}$

La política de salud en relación con el aborto es relativamente reciente. Se inicia en 1989 con el seminario-taller Lucha contra el aborto, organizado por el Ministerio de Salud y la Conferencia Episcopal. La consideración de este debate fue una de las principales motivaciones para introducir los servicios de anticoncepción en la prestación de servicios públicos en 1992. ${ }^{4}$ En 1994, se consideró el tratamiento de las complicaciones posaborto como un asunto prioritario de salud pública, siendo abordado en la Declaración de principios sobre población y desarrollo sostenible, ${ }^{5}$ que se presentó en la Conferencia Internacional sobre la Población y el Desarrollo (CIPD, Cairo, 1994), y se reiteró en

\footnotetext{
a Ipas, La Paz, Bolivia.

b Pathfinder International, La Paz, Bolivia.
} 
1999 con motivo de la conferencia Cairo+5, en el párrafo 63iii. El apoyo institucional a estas estrategias fue previsto en el Plan vida de reducción de la mortalidad materna e infantil $^{6}$ para reducir las complicaciones del aborto. En 1995 se estableció el Seguro Nacional de Maternidad y Niñez (SNMN), que fue ampliado en 1999 a Seguro Básico de Salud (SBS), y transformado en 2002 a Seguro Universal Materno Infantil (SUMI), que incluyó entre sus prestaciones la atención a mujeres con complicaciones de HPME.

\section{PROGRAMA DE ATENCIÓN A MUJERES CON HPME}

A partir de un estudio que el Ministerio de Salud encomendó a Ipas, en 1996 se acordó implementar la aspiración manual endouterina (AMEU) como una técnica alternativa al legrado uterino instrumental (LUI), con el propósito de reducir los gastos de hospitalización y mejorar la calidad de atención de las complicaciones del aborto. Este proceso fue formalizado en 1999 mediante la Resolución 0133 del Ministerio de Salud, que resolvió "adecuar los servicios de emergencia obstétrica para mejorar la calidad de las prestaciones, disminuyendo los costos de intervención y los tiempos de estadía en los servicios mediante la introducción de la AMEU en los servicios de atención posaborto". A partir de 1999, la cobertura y calidad de estos servicios se ha extendido continuamente gracias al apoyo técnico y financiero que la USAID y DFID han otorgado a Ipas y Pathfinder para ayudar al Ministerio de Salud a implementar el Programa de Atención a Mujeres con HPME. Este Programa se realizó en las capitales de los nueve departamentos del país, abarcando ocho hospitales especializados de tercer nivel, 53 hospitales básicos de segundo nivel y 57 centros de salud de primer nivel. Inicialmente, Pathfinder International e Ipas-Bolivia trabajaron en forma conjunta para poner en marcha el Programa en las ciudades de La Paz y Santa Cruz, hasta obtener un sistema estandarizado de capacitación, equipamiento y seguimiento. Para la extensión del Programa, cada organización se responsabilizó de cuatro departamentos, con excepción de La Paz, en donde se mantuvo el apoyo de ambas instituciones.

La estrategia de intervención implementada en Bolivia se realizó en cuatro etapas:

- Negociación y coordinación con quienes tomaban decisiones en los ámbitos nacional, departamental y local para la firma de convenios.

- Realización de un diagnóstico de necesidades en los centros elegidos para la intervención.

- Capacitación del personal (médicos, enfermeras, residentes, auxiliares de enfermería y otros) en el "Modelo integral de calidad" y la técnica de AMEU mediante una metodología activo-participativa, con sesiones teóricas y prácticas en las que el tema de los derechos humanos sexuales y reproductivos es un eje transversal. Esta modalidad de capacitación utiliza modelos pélvicos y práctica clínica en pacientes para asegurar la adquisición de habilidades y destrezas apoyadas en guías de aprendizaje y listas de verificación basadas en la competencia. La capacitación dura 40 horas con una dotación posterior de equipamiento para la AMEU, insumos y medicamentos básicos.

- "Supervisión capacitante" e instrumentalizada que pretende estandarizar el desempeño tanto del personal capacitado como del personal nuevo. Para ello, se elaboraron y emplearon instrumentos que miden la competencia y el grado de 
apropiación del protocolo de atención del Manual de normas, reglas, protocolos y procedimientos técnicos para el manejo de las hemorragias de la primera mitad del embarazo. Estos instrumentos permiten la interacción entre el supervisor y el supervisado, fortaleciendo así conocimientos y habilidades, así como obtener compromisos individuales para el mejoramiento continuo de la calidad del servicio.

Inicialmente, el modelo abarcaba tres componentes: servicios de planificación familiar posaborto, atención de urgencia a las complicaciones posaborto, y vinculación con otros servicios de salud sexual y reproductiva. ${ }^{\mathrm{C}}$ En septiembre de 2002, como consecuencia de la reformulación hecha al modelo por el Consorcio Atención Postaborto (véase "Elementos esenciales de la atención posaborto: un modelo ampliado y actualizado", de la Comisión Especial de Comunidad del Consorcio APA, en esta misma obra), se agregaron dos elementos: la orientación y asesoría y la vinculación con otros servicios de salud sexual y reproductiva, y servicios de salud en general.

\section{RESULTADOS}

Según las bases de datos de Ipas-Bolivia y Pathfinder International, el número de mujeres atendidas con AMEU en los centros de salud del Programa se ha incrementado de 702 en el año 2000, a 6005 en el 2003, para un total de 41278 usuarias atendidas por HPME con los dos procedimientos disponibles (LUI y AMEU) entre 2000 y 2003; de ellas, 16186 fueron atendidas con AMEU y 7494 con LUI. Sin embargo, la proporción de mujeres atendidas con AMEU aumentó de $11.6 \%$ en el año 2000, a 44\% en el año 2003.

En este periodo se orientó a 30576 mujeres atendidas por complicaciones hemorrágicas, de las cuales 12052 egresaron con anticoncepción y 12705 fueron referidas a otros servicios de salud sexual y reproductiva. En el año 2000, 54\% de las 6062 mujeres atendidas por HPME recibieron orientación sobre anticoncepción, y 19\% recibió un método anticonceptivo; en el 2003, mientras tanto, 79\% de las 13499 mujeres atendidas por HPME recibieron orientación y 30\% recibió un método anticonceptivo.

Entre los años 2000 y 2003, la permanencia hospitalaria de las mujeres descendió de 36 a 18 horas promedio en el caso del LUI, y de 18 a seis horas en los casos de AMEU. En ese mismo período, 3489 proveedores de salud fueron capacitados y otros 440 recibieron retroalimentación y actualización.

Si bien el SUMI reconoce el pago del equivalente de 8.90 dólares (EUA) por cada atención de HPME, independientemente de que el caso se haya resuelto con LUI o AMEU, el costo real del tratamiento con el legrado es de 16.20 dólares (EUA), mientras que con la AMEU es de 4 dólares (EUA). Al realizar un ejercicio de análisis de costos de las hemorragias resueltas con AMEU y LUI en el año 2003, resultó que resolver

\footnotetext{
${ }^{\mathrm{c}}$ En este trabajo, se entiende como servicios de salud reproductiva a los de embarazo, parto y puerperio; anticoncepción, citología vaginal, atención de enfermedades de transmisión sexual e infertilidad.
} 
7494 casos con el LUI tuvo un costo total para los hospitales de 129502 dólares (EUA); mientras tanto, la resolución de 6005 casos con AMEU tuvo un costo total de 24020 dólares (EUA). Esto significa que si los 7494 casos resueltos con el LUI se hubieran atendido con AMEU, los hospitales hubieran ahorrado el equivalente de 97526 dólares (EUA). Para resumir, la AMEU representa 25\% del gasto de cada caso resuelto con LUI.

\section{LECCIONES APRENDIDAS}

\section{En cuanto a políticas}

- La sensibilización de las autoridades departamentales de las ciudades de La Paz y Santa Cruz, y de los directores de los principales hospitales de las mismas ciudades de Bolivia, mediante una visita a servicios de APA en Perú, motivó y sostuvo el compromiso político adquirido. ${ }^{\mathrm{d}}$

- El trabajo de cabildeo realizado por Ipas-Bolivia y Pathfinder International ante las autoridades del Ministerio de Salud, permitió reducir la barrera económica de acceso a los servicios al incluir la atención a las HPME como parte del Seguro Básico de Salud, que posteriormente mantuvo el SUMI y que aún está vigente. Esa labor de cabildeo permitió que la anticoncepción posaborto y la reposición de equipos, insumos y medicamentos se incorporara al SUMI para ofertar esta prestación.

- Se conformó el Comité Interinstitucional Coordinador para la Atención Posaborto (CICAPA), que integraron organizaciones no gubernamentales, agencias de cooperación y el Ministerio de Salud, y que permitió elaborar y publicar el Manual de normas, reglas, protocolos y procedimientos técnicos para el manejo de las HPME, que reglamenta la atención de parte de los proveedores de salud. En el año 2004 se modificó el Manual con la introducción de servicios de atención de las HPME en el primer nivel de atención, la actualización tecnológica en AMEU con las cánulas EasyGrip producidas por Ipas, y la incorporación de los cinco elementos del Modelo de APA.

- El Registro Sanitario número M.I. 22976 y 22977/2001, otorgado por el Ministerio de Salud para la comercialización en Bolivia de la tecnología de la AMEU asegura la continuidad en el abastecimiento de equipos.

- La introducción del "Modelo de atención a las HPME" dentro de la currícula de las Facultades de Medicina y Enfermería en seis universidades, aseguró la continuidad de la formación de recursos humanos en este tema.

\footnotetext{
${ }^{\mathrm{d}}$ El intercambio de profesionales de salud interesados en la incorporación de la APA en sus servicios fue organizado por Ipas Bolivia e Ipas Perú. Directores de tres hospitales bolivianos y representantes del Ministerio de Salud de Bolivia, Ipas Bolivia e Ipas EUA, observaron la entrega de servicios en varios hospitales de Lima, Perú, y tuvieron la oportunidad de entrevistarse con profesionales que llevaban a cabo los programas de APA. Al regresar a Bolivia, se inició un proyecto nacional de investigación operativa sobre APA en los hospitales representados por los participantes.
} 


\section{En cuanto a instituciones}

- El procedimiento de AMEU es una técnica de fácil aplicación que no necesariamente requiere de especialistas en ginecología y obstetricia; médicos generales y otros proveedores debidamente capacitados pueden aplicarla en forma satisfactoria. Por ser una técnica que combina el uso de anestesia local paracervical con el manejo conductual del dolor, se puede utilizar sin la presencia de un anestesiólogo, lo cual facilita la resolución de casos con menor nivel de complejidad, que son la mayor parte de los establecimientos de salud.

\section{En cuanto a recursos humanos}

- La capacitación de proveedores de diferentes especialidades (ginecoobstetras, anestesiólogos, residentes, médicos generales, enfermeras, trabajadoras sociales, psicólogas y personal administrativo), ha permitido introducir el modelo en la oferta de atención integral a las usuarias.

- La capacitación, supervisión capacitante y la introducción del modelo de atención dentro de la currícula universitaria en las facultades de Medicina y Enfermería, son elementos necesarios para el sostenimiento de los servicios en el mediano plazo.

- Con la introducción del Programa se ha logrado establecer la oferta de servicios de orientación y anticoncepción; de esta manera, se fortalecen también los derechos de las usuarias.

\section{En cuanto a infraestructura y equipamiento}

- La entrega inicial y oportuna del equipamiento de AMEU y de los insumos en los servicios intervenidos permite implementar el modelo de inmediato.

- La existencia de un distribuidor comercial y el registro sanitario oficial permiten y garantizan la disponibilidad y accesibilidad de la tecnología de la AMEU para el sector público y privado.

- Es necesario integrar los servicios clínicos con los de suministros para garantizar la disponibilidad de los insumos; ello se facilita con la implementación del Sistema Nacional Único de Suministros (SNUS) ${ }^{\mathrm{e}}$ mediante las Farmacias Institucionales Municipales (FIM), su brazo operativo en las instituciones públicas de salud.

\section{En cuanto a las usuarias y la comunidad}

- La implementación del tratamiento ambulatorio de las HPME con anestesia local, facilitó la interrelación entre usuarias y proveedores y disminuyó los riesgos por el uso de anestesia general; al mismo tiempo, favoreció la satisfacción de las usuarias al permitir su más pronto regreso a casa.

\footnotetext{
e Este órgano de gobierno sirve para el manejo logístico y administrativo de todos los insumos y medicamentos del sistema de salud del país.
} 
- La orientación y asesoría alcanzó a $60 \%$ del total de mujeres atendidas por HPME; sin embargo, las pacientes que fueron tratadas con AMEU se beneficiaron más de esta práctica (81\%) que las tratadas con LUI (47\%).

- La anticoncepción posaborto aumentó después de la implementación del Programa. Sin embargo, tiene una relación directa con las usuarias que recibieron orientación durante su tratamiento; $40 \%$ de las mujeres que recibieron asesoría eligieron un método anticonceptivo.

\section{CONCLUSIONES}

El modelo de atención a mujeres con HPME, que incluye la resolución de este problema mediante las técnicas de LUI o AMEU, se ha incorporado en las políticas de salud oficiales de Bolivia. A fin de mejorar el acceso a los servicios y asegurar el sostenimiento del Programa, el SUMI ha incluido dentro de sus prestaciones la atención a las HPME sin costo para las usuarias.

La disponibilidad del Manual de normas, reglas, protocolos y procedimientos técnicos para el manejo de las HPME asegura la calidad de atención y estandariza el manejo de las usuarias que presentan este tipo de hemorragias.

Los hospitales y centros de salud que fueron objeto de la intervención, han implementado satisfactoriamente la técnica de la AMEU como parte de sus prestaciones cotidianas, disminuyendo los costos de la atención hospitalaria, reduciendo la duración promedio de la estancia hospitalaria y las complicaciones, y logrando mayores niveles de satisfacción de las usuarias.

En áreas rurales, una buena alternativa de atención a las HPME es la anestesia local, tomando en cuenta que los servicios de primer nivel no cuentan con anestesiólogos.

La capacitación de médicos generales y de proveedores intermedios en el tratamiento a las HPME con la técnica de AMEU, permitiría atender de manera ambulatoria a las usuarias en los servicios de menor nivel de complejidad, reduciendo la necesidad de la referencia y el riesgo de complicaciones durante el traslado.

\section{RECOMENDACIONES}

- Introducir la técnica de la AMEU en centros de primer nivel del área rural.

- Procurar mayor difusión entre los proveedores de salud y la comunidad en general, sobre las prestaciones del SUMI para atender las HPME.

- Gestionar con los Directorios Locales de Salud (instancia normativa de gestión compartida con salud, los municipios y la comunidad como parte del nuevo modelo de gestión) recursos para la adquisición y reposición de los equipos de AMEU, lo que permitirá dar continuidad al programa.

- Fortalecer y completar los servicios implementados en los nueve departamentos de Bolivia con supervisiones capacitantes permanentes, a fin de mejorar la calidad de la atención.

- Socializar y difundir el Manual de normas, reglas, protocolos y procedimientos técnicos para el manejo de las HPME entre los proveedores de salud de todos los niveles de atención. 
- Apoyar la incorporación del modelo al interior de los centros de educación superior para garantizar la sostenibilidad del programa.

- Fomentar la integración de las redes de salud para el seguimiento continuo del programa.

- Propiciar la constitución y funcionamiento de las redes sociales como organismos de control social, vigilancia comunitaria, referencia oportuna de usuarias con complicaciones, comunicación educativa y planificación participativa local.

- Desarrollar un sistema informático amigable que permita la recolección de la información y su análisis para la toma de decisiones.

- Fortalecer las redes de referencia y contrarreferencia en los lugares donde no existe atención a las complicaciones hemorrágicas de la primera mitad del embarazo.

\section{Referencias}

1. Instituto Nacional de Estadística: Salud de las mujeres en Bolivia. Divulgación de datos preliminares de la ENDSA 2003, La Paz, Bolivia, 2003.

2. Ministerio de Salud y Deportes: Programa Nacional de Salud Sexual y Reproductiva. Quinquenio 1997-2002. La Paz, Bolivia, 1999.

3. Dibbits I, Terrazas M: Hablar sobre el aborto no es fácil. La Paz, Bolivia: TAHIPAMU, 1995.

4. Del Pozo E: Debate sobre el aborto y la Iglesia. Ipas, La Paz, Bolivia, 1995.

5. Ministerio de Desarrollo Humano, Servicio Nacional de Salud: Declaración de principios sobre población y desarrollo sostenible, La Paz, Bolivia, 1994.

6. Ministerio de Desarrollo Humano, Servicio Nacional de Salud: Plan vida de reducción de la mortalidad materna e infantil, 1994 a 1997. La Paz, Bolivia, 1994. 



\title{
Calidad de la prestación \\ del servicio en la atención \\ posaborto en Guatemala
}

\author{
Edgar Kestler, ${ }^{a}$ Linda Valencia, ${ }^{b}$ \\ Vinicio del Vallec y Alejandro Silva ${ }^{c}$
}

\section{INTRODUCCIÓN}

Los ingresos hospitalarios por abortos incompletos, muchos de ellos complicados, continúan siendo un problema importante en la red de servicios hospitalarios de Guatemala. Además, el aborto es la cuarta causa de muerte materna en el país. ${ }^{1}$ Bajo la ley actual, el aborto electivo es ilegal y sólo está permitido para salvar la vida de la madre. ${ }^{2}$ En consecuencia, se realiza en secreto y en condiciones higiénicas deficientes, lo cual lleva a que las mujeres sufran serios problemas de salud que pueden incluso terminar en su muerte. El Ministerio de Salud Pública y Asistencia Social de Guatemala (MSPAS) y el Centro de Investigación Epidemiológica en Salud Sexual y Reproductiva (CIESAR), un centro afiliado al MSPAS, han trabajado estratégicamente desde el año 2003 para desarrollar e implementar un programa de atención posaborto (APA) con el mandato del MSPAS de reducir la mortalidad materna por aborto. Este programa enfatizó la implementación de intervenciones para mejorar el tratamiento quirúrgico para la evacuación endouterina e introducir asesoría y proporcionar métodos anticonceptivos efectivos antes del egreso hospitalario de la mujer.

Los hospitales distritales del país son unidades ubicadas en cada distrito de salud, que disponen de equipo multidisciplinario para desarrollar programas de prevención, recuperación y rehabilitación; se trata de centros de referencia de los puestos y centros de salud que atienden urgencias médicas las 24 horas del día los 365 días del año. Las principales intervenciones realizadas en 22 (67\%) de los 33 hospitales distritales fueron para fortalecer la capacidad técnica del personal médico y paramédico en el desarrollo de los pilares de la APA, buscar el sostenimiento del programa de APA, mejorar la infraestructura

\footnotetext{
a Centro de Investigación Epidemiológica en Salud Sexual y Reproductiva, ciudad de Guatemala, Guatemala.

b Unidad de Provisión de Servicios del Tercer Nivel, Ministerio de Salud Pública, ciudad de Guatemala.

c Programa Nacional de Salud Reproductiva, Ministerio de Salud Pública, ciudad de Guatemala.
} 
básica de los hospitales, ${ }^{\mathrm{d}}$ disponer del equipo necesario para realizar la aspiración manual endouterino (AMEU), desarrollar materiales de educación y comunicación relacionados con la técnica de AMEU y las bases de la mensajería, crear un sistema de vigilancia para monitorear la morbilidad y mortalidad relacionadas con las complicaciones del aborto, fortalecer las políticas de salud a través del cumplimiento de las normas y, finalmente, construir consensos sobre a la importancia del programa de APA.

Datos publicados ${ }^{3}$ muestran que entre junio de 2003 y diciembre de 2004, un total de 13928 mujeres con aborto incompleto fueron admitidas en los 22 hospitales distritales; de ellas, $8359(60 \%)$ presentaban abortos menores a 13 semanas de gestación. El análisis realizado mostró que el uso de la AMEU aumentó de 38 a 68\%. De igual modo, se encontró que la proporción de mujeres que recibió asesoría aumentó de 31 a $78 \%$. e $^{2}$ Por último, la proporción de mujeres que seleccionaron métodos anticonceptivos antes del egreso hospitalario aumentó también, de 20 a $49 \%$.

Estos resultados cuantitativos muestran el éxito del programa de APA en Guatemala. Sin embargo, como parte del seguimiento al desarrollo del programa, se hace necesario evaluar la calidad del servicio que en la actualidad se brinda a las pacientes posaborto para determinar si los objetivos establecidos al inicio del proyecto se cumplieron y permitir a los diseñadores de políticas y los gerentes de programas usar los resultados para tomar medidas correctivas. ${ }^{4}$

El presente texto ofrece los resultados de la evaluación de calidad que se realizó en una muestra aleatoria de 22 hospitales departamentales en donde se ha implementado el programa de APA. El objetivo general de la investigación fue evaluar la calidad de los servicios relacionados con la APA en la red hospitalaria del país. Como objetivos específicos se plantearon la necesidad de evaluar la satisfacción de la usuaria a través de una entrevista de salida, y conocer los niveles de satisfacción de la atención ofrecida a mujeres que ingresaron a los hospitales por aborto incompleto.

\section{MATERIAL Y MÉTODOS}

Durante los meses de enero a marzo de 2005, cinco profesionales previamente capacitados realizaron entrevistas de salida en dos hospitales. La entrevista de salida es una herramienta de medición de la satisfacción de la usuaria y de evaluación de la gestión del programa de APA. La entrevista se realizó el mismo día que la usuaria egresaba del hospital al concluir su tratamiento por aborto incompleto o sus complicaciones. Se hizo contacto con las mujeres cuando abandonaban el hospital (en los primeros 100 metros), y se les solicitó su consentimiento para hacer la entrevista. En las preguntas que requerían un puntaje se utilizó una escala de uno a diez; para mejor comprensión de la usuaria, el número mínimo se identificaba con una carita triste y el mayor con una carita feliz.

\footnotetext{
d Se reconstruyeron áreas de la misma unidad que no se utilizaban o estaban subutilizadas usando fondos mínimos del proyecto, incluyendo la construcción de paredes divisorias, la apertura de ventanas y el mejoramiento de la ventilación.

${ }^{\text {e }} \mathrm{La}$ asesoría incluye, entre otros temas, discusiones sobre los derechos sexuales y reproductivos, uso de los métodos anticonceptivos y conceptos básicos sobre los peligros del aborto inducido en condiciones de riesgo.
} 
Los criterios de participación en el estudio fueron que la mujer hubiera ingresado al hospital para tratamiento del aborto incompleto, sin importar la edad gestacional y las complicaciones a su ingreso, y que tuviera egreso indicado después del tratamiento médico. No se entrevistaron mujeres que tuvieron egreso hospitalario contraindicado, ni mujeres que no hablaran castellano.

\section{CÁLCULO DE LA MUESTRA}

Se realizó un diseño de muestreo estratificado y por conglomerados; el personal que estaba a cargo de los hospitales fueron los estratos, mientras los conglomerados fueron los 22 hospitales participantes del programa, tomando en cuenta el número de abortos admitidos cada mes. Finalmente, el tamaño de la muestra se calculó tomando en cuenta los parámetros de la estimación de APA a nivel nacional y una pérdida de $10 \%$ por no respuesta, entre otros factores. El tamaño de muestra calculado fue de 211 casos de mujeres que egresaron de tratamiento de aborto incompleto. Dado que se tenían cinco estratos o personas a cargo de los grupos de hospitales, se calculó un tamaño de muestra inicial (mujeres que egresaban después del tratamiento por aborto incompleto) por estrato de $211 / 5=42$ casos por persona. Por último, para fortalecer el cálculo de la muestra, se asignaron 50 entrevistas por persona, lo que hizo que el total de muestra para el nivel nacional fuera de 250 .

La muestra de hospitales seleccionados al azar incluyó los de Antigua, Cobán, Cuilapa, Chimaltenango, Chiquimula, Mazatenango, Quetzaltenango, Retalhuleu, Totonicapán y Zacapa, en donde se entrevistaron a 25 mujeres por hospital. Para el estudio se diseñó un cuestionario estructurado con preguntas cerradas; de ellas, cinco evaluaban la calidad del tratamiento para la evacuación uterina, seis valoraban la calidad de la asesoría ofrecida, cuatro se referían al ofrecimiento de métodos anticonceptivos efectivos antes del egreso hospitalario, y las dos últimas medían la satisfacción general de la mujer durante su estancia hospitalaria.

\section{RESULTADOS}

De las 250 mujeres entrevistadas, 19\% correspondió a mujeres adolescentes menores de 19 años; 47\% fueron mujeres de entre 20 y 29 años; 30\% representaba a mujeres de entre 30 y 39 años, y $4 \%$ eran mujeres de 40 a 43 años.

\section{Tratamiento o servicio de evacuación endouterina}

Las preguntas sobre el tratamiento evaluaban la percepción que la mujer tenía sobre la atención recibida para la evacuación endouterina. Uno de los aspectos que se enfatizan durante los cursos de capacitación en APA se refiere al derecho que las mujeres tienen a conocer la información sobre los métodos disponibles para realizar dicha evacuación; su derecho a esta información les concede la prerrogativa de elegir el método que más les convenga. Los datos mostraron que hay todavía deficiencia por parte del personal médico para explicar estos avances de la medicina: sólo a $18 \%$ de las mujeres se les 
explicó que existían tratamientos diferentes para la evacuación endouterina. Sin embargo, llama la atención que cuando se explicaban las diferentes técnicas y se les pedía seleccionar la que más les convenía, 12\% de las mujeres eligieron la técnica de la AMEU, en comparación con 3\% que seleccionó el LUI; 66\% dijo haber recibido información sobre las precauciones y señales de peligro por el procedimiento; la información más proporcionada fue sobre dolor (24\%), fiebre (21\%) y hemorragia (19\%). Un 2\% recibió información sobre otras señales de peligro posteriores al procedimiento.

Sólo 65\% sabía el tipo de anestesia que se había utilizado durante la evacuación endouterina; $86 \%$ de estas mujeres dijeron haber sentido poco dolor durante el tratamiento, y $7 \%$ dijo haber sentido mucho o regular dolor, respectivamente. De las mujeres a quienes se les practicó la AMEU, 14\% dijo haber experimentado mucho dolor, 14\% señaló un dolor regular, y $72 \%$ habló de poco o nada de dolor. Cabe anotar que con la AMEU la mujer está despierta y que se utiliza anestesia paracervical además del soporte de la asesoría que se brinda durante el procedimiento.

\section{Consejería}

Respecto a la consejería ofrecida durante la hospitalización, las respuestas muestran que sus efectos medidos, como sentirse apoyada durante la estancia hospitalaria a raíz de un evento emocionalmente difícil como es el aborto, y saber la razón de su hospitalización, presentan proporciones altas (94 y 97\%, respectivamente). Sin embargo, sólo 65\% de las mujeres dijeron conocer uno de los principales mensajes que se insiste se ofrezca durante la asesoría - el regreso de la ovulación posaborto en los 15 días posteriores al procedimiento y la posibilidad de quedar embarazada-; al verificar la exactitud del conocimiento mediante la pregunta de en cuántos días puede volver a quedar embarazada después del procedimiento de evacuación endouterina, sólo $21 \%$ respondió correctamente que podía quedar embarazada entre 14 y 15 días después del tratamiento; $38 \%$ creía que podía ocurrir un embarazo después de 20 días, $61 \%$ de las mujeres reportaron también que los prestadores les habían preguntado si deseaban embarazarse pronto.

\section{Anticoncepción posaborto efectiva antes del egreso hospitalario}

De las mujeres entrevistadas, $86 \%$ recibió información sobre sus opciones anticonceptivas. A pesar de que 58\% había aceptado utilizar algún método anticonceptivo, únicamente 57\% egresó con uno. Sólo una mujer seleccionó un método anticonceptivo no moderno. Así también, 72\% de las entrevistadas manifestaron que la información sobre métodos anticonceptivos ofrecida durante la hospitalización fue suficiente para la selección de uno de ellos.

\section{Satisfacción general}

En general, las mujeres entrevistadas manifestaron una buena satisfacción por la atención recibida del sistema de salud: 94\% dijo que recomendaría el hospital a una amiga 
para el tratamiento de un aborto incompleto; sólo 2\% dijo haber recibido algún maltrato por parte de cualquier persona durante su estancia.

\section{CONCLUSIONES}

Hablar de calidad es referirse a un conjunto de características, atributos y especificaciones que los servicios poseen y que permiten clasificarlos en categorías relacionadas con la satisfacción de necesidades y expectativas de las usuarias. Las principales características de los programas para la APA están dadas por la tecnología ofrecida (procedimiento de AMEU y métodos anticonceptivos); por la forma en que se brinda la información (claridad, utilidad, confidencialidad, derecho a decidir y actualidad), y por los servicios ofrecidos (oportunidad, cortesía, respeto, apego a normas técnicas, entre otros). El cumplimiento de estas acciones se evaluó en una entrevista de salida como herramienta de medición de la satisfacción que la usuaria manifestó hacia el programa de APA.

En general, el respeto a los derechos reproductivos de la usuaria, medidos a través de conocer y seleccionar libre y voluntariamente el método de evacuación endouterina (LUI o AMEU) y su elección con base en la información ofrecida a la mujer, no es cumplido por el personal de salud; por ello, es necesario que continúe la capacitación sobre la importancia del cumplimiento de tal derecho. Sin embargo, lo que sí se cumple es el derecho de la mujer a decidir de forma libre y voluntaria el método anticonceptivo que desea. ${ }^{5}$

De las entrevistadas, $57 \%$ egresó con un método anticonceptivo efectivo: estos datos son muy parecidos a los que se reportan en los indicadores de proceso que el programa recolecta de manera rutinaria. Estos datos confirman, asimismo, la aceptación y predilección que las mujeres de Guatemala tienen hacia el método inyectable (38\%), y son parecidos al diagnóstico nacional publicado por el Ministerio de Salud Pública de Guatemala en el año 2002. ${ }^{6}$ Finalmente, 94\% de las usuarias entrevistadas manifestaron que recomendarían el hospital a una familiar o amiga en caso de requerir tratamiento de complicaciones derivadas de un aborto, lo que indirectamente refleja su satisfacción con la atención médica recibida.

A pesar de que las autoridades de salud de Guatemala han asumido un liderazgo para mejorar la calidad de la atención a la salud de las mujeres introduciendo el concepto de APA en los 22 hospitales distritales, es necesario que esta implementación se realice en toda la red hospitalaria del país. Con los resultados de la investigación que aquí se presentan, se comprueban excelentes resultados sobre a la introducción de métodos anticonceptivos posaborto en los hospitales intervenidos. Los datos comprueban, además, que más de la mitad de las mujeres admitidas por abortos incompletos egresan del hospital con un método anticonceptivo efectivo, a pesar de que no existe información sobre la continuidad en el uso del método seleccionado; tampoco se sabe si la mujer vuelve a hacer contacto con los servicios de salud en meses subsiguientes. Será necesario realizar esfuerzos en un futuro próximo para obtener este tipo de información.

\section{AGRADECIMIENTOS}

Este trabajo fue posible gracias a la activa participación del personal de salud de la red de servicios hospitalarios de Guatemala en el Programa Nacional de Atención Posaborto. Agradecemos también a los facilitadores 
$40 \quad \begin{aligned} & \text { Capítulo } 4 \\ & \text { Avances en la atención posaborto en América Latina y el Caribe . . . }\end{aligned}$

hospitalarios: Francisco Ramírez, Leonardo Ortuño, Consuelo Arriola, Roberto Flores, Ivannova Ruiz, Marisol Sandoval y María del Rosario Nájera, por el dedicado trabajo y profesionalismo que mostraron durante el programa. Finalmente, agradecemos el apoyo económico de la Fundación Erik E. y Edith H. Bergstrom que hizo posible este proyecto.

\section{Referencias}

1. Ministerio de Salud Pública y Asistencia Social de Guatemala: Línea basal de mortalidad materna para el año 2000. Informe final. Guatemala, marzo, 2003.

2. Código Penal de Guatemala, Decreto Núm. 17-73. Artículos 133, 137, 1999.

3. Kestler E, Valencia L, Del Valle V, Silva A: Scaling-Up Postabortion Care (PAC) in Guatemala: Initial Success at National Level. En: Reproductive Health Matters 14(27); 2006, 138-147.

4. Van Driel ML, De Sutter AI, Christiaens TC et al:: Quality of care: The need for medical, contextual and policy evidence in primary care. En: Journal of Evaluation in Clinical Practice 11 (5), 2005, 417-429.

5. Barnett B: Quality focuses on clients' needs. En: Network 17(4); 1997, 13-7.

6. Ministerio de Salud Pública y Asistencia Social de Guatemala. 2002. Expandiendo opciones en salud reproductiva. Diagnóstico para identificar intervenciones prioritarias que mejoren el acceso y la calidad de los servicios básicos de salud materna en Guatemala. Organización Mundial de la Salud, Organización Panamericana de la Salud. Guatemala. 


\section{Atención posaborto en Honduras}

Ruth Maria Medina ${ }^{a}$ y Ricardo Vernon ${ }^{b}$

\section{INTRODUCCIÓN}

En Honduras, el aborto está prohibido en cualquier situación; la ley define sanciones al proveedor de servicios de salud, a la mujer y a cualquier persona implicada en la interrupción voluntaria de un embarazo; por ello, prácticamente todos los procedimientos se realizan en condiciones de inseguridad y clandestinidad, lo que ocasiona graves riesgos para la salud de las mujeres. Según la Encuesta de Mortalidad Materna de 1996, ${ }^{1}$ hasta $10 \%$ de las muertes maternas se deben al aborto, sin que pueda determinarse cuántas de esas muertes pueden atribuirse al aborto provocado, inseguro y clandestino.

A nivel nacional, no existen cifras reales sobre el número de interrupciones de embarazos que ocurren cada año, pues las mujeres que no tienen complicaciones derivadas de abortos inducidos no acuden a los servicios de salud, y la mayoría de las que llegan a tenerlas no acuden a los servicios públicos por temor a ser penalizadas. Aun así, la segunda causa de los egresos hospitalarios de mujeres son las complicaciones de abortos mal practicados, sólo superada por los partos sin complicaciones. ${ }^{2}$

El estigma que rodea el aborto inducido suele influir negativamente sobre la atención que se brinda a las mujeres que acuden a las unidades por un aborto espontáneo, quienes también requieren una atención inmediata de calidad y con calidez. En ambos casos, la atención a las mujeres se había centrado, tradicionalmente, en el tratamiento de urgencia, sin buscar satisfacer las múltiples necesidades de información, orientación y servicios de salud reproductiva de otro tipo, como los de atención a enfermedades de transmisión sexual, la citología vaginal o infertilidad. Inclusive, era frecuente encontrar casos en donde la evacuación endouterina se hacía en forma tardía — hasta dos días después

\footnotetext{
a Secretaría de Salud, Región Metropolitana de Tegucigalpa, Honduras.

b Programa Fronteras de la Salud Reproductiva, Population Council, México, D.F.
} 
del ingreso al hospital-, lo que obligaba a que la mujer permaneciera en ayuno prolongado y sin ninguna explicación sobre su estado de salud. Esta situación se atribuía a actitudes punitivas y moralistas del personal sanitario.

En 1995, la Secretaría de Salud reconoció abiertamente que el aborto que ocurre en condiciones de riego era una de las principales causas de muerte materna; fue por eso que se diseñaron normas de atención integral a la mujer, normas de manejo de urgencias obstétricas y otros protocolos de atención para lograr que quienes acudían a los servicios de salud con un aborto en curso - sin importar la causa - recibieran un trato digno, humano y de calidad. Cabe aclarar que tales normas y protocolos se desarrollaron en el contexto de un programa amplio que daba un papel central al fortalecimiento y ampliación de los servicios de anticoncepción, de la atención obstétrica de urgencia y de la atención del parto por personal calificado en general, y del parto institucional en particular. ${ }^{3}$

\section{PRUEBA PILOTO DE UN PROGRAMA DE ATENCIÓN POSEVENTO OBSTÉTRICO}

El primer paso para desarrollar en Honduras los programas de atención posaborto se dio en el contexto de una investigación operativa hecha entre 1996 y 1998 en el Hospital Materno Infantil de Tegucigalpa, el más grande y de mayor cobertura en el país, con apoyo del Population Council. En esta investigación se hizo un estudio diagnóstico inicial para identificar las necesidades de las mujeres que tenían un evento obstétrico (parto, cesárea o aborto). Con base en esa información se desarrolló y probó un modelo para atender a tales necesidades. ${ }^{4}$

El diagnóstico incluyó un estudio de observación sobre la manera en que el hospital ofrecía los servicios, así como entrevistas a todas las mujeres que habían tenido un evento obstétrico; estas entrevistas ocurrían al momento de ser dadas de alta del hospital. Los estudios mostraron que la mayoría de las mujeres que ingresaban con un aborto incompleto deseaban recibir un método anticonceptivo antes de su alta, pero que el personal rara vez lo ofrecía. Los autores distinguieron, igualmente, la importancia de informar a las mujeres sobre el tratamiento que recibían dentro del hospital y acerca de los cuidados que debían tener al egresar, al igual que la necesidad de establecer protocolos para el manejo del dolor y disminuir el tiempo de la estancia hospitalaria.

Con base en estos insumos se diseñó un modelo de atención que incluía la sensibilización de médicos, enfermeras y auxiliares de enfermería sobre el problema existente; la capacitación en metodología anticonceptiva, en inserción del dispositivo intrauterino y en asesoría; la oferta sistemática de métodos anticonceptivos; y el uso de la aspiración manual endouterina (AMEU), técnica en la cual se ofreció capacitación en Nicaragua a personal médico, contando con el apoyo de Ipas. El proyecto proporcionó también el equipo necesario, elaboró material educativo para las usuarias y desarrolló protocolos para el manejo del dolor.

En los tres años de duración del proyecto se entrevistaron, al ser dadas de alta, a 100 mujeres atendidas por complicaciones derivadas de abortos. Los resultados mostraron que en 1997, después de la intervención, hasta $80 \%$ de quienes fueron hospitalizadas por abortos incompletos fueron informadas sobre su condición de salud y el tratamiento que habían recibido, y que más de la mitad recibieron un método anticonceptivo 
antes del egreso. Se logró, asimismo, que 50\% de los procedimientos fueran realizados con AMEU, lo que disminuyó el periodo de recuperación y estancia hospitalaria, y liberó el uso de las salas de séptico y de operaciones en donde solían hacerse los legrados uterinos instrumentales. Finalmente, los niveles de dolor reportados disminuyeron. ${ }^{4}$

\section{INVESTIGACIÓN OPERATIVA SOBRE UN MODELO DE EXTENSIÓN DE LOS SERVICIOS}

Con base en la experiencia del primer proyecto, entre 1999 y 2001 la Secretaría de Salud extendió los servicios de atención posevento obstétrico a otros cinco hospitales con el apoyo del Programa Fronteras de la Salud Reproductiva del Population Council. La experiencia del primer proyecto permitió desarrollar un modelo para expandir los servicios, que incluía como primer paso la elaboración de un diagnóstico para identificar las necesidades de capacitación y equipamiento. El diagnóstico mostró que cinco de los siete hospitales que se incluyeron en el proyecto ofrecían ya algunos servicios de anticoncepción posevento obstétrico, pero que en tres de ellos la cobertura de anticoncepción en las pacientes al momento de ocurrir el alta hospitalaria era menor a 5\%; los dos restantes tenían una cobertura de 19 y $28 \%$. El diagnóstico mostró también que dos hospitales no ofrecían condiciones propicias para participar en la actividad de fortalecimiento, por lo que el proyecto se concentró en los hospitales ubicados en las ciudades de Juticalpa, La Ceiba, La Esperanza, Santa Rosa y Tegucigalpa (Maternidad del Hospital General San Felipe). ${ }^{5}$

Al igual que en el Hospital Escuela, a los prestadores de servicios del hospital y de los centros de salud adyacentes se les capacitó en consejería, metodología anticonceptiva y técnicas de comunicación y promoción (la inclusión del personal de los centros de salud permitió fortalecer un sistema de referencias de las complicaciones que se detectaran). Del mismo modo, se amplió la variedad de métodos disponibles introduciendo el dispositivo intrauterino posparto-posaborto, y se proporcionó el equipo faltante requerido para prestar los servicios y el material educativo para pacientes. Finalmente, se celebraron reuniones trimestrales con los prestadores de servicios de las salas de ginecoobstetricia a fin de analizar las estadísticas de servicios y los resultados de las encuestas a usuarias, un elemento clave que permitió enfocar los esfuerzos del personal en la consecución de logros medibles. Se hicieron tres encuestas —inicial, intermedia y final-, que permitieron entrevistar, respectivamente, a 24, 59 y 71 mujeres en posaborto antes del alta hospitalaria.

Las mujeres que ingresaron por un aborto incompleto representaron cerca de $10 \%$ de todos los eventos obstétricos atendidos. Los datos de las 154 mujeres entrevistadas en las encuestas inicial, intermedia y final mostraron que, en comparación con las mujeres atendidas por parto o por cesárea, quienes ingresaron por un aborto complicado tenían mayor edad y también un promedio mayor de embarazos previos. Una proporción más grande era soltera, y dos terceras partes no querían tener más hijos en el futuro. Sólo una cuarta parte deseaba el embarazo al ocurrir, y aunque $60 \%$ hubiera preferido no embarazarse, cuando ello sucedió, en efecto, $30 \%$ pensó que estaba bien que así hubiera ocurrido. Un poco más de $20 \%$ dijo que estaba usando un método cuando el embarazo se presentó. En general, los datos sugerían que cuando menos una tercera parte de las mujeres entrevistadas habían tenido un aborto espontáneo. Cerca de $70 \%$ dijo que su pareja sabía que estaba hospitalizada, y de ellas, más de $70 \%$ indicó que su 
pareja estaba presente en el hospital. Cerca de $80 \%$ señaló que le gustaría que el personal del hospital hablara con la pareja acerca del tratamiento que se le había dado, los cuidados que debía observar al regresar a casa y los métodos anticonceptivos que podía utilizar para evitar un nuevo embarazo, lo que subrayó la importancia de involucrar a la pareja en los programas de atención posaborto.

Las reuniones con el personal de salud se centraron en el análisis de cuatro variables dependientes: cobertura de anticoncepción posevento obstétrico, proporción de mujeres que decían haber recibido información sobre métodos anticonceptivos durante su estancia, la proporción que decía que les habían ofrecido métodos, y la demanda insatisfecha de anticoncepción, que se define como la proporción de mujeres que decían haber deseado un método antes del egreso hospitalario sin que, en efecto, lo hubieran recibido. La cobertura de anticoncepción posaborto aumentó de $13 \%$ en la encuesta inicial a 54\% en la final; la proporción de mujeres que recibieron información sobre métodos anticonceptivos durante su estancia aumentó de 17 a $85 \%$, cifra similar a la de la oferta de métodos; mientras tanto, la demanda insatisfecha disminuyó de 48 a $21 \%$. Los datos confirmaron la buena aceptación de los servicios de atención posaborto, tanto para los prestadores como para los usuarios de los servicios. ${ }^{5}$

\section{EXTENSIÓN AL RESTO DEL SISTEMA HOSPITALARIO}

Desde 2001, cuando la primera ola de expansión terminó, la Secretaría de Salud ha extendido los servicios integrales de atención posaborto a toda la red hospitalaria que existe en el país, que incluye los hospitales nacionales Mario Catarino Rivas y Materno Infantil, los hospitales regionales del Sur, de Occidente en Santa Rosa de Copán y el San Francisco, y los hospitales de área Gabriela Alvarado, El Progreso, Puerto Cortés, Santa Bárbara, Tela y Tocoa. Con el apoyo técnico y financiero de diferentes agencias donantes, se ha dotado a los hospitales de equipo y de los insumos necesarios, y se ha capacitado al personal para prestar los servicios de APA, incluyendo el tratamiento de la urgencia con la técnica de AMEU y los programas de anticoncepción posevento obstétrico que están incluidos en las normas oficiales de prestación de los servicios. ${ }^{6}$ Sin embargo, para mejorar la calidad es necesario superar múltiples problemas, incluyendo la poca disposición del personal para proporcionar la información y asesoría que las pacientes requieren, la carencia de recursos humanos, la falta de equipo completo de AMEU y de espacios adecuados para prestar los servicios, así como los horarios restringidos de atención.

\section{LA APA EN EL PRIMER NIVEL DE ATENCIÓN}

En cuanto a la atención ambulatoria de las mujeres con abortos incompletos y complicados en las comunidades y los centros de salud, debe decirse que aún queda mucho por hacer, pues las actividades para que ello sea posible inician apenas en algunos lugares, mientras que en otros están en proceso de fortalecimiento. Sin embargo, se han establecido normas de atención ${ }^{7}$ y se ha iniciado la capacitación y el equipamiento para que los servicios puedan proporcionarse. Las normas indican que:

- En el ámbito comunitario, la partera tradicional capacitada debe poder reconocer los síntomas y signos de un aborto y de algunas complicaciones graves posaborto, 
dado que es ella quien hace la referencia al centro de salud más cercano para que la paciente pueda recibir el tratamiento necesario.

- Los Centros de Salud Rurales (CESARES), cuyo personal son auxiliares de enfermería, se limitan a realizar el diagnóstico basados en la historia clínica y el examen físico (no pélvico), por lo que sólo pueden prestar una atención básica elemental de acuerdo con lo que establece la Norma nacional de atención a la salud materna-neonatal 2005, y referencia urgente al nivel hospitalario que pueda atender integralmente a la usuaria.

- Los Centros de Salud con Médico (CESAMO), situados en áreas urbanas, cuentan con personal médico capacitado y algún equipo y medicamento apropiados. En ellos se hace la preparación del traslado. En algunas unidades de salud, y sobre todo en ciudades importantes como Tegucigalpa, la evacuación endouterina se realiza con AMEU; el resto realiza la referencia urgente al nivel hospitalario.

- En los hospitales, si el médico general capacitado y/o el ginecoobstetra diagnostica aborto incompleto, el manejo se realiza de acuerdo con la cantidad de sangrado y la edad gestacional, y dependiendo también si se trata de un aborto séptico o no. De preferencia, la evacuación endouterina se lleva a cabo con la técnica de AMEU. Igualmente, se atienden las complicaciones posaborto y se maneja el dolor con anestesia local o general. La Norma nacional de atención a la salud materna-neonatal 2005 hace hincapié en la importancia de orientar a la mujer sobre el uso de métodos anticonceptivos y de suministrarle los que estén a su alcance.

Se excluye que en el futuro los esfuerzos seguirán orientados a brindar una atención de calidad a las mujeres que tienen un aborto incompleto o con complicaciones, así como a prevenir los embarazos no deseados.

\section{AGRADECIMIENTOS}

Algunos de los estudios cuyos resultados aparecen en este artículo se realizaron con el generoso apoyo del pueblo estadounidense a través de la Agencia de los Estados Unidos para el Desarrollo Internacional (USAID), bajo los términos del Acuerdo de Cooperación No. HRN-A-00-98-00012-00 (Programa Fronteras de la Salud Reproductiva del Population Councill. Los contenidos son responsabilidad de los autores y no necesariamente reflejan los puntos de vista de USAID, del Gobierno de EUA o del Programa Fronteras de la Salud Reproductiva.

\section{Referencias}

1. Secretaría de Salud de Honduras. (1997). Encuesta de mortalidad materna 1996. Tegucigalpa, Honduras, 1997

2. Secretaría de Salud de Honduras: Boletín de información estadística de atención hospitalaria. Departamento de Planeación y Estadística. Secretaria de Salud. Tegucigalpa, Honduras. 2001.

3. Secretaría de Salud de Honduras. Departamento de Atención Integral a la Mujer. Programa de Disminución de la Mortalidad Materna. Secretaría de Salud, Teguigalpa, Honduras, 1996.

4. Medina R, Lundgren R, Mendoza I: Fortalecimiento del Programa de Planificación Familiar Posparto y Posaborto en el Hospital Escuela Bloque Materno Infantil, Secretaria de Salud, Honduras. Informe final. INOPAL III. Tegucigalpa, Honduras, Population Council, agosto, 1998. 
$46 \quad \begin{aligned} & \text { Capítulo } 5 \\ & \text { Avances en la atención posaborto en América Latina y el Caribe . . . }\end{aligned}$

5. Medina R, Vernon R, Mendoza I, Aguilar C: Expansión de la anticoncepción posparto/posaborto en Honduras. Informe final. Secretaría de Salud de Honduras y Fronteras/Population Council, Tegucigalpa, Honduras, 2000.

6. Secretaría de Salud de Honduras: Normas y procedimientos para la atención integral a la mujer. Secretaría de Salud de Honduras, septiembre, 1999.

7. Secretaría de Salud de Honduras: Norma nacional de atención a la salud materna-neonatal 2005. Tegucigalpa, Honduras. 


\title{
Atención posaborto: la experiencia de México en el mejoramiento de los servicios
}

\author{
Deborah L.Billings, ${ }^{a}$ Deyanira González de León, ${ }^{b}$ \\ Rubén Ramirez ${ }^{a}$ y M. Virginia Chambers ${ }^{c}$
}

\section{INTRODUCCIÓN}

A 10 años de la Conferencia Internacional sobre la Población y el Desarrollo (CIPD, Cairo, 1994), un importante reto para los sistemas de salud a escala internacional es lograr una amplia disponibilidad de servicios de atención posaborto (APA) para el mayor número posible de mujeres. ${ }^{1}$ Tal reto cobra una relevancia particular en el contexto de los países en desarrollo, cuyas leyes sobre el aborto suelen ser restrictivas y en los cuales la mortalidad y morbilidad asociadas a la interrupción del embarazo practicado en condiciones inseguras es elevada.

En este capítulo se revisa el contexto y se analiza la disponibilidad y calidad de los servicios de APA en México, donde las principales instituciones de salud del sector público - Secretaría de Salud (SSA), Instituto Mexicano del Seguro Social (IMSS), Programa IMSS Oportunidades y el Instituto de Seguridad y Servicios Sociales para los Trabajadores del Estado (ISSSTE) — han instrumentado programas para que la APA sea un componente rutinario de los servicios de obstetricia que se ofrecen en los hospitales de segundo y tercer nivel de atención; sólo dos de estas instituciones —el Programa IMSS Oportunidades y la SSA - han diseñado y operado programas para incorporar la APA con la aspiración manual endouterina (AMEU) en unidades de primer nivel de atención del medio rural.

Los beneficios del uso de este modelo en México hablan de una mayor satisfacción de las usuarias y los proveedores, del mejoramiento de la calidad técnica de los servicios, del aumento de la anticoncepción posaborto, de una disminución importante en el tiempo de estancia hospitalaria y del abatimiento de los costos de la atención. ${ }^{2-5}$ Hasta la fecha

\footnotetext{
a Ipas México, A.C., México, D.F.

b Universidad Autónoma Metropolitana, Unidad Xochimilco, México, D.F.

c Ipas, Chapel Hill, N.C., EUA.
} 
se calcula que los programas de capacitación en APA con AMEU han cubierto a más de 30000 prestadores de servicios de salud en todo el territorio nacional. ${ }^{6}$

\section{CONTEXTO DEL ABORTO EN MÉXICO}

En México, el aborto está penalizado. Sin embargo, los códigos penales de las 32 entidades federativas del país contemplan distintas circunstancias bajo las cuales la interrupción del embarazo no es punible; todos lo autorizan en casos de violación, 27 de ellos cuando el embarazo pone en peligro la vida de la mujer, 13 cuando el producto tiene malformaciones genéticas o congénitas, nueve cuando el embarazo pone en peligro la salud de la mujer, ocho cuando el embarazo fue producto de una inseminación artificial no consentida, y solamente uno por razones socioeconómicas graves, siempre y cuando la mujer tenga tres o más hijos. ${ }^{7}$

A pesar de la existencia de este marco jurídico, son muy pocas las interrupciones del embarazo que se resuelven bajo el amparo de la legislación. Los códigos penales de los estados carecen, en general, de los instrumentos normativos adecuados para dar cumplimiento a las leyes, mientras que son aún muy pocos los hospitales públicos del país que cuentan con personal sensibilizado y capacitado para ofrecer servicios de aborto legal. ${ }^{8}$ Además, aun cuando existen los reglamentos y normas para que las mujeres tengan acceso al aborto legal en forma expedita, como en el caso del Distrito Federal, ${ }^{d}$ una proporción importante de la población mexicana desconoce la legislación y los procedimientos jurídicos y administrativos para hacer que se cumpla. ${ }^{10}$ Los resultados de una encuesta de opinión aplicada a una muestra representativa de la población mexicana en el año 2000 dan cuenta de este desconocimiento; 44\% de las personas entrevistadas señaló que el aborto era ilegal bajo cualquier circunstancia. ${ }^{11}$

Por las restricciones que existen en toda la República Mexicana para la práctica del aborto, la mayoría de las mujeres que interrumpen un embarazo lo hacen por motivos que no están contemplados en las leyes vigentes. La situación del aborto refleja las condiciones de desigualdad social que prevalecen en el país. Son relativamente pocas las mujeres que tienen acceso a servicios médicamente seguros para interrumpir un embarazo no deseado, ya que sus costos son, en general, elevados y están fuera del alcance de la mayoría. ${ }^{7}$

La información disponible sobre el aborto debe manejarse con cautela; dada su situación legal, no se sabe con precisión cuántas mujeres recurren anualmente a él, y tampoco es posible estimar con exactitud la frecuencia de las complicaciones y las muertes que ocasiona. Las estadísticas no incluyen todos los abortos inducidos que no se complican, ni tampoco los de aquellas mujeres que sufren complicaciones pero que por distintas causas no reciben atención médica. Además, los registros hospitalarios no permiten distinguir entre los abortos inducidos y los espontáneos.

\footnotetext{
d En agosto del 2000, la Asamblea Legislativa del Distrito Federal aprobó por mayoría modificaciones al Código Penal en materia de aborto. La reforma contempla los procedimientos juridicoadministrativos para dar cumplimiento a las disposiciones legales y para que la interrupción del embarazo se realice en las instituciones del sector público; establece también responsabilidades para el personal médico, así como plazos y requisitos para autorizar las intervenciones. ${ }^{9}$
} 
Una estimación realizada en el decenio de 1990-1999, indicó que alrededor de 40\% de los embarazos que ocurren en el país eran no deseados, calculándose que $17 \%$ terminaba en un aborto inducido, y el $23 \%$ restante en un nacimiento no deseado. ${ }^{12}$ Otra fuente señala que a mediados de ese mismo decenio, la cifra anual de abortos era de 1700 000, estimándose que la mitad, es decir 850 000, eran inducidos. ${ }^{13}$ Recientemente, el Consejo Nacional de Población ${ }^{14}$ calculó que la incidencia del aborto disminuyó de 230000 por año en el periodo 1985-1987, a 196000 en el periodo 1995-1997.

Las complicaciones del aborto representan una de las principales causas de morbilidad hospitalaria en todas las instituciones de salud del sector público, que en 1999 atendieron 123223 casos. En la SSA, que atendió 68874 casos, las complicaciones derivadas del aborto ocuparon el cuarto lugar de la morbilidad hospitalaria por todas las causas. El IMSS atendió en aquel año 31023 eventos, y el ISSSTE e IMSS Oportunidades alrededor de 9600 casos. ${ }^{15}$ Se ha documentado que la atención a las mujeres con complicaciones derivadas de un aborto inseguro consume, después de los partos normales, la mayor parte de los recursos gubernamentales destinados a la atención de la salud reproductiva. ${ }^{3}$

Un análisis sobre la mortalidad materna en México mostró que para las mujeres que habitan en zonas de alta marginación, el riesgo de morir por un aborto inseguro duplica el de aquellas que tienen mejores condiciones socioeconómicas. ${ }^{16}$ En el año 2002, el aborto representó la tercera causa de mortalidad materna en el país. ${ }^{17}$ Ese año se reportaron 97 defunciones por aborto, las cuales representaron poco más de 7\% de las 1309 muertes maternas registradas a nivel nacional. Frente a este dato cabe señalar que en el 2002 murieron también 238 mujeres a causa de hemorragias obstétricas, y que de acuerdo con algunos análisis ${ }^{18,19}$ muchas de esas defunciones maternas podrían atribuirse a complicaciones del aborto.

\section{ATENCIÓN POSABORTO EN LAS INSTITUCIONES PÚBLICAS DE SALUD EN MÉXICO}

En México, los primeros programas buscaron introducir la APA como una medida para disminuir las complicaciones asociadas con el aborto inseguro e incrementar el costoeficicacia de los servicios.

\section{SECRETARÍA DE SALUD (SSA)}

En México, el primer programa estatal de atención posaborto fue puesto en marcha por la Secretaría de Salud, que ofrece servicios de salud a la población urbana y rural que no tiene acceso a la seguridad social, la cual representa alrededor de $40 \%$ de los habitantes del país, en su mayor parte de los sectores pobres. ${ }^{20} \mathrm{La}$ SSA tiene centros de salud urbanos y rurales de primer nivel, así como hospitales generales y especializados en todo el territorio nacional; a la SSA pertenecen también los diez Institutos Nacionales de Salud con que cuenta el país.

En 1988, la SSA inició en el estado de Michoacán un programa piloto de tres años a fin de introducir la AMEU para el tratamiento del aborto incompleto y mejorar la calidad de los servicios de anticoncepción posaborto en los cuatro principales hospitales de la entidad. Las actividades del proyecto incluyeron un taller de formación para ginecoobstetras y la 
capacitación subsiguiente de otros profesionales de los equipos de salud. El personal que participó en esta actividad recabó datos sobre la seguridad y eficacia de la APA, sus complicaciones y el uso de anticonceptivos en mujeres atendidas bajo este modelo. Los datos que se obtuvieron indican que el uso de anticonceptivos aumentó de 25 a $67 \%$, se acortó el tiempo de espera de las pacientes para ser atendidas, y que disminuyó de la morbilidad y mortalidad asociadas al aborto. Posteriormente, en un lapso aproximado de seis años, los servicios de APA se ampliaron a todos los hospitales de la SSA en el estado de Michoacán, así como a los centros de salud de primer nivel más importantes en áreas urbanas.

A partir de esta experiencia piloto, durante el decenio de 1990-1999, la SSA amplió la cobertura de los servicios de APA con AMEU a otros lugares del país, e intensificó los programas de capacitación. El modelo se incorporó a los sistemas de información gerencial de la institución, se crearon normas para el manejo clínico de las pacientes y se establecieron directrices para agilizar la adquisición de instrumental.

En julio del 2000, la SSA publicó el Lineamiento técnico para la prevención, diagnóstico y manejo de la hemorragia obstétrica, ${ }^{21}$ que fue distribuido en todas las unidades de salud del sector público del país. Dicho documento plantea que la AMEU, recomendada por la Federación Internacional de Ginecología y Obstetricia (FIGO) y avalada por la Organización Mundial de la Salud (OMS), es la primera opción para el tratamiento de mujeres con abortos incompletos. ${ }^{6}$ El lineamiento enfatiza la responsabilidad de los servicios de salud para proporcionar servicios de APA con AMEU a las mujeres atendidas en el segundo y tercer niveles de atención.

\section{INSTITUTO MEXICANO DEL SEGURO SOCIAL (IMSS)}

El IMSS ofrece servicios de salud a los trabajadores del sector formal de la economía y a sus familias bajo el régimen de la seguridad social. En el 2002, la población derechohabiente del IMSS en todo el país era de 46.1 millones de personas, lo que representaba casi la mitad de la población total. ${ }^{22}$ El IMSS cuenta con una amplia red de servicios de salud distribuidos en todo el territorio nacional, incluyendo unidades y clínicas de medicina familiar, hospitales generales y de especialidades, y centros hospitalarios regionales de alta especialización.

Para mejorar la calidad y eficacia de la atención a las mujeres con aborto, en 1992 el IMSS introdujo en sus servicios médicos la APA con AMEU a través de un programa piloto que operó en cuatro hospitales de segundo nivel especializados en ginecología y obstetricia. Una vez que los servicios se establecieron, esos hospitales funcionaron como centros de capacitación para el personal médico del IMSS a nivel nacional. Posteriormente se estableció por lo menos un centro de capacitación en APA en cada estado; por último, el programa se concentró en los hospitales docentes y en aquéllos con altas casuisticas de mujeres que necesitaban tratamiento por abortos incompletos.

El proyecto logró incorporar servicios de APA de alta calidad en todos los hospitales del IMSS que atendieron anualmente un mínimo de 250 mujeres con abortos incompletos, incluyendo 82 de los 196 hospitales que ofrecían atención obstétrica. ${ }^{23}$ Una medida clave para lograr que los servicios de APA fueran eficaces y sostenibles fue la inclusión de la AMEU en el "Programa nacional del sistema de capacitación en técnicas quirúrgicas simplificadas para la atención a la salud reproductiva", el cual sólo contemplaba en su inicio la capacitación en minilaparotomía y vasectomía sin bisturí. 


\section{PROGRAMA IMSS OPORTUNIDADES}

El Programa IMSS Oportunidades (anteriormente IMSS Solidaridad) fue creado por este instituto para atender a poblaciones sin acceso a servicios de salud en zonas rurales marginadas. El programa cuenta con hospitales rurales pequeños y con más de 3000 instalaciones de primer nivel. En el año 2000 operaba en 17 estados del país, con una cobertura de 10.9 millones de personas; en el 2003, la población indígena que tuvo acceso a estos servicios fue de 3.6 millones. $^{24}$

La incorporación de la APA en instalaciones del Programa IMSS Oportunidades se dio a raíz de que sus autoridades en el nivel central percibieron que el tiempo que tomaba a una mujer llegar a los servicios de urgencia con capacidad para tratar las complicaciones del aborto, a menudo prolongado, contribuía a elevar la incidencia de la morbilidad y la mortalidad por esta causa.

Desde el año 2000, el Programa IMSS Oportunidades ha instrumentado una estrategia para introducir la APA con AMEU en el primer nivel de atención: en la primera fase se capacitaron 144 prestadores de servicios de salud ubicados en unidades de medicina rural; 25 para el 2003 se había logrado capacitar al personal de 71 hospitales rurales y de 65 unidades médicas rurales. ${ }^{6}$ En la actualidad, este programa cuenta con servicios de APA con AMEU en seis delegaciones estatales —Chihuahua, Durango, Puebla, Veracruz Norte, Veracruz Sur y Yucatán-; en ellas, todo el personal de los hospitales rurales, unidades de medicina rural y albergues maternos está capacitado para proporcionar servicios integrales a mujeres con complicaciones derivadas del aborto; los supervisores, por su parte, pueden capacitar en el trabajo al nuevo personal. Además, se modificaron los sistemas de vigilancia e información institucionales para incluir indicadores de evaluación del modelo.

En el 2001 y 2002, IMSS Oportunidades atendió 225613 partos y 16891 abortos (12 733 en el primer trimestre). En el 2001, 55.5\% de los abortos se trataron con AMEU, mientras que en el 2002 la cifra se elevó a 59\%. En el primer semestre del 2003, $58.6 \%$ de los 2718 abortos en el primer trimestre fueron atendidos con AMEU, lo que muestra la institucionalización de la técnica. ${ }^{25}$

\section{INSTITUTO DE SEGURIDAD Y SERVICIOS SOCIALES PARA LOS TRABAJADORES DEL ESTADO (ISSSTE)}

El ISSSTE, que en el 2001 tenía una población derechohabiente de 10.2 millones de personas, ${ }^{23}$ comenzó en 1997 un programa de APA con AMEU. Antes de que este programa iniciara, todos los hospitales utilizaban el legrado uterino instrumental (LUI) para resolver los casos de aborto incompleto. Como parte de este programa, los hospitales del ISSSTE ubicados en las ciudades de Acapulco, Distrito Federal, Morelia, Puebla y Toluca, funcionaron como centros de capacitación y evaluación en APA con AMEU, y en ellos se identificaron los procesos necesarios para adaptar los nuevos modelos de atención y extenderlos a otras unidades del segundo nivel de atención. ${ }^{26}$

\section{RESULTADOS DE ALGUNOS ESTUDIOS SOBRE ATENCIÓN POSABORTO EN MÉXICO}

En este apartado se presentan resultados de estudios sobre el modelo de APA realizados en México, con la finalidad de mostrar los beneficios que ofrece tanto para las mujeres como para las instituciones de salud. 


\section{ASESORIA, INFORMACIÓN Y ANTICONCEPCIÓN POSABORTO}

El cuadro 6-1 resume los resultados de dos estudios, uno realizado en un hospital de la SSA en la ciudad de Oaxaca, ${ }^{27}$ y otro que se llevó a cabo en seis hospitales del IMSS en el Distrito Federal, ${ }^{2}$ en términos de la información y de la entrega de métodos anticonceptivos a pacientes de APA antes de su alta hospitalaria.

El estudio de Oaxaca evaluó los efectos de una intervención que consistió en la instrumentación de un programa integral de APA. Los resultados mostraron que la proporción de mujeres que recibieron información sobre signos de complicaciones, retorno de la fecundidad y reinicio de las relaciones sexuales se duplicó, mientras la proporción de mujeres que recibió un método anticonceptivo pasó de 29.5 a $59.7 \%$.

En cuanto al estudio que se llevó a cabo en seis hospitales del IMSS en el Distrito Federal, los datos muestran que, independientemente de la técnica quirúrgica utilizada para el tratamiento de la urgencia -AMEU o LUI-, la puesta en marcha del modelo de APA mejoró la información a pacientes y la entrega de métodos (de 64.4 a 77.8\%). La mayor diferencia entre los hospitales de Oaxaca y del IMSS en el Distrito Federal fue el tipo de método entregado; en Oaxaca fue principalmente el inyectable y el dispositivo intrauterino (DIU) (51.2 y 16.3\% en la posintervención, respectivamente), mientras que en el IMSS del Distrito Federal fue el DIU y el hormonal oral (77.4 y $16.4 \%$, respectivamente).

CUADRO 6-1.

Atención recibida durante el proceso de APA: asesoría y anticoncepción posaborto

\begin{tabular}{|c|c|c|c|c|}
\hline \multirow{3}{*}{ Variable } & \multicolumn{4}{|c|}{ Hospital } \\
\hline & \multicolumn{2}{|c|}{ Ssa, Oaxaca } & \multicolumn{2}{|c|}{$\begin{array}{l}\text { Seis hospitales IMSS, } \\
\text { Distrito Federal }\end{array}$} \\
\hline & $\begin{array}{c}\text { Pre- } \\
\text { intervención } \\
\% \\
\text { (número de } \\
\text { mujeres) }\end{array}$ & $\begin{array}{c}\text { Pos- } \\
\text { intervención } \\
\% \\
\text { (número de } \\
\text { mujeres) }\end{array}$ & $\begin{array}{c}\text { APA con } \\
\text { AMEU } \\
\% \\
\text { (número de } \\
\text { mujeres) }\end{array}$ & $\begin{array}{c}\text { APA con LUI } \\
\% \\
\text { (número de } \\
\text { mujeres) }\end{array}$ \\
\hline \multicolumn{5}{|c|}{ La paciente recibió información sobre: } \\
\hline Signos de complicaciones & $\begin{array}{l}3.0 \\
(132)\end{array}$ & $\begin{array}{l}50.7^{*} \\
(207)\end{array}$ & $\begin{array}{l}32.3 \\
(251)\end{array}$ & $\begin{array}{l}36.6^{*} \\
(270)\end{array}$ \\
\hline Retorno de la fecundidad & $\begin{array}{l}19.1 \\
(131)\end{array}$ & $\begin{array}{l}54.4^{*} \\
(204)\end{array}$ & $\begin{array}{l}49.7 \\
(151)\end{array}$ & $\begin{array}{l}63.7^{*} \\
(192)\end{array}$ \\
\hline Reinicio de relaciones sexuales & $\begin{array}{l}14.4 \\
(132)\end{array}$ & $\begin{array}{l}38.8^{*} \\
(206)\end{array}$ & $\begin{array}{l}20.7 \\
(251)\end{array}$ & $\begin{array}{l}39.6^{*} \\
(270)\end{array}$ \\
\hline $\begin{array}{l}\text { La paciente recibió un método } \\
\text { anticonceptivo }\end{array}$ & $\begin{array}{l}29.5 \\
(132)\end{array}$ & $\begin{array}{l}59.7^{*} \\
(206)\end{array}$ & $\begin{array}{l}64.4 \\
(251)\end{array}$ & $\begin{array}{l}77.8^{*} \\
(270)\end{array}$ \\
\hline $\begin{array}{l}\text { Fuentes: seis hospitales del Imss en el } \\
{ }^{*} p>05\end{array}$ & et al. (2003) & I de la Ssa $e$ & a, Langer & \\
\hline
\end{tabular}


De acuerdo con datos recabados por el Consejo Nacional de Población, ${ }^{28}$ la cobertura de anticoncepción posaborto es similar a la que se obtuvo durante el periodo del posparto en el IMSS y el IMSS Oportunidades durante los años 2001 a 2003. En el IMSS, alrededor de 65\% de las mujeres en el posparto y $64 \%$ de las mujeres en el postaborto recibieron un método en esos años; mientras tanto, en el IMSS Oportunidades la anticoncepción posparto osciló entre 83.6 y $82.1 \%$, comparada con 82.3 y $86.9 \%$ de las mujeres en el posaborto.

\section{TIEMPOS DE ESTANCIA Y COSTOS DE LA ATENCIÓN}

Dos estudios que se realizaron en un hospital del IMSS en el Distrito Federal ${ }^{4}$ y en uno de la SSA en la ciudad de Oaxaca, compararon el tiempo de estancia hospitalaria y el costo de la atención posaborto de pacientes hospitalizadas y tratadas con LUI por abortos incompletos, con el tiempo de estancia y el costo de usuarias atendidas en forma ambulatoria con AMEU. La atención ambulatoria con AMEU logró disminuir la estancia promedio de las pacientes en $42.1 \%$ en el Distrito Federal (de 19.7 horas a 11.4 horas) y en $35.6 \%$ en Oaxaca (de 27 horas a 17.4 horas), respecto a la atención con LUI. Como consecuencia, los costos disminuyeron en $56.3 \%$ (el equivalente a 150.58 a 65.73 dólares [EUA]) en el Distrito Federal, y en 31.9\% (el equivalente a 264.47 a 180.22 dólares [EUA]) en Oaxaca.

\section{COMENTARIOS FINALES}

Una respuesta integral para disminuir los embarazos no deseados y los abortos inseguros en México supone mejorar los programas de educación sexual, promover la anticoncepción de emergencia, crear servicios para atender las necesidades específicas de anticoncepción de la población adolescente, y aumentar la cobertura y calidad de los programas de planificación familiar. Estas medidas implican, a su vez, el mejoramiento de los procesos de formación y capacitación de personal, tanto en las facultades de medicina y enfermería como en los servicios de salud.

Es urgente, asimismo, asegurar mayores niveles de calidad técnica y humana en la atención que reciben las mujeres con complicaciones derivadas del aborto inseguro, lo cual requiere ampliar la red de servicios que operan bajo el modelo de la APA con AMEU. En este sentido, debe considerarse que atender correcta y sensiblemente a una mujer en situación de aborto significa ofrecerle un servicio de salud al que tiene legítimo derecho.

En este capítulo se revisaron algunas de las experiencias más significativas en México para la creación de servicios de APA, que incluyen, entre otros componentes, el uso de la AMEU como el procedimiento técnico de primera elección en el tratamiento de urgencia de las mujeres con hemorragia obstétrica ${ }^{\mathrm{e}}$ y con complicaciones del aborto.

\footnotetext{
e La hemorragia obstétrica y sus complicaciones constituyen la segunda causa de mortalidad materna en México.
} 
El valor de estas experiencias radica en que han significado respuestas adecuadas de los servicios de salud a las necesidades de atención de mujeres en situación de aborto y posaborto. Al mismo tiempo, el cambio en los modelos de atención ha permitido al IMSS, a IMSS Oportunidades, a la SSA y al ISSSTE reducir el costo del tratamiento y el uso de su capacidad instalada.

Las estrategias para incorporar la APA han sido congruentes con el derecho de las mujeres a recibir atención y servicios de salud de la mejor calidad posible, ${ }^{\mathrm{f}}$ así como con otros derechos que garantizan su acceso a los beneficios del progreso científico y sus aplicaciones, y al uso de las tecnologías modernas disponibles para la atención de la salud, como las relativas a la anticoncepción y a la atención del aborto y el posaborto.

Cabe señalar que en México el factor crítico para ampliar la red de servicios de APA con AMEU es lograr su institucionalización formal más allá de las experiencias piloto a nivel estatal o regional. No obstante, en el presente existen las bases para lograrlo.

- E1 Lineamiento técnico para la prevención, diagnóstico y manejo de la hemorragia obstétrica $^{22}$ de la SSA considera a la AMEU como la primera opción para el tratamiento de las mujeres con aborto incompleto, completo, en evolución, inevitable y diferido, o con diagnóstico de huevo muerto retenido.

- El instrumental para la AMEU está incluido en el "Cuadro básico y catálogo de material de curación y prótesis del sector salud" (Comisión Interinstitucional del Cuadro Básico de Insumos del Sector Salud), así como en el "Cuadro básico institucional de material de curación" del IMSS.

Debe mencionarse que a pesar de los avances que se han obtenido con la aplicación del modelo de la APA, existen todavía resistencias por parte de los ginecoobstetras, que impiden que la AMEU se convierta en la técnica quirúrgica de elección para el tratamiento de urgencia de las complicaciones del aborto. ${ }^{6}$ Un estudio realizado en hospitales de la SSA y del IMSS en el estado de Morelos, mostró que los factores más relevantes para que el personal médico no elija la AMEU como primera opción incluyen la falta de enfermeras capacitadas en su uso y en el apoyo emocional a las pacientes, las dificultades de acceso al instrumental dentro de los hospitales, el mayor consumo de tiempo por una limitada experiencia de uso y mayores dificultades para el manejo del dolor. ${ }^{29} \mathrm{La}$ consideración de estos elementos es muy importante en los procesos de incorporación del modelo de la APA en cualquier servicio de salud. Además, lograr que la AMEU sea incluida en los programas académicos de todas las licenciaturas en medicina y enfermería es un requisito fundamental para que se le considere, eventualmente, como la mejor opción en el manejo quirúrgico de urgencia de las mujeres en situación de aborto.g

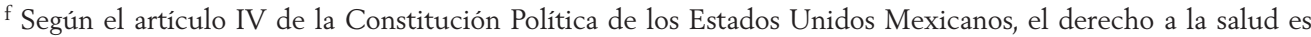
una garantía frente a la cual el Estado está obligado.

g Una revisión de los planes de estudio de 11 escuelas de medicina mexicanas, realizada en el 2001, mostró que la técnica de AMEU es, al parecer, un procedimiento ausente en la formación quirúrgica de la mayoría de los médicos; en esta revisión, la AMEU sólo se encontró como contenido curricular en el Programa de Internado de la Facultad de Medicina de la Universidad Nacional Autónoma de México. ${ }^{30}$ Recientemente, Quiroz et al. ${ }^{6}$ reportaron que en la actualidad la AMEU forma parte de los contenidos de cursos optativos de salud reproductiva en la facultad mencionada, así como de los programas de nueve escuelas de enfermería en los estados de Veracruz y Chiapas.
} 


\section{Referencias}

1. Engenderhealth/Ipas: Making postabortion care services to scale: Quality, access, sustainability. Informe de un taller internacional. Mombasa (Kenya), mayo de 2000. Engenderhealth/Ipas, Nueva York. 2001.

2. Billings DL, Fuentes J, Pérez, R: Comparing the Quality of Three Models of Postabortion Care in Public Hospitals in Mexico City. En: International Family Planning Perspectives 29(3),2003:112-120.

3. Brambila C, Langer A, García C, Molina A, Heimburger A, Barahona V: Análisis de costos de los servicios postaborto en el Hospital General Aurelio Valdivieso, Oaxaca, México. The Population Council, México. 1998.

4. Fuentes J, Billings DL, Cardona JA, Otero JB: Una comparación de tres modelos de atención postaborto en México. Population Council, México. 1998.

5. Fuentes J, Wrooman E, Pérez R, Flores B, Cardona A: Evolución de la introducción de la aspiración manual endouterina en hospitales del IMSS. En: Revista Médica del IMSS Vol. 39, Núm. 5, 2001:393-401.

6. Quiroz G, Billings DL, Gasman N: Aspiración manual endouterina (AMEU): Tecnología adecuada para la atención de calidad a mujeres en situación de aborto. En: Gaceta Médica de México, Vol. 139, Suplemento Núm.1, 2003:65-73.

7. Grupo de Información en Reproducción Elegida: Miradas sobre el aborto. GIRE, México, D.F., 2002.

8. Billings DL, Moreno C, González de León D, et al.: Constructing access to legal abortion services in Mexico City. En: Reproductive Health Matters, Vol. 10, Núm. 19, 2002:86-94.

9. Asamblea Legislativa del Distrito Federal: Decreto por el que se reforman y adicionan diversas disposiciones del Código Penal para el Distrito Federal. En: Gaceta Oficial del Distrito Federal, décima época, No. 148, 24 de agosto, 2000.

10. Lara D, García S, Strickler J et al.: El acceso al aborto legal de las mujeres embarazadas por violación en la ciudad de México. En: Gaceta Médica de México, Vol. 139, Suplemento Núm. 1, 2003:77-90.

11. García S, Becker D: ¿Qué piensan y opinan las y los mexicanos sobre el aborto? Resultados de una encuesta nacional de opinión. Population Council/Grupo IDM. México, D.F. 2001.

12. The Alan Guttmacher Institute: Aborto clandestino: una realidad latinoamericana. AGI, Nueva York.1994.

13. López R: El aborto como problema de salud pública. En: Elu MC, Langer A. (Eds). Maternidad sin riesgos en México. México: Comité Promotor de la Iniciativa por una Maternidad sin Riesgos en México/Instituto Mexicano de Estudios Sociales, México, D.F., 1994: 85-90,

14. Consejo Nacional de Población: Cuadernos de Salud Reproductiva. República Mexicana. CONAPO, México, D.F. 2000.

15. Instituto Nacional de Estadística, Geografía e Informática: Estadísticas del Sector Salud y Seguridad Social. Cuaderno Núm. 17. INEGI, Aguascalientes, Ags. 2001.

16. Lozano R, Hernández B, Langer A: Factores sociales y económicos de la mortalidad materna en México. En: Elu MC, Langer A (Eds). Maternidad sin riesgos en México. Instituto Mexicano de Estudios Sociales, A.C. y Comité Promotor de la Iniciativa por una Maternidad sin Riesgos en México, México, D.F., 1994: 43-52.

17. Secretaría de Salud: Estadísticas de mortalidad relacionada con la salud reproductiva. México 2002. En: Salud Pública de México, Vol. 46, Núm. 1, 2004: 75-88.

18. Langer A: El embarazo no deseado: impacto sobre la salud y la sociedad en América Latina y el Caribe. En: Revista Panamericana de Salud Pública, Vol. 11, Núm. 3, 2002:192-204.

19. Langer A: Embarazo no deseado y aborto inseguro: su impacto sobre la salud en México. En: Gaceta Médica de México, Vol. 139, Suplemento 1, 2003:3-7. 
20. Secretaría de Salud: Programa Nacional de Salud 2001-2006. SSA, México, D.F. 2001.

21. Secretaría de Salud. Lineamiento técnico para la prevención y manejo de la hemorragia obstétrica. SSA, Dirección General de Salud Reproductiva, México, D.F. 2000.

22. Instituto Nacional de Estadística, Geografía e Informática: México, D.F. 2000. (www.inegi.gob.mx)

23. Chambers V, Fuentes J, Catotti DN: Ampliación de los servicios de atención postaborto: lecciones aprendidas durante una década de experiencia en México. Ipas, Chapel Hill, NC. 2001.

24. Instituto Mexicano del Seguro Social: IMSS, México 2004. (www.imss.gob.mx).

25. Ipas: Reporte interno. Ipas, Chapel Hill, NC. 2003.

26. Gómez F, Billings DL, Pojo JA et al.: Evaluación operacional de una estrategia para mejorar la calidad de los servicios de atención postaborto en el ISSSTE. En: Archivos de Medicina Familiar 1(3), 1999:81-87

27. Langer A, Heimburger A, García C, Winikoff B: Improving postabortion care in a public hospital in Mexico. En: Haberland, N, Measham, D. (Eds). Responding to Cairo: Case studies of changing practice in reproductive health and family planning. Population Council, Nueva York. 2002.

28. Consejo Nacional de Población: Informe de ejecución 2001-2003 del Programa Nacional de Población, 2001-2006. CONAPO, México D.F. 2003.

29. Sánchez J, Brachet V, Billings DL, et al.: Obstáculos a la utilización de la aspiración manual endouterina en el tratamiento del aborto incompleto en hospitales públicos del estado de Morelos, México. Tesis de Maestría en Administración de Servicios de Salud, Instituto Nacional de Salud Pública, Cuernavaca, Mor. 2000.

30. González de León D, Billings DL, Gasman N, Ramírez R: Incorporación de la salud sexual y reproductiva y de la atención integral a la mujer con aborto en los programas de licenciatura en medicina. Ipas México, México, D.F.2002. 


\section{Vinculación de la atención posaborto y los servicios de anticoncepción en Nicaragua}

Estela Rivero-Fuentes, ${ }^{a}$ Ricardo Vernon, ${ }^{a}$

Freddy Solis, ${ }^{b}$ Adilia Gadea, ${ }^{b}$ y Ana del Carmen Rojas ${ }^{b}$

\section{INTRODUCCIÓN}

En este capítulo se presentan algunos de los resultados principales de un estudio hecho en Nicaragua entre junio y agosto de $2006^{\mathrm{c}}$ sobre la situación de la atención posaborto (APA). Los objetivos principales del estudio fueron evaluar si la APA se implementa observando las prácticas nacionales e internacionales recomendadas, y detectar los factores que influyen sobre su productividad. Los resultados que se ofrecen se limitan a analizar la vinculación de los servicios de APA con los de anticoncepción, el cuarto elemento del modelo de atención integral posaborto, según lo define el Consorcio Atención Postaborto. ${ }^{3}$

\section{CONTEXTO}

Se estima que cuando se realizó el estudio, ocurrían en Nicaragua entre 17000 y 43000 abortos anuales. ${ }^{4}$ Durante el 2005, los hospitales del Ministerio de Salud (MINSA) prestaron servicios de APA a 5500 mujeres. $^{5}$

Durante los decenios de 1980-1989 y 1990-1999, y en especial durante los primeros años del nuevo siglo, el MINSA realizó esfuerzos importantes para implantar un modelo de APA a nivel nacional. En 1989, Ipas inició una colaboración con el MINSA

\footnotetext{
a Programa Fronteras de la Salud Reproductiva, Population Council, México, D.F.

${ }^{\mathrm{b}}$ Alva, S.A., Managua.

${ }^{\mathrm{C}}$ Cuando se recabaron los datos, el aborto terapéutico se permitía en los casos en que tres médicos y la mujer o su pariente más cercano estuvieran de acuerdo en la necesidad de practicarlo. ${ }^{1}$ Desde noviembre de 2006, la legislación nicaragüense prohíbe el aborto terapéutico en cualquier instancia. ${ }^{2}$ El debate público que acompañó a este cambio podría haber ocasionado confusión entre las mujeres y los proveedores respecto a la legalidad de la APA (que en realidad no se vio afectada por el cambio legislativo), lo que a su vez podría disminuir la calidad y el acceso a los servicios de APA. Así, los resultados de este estudio podrían servir como línea de base para evaluar en un futuro el impacto colateral de la nueva legislación sobre estas variables.
} 
en la que se lanzó un programa nacional de capacitación para la atención a mujeres con abortos incompletos. En dicho programa se introdujo la técnica de aspiración manual endouterina (AMEU) y la oferta de servicios de anticoncepción posaborto. Como resultado de esta colaboración, a fines de 1995 se había capacitado a personal de salud de varios niveles de atención en el uso de la técnica de AMEU, y se prestaban servicios de APA en 30 unidades de salud pública.

Entre los años 2000 y 2002 se publicaron y entraron en vigor tres documentos que abordan el manejo de las mujeres que buscan atención por complicaciones de un aborto y orientan sobre el uso de la AMEU. Según tales documentos, los centros de salud con camas, los hospitales departamentales y el hospital de referencia nacional, deben brindar atención a la mujer que acude con un aborto en curso. ${ }^{6,7,8}$ En teoría, estas unidades deberían contar con los recursos médicos, equipos, medicamentos e infraestructura para diagnosticar y brindar atención inmediata a mujeres en situación de aborto, identificar y tratar sus complicaciones, dar asesoría en planificación familiar y ofrecer métodos anticonceptivos, así como orientaciones sobre cuidados generales en el posaborto.

Un estudio realizado en el año 2003 mostró que de las 47 unidades de salud habilitadas para ofrecer servicios de APA, 85\% tenía el servicio disponible. Casi todas las unidades ofrecían servicios de AMEU, pero siete (18\%) sólo ofrecían el legrado uterino instrumental (LUI), mientras 20 unidades carecían del equipo completo para realizar el procedimiento de evacuación cuando fuera necesario. El mismo estudio encontró que otras debilidades en la APA estaban relacionadas con la interacción con otros servicios de salud y con la planificación familiar, pues a pesar de que todas las unidades visitadas pueden suministrar métodos anticonceptivos modernos, las pacientes a menudo no tenían acceso a ellos, especialmente durante los turnos nocturnos y los fines de semana. El estudio mostró también que los registros clínicos estaban incompletos o no existían en la mayor parte de las unidades. Finalmente, la estancia promedio fue de 24 horas, un lapso demasiado elevado para que el servicio pudiera considerarse ambulatorio. ${ }^{5}$

\section{ESTUDIO DE LA SITUACIÓN DE LA ATENCIÓN POSABORTO EN EL 2006}

Entre julio y agosto del 2006, Alva, S.A. y el Programa Fronteras de la Salud Reproductiva del Population Council realizaron un análisis de la situación de la atención posaborto en 11 hospitales del Ministerio de Salud de Nicaragua, en donde se hizo una encuesta entre prestadores de servicios relacionados con la APA y mujeres atendidas por abortos. En total, se entrevistaron 78 prestadores de servicios y 26 mujeres. Se realizaron, además, entrevistas a profundidad con diez informantes clave, incluyendo un representante de una agencia de cooperación; los responsables del programa de planificación familiar, del programa de atención integral a la mujer y del programa de prevención en dos regiones del Sistema Local de Atención Integral de Salud (SILAIS); la representante de una red de organizaciones no gubernamentales que trabaja en salud reproductiva; un representante de Profamilia; y un representante del MINSA que participó en la elaboración de la última versión de las normas de planificación familiar.

La siguiente sección presenta los resultados más relevantes del estudio en lo que atañe a la integración de servicios de anticoncepción y de atención a mujeres en el periodo posaborto. Este enfoque se justifica porque el estudio realizado en el $2003^{5}$ detectó que ésta era una de las áreas más débiles de la APA en Nicaragua, y a partir de enton- 
ces varias agencias han trabajado en colaboración con el MINSA para resarcir algunos de los problemas encontrados.

\section{RESULTADOS}

De las mujeres entrevistadas, 35\% no deseaba tener más hijos en el futuro, y $75 \%$ de las que sí deseaban más hijos querían posponer su próximo embarazo dos años cuando menos. Este deseo por retrasar o evitar el próximo embarazo repercute en que $75 \%$ de las mujeres atendidas por complicaciones por aborto en Nicaragua quisiera empezar a utilizar un método anticonceptivo antes de dejar el hospital, y el resto en los tres meses siguientes.

Los servicios de APA satisfacen esta demanda por métodos anticonceptivos de forma parcial, pues sólo $50 \%$ de las mujeres entrevistadas recibió asesoría en planificación familiar, y únicamente dos de cada cinco que hubieran querido dejar el hospital con un método anticonceptivo lo recibieron antes del alta hospitalaria. Cuando se preguntó a las mujeres por qué no recibieron un método, la razón que más argumentaron fue que el personal de salud no se los ofreció (73\%). Las otras razones fueron que ese mismo personal sugirió que las mujeres deben esperar antes de iniciar el uso (20\%) y que el hospital no tenía el método que ellas querían (10\%). A ninguna de las mujeres que hubieran querido recibir un método antes del alta hospitalaria se le dio una referencia para obtener un anticonceptivo en otro lado, aunque sólo dos mujeres no sabían a dónde acudir para obtener el método que deseaban.

Casi todas las mujeres que dejaron el hospital con un método anticonceptivo obtuvieron el que deseaban. Seis de las ocho informantes a quienes se les dio un método recibieron inyecciones hormonales, una mujer recibió un dispositivo intrauterino (DIU) y otra fue esterilizada. Una mujer que recibió inyecciones hormonales hubiera preferido que se le insertara un DIU, mientras que en otro hospital, quien recibió un DIU hubiera preferido que se le aplicaran inyecciones hormonales.

Aunque todas las mujeres que recibieron un método anticonceptivo dijeron haber recibido asesoría en planificación familiar, la información que recibieron se limitó a aspectos prácticos sobre los métodos con que salieron, como cuándo regresar por la próxima inyección y a dónde acudir para que se la aplicaran, o como comprobar que el DIU estuviera en su lugar. A la mujer que fue esterilizada se le dijo que el procedimiento era no reversible y que no podría tener hijos después de la operación. Pero ninguna recibió información sobre los posibles efectos secundarios, lo que puede afectar la satisfacción futura con el uso del método, e incluso provocar su abandono al experimentar efectos secundarios sobre los que no se les advirtió.

Las entrevistas con los prestadores de servicios e informantes clave revelan varios factores que pueden explicar la razón por la que no todas las mujeres atendidas por complicaciones posaborto reciben la asesoría en planificación familiar y los métodos anticonceptivos que desean. Entre éstos se encuentran:

a) La capacitación a los proveedores no hace suficiente énfasis en la necesidad de ofrecer asesoría y métodos anticonceptivos a mujeres en el posaborto, e informar a las mujeres cuán pronto vuelven a ser fértiles después de ser tratadas.

b) La capacitación no cubre todos los temas deseados o no tiene la calidad necesaria. Por ejemplo, a pesar de que tres de cada cuatro prestadores de servicios entrevistados han recibido algún entrenamiento sobre planificación familiar para mujeres 
posaborto, de los 71 responsables de dar asesoría a quienes entrevistamos, sólo cuatro dijeron saber que las mujeres pueden volver a ser fértiles antes de que pasen 15 días. El resto cree que la fertilidad no regresa antes de un mes después de las complicaciones posaborto, y algunos incluso creen que la fertilidad tarda entre tres meses y un año en regresar. Estas ideas pueden contribuir a que los prestadores de servicios no perciban la necesidad de ofrecer asesoría y métodos antes del alta, pues ellos mismos no creen que exista el riesgo inmediato de un embarazo no planeado.

c) No todos los hospitales ofrecen la misma variedad de métodos anticonceptivos a las mujeres después del aborto, y en algunos hospitales la oferta se limita a uno o dos métodos. De los 11 hospitales visitados, nueve tienen algún método anticonceptivo disponible para mujeres después del aborto, ya sea antes o después del alta hospitalaria. En siete existe una buena oferta de métodos anticonceptivos, que incluye anticonceptivos orales, DIU, métodos inyectables, condones y esterilización femenina. En un hospital, la oferta se limita a DIU y métodos inyectables, y en otro sólo se ofrecen inyecciones.

d) Aunque los prestadores de servicios estén dispuestos a dar anticonceptivos a las mujeres atendidas por complicaciones por aborto, el desabasto de métodos limita las opciones disponibles. El día en que el equipo del estudio visitó los hospitales, sólo uno de los ocho que dijeron insertar el DIU tenía el método disponible, y de los nueve hospitales que dijeron administrar inyectables, dos tenían el método en reserva.

e) Algunos de los hospitales se limitan a ofrecer servicios de planificación de lunes a viernes, aunque las mujeres son atendidas (y dadas de alta) por complicaciones por aborto todos los días. De los nueve hospitales que dijeron dar anticonceptivos antes del alta hospitalaria, tres ofrecen métodos sólo de lunes a viernes. Las mujeres atendidas el fin de semana tienen menores probabilidades de recibir asesoría y un método anticonceptivo que quienes son atendidas entre semana.

f) La consejería a mujeres después del aborto, incluyendo la de planificación familiar, comúnmente recae en médicos y residentes, quienes están involucrados en múltiples actividades y tienen poco tiempo que dedicar para dar una asesoría cuidadosa. De los médicos y residentes entrevistados, $85 \%$ dijo estar involucrado en lo relacionado con mujeres que han abortado. Entre las enfermeras, el porcentaje es menor $(61 \%)$.

g) La demanda por servicios de planificación familiar parece rebasar las capacidades de los prestadores encargados de este servicio. Al pedir a los proveedores involucrados en la consejería y entrega de métodos anticonceptivos posaborto sus sugerencias para mejorar estos servicios, solían referirse a aumentar el número de personal, ampliar los horarios y acomodar espacios que garanticen confidencialidad. Uno de los prestadores entrevistados, por ejemplo, propuso: "que se involucre más a las enfermeras en la capacitación y asesoría". Entre las sugerencias específicas para ampliar el horario de planificación familiar, se encuentran: abastecer métodos siete días a la semana, o tener personal capacitado en planificación familiar en la tarde, o bien implementar charlas grupales de métodos anticonceptivos.

h) Las normas de planificación familiar no son conocidas por los prestadores de servicios encargados de la atención y asesoría a mujeres posaborto. Las normas vigentes al momento del estudio identifican la anticoncepción posaborto como una de las estrategias principales del MINSA en términos de planificación fami- 
liar, y establecen que los hospitales que brindan APA deben desarrollar e implementar un plan de asesoría en temas de planificación familiar y garantizar la disponibilidad adecuada y oportuna de los diferentes métodos anticonceptivos. ${ }^{9} \mathrm{Sin}$ embargo, en cinco de los hospitales visitados la persona responsable del programa de atención a mujeres posaborto no conocía tales normas, mientras que en tres de los hospitales se conocían las normas pero no había una copia accesible.

i) Las normas de planificación familiar nacional vigentes al momento del estudio no establecían de manera clara y específica cómo y cuándo se deben de entregar los diferentes métodos anticonceptivos a las mujeres posaborto. ${ }^{9}$ En consecuencia, los hospitales visitados se han organizado de diferente manera para prestar estos servicios. Algunos ofrecen métodos anticonceptivos sólo en el área de consulta externa, mientras que otros lo hacen en el área de consulta externa (principalmente métodos hormonales y de barrera) o bien en las salas (en especial el DIU y la esterilización femenina). En los hospitales varía también el tiempo de entrega de los métodos después de la APA. De ocho unidades que dijeron insertar el DIU antes del alta hospitalaria, cinco realizan la inserción en las primeras dos horas después de la evacuación uterina, en dos se hace entre tres y siete horas después, y en uno más la inserción ocurre hasta ocho o más horas después.

Los directivos del MINSA y las personas involucradas en la redacción de las nuevas normas de planificación familiar que fueron entrevistadas, reconocen esta adaptabilidad de los servicios, como lo muestra el siguiente fragmento de una entrevista con una trabajadora de una agencia de cooperación, quien comenta sobre las estrategias locales para garantizar la oferta de servicios de planificación familiar:

\begin{abstract}
...es diferencial porque no existe en sí una norma que diga cómo va a ser la prestación de servicios y cada lugar lo ha adecuado de acuerdo con su caracteristica a las condiciones que tiene esta estructura y la cantidad de recursos. Por ejemplo, en Jinotega se habla de un sistema de atención integral donde en una sola clínica brindan todos los servicios, pero esa realidad es diferente, por ejemplo, en Bluefields como en Managua los servicios están separados.
\end{abstract}

Sin embargo, parecen no existir mecanismos que fomenten la retroalimentación sistemática entre lo que sucede en el campo y las normas y disposiciones del MINSA, que en ocasiones desconoce lo que ya estaba funcionando en la práctica. Un buen ejemplo es que, a partir de la pérdida de insumos anticonceptivos en algunos hospitales, el MINSA mandó que todos ellos entregaran métodos a las pacientes sólo en la farmacia. Algunos de los hospitales visitados se habían organizado ya para distribuir los métodos anticonceptivos directamente en el programa de planificación familiar, y a partir de la modificación tuvieron que cambiar sus prácticas, lo que ocasionó pérdida de usuarias.

j) No hay ningún mecanismo que permita identificar las estrategias que funcionan y que facilite su implementación en otros sitios. Por ejemplo, el personal de uno de los hospitales visitados diseñó un nuevo sistema de registro porque sentía que el sistema del MINSA no era suficiente para dar seguimiento a sus pacientes. El sistema que idearon mejora el registro del MINSA al capturar también el nombre, dirección, edad y método anticonceptivo administrado a la paciente. Cuando organizan brigadas de salud, esta información sirve para dar seguimiento doméstico a las mujeres sobre su método. Hasta el momento, esta innovación no ha sido compartida con ningún otro hospital. 


\section{CONCLUSIONES Y RECOMENDACIONES}

Los análisis de situación sirven para detectar qué se está haciendo bien en los programas estudiados y proveer elementos para continuar los esfuerzos en esa dirección. Sirven también para identificar oportunidades de mejoramiento. En el caso de Nicaragua, este estudio muestra que el MINSA ha realizado un importante esfuerzo para proveer servicios de planificación familiar a las mujeres atendidas por complicaciones posaborto. Entre los logros de este organismo que deben recalcarse están la inclusión de la planificación familiar posaborto en las normas nacionales de planificación familiar, así como la capacitación en asesoría y métodos anticonceptivos de la mayoría de los prestadores de servicios. Entre los aspectos que podrían mejorarse están la diseminación de las normas de planificación familiar en los hospitales, el conocimiento de los prestadores de servicios de cuándo se normaliza la fertilidad de las mujeres tratadas por complicaciones por aborto, los horarios de los servicios de planificación familiar y el abasto de métodos anticonceptivos. Entrevistas con agentes del MINSA y las agencias de cooperación que lo apoyan, incluyendo USAID y UNFPA, muestran que algunos de estos problemas ya son de su conocimiento y que en la actualidad se encuentran trabajando en su resolución. Las siguientes propuestas pueden ayudar en esta tarea:

- Organizar un foro o un espacio donde los hospitales y centros de salud compartan sus innovaciones y prácticas exitosas. El estudio mostró que ante la ausencia de lineamientos claros de cómo organizar los servicios, algunos hospitales han ideado soluciones ingeniosas que les han servido para mejorar su calidad y vincular los servicios de planificación familiar con los de APA. Los otros hospitales y centros de salud del país se beneficiarían de conocer estas experiencias.

- Diseñar y probar, en colaboración con los prestadores de servicios involucrados en la atención a mujeres después de un aborto y en planificación familiar, distintas alternativas de integración de ambos servicios.

- Garantizar el abasto de una variedad de métodos anticonceptivos en todos los hospitales y centros de salud que atienden a mujeres después de un aborto.

- Extender el horario de los servicios de planificación familiar a los fines de semana.

- En los lugares en donde no sea posible ofrecer servicios de planificación familiar a través de la estructura actual, una alternativa es capacitar a los prestadores de servicios involucrados en la APA para que ellos mismos brinden consejería en planificación familiar antes del alta hospitalaria. Los proveedores pueden entregar una referencia para que las mujeres que así lo deseen regresen a la clínica de planificación familiar en un futuro próximo y suministrarles un método de barrera que les permita protegerse hasta su regreso.

- Involucrar más a las enfermeras en la consejería para mujeres después de un aborto, incluyendo la asesoría en planificación familiar.

- Una vez que las nuevas normas de planificación familiar estén listas, asegurar su distribución a todos los hospitales y centros de salud afiliados al MINSA. Dentro de los hospitales, dicha divulgación no debe limitarse a las clínicas de planificación familiar, sino ampliarse hacia todas las áreas relacionadas con la atención obstétrica y materna. Ello puede lograrse si se organizan actividades de difusión al interior de los hospitales a donde acudan, de manera conjunta, el personal de las clínicas de planificación familiar, ginecoobstetricia, maternidad, urgencias, y posaborto. 
- Asegurar que el personal de salud involucrado en la asesoría a mujeres atendidas por complicaciones por aborto posea información actualizada y correcta sobre la normalización de la fertilidad y el riesgo de embarazo de dichas mujeres. Esto puede lograrse revisando la currícula de las capacitaciones en consejería en planificación familiar, especialmente para mujeres que ha tenido abortos, y de cursos de actualización.

\section{AGRADECIMIENTOS}

Este estudio se realizó con el apoyo del pueblo estadounidense a través de la Agencia de los Estados Unidos para el Desarrollo Internacional (USAID), bajo los términos del Acuerdo de Cooperación No. HRN-A-00-98-0001200 (Programa Fronteras de la Salud Reproductiva del Population Council). Los contenidos son responsabilidad de los autores, y no necesariamente reflejan los puntos de vista de USAID, del Gobierno de EUA o del Programa Fronteras de la Salud Reproductiva.

Los autores agradecen los comentarios y retroalimentación a lo largo del estudio de las doctoras Claudia Evans, Flor de María Cardoza, Josefina Bonilla y Alma Fabiola Morales; de los doctores Jorge Orochena y Wilmer Beteta y de Ximena Gutiérrez. Además, ofrecen el más sincero agradecimiento a todos los prestadores de servicios y mujeres que compartieron sus opiniones y experiencias. Los autores asumen la responsabilidad de los posibles errores que aparezcan en este capítulo.

\section{Referencias}

1. Harvard Annual Review of Population Law: Capítulo V. Del aborto del Código Penal. Nicaragua (http://annualreview.law.harvard.edu/population/abortion/Nicaragua.abo.htm).

2. Asamblea del Gobierno de Nicaragua. Ley de Derogación al Artículo 165 del Código Penal Vigente 2006. (http://legislacion.asamblea.gob.ni/Normaweb.nsf/b34f77cd9d23625e06257265005 d21fa/ cb461294f9939e56062572340070aae9?OpenDocument). Consulta realizada el 15 de marzo de 2007.

3. Comisión Especial de Comunidad del Consorcio Atención Posaborto. Elementos Esenciales de Atención Posaborto: Un Modelo Desarrollado y Actualizado. En: APA en Acción. Núm. 2. Suplemento Especial, septiembre 2002.

4. Organización Panamericana de la Salud. Derogación del Aborto Terapéutico en Nicaragua: Impacto en Salud. Salud de la Familia y la Comunidad, OPS/OMS, Nicaragua 2007. (http://www.ops.org.ni/index.php?option=com_remository\&Itemid=34\&func=fileinfo\&id=292). Consulta realizada el 15 de marzo de 2007.

5. Ipas Un diagnóstico nacional de la atención posaborto en Nicaragua 2003. (http://www.ipas.org/ publications/es/NICAPAC_SO3_es.pdf). Consulta realizada el 15 de marzo de 2007.

6. Ministerio de Salud. Pautas generales para la organización y normatización de la atención a la emergencia obstétrica. Managua, Nicaragua. 2000.

7. Ministerio de Salud. Protocolo para la atención obstétrica y pediátrica. Managua, Nicaragua. 2001.

8. Ministerio de Salud Protocolo para el manejo del aborto. Managua, Nicaragua. 2002.

9. Ministerio de Salud. Dirección de Atención Integral a la Mujer y Adolescencia. Normas de Planificación Familiar. Managua, noviembre. 2004. 



\section{Calidad y acceso a la atención posaborto en Perú}

Janie Benson ${ }^{a}$ y Victor Huapaya ${ }^{b}$

\section{INTRODUCCIÓN}

Este capítulo ofrece los hallazgos de tres estudios realizados en Perú entre 1996 y 2002, con el propósito de abordar el problema de las complicaciones derivadas del aborto. El primero de ellos describe la disponibilidad y distribución de los servicios de atención posaborto (APA) en los establecimientos de atención pública de ese país. Los otros dos estudios exponen los resultados de intervenciones para introducir servicios de APA en diversos establecimientos de salud. Finalmente, se ofrecen recomendaciones para mejorar la calidad y el acceso a la APA en Perú y las implicaciones de los hallazgos para programas y políticas en América Latina.

\section{CONTEXTO DE LA ATENCIÓN POSABORTO EN PERÚ}

La legislación sobre aborto en Perú es sumamente restrictiva. Las indicaciones que justifican un aborto legal se limitan a salvar la vida de la mujer o a "evitar daños serios a su salud". ${ }^{1}$ Sin embargo, las mujeres peruanas recurren con frecuencia al aborto clandestino, como lo demuestra una de las tasas estimadas de aborto más elevadas de la región: 51.8 por cada 1000 mujeres en edad reproductiva. ${ }^{2}$ Más aún, entre los años 1994 y 2001, se registró un incremento en la razón de abortos por cada 100 nacidos vivos, de 43 a $54 .^{3}$

La prevalencia de uso de anticonceptivos entre las mujeres casadas o unidas ha aumentado de manera constante, y llegó a $69 \%$ en el año 2000 , incluyendo $17.5 \%$ de métodos tradicionales de planificación familiar. ${ }^{4}$ A consecuencia de este incremento y de las altas tasas de aborto, la tasa global de fecundidad se redujo de 4.3 nacidos vivos por mujer en 1986, a 2.9 en el año $2000 .^{4}$

\footnotetext{
${ }^{a}$ Ipas, Chapel Hill, N.C., EUA.

b Al momento de elaborar este capítulo, el coautor se desempeñaba en Ipas, Chapel Hill, NC.
} 
Se calcula que en 1994 se realizaron en Perú aproximadamente 270000 abortos inducidos, cifra que se incrementó a poco más de 350000 en 2001. ${ }^{3}$ Muchos de esos procedimientos se realizaron en condiciones inseguras; es decir, los practicaron prestadores de servicios no capacitados que trabajan en escenarios carentes de higiene. ${ }^{5}$ De las mujeres peruanas que se someten a un aborto, $14 \%$ tiene altas probabilidades de requerir hospitalización, y de ellas, las mujeres pobres de áreas rurales están más expuestas al riesgo de sufrir complicaciones que requieran hospitalización. ${ }^{3}$ En 2001, se registraron en Perú poco más de 50000 ingresos para tratamiento de complicaciones derivadas de un aborto; pero esta cifra no incluye a mujeres internadas por complicaciones de un aborto espontáneo. ${ }^{3}$

A pesar de la reducción en la tasa de mortalidad materna (TMM), de 265 muertes por cada 100000 nacidos vivos entre 1990 y 1996, a 185 muertes por cada 100000 nacidos de 1994 a 2000, el indicador sigue siendo elevado para los estándares de América Latina. ${ }^{4}$ Aunque no se conoce la proporción de muertes maternas ocasionadas por complicaciones de un aborto, el Ministerio de Salud (MINSA) las considera una de las principales causas de mortalidad materna. ${ }^{6}$ Asimismo, la Organización Mundial de la Salud estima que en América del Sur, 24\% de las muertes maternas se pueden atribuir al aborto inseguro, una de las proporciones más elevadas entre las diferentes subregiones del mundo. ${ }^{5}$

En años recientes, el MINSA ha participado en varios esfuerzos para mejorar los servicios de APA. Además de las investigaciones operativas descritas en este capítulo, el MINSA y Pathfinder International iniciaron en 1996 un proyecto para mejorar dichos servicios en más de 40 hospitales del país. Aunque en los últimos años se han nombrado funcionarios conservadores en puestos importantes del MINSA, los nuevos mandos han expresado su apoyo a los programas de planificación familiar y salud reproductiva.

\section{MÉTODOS DE LOS TRES ESTUDIOS}

Inventario nacional de servicios posaborto del sector público

El objetivo del inventario nacional fue determinar la disponibilidad, distribución, utilización y características de los servicios de APA en hospitales y centros de salud del sector público de Perú. A petición del MINSA, Ipas desarrolló un sencillo instrumento para recopilar datos sobre servicios de APA; este instrumento se envió a los coordinadores de planificación familiar y salud reproductiva de las 37 unidades administrativas del MINSA. Debido a que tres unidades no participaron en el estudio, la muestra comprende puntos de prestación de salud de 34 unidades distribuidas en todo el país. Los datos requeridos por el instrumento fueron recolectados por los coordinadores entre abril y junio del año 2001 (cubriendo el periodo del año 2000) en todos los hospitales y centros de salud bajo su supervisión. Se incluyeron también datos a partir del sistema de información del MINSA. Se obtuvo información de 120 hospitales y 931 centros de salud; ${ }^{7}$ es decir, de todos los establecimientos listados en el censo de infraestructura del MINSA que cuentan con personal y/o infraestructura física para prestar servicios de evacuación uterina por aborto incompleto en las 34 unidades administrativas incluidas en el estudio. 


\section{Sostenimiento de la APA en un hospital urbano}

Entre 1996 y 1998, los autores evaluaron la efectividad de una intervención programática de capacitación en APA y entrega de servicios en el Hospital D.A. Carrión, un centro de atención terciaria ubicado en el área metropolitana de Lima, para: a) documentar los cambios en el tratamiento clínico de pacientes en APA; b) evaluar la efectividad de integrar la planificación familiar con el tratamiento de complicaciones derivadas de un aborto, y c) evaluar los cambios en cuanto a utilización de recursos para atención posaborto.

La intervención abarcó la capacitación del personal; el cambio de técnicas de evacuación (de legrado uterino instrumental [LUI] a aspiración manual endouterina [AMEU]); asesoría y métodos anticonceptivos, y la reorganización de los servicios de APA (de la hospitalización de las pacientes a la prestación de servicios ambulatorios en la sala de urgencias de ginecoobstetricia).

A principios de 1998, al concluir este estudio, el hospital ya no recibió recursos externos para la atención posaborto; por ello, en el 2000 y 2001 se llevó a cabo un estudio de seguimiento para determinar si permanecían las mejoras en la prestación de servicios que se habían implementado en el hospital. ${ }^{8}$

En ambos estudios se obtuvieron medidas pre y posintervención de las siguientes variables:

- Uso de AMEU para tratamiento de un aborto incompleto. Esta información se obtuvo de los libros de registro quirúrgico del hospital de los periodos octubre de 1996 a enero de 2001; después, se hicieron los cálculos necesarios para determinar el porcentaje mensual de pacientes con aborto incompleto por embarazos de 12 semanas o menos, para quienes se había indicado tratamiento con AMEU.

- Asesoría posaborto en planificación familiar y provisión de métodos. En el primer estudio, esta información se obtuvo entrevistando a 102 mujeres después de recibir APA en cada uno de los periodos pre (1996) y pos (1997) intervención. Todas las mujeres habían sido atendidas con AMEU y habían tenido embarazos de no más de 12 semanas sin complicaciones adicionales; en el estudio de seguimiento de 2000 a 2001 se entrevistaron a 119 pacientes de APA. Todas las entrevistadas dieron su consentimiento para la entrevista.

- Duración de la hospitalización y costo de la atención. Para cada etapa se usó una metodología de valoración rápida que incluía la observación de muestras pequeñas y de conveniencia de pacientes de APA, desde su llegada al hospital hasta su salida (etapa 1: $n=17$; etapa 2: $n=17$; etapa 3: $n=18$ ). El personal a cargo de la recopilación de datos registró el tiempo que las pacientes estuvieron en cada punto del proceso de la atención, el tipo de prestadores y el tiempo que dedicaron para atender a las pacientes, así como el tipo y cantidad de medicamentos, suministros y equipo utilizados. De los registros del hospital se obtuvieron los costos de salarios y prestaciones de los proveedores, los de los medicamentos y suministros, y los de los costos operativos. Para cada etapa se calculó la duración promedio de la estancia hospitalaria y los costos promedio de la atención.

Para entender mejor los factores que afectan el sostenimiento de los servicios de APA, se hicieron 13 entrevistas cualitativas con preguntas abiertas a prestadores y administradores del hospital, funcionarios del MINSA y representantes de organizaciones internacionales que trabajan en el área de APA en Perú. 


\section{Expansión del acceso a la APA en un escenario rural}

El último estudio se hizo en el departamento de Ayacucho, localizado en la sierra sur central de los Andes, que es uno de los departamentos más pobres de Perú y que ha sufrido 20 años de violencia social a raíz de la guerra civil entre insurgentes maoístas y el gobierno peruano. En Ayacucho, sólo 33\% de las mujeres en unión utilizan un método moderno de anticoncepción, una de las tasas más bajas entre los departamentos de ese país. ${ }^{4}$ Con el propósito de mejorar la calidad y el acceso a los servicios de APA, las autoridades locales del MINSA e Ipas seleccionaron a ocho hospitales y seis de los 37 centros de salud que tenían acceso al principal hospital de referencia de Ayacucho. ${ }^{9}$ Entre julio y octubre de 2001, un experimentado ginecoobstetra, miembro del equipo de capacitación, evaluó la capacidad que estos 14 establecimientos de salud tenían para proporcionar servicios de atención posaborto. Más tarde, los servicios continuos de vigilancia se encargaron de recolectar la información, y al concluir el proyecto se hizo una evaluación final.

La intervención duró un año (2001 a 2002) y cubrió varias actividades, como cursos de capacitación, conferencias para estudiantes que iniciaban su año de servicio social obligatorio en Ayacucho, entrenamiento en el lugar de trabajo en los sitios de prestación de servicios, capacitación de los responsables del proyecto en un hospital limeño y visitas de supervisión. De igual modo, todos los sitios participantes recibieron instrumental para la AMEU y se donó equipo adicional al principal hospital de referencia a fin de desarrollar una unidad de servicios ambulatorios de APA.

Se seleccionaron tres indicadores para medir las mejoras en la prestación de servicios: uso de AMEU para el tratamiento de un aborto incompleto, mejoras en la calidad de los servicios de APA y grado de aceptación de métodos anticonceptivos posaborto.

Se emplearon cuatro instrumentos para recopilar la información. El primero de ellos fue el sistema "EvalAPA", desarrollado antes por Ipas, que permite a los establecimientos de salud evaluar rápidamente la calidad de sus servicios utilizando una sencilla lista de verificación. ${ }^{10}$ Otros métodos de recopilación de datos incluyeron la puesta en marcha de un registro clínico computarizado de pacientes llamado "InfoAPA", la observación directa de los establecimientos participantes y de los servicios prestados, la aplicación de un cuestionario semiestructurado a prestadores potenciales de APA e informes de visitas de supervisión.

\section{HALLAZGOS}

Inventario nacional de APA

Un 65\% (78/120) de los hospitales y 14\% (128/931) de los centros de salud ${ }^{7}$ dijeron proporcionar tratamientos de APA (20\% de las 1051 unidades de salud); 76 de las 166 provincias $(46 \%)$ en las que se recabaron datos no cuentan con establecimientos de salud que ofrezcan servicios de APA, ${ }^{7}$ lo que repercute en más de 900000 mujeres en edad reproductiva, siendo las más afectadas las que viven en áreas rurales.

Más de 90\% (188/206) de los establecimientos que ofrecen APA proporcionaron estadísticas sobre las pacientes atendidas en el año anterior al estudio. Los 188 hospitales y centros de salud atendieron a 26924 pacientes en el año 2000, una cifra que contrasta con los 7944 casos de APA registrados en el sistema oficial de información del 
MINSA. ${ }^{c}$ De los establecimientos participantes, 20\% (34 hospitales y dos centros de salud) atendió a $80 \%$ de las pacientes de APA. ${ }^{7}$

De los establecimientos que proporcionaron estadísticas de servicio, $17 \%$ (32/188) utilizó la AMEU; pero el porcentaje de casos tratados con este procedimiento varió ampliamente de un establecimiento a otro. Asimismo, una mayor proporción de los hospitales (33 de 72), en comparación con los centros de salud (7\% de 116 centros) usaron AMEU. De las 26924 mujeres que recibieron tratamiento por complicaciones derivadas de un aborto en los sitios encuestados, se encontró que $29 \%$ fue tratada con AMEU. $^{7}$

\section{Sostenimiento de la APA en un hospital urbano}

Las pacientes de APA que participaron en las tres etapas del estudio presentaron características sociodemográficas y de salud reproductiva similares; ${ }^{8}$ la edad promedio fue de entre 25 y 29 años, y el nivel educativo fue elevado: 13.7\% para pacientes en la primera etapa, mientras que en las etapas segunda y tercera, casi una cuarta parte tenía más de 12 años de estudio. En las tres etapas, entre 58 y 63\% de las pacientes eran amas de casa; entre 34 y $37 \%$ de las entrevistadas informaron que el embarazo que habían perdido había sido deseado, y entre 21 y 30\% dijo que no deseaba embarazarse en el futuro. 8,11 Entre 77 y $96 \%$ de las mujeres en las tres etapas reportaron haber usado alguna vez un método anticonceptivo. ${ }^{8,11}$

Al hospital participante en el estudio acuden cada año entre 400 y 500 mujeres que buscan tratamiento para abortos incompletos por embarazos de 12 semanas o menos. Antes de comenzar el estudio, se practicaba el legrado a todas las mujeres que requerían una evacuación uterina. Después de capacitar a los prestadores del hospital, a principios de 1997, y de inaugurar una sala de urgencias de ginecoobstetricia donde se ofrecían servicios de APA, el uso de la AMEU aumentó consistentemente al paso de los meses, y para finales de ese mismo año ya se atendía con este último método a $83 \%$ de las pacientes que requerían APA. ${ }^{8}$ Desde entonces se ha mantenido alta la proporción de pacientes atendidas con AMEU: más de $90 \%$ durante la mayor parte de 1998, y más de $98 \%$ en 1999 y $2000 .^{8}$

Los hallazgos de la primera medición mostraron que la disponibilidad de los servicios de anticoncepción posaborto era muy limitada antes de la intervención, puesto que sólo un poco más de la tercera parte de las mujeres eran informadas de que podían embarazarse incluso antes del regreso de su menstruación; a menos de $20 \%$ se le dio información sobre planificación familiar durante su estancia en el hospital, y casi ninguna recibió un método anticonceptivo antes de ser dada de alta. El cuadro 8-1 muestra que estos indicadores mejoraron sustancialmente después de la intervención y continuaron mejorando aun después del término del proyecto: en el año 2000, se daba información

\footnotetext{
${ }^{\mathrm{c}}$ El subregistro de admisiones de pacientes APA es un fenómeno común en muchos de los sistemas de salud pública de América Latina y otras regiones (Bertrand y Escudero, 2002). El carácter clandestino del aborto inducido y sus complicaciones, así como los inadecuados sistemas de recolección, análisis y uso de la información, son factores que contribuyen a esta situación.
} 
$70 \quad \begin{aligned} & \text { Capítulo } 8 \\ & \text { Avances en la atención posaborto en América Latina y el Caribe ... }\end{aligned}$

CUADRO 8-1.

Información y métodos de planificación familiar posaborto proporcionados a pacientes

de APA, por etapa, porcentaje de informantes. Hospital D.A. Carrión, Perú, 1996 a 2001

\begin{tabular}{l|c|c|c}
\multicolumn{1}{c|}{ Variable } & $\begin{array}{c}\text { Etapa 1 } \\
\mathrm{n}=102 \\
(1996)\end{array}$ & $\begin{array}{c}\text { Etapa 2 } \\
\mathrm{n}=102 \\
(1997)\end{array}$ & $\begin{array}{c}\text { Etapa 3 } \\
\mathrm{n}=119 \\
(2000-2001)\end{array}$ \\
\hline $\begin{array}{l}\text { Se le informó acerca del riesgo de } \\
\text { quedar embarazada inmediatamente }\end{array}$ & 38.4 & $64.7^{1}$ & 72.3 \\
\hline $\begin{array}{l}\text { Se le proporcionó información sobre } \\
\text { planificación familiar }\end{array}$ & 18.2 & $77.5^{1}$ & $89.1^{2}$ \\
\hline $\begin{array}{l}\text { Se le proporcionó un método } \\
\text { anticonceptivo }\end{array}$ & 2.0 & $58.8^{1}$ & $86.6^{2}$ \\
\hline $\begin{array}{l}\text { ? } p<0.05 \text { para la primera etapa en comparación con la segunda. } \\
2 \mathrm{p}<0.05 \text { para la segunda etapa en comparación con la tercera. }\end{array}$ & & \\
\end{tabular}

sobre anticonceptivos y los recibían antes del alta hospitalaria más de $85 \%$ de las mujeres. En ambas etapas posintervención, los métodos ofrecidos con más frecuencia fueron los inyectables (55.9 y $45.6 \%$ de las pacientes que aceptaron un método, respectivamente) y los anticonceptivos orales (39.0 y $34.0 \%$, respectivamente). ${ }^{8,11}$

Antes de la intervención, la atención posaborto implicaba ingresar a la paciente y que permaneciera hospitalizada una noche; el tratamiento utilizado para la evacuación uterina era el legrado y se practicaba en un quirófano. Después de la intervención, la atención posaborto se convirtió en un servicio ambulatorio, donde la admisión, tratamiento, recuperación y servicios posaborto de planificación familiar se ofrecían en una sala de urgencias de ginecoobstetricia; la técnica de evacuación uterina pasó a ser la AMEU. Este cambio de organización en la prestación de los servicios se reflejó en la reducción del tiempo estimado que las pacientes permanecían en el hospital, de 33.3 a 6.4 horas. En la tercera etapa, el hospital pudo mantener esta mejora, ya que la estancia promedio registrada fue de 6.7 horas. $^{8}$

Por otra parte, se observó también una reducción en el tiempo entre la llegada de la paciente al hospital y el momento en que recibía el tratamiento. En la primera etapa, las pacientes tenían que esperar en promedio 5.3 horas antes de ser sometidas al procedimiento, tiempo que se redujo a 2.9 horas en la segunda etapa y a 2.6 horas en la tercera. ${ }^{8}$

Finalmente, se registraron también disminuciones en los costos de la atención. El costo promedio total de la atención por paciente era del equivalente a 118.73 dólares (EUA) en la primera etapa. Al convertir los servicios de APA en ambulatorios, los costos se redujeron significativamente al equivalente de 45.13 dólares (EUA) debido a la marcada disminución de la estancia hospitalaria y los consiguientes costos administrativos. $^{8}$ Los ahorros obtenidos de la primera y segunda etapas permitieron que el hospital liberara recursos que se canalizaron a otros servicios, por lo que los gastos reales del hospital no se redujeron. En la tercera etapa se estimó que los costos totales por paciente eran el equivalente de 33.45 dólares (EUA) ${ }^{8}$ La reducción observada entre la segunda 
y tercera etapas se podría atribuir a una serie de factores, incluyendo salarios estancados, amplias fluctuaciones de los costos de medicamentos y suministros en Perú, y una sensible devaluación del sol respecto al dólar estadounidense.

Los resultados de las entrevistas con informantes clave ayudaron a entender las razones del sostenimiento de los servicios de APA a largo plazo. En el MINSA, el director del hospital entre 1995 y 2001, lo mismo que otros dirigentes, apoyaron sin titubeos las mejoras a los servicios de APA por percibir que la intervención reduciría la estancia hospitalaria de las pacientes y los costos asociados, y mejoraría la eficacia y calidad de la atención. ${ }^{8}$ Por su parte, el director de la clínica de planificación familiar promovió también, resueltamente, el programa de APA.

En un principio, la capacitación de los prestadores se enfocó a servicios APA presentes y futuros; ${ }^{8}$ es decir, a quienes en ese momento eran proveedores de servicios primarios (residentes de segundo y tercer año y obstetrices), así como a futuros capacitadores y prestadores de servicios (p. ej., residentes de primer año). Los residentes adoptaron rápidamente el uso de la AMEU, y en la actualidad entrenan a nuevos residentes en dicha técnica. Las obstetrices, por su parte, demostraron ser un factor esencial para el éxito del programa, por su amplia experiencia y lo diverso de sus responsabilidades, en particular en el área de asesoría sobre planificación familiar posaborto y en la provisión de métodos.

La sala de urgencias se encuentra bien abastecida, pues dispone de suficientes suministros y de equipo ginecoobstétrico para la prestación de servicios de APA. ${ }^{8}$ Las obstetrices han incorporado igualmente a su labor de rutina el traslado de anticonceptivos de la clínica de planificación familiar a la sala de urgencias a fin de garantizar la disponibilidad de métodos para pacientes de APA. Cuando se llevó a cabo el estudio de la tercera etapa, se encontró que los proveedores seguían utilizando el instrumental para AMEU que se había donado al hospital, y que el personal administrativo del hospital procuraba añadir ese tipo de equipo a la lista estándar de suministros.

La nueva unidad de urgencia promovió el sostenimiento de los servicios APA al concentrar prácticamente todos los componentes de ese tipo de atención en un mismo lugar. ${ }^{8}$ Por ejemplo, la reorganización facilitó que se establecieran vínculos entre el tratamiento clínico y la planificación familiar posaborto. Además, no se implementó el programa de manera vertical e independiente, sino que se le incorporó al paquete general de servicios ginecoobstétricos que se venían ofreciendo en la sala de urgencias.

Desde mucho antes de iniciarse el estudio, el hospital había contemplado construir una unidad de urgencias ginecoobstétricas, un proyecto que finalmente se hizo realidad gracias al patrocinio del MINSA. Cabe hacer notar aquí que pocos hospitales públicos en América Latina cuentan con los recursos necesarios para crear una sala de este tipo. El personal entrevistado para el estudio de sostenimiento subrayó que aunque la sala de urgencias había mejorado el escenario de atención, no era un prerrequisito para la implementación de servicios ambulatorios de alta calidad; ${ }^{8}$ prueba de ello es que hospitales de otras ciudades del Perú han transformado la atención posaborto en un servicio ambulatorio y han obtenido mejoras en cuanto a calidad y eficacia sin haber efectuado grandes inversiones en infraestructura. ${ }^{12}$

En suma, la combinación del sólido liderazgo administrativo y clínico, la capacitación en servicios actuales y futuros, la participación de distintos tipos de personal en la prestación de servicios APA y la disponibilidad de suministros y equipo, incluyendo anticonceptivos e instrumental para AMEU, contribuyeron al sostenimiento de la atención posaborto en el largo plazo en este hospital.., 13 


\section{Expansión del acceso a la APA en un escenario rural}

La evaluación inicial de los 14 establecimientos de salud realizada al inicio del proyecto reveló que 12 de ellos (86\%) hacían la evacuación uterina mediante el legrado, y que en ninguno se utilizaba la AMEU. Durante el proyecto, los 14 puntos de prestación trataron a las pacientes posaborto con AMEU, de manera que en cada provincia de Ayacucho se habilitó un establecimiento que proporcionaba servicios integrales de APA. Para garantizar que los prestadores de servicios pudieran usar las habilidades recién adquiridas, el coordinador del proyecto hizo visitas de supervisión a cada hospital y centro participante, y en cada establecimiento se nombró a un experto para ofrecer soporte técnico y ayudar a responder las preguntas del personal. El uso de la AMEU aumentó en el transcurso del año de duración del proyecto, y ya para el último trimestre, en los 14 puntos de prestación del servicio incluidos en este estudio, $65 \%$ de las evacuaciones uterinas por embarazos de hasta 12 semanas se practicaban con AMEU. ${ }^{9}$

Como consecuencia de la intervención se pudo documentar una reducción en el tiempo que las pacientes esperaron entre su llegada al establecimiento y el momento en que la evacuación uterina se hizo. Antes de la intervención, el tiempo de espera era de alrededor de 24 horas. Después de la intervención, disminuyó a 11.6 horas en los establecimientos que siguieron utilizando el legrado durante la transición a AMEU, y llegó a 4.1 horas al haberse completado la implementación de dicha técnica como servicio ambulatorio. ${ }^{9}$ Se encontró que uno de los factores clave de la adopción de la AMEU fue la capacitación y el apoyo brindados a las obstetrices, quienes realizaban la evacuación uterina bajo la supervisión de los médicos del centro.

De igual manera, se registraron cambios positivos en los servicios de anticoncepción posaborto. Con la evaluación inicial, el personal del proyecto encontró que sólo $21.1 \%$ de las pacientes de APA egresaban del establecimiento de salud con un método anticonceptivo, cifra que se duplicó después de la intervención (42.8\%). En cuanto a asesoría en planificación familiar, el porcentaje de pacientes que recibió este servicio aumentó de 89.5 a $94.2 \% .^{9}$

\section{IMPLICACIONES Y RECOMENDACIONES DERIVADAS DE LOS HALLAZGOS}

Los tres proyectos cuyos resultados se presentan en este capítulo describen tanto las deficiencias observadas en la atención posaborto ofrecida por muchos de los establecimientos de salud en Perú, como las intervenciones que han tenido éxito mejorándolas y cuya replicación podría incrementar de manera notable la calidad y el acceso a estos servicios. El inventario nacional confirma que los servicios de APA en Perú están concentrados en hospitales (aunque cerca de un tercio no ofrecen estos servicios) y que las mujeres de áreas rurales, las más vulnerables al riesgo de sufrir complicaciones por un aborto, son las que tienen menor acceso al tratamiento en localidades cercanas.

El hospital urbano de Lima que participó en el estudio, junto con el proyecto rural de Ayacucho, son un claro ejemplo de que incluso los establecimientos que han proporcionado servicios de baja calidad por mucho tiempo pueden mejorarlos drásticamente, y que las intervenciones en todos los niveles del sistema de salud, incluso en escenarios rurales de bajos recursos, son viables. Como la mayoría de los hospitales y centros de 
salud de Perú ofrecen atención a partos obstétricos, incorporar la APA al paquete rutinario de servicios de esos centros no representaría un reto formidable ni de alto costo. ${ }^{8}$

Además de especialistas en ginecoobstetricia y médicos generales, se deberían autorizar y capacitar a las obstetrices que laboran en los centros de salud para prestar los servicios de APA, incluyendo practicar la evacuación uterina de urgencia para el tratamiento de un aborto incompleto de primer trimestre, así como estabilizar y referir los casos más complicados. ${ }^{8}$ Muchos de los suministros, equipos y productos anticonceptivos disponibles para partos y servicios rutinarios de planificación familiar pueden utilizarse para la APA. En términos de logística, sólo sería necesario equipar a los establecimientos con el instrumental correspondiente, que debería incluirse en la lista estándar de suministros del MINSA.

Las dos intervenciones documentan mejoras importantes en la asesoría anticonceptiva y la provisión de métodos. Un componente esencial de la atención posaborto fue poder establecer vínculos funcionales entre el tratamiento de un aborto y los servicios de planificación familiar. Estos resultados son consistentes con otros proyectos de APA realizados en América Latina y África. ${ }^{14,15,16}$ Ofrecer a las pacientes información y servicios de entrega de métodos anticonceptivos antes del alta hospitalaria es una estrategia efectiva para reducir la recurrencia de embarazos no deseados y de abortos inseguros. ${ }^{17}$ Debe recordarse que la APA es una medida secundaria de prevención; que la prevención misma de embarazos no deseados mediante la anticoncepción debe seguir fortaleciéndose, y que tal fortalecimiento debe incluir la asesoría, el proceso de elección y consentimiento informado y el mejoramiento de la calidad de los servicios de esterilización femenina voluntaria a fin de evitar violaciones a los derechos humanos y mantener el apoyo del programa de planificación familiar. ${ }^{18,19}$

Sin embargo, incluso con una mayor disponibilidad y calidad de los servicios de anticoncepción, continuarán los embarazos no deseados y habrá mujeres que los enfrenten mediante un aborto. En años recientes, se ha incrementado el uso de la prostaglandina misoprostol para provocar el aborto. ${ }^{3}$ En Perú, el uso de este medicamento, que se puede obtener sin receta en las farmacias, al igual que las mejoras en la calidad de los servicios clandestinos de aborto inducido, ha disminuido la tasa de complicaciones severas derivadas del procedimiento, como son la septicemia y la perforación uterina. ${ }^{12,3} \mathrm{La}$ liberalización de la ley actual en materia de aborto, así como la expansión de servicios seguros y de costo accesible para la provisión de abortos electivos, produciría importantes reducciones en las tasas de mortalidad y morbilidad asociadas al procedimiento. Asimismo, dicho proceso se facilitaría mediante cambios en políticas y prácticas, como ofrecer servicios seguros, legales y electivos para todas las indicaciones en que la ley actual permite un aborto.

\section{Referencias}

1. Comité de América Latina y el Caribe para la Defensa de los Derechos de la Mujer, Cladem y The Center for Reproductive Law and Policy y Demus: Estudio para la Defensa de los Derechos de la Mujer: Derechos sexuales y reproductivos de las mujeres en el Perú: Reporte sombra. Lima. 1998.

2. Singh S, Wulf D: Estimated levels of induced abortion in six Latin American countries. En: International Family Planning Perspectives: 20,1994:4-13. 
3. Ferrando D: El aborto clandestino en el Perú, hechos y cifras. Centro de la Mujer Peruana Flora Tristán y Pathfinder International, Lima. 2002.

4. Instituto Nacional de Estadística e Informática, Measure/DHS+, Macro International, Inc., USAID y UNICEF. Encuesta demográfica y de salud familiar 2000. Instituto Nacional de Estadística e Informática, Lima. 2001.

5. World Health Organization: Unsafe abortion: Global and regional estimates of incidence of and mortality due to unsafe abortion with a listing of available country data. 3a. edición, Ginebra, 1998.

6. Ministerio de Salud: El desafio del cambio de milenio. Un sector salud con equidad, eficiencia y calidad, lineamientos de politica de salud, 1995-2000. Lima. 1995.

7. Huapaya V, Benson J, Verástegui H, Parra J: Results of a national postabortion care service survey in Peru. Ponencia presentada en la reunión anual de la American Public Health Association, Filadelfia, 2002.

8. Benson J: Sustainability of postabortion care in Peru. Disertación doctoral, University of North Carolina at Chapel Hill, School of Public Health, Department of Maternal and Child Health. Chapel Hill, NC. 2003.

9. Ipas: Expanding access to postabortion care in Ayacucho. Informe final para la Columbia University, AMDD Project. Chapel Hill, NC. 2003.

10. Greenslade FC y Jansen WH: Postabortion care services: An update from PRIME. En: Resources for Women's Health;1,1-12. Ipas, Chapel Hill, NC.1998.

11. Benson J, Huapaya V, Abernathy M, King T: Improving quality and lowering costs in an integrated postabortion care model in Peru. Informe final para el proyecto INOPAL II. Ipas, Carrboro, NC. 1998.

12. Benson J, Huapaya V: Sustainability of postabortion care in Peru: Report of rapid assessment visits to four hospitals. Informe final para el proyecto Fronteras de la Salud Repropductiva. Ipas, Chapel Hill, NC. 2002.

13. Population Council. Leadership facilitates sustainability of postabortion care services. En: OR Summaries 42 (en línea). 2004. Disponible en: www.popcouncil.org.

14. Langer A, García-Barrios C, Heimburger A et al.: Improving postabortion care with limited resources in a public hospital in Oaxaca, Mexico. En: Huntington D y Piet Pelon NJ (Eds.), Postabortion Care. Lessons from Operations Research. The Population Council, Nueva York. 1999.

15. Solo J, Billings DL, Aloo-Obunga C et al.: Creating linkages between incomplete abortion treatment and family planning services in Kenya. En: Studies in Family Planning; 30, 1999:17-27.

16. Billings DL, Fuentes Velásquez J, Pérez-Cuevas R: Comparing the quality of three models of postabortion care in public hospitals in Mexico City. En: International Family Planning Perspectives; 29, 2003:112-120.

17. Johnson BR, Ndhlovu S, Farr S, Chipato T: Reducing unplanned pregnancy and abortion in Zimbabwe through postabortion contraception. En: Studies in Family Planning; 33, 2002:195-202.

18. Sims C: Using gifts as bait, Peru sterilizes poor women. En: New York Times, febrero 14, 1998:1,12.

19. Center for Reproductive Law and Policy, CRLP: CRLP brokers landmark settlement in coercive sterilization of Peruvian woman (en línea). (3 de noviembre de 2002. Disponible en: http://www.crlp.org. 


\title{
Calidad de la consejería durante la atención posaborto en República Dominicana
}

\author{
Estela Rivero-Fuentes, ${ }^{a}$ Marija Miric, ${ }^{b}$ Ricardo Vernon, ${ }^{a}$ \\ Gisela Quiterio ${ }^{c}$ y Maritza Molina ${ }^{c}$
}

\section{INTRODUCCIÓN}

A partir de los reportes de una elevada mortalidad materna a finales del decenio de 1990-1999 y principios del siglo XXI, la Secretaría de Estado de Salud Pública y Asistencia Social (SESPAS), y las agencias de cooperación que la apoyan, han realizado importantes esfuerzos por mejorar la calidad de la atención obstétrica en República Dominicana. Para documentar los avances logrados e identificar algunas de las brechas que todavía falta cerrar, este capítulo ofrece los resultados principales de un estudio realizado entre julio y septiembre de 2006, sobre la situación de la atención posaborto (APA). Los hallazgos muestran que en los últimos cuatro años se han conseguido importantes logros para mejorar la calidad de la APA, sobre todo en lo que atañe al uso de la aspiración manual endouterina (AMEU), capacitación del personal de salud, normatividad de la atención posaborto y sostenimiento financiero del programa posaborto. Sin embargo, todavía es posible lograr mejoras adicionales, principalmente relacionadas con la sensibilización de los prestadores de servicios acerca de las necesidades emocionales y de información de las mujeres. Es posible que la continuidad de los esfuerzos realizados hasta la fecha por la SESPAS y sus aliados, repercutan en la solución de los problemas identificados en este documento. Para contribuir a ese propósito, este capítulo concluye con algunas recomendaciones de acciones concretas. El texto está organizado presentando, en primer lugar, el contexto de la APA en República Dominicana, incluyendo una breve descripción de las iniciativas emprendidas para mejorar su calidad. A continuación, se describe la metodología utilizada en el estudio de situación en el cual se basan los resultados de este estudio. Enseguida se presentan los resultados principales de

\footnotetext{
a Programa Fronteras de la Salud Reproductiva, Population Council, México D.F.

b Synergy Consulting, Santo Domingo, República Dominicana.

c Centro de Estudios Sociales y Demográficos, A.C. (CESDEM), Santo Domingo, República Dominicana.
} 
76 \begin{tabular}{l|l} 
Capítulo 9 \\
Avances en la atención posaborto en América Latina y el Caribe . . .
\end{tabular}

la investigación. Por cuestiones de espacio y exposición, los hallazgos de diferentes instrumentos de observación se presentan de forma conjunta. Para concluir, el capítulo ofrece una sección de lecciones aprendidas y recomendaciones.

\section{CONTEXTO DE LA ATENCIÓN POSABORTO EN REPÚBLICA DOMINICANA}

La Encuesta Demográfica y de Salud del $2002^{1}$ estimó que, a pesar de que $98 \%$ de las mujeres embarazadas acuden a una consulta prenatal como mínimo, y que $96 \%$ tiene sus partos en hospitales, en el periodo 1992-2002 la mortalidad materna en el país fue de 178 decesos por cada 100000 nacidos vivos. Esta cifra, ligada a reportes de baja calidad en la atención obstétrica, ${ }^{2}$ a la estimación de que una de cada cinco muertes maternas ocurre a causa de un aborto, y a que una de cada diez es causada por hemorragias, ${ }^{3}$ contribuyó a que la SESPAS, con el apoyo de la Agencia de los Estados Unidos para el Desarrollo Internacional (USAID), a través de su proyecto Conecta, junto con otras agencias de cooperación internacional como el Fondo de Población de las Naciones Unidas (UNFPA) y la Organización Pana-mericana de la Salud (OPS), emprendieran varias acciones para mejorar la calidad de la atención obstétrica, incluyendo la APA, en República Dominicana.

En este país, la mayoría de las complicaciones por aborto son atendidas en la red de hospitales y clínicas de la SESPAS, que cubre a cerca de $80 \%$ de la población. En el 2004, los hospitales y clínicas de este organismo atendieron 23438 complicaciones por aborto; de estos casos, una tercera parte se concentró en las tres maternidades nacionales. Sólo en la Maternidad de los Minas se atendieron 4260 casos de este tipo, lo que equivale a 12 casos diarios. ${ }^{4}$

Una evaluación realizada en el 2002 en 17 hospitales $^{2}$ encontró múltiples problemas en tales instalaciones, entre ellos que el número de mujeres que acudían por complicaciones derivadas de abortos superaba la capacidad del personal médico y de las áreas destinadas para este servicio, circunstancia que obligaba a las pacientes a esperar largas horas en condiciones que solían ser insalubres. Otros problemas reportados fueron la falta de privacidad durante la atención a las mujeres; los prestadores de servicios no cumplían con los lineamientos para la prestación de los servicios y no había mecanismos para remediar este problema; ninguno de los hospitales visitados realizaba aspiraciones manuales endouterinas (AMEU); ausentismo de los especialistas y personal médico; los paramédicos que podían proporcionar atención obstétrica pocas veces contaban con la capacitación apropiada para atender las urgencias; y las mujeres con complicaciones derivadas de abortos no recibían, en general, consejería ni métodos de planificación familiar.

Para ayudar a resolver dichos problemas, el proyecto Conecta de USAID empezó a poner en marcha, en enero del 2007 y a nivel nacional, la "Estrategia nacional de cuidados obstétricos de emergencia", la cual establece que la APA debe incluir la consejería, acceso a métodos de planificación familiar y atención de la urgencia con AMEU. De igual manera, las "Normas nacionales para el manejo de las principales urgencias obstétricas" 5 se modificaron en el 2006 para establecer como política nacional el uso de la AMEU en el periodo posaborto menor de 12 semanas. Además de contar ahora con el marco institucional para fortalecer la atención posaborto, la SESPAS y sus colaboradores han emprendido acciones para mejorar la calidad de la APA. A partir del 2003 se ha capa- 
citado en la técnica de AMEU a gran parte del personal de siete hospitales; la currícula de la especialidad de ginecoobstetricia incluye ahora los cuidados obstétricos de urgencia; y la compra de materiales (incluyendo los equipos de AMEU y los métodos anticonceptivos) depende ahora de los hospitales y no de donaciones. Como resultado, el uso de la AMEU ha alcanzando niveles de $90 \%$ en algunos de los hospitales más grandes del país. Asimismo, se ha logrado que hospitales grandes no padezcan desabasto de materiales para realizar este procedimiento, o de métodos anticonceptivos en las salas de partos y de posaborto. ${ }^{6}$

\section{METODOLOGÍA}

Para identificar obstáculos a la calidad de la APA y proponer posibles estrategias de mejoría, el Programa Fronteras de la Salud Reproductiva del Population Council, el Centro de Estudios Sociales y Demográficos, A.C. (CESDEM) y Synergy Consulting realizaron en los meses de julio a septiembre del 2006 un estudio de la situación de la APA en República Dominicana; como parte del estudio, el equipo hizo 161 entrevistas estructuradas con mujeres que estaban en el hospital por complicaciones posaborto, y con 210 prestadores de servicios que trabajan en atención posaborto en 37 hospitales públi$\cos ^{\mathrm{d}}{ }^{\mathrm{d}}$ Además, se hicieron entrevistas con tres mujeres que fueron atendidas por complicaciones de aborto, con seis directores de hospitales donde se atiende a mujeres con dichas complicaciones, y con 13 prestadores de servicios, incluyendo cinco médicos ginecoobstetras, cuatro enfermeras y cuatro prestadores de servicios del área de planificación familiar.

Al presentar en este texto los resultados más importantes del estudio, se hace hincapié en los hallazgos concernientes a la consejería, información y servicios de planificación familiar brindados a las mujeres durante su estancia hospitalaria. Como ya se ha señalado, para facilitar la exposición, los resultados obtenidos de los cinco instrumentos de observación diferentes se presentan de manera conjunta.

\section{RESULTADOS}

Este estudio confirma los avances logrados por la SESPAS y sus aliados en lo relativo al uso de la técnica de AMEU y al entrenamiento de los prestadores de servicios involucrados en la APA. De los 64 prestadores que realizan evacuaciones uterinas en casos de atención posaborto, $56 \%$ utiliza la técnica de AMEU. Este porcentaje es mayor en las maternidades nacionales (88\%) y los hospitales regionales (55\%) en comparación con los hospitales locales (38\%). La capacitación en AMEU ha repercutido directamente en su uso, pues $71 \%$ de los prestadores de servicios que han sido entrenados dijeron utilizar la técnica. El 29\% que ha sido capacitado en la AMEU pero no lo practica, argumenta como razón que el hospital no cuenta con los instrumentos necesarios.

\footnotetext{
${ }^{\mathrm{d}}$ De los hospitales visitados, 35 son administrados por la SESPAS, y los 2 restantes los administra el Instituto Dominicano del Seguro Social (IDSS).
} 
Dos de los elementos esenciales del modelo de APA sustentado por el Consorcio Atención Postaborto - la consejería y la provisión de servicios de planificación familiaconsisten en identificar y responder a las necesidades emocionales y de salud de las mujeres, y proporcionales información y los métodos necesarios para responder a tales necesidades. ${ }^{7}$ La experiencia en República Dominicana muestra que en la práctica estos dos elementos se cumplen de forma deficiente.

Es raro que los prestadores de servicios dediquen tiempo para hablar con las mujeres sobre sus necesidades de salud en general, y en numerosas ocasiones ni siquiera les dan la información necesaria para que puedan cuidarse adecuadamente una vez que abandonan el hospital. En las entrevistas realizadas con mujeres que estaban egresando después de ser atendidas por complicaciones por aborto, se encontró que una de cada cuatro no sabía que el sangrado abundante, expulsión de coágulos, flujo vaginal con mal olor, fiebre, mareos, náuseas y vómito, eran indicadores de posibles complicaciones que requerían su regreso al hospital. De las mujeres entrevistadas, la mitad dijo que le hubiera gustado recibir más información sobre cómo cuidarse después del tratamiento y acerca de los métodos de planificación familiar. Además, 30\% dijo que le hubiera gustado recibir información sobre otros temas de salud, incluyendo el VIH/SIDA y las enfermedades de transmisión sexual.

En los hospitales visitados no sólo no se cumple con la función informativa de la consejería, sino que los prestadores de servicios obvian las necesidades emocionales de las mujeres y, en ocasiones, se muestran hasta groseros haciendo comentarios que se suman a la carga emocional de las mujeres en vez de aliviarlas. Aunque sólo 10\% de quienes fueron entrevistadas se quejaron de forma espontánea de que alguno de los prestadores de servicios había sido grosero, las narraciones de lo ocurrido en estos casos, y las observaciones directas de los maltratos a las pacientes durante las visitas a los hospitales ilustran el trato brusco y poco sensible por parte de los prestadores de servicios. Varias mujeres comentaron que, al atenderlas, los prestadores de servicios las acusaron de haberse provocado el aborto. Otro incidente común es que los médicos y enfermeras se molesten cuando las pacientes les plantean preguntas, dejando a las mujeres sin respuestas; ello es evidente en el siguiente testimonio:

Después de estar esperando por mucho tiempo, le pregunté a la doctora cuándo me iban a atender. Ella me dijo: No me pregunte..., que soy yo la que sé cuándo lo voy hacer.

Resultados similares se observan en lo referente a la consejería sobre planificación familiar. En general, los prestadores de servicios no se preocupan por las intenciones reproductivas de las mujeres que están padeciendo una complicación derivada de un aborto, y tampoco se toman el tiempo para hablar con ellas acerca de su regreso a la fertilidad, o qué hacer para prevenir nuevos embarazos no planeados. Al no recibir este tipo de información, muchas mujeres dejan el hospital con ideas erróneas que pueden repercutir en el uso que hagan a futuro de métodos anticonceptivos, al tiempo que las mantienen en riesgo de embarazos no planeados. Sólo 7\% de las mujeres entrevistadas dijeron que durante su estancia hospitalaria algún proveedor de salud había preguntado sobre sus intenciones o planes de tener hijos en el futuro; $30 \%$ recibió información sobre cuándo se normalizaría su fecundidad y estaría en riesgo de quedar embarazada; seis de cada diez mujeres que no recibieron información sobre este dato dejaron el hospital pensando que no podían volver a embarazarse sino hasta que regresara su periodo menstrual, un mes después de que terminó su embarazo, o con desconocimiento de una fecha aproximada. 
Sólo 9\% de las entrevistadas deseaba volver a embarazarse antes de que pasaran 12 meses. De las mujeres que quieren postergar su próximo embarazo cuando menos un año, sólo una de cada cuatro recibió consejería en planificación familiar, y a 1 de cada 10 se le suministró un método anticonceptivo antes de dejar el hospital, a pesar de que 8 de cada 10 hubieran querido recibir uno. La razón principal por la que las mujeres abandonaron el hospital sin un método anticonceptivo fue que nadie se los ofreció durante su estancia (78\%). Otras causas son que un prestador de servicios les recomendó que esperaran (11\%) y que el hospital no tenía métodos disponibles (4\%).

En el caso de la República Dominicana, la capacitación de los prestadores de servicios en consejería para las mujeres en posaborto no ha contribuido a que ésta se lleve a la práctica totalmente. De los prestadores que brindan ese servicio, $68 \%$ ha recibido capacitación sobre cómo brindar esa orientación cuando menos una vez en su vida. Un porcentaje similar (64\%) ha recibido entrenamiento en anticoncepción para mujeres con complicaciones por aborto. Pero, a pesar de esa capacitación, los prestadores no reconocen la necesidad de hablar con las mujeres sobre sus necesidades emocionales o de salud después de ser atendidas, y es común que crean que la consejería es necesaria sólo en los casos de mujeres que se encuentran visiblemente afectadas por el procedimiento, como se percibe en la siguiente respuesta de un jefe de ginecoobstetricia, cuando se le preguntó si la consejería era parte de los servicios que ofrecían en el hospital a las mujeres con complicaciones derivadas de un aborto:

...Bueno, pacientes que se identifican con cierto trastorno, digamos psicológico, generalmente se mandan a Psicología para que se les de una atención más apropiada.

Otros factores que contribuyen a que los prestadores de servicios no den la consejería siguiendo las recomendaciones, a pesar de que han sido capacitados para ello, son la falta de tiempo (todos prestan servicios en otras áreas del hospital) y algunas ideas preconcebidas sobre las mujeres que atienden; en particular, el personal médico tiende a descalificar a las personas de bajo nivel educativo como interlocutoras válidas y, por lo mismo, limita la información, e incluso la libertad de decisión de esas mujeres:

¿Hasta qué punto una paciente semianalfabeta o analfabeta sabe lo que le conviene y lo que no le conviene? Porque si le conviene esterilizarse a una paciente con seis y siete muchachos, que no trabaja —i¿Por el hecho que no quiere?! ... Pero, ¿cuál es la razón que tú esgrimes para decir que "Yo quiero seguir teniendo hijos"? ¿En base a qué?

A pesar de que la mayoría de los prestadores de servicios no identifica la necesidad de orientar a las mujeres con complicaciones por aborto, algunos señalan con preocupación la falta de orientación a las pacientes y la poca vinculación con el programa de planificación familiar, en especial en el caso de adolescentes:

Descubrimos que había debilidad en eso, o sea, en la orientación psicológica en los abortos en las adolescentes y los programas de planificación. A veces el médico actuaba mecánicamente, le hacían el legrado y la despachaban... Tenemos jóvenes de 13 a 14 años que se embarazan varias veces y a veces una de 15 años que se ha embarazado dos veces -entonces vemos que hay un fallo. El sistema de educación y de orientación hacia la planificación está fallando, porque esa paciente no debió volver. 
Otro hallazgo del estudio es que las mujeres pasan demasiado tiempo en el hospital esperando ser atendidas, o entre que se les examina, se les realiza evacuación uterina y se les da de alta. Las pacientes están solas la mayor parte de ese tiempo, sin una supervisión. Esos tiempos muertos, además de representar un costo para los hospitales, podrían utilizarse para dar información a las mujeres u ofrecerles consejería.

La mitad de las entrevistadas tuvo que esperar al menos dos horas antes de ser examinadas por primera vez, y una cuarta parte esperaron al menos 15 horas. Dado que los prestadores de servicios que trabajan en la atención a mujeres con complicaciones por aborto suelen estar ocupados en otras áreas del hospital más dinámicas — como la sala de maternidad-, la demora en atenderlas, aun después de que han sido examinadas y diagnosticadas por primera vez, puede tomar más de ocho horas. Durante el estudio se encontraron varios casos de mujeres que llegaron al hospital antes de las siete horas y no fueron dadas de alta sino hasta la noche del mismo día o la mañana del día siguiente. La mayor parte de ese tiempo fue un tiempo muerto, como retrata la observación del caso de una paciente:

Delia ${ }^{e}$ acudió al hospital a las 13 horas, buscando atención por complicaciones de aborto. La ingresaron esa misma tarde, y fue canalizada a las 21. Cerca de las 19 horas pasó una doctora para informarles a las pacientes en la sala que las atenderían cerca de las 12 de la noche porque había muchas cesáreas pendientes. A las 21 horas se llevaron a Delia al quirófano, pero la devolvieron porque se presentó otra emergencia. Delia amaneció sangrando, en una cama sin sábanas, y sin que pasara ningún médico por la sala durante la noche. Se le practicó el legrado a las 11 horas del otro día, luego de lo cual, bajo los efectos de la anestesia, pasó varias horas tirada en una cama en la sala de legrado, sólo parcialmente cubierta con su propia blusa y una parte de la sábana ensangrentada.

\section{PRINCIPALES LECCIONES APRENDIDAS $Y$ RECOMENDACIONES}

Los resultados de este estudio muestran que la situación de la APA en República Dominicana ha mejorado en los últimos cuatro años, sobre todo en lo relativo a su marco institucional y a la existencia de normas que expliciten sus componentes elementales, en la capacitación de los prestadores de servicios en el uso de la técnica AMEU, y en la práctica de dicha técnica. Sin embargo, al momento de realizarse este estudio existían todavía algunas brechas en la calidad de la APA. Los prestadores siguen sin identificar las necesidades de salud física y emocional de las mujeres, y ellas continúan sin recibir la información que les ayude a satisfacer tales necesidades. A un gran porcentaje de las mujeres no se le informa cómo cuidarse al salir del hospital, cuándo pueden volver a embarazarse, o cómo evitar un embarazo no planeado en el futuro. Como resultado de esta falta de información, las mujeres dejan el hospital con ideas erróneas y con una necesidad insatisfecha por métodos de planificación familiar. El estudio detectó también que algunas mujeres reciben un trato brusco e incluso son víctimas de comentarios

\footnotetext{
e El relato se basa en la observación de servicios realizada en un hospital. El nombre de la mujer fue cambiado para proteger su identidad.
} 
ofensivos por parte de los prestadores de servicios. Otro problema detectado es que las mujeres pasan mucho tiempo en el hospital sin que se les atienda, y que esos tiempos no suelen aprovecharse.

Una causa de estos problemas es que los prestadores de servicios responsables de atender a las mujeres con complicaciones por aborto casi siempre están ocupados en otras áreas del hospital (generalmente la sala de maternidad), donde la demanda es mayor y la atención es impostergable. Por tanto, sus visitas a las mujeres atendidas por complicaciones por aborto son esporádicas y ocurren sólo cuando sus otras ocupaciones se los permiten. Del mismo modo, los prestadores de servicios no reconocen la necesidad de dar consejería, a pesar de haber recibido capacitación en el tema. Muchos tienen ideas preconcebidas sobre las necesidades de las mujeres que atienden, desconocen la capacidad de las que tienen un bajo nivel educativo para entender los mensajes que les transmiten y para tomar decisiones, y son insensibles a sus necesidades emocionales.

Como resultado de estas observaciones, se considera que las siguientes acciones podrían ayudar a mejorar la calidad de la APA en contextos con problemas similares.

- Elaborar y aplicar guías cortas que contengan la información básica que debe proporcionarse a toda mujer atendida con complicaciones derivadas de un aborto, incluyendo el tema de la planificación familiar.

- Aumentar la vinculación entre la APA y el programa de planificación familiar. Dos alternativas para hacerlo posible son: 1) programar visitas regulares de los prestadores de servicios del programa de planificación familiar al área en donde se atiende a las mujeres con complicaciones por aborto, y 2) entrenar a los prestadores de servicios en el área de posaborto para que den consejería en planificación familiar y refieran a las mujeres interesadas en utilizar un método al área de planificación familiar.

- Revisar la currícula de las capacitaciones en consejería a mujeres después de un aborto para enfatizar la necesidad de detectar los problemas emocionales y de salud física de las mujeres.

- Aprovechar los tiempos muertos, mientras las mujeres esperan ser atendidas o ser dadas de alta del hospital, para detectar otras necesidades de salud y dar información que ayude a saldar esas necesidades. Algunas alternativas concretas para hacer esto son:

- Instalar en las salas de espera o de recuperación sistemas audiovisuales con información sobre los métodos anticonceptivos disponibles y sus características.

- Poner al alcance de las pacientes folletos informativos sobre temas como planificación familiar, enfermedades de transmisión sexual y VIH/SIDA que puedan llevarse a su casa.

- Organizar la aplicación de un instrumento de detección sistemática de necesidades por parte de las enfermeras, para que las referencias necesarias se realicen posteriormente, mientras las pacientes esperan ser dadas de alta.

\section{AGRADECIMIENTOS}

Este proyecto se realizó con el apoyo del pueblo estadounidense a través de la Agencia de los Estados Unidos para el Desarrollo Internacional (USAID), bajo los términos del Acuerdo de Cooperación Núm. HRN-A-00-98-00012-00 
(Programa Fronteras de la Salud Reproductiva del Population Council). Los contenidos son responsabilidad de los autores y no necesariamente reflejan los puntos de vista de USAID, del Gobierno de EUA o del Programa Fronteras de la Salud Reproductiva.

Los autores de este capítulo reconocen la participación en el estudio de las siguientes personas e instituciones: Sonia Báez coordinó el trabajo de campo de las entrevistas semiestructuradas; Edwin Feliz supervisó la captura de estas entrevistas; el equipo del CESDEM se encargó de los aspectos logísticos y administrativos del estudio; Johanna Diplán, Mildred Martínez, Leonardo Díaz, Judith de la Rosa Turbides, Ivan Miric y Ricardo Vázquez participaron en el diseño, entrevistas y digitación del componente cualitativo, todos ellos de Synergy Consulting; la Dirección General Materno-Infantil y Adolescentes (DIGEMIA), facilitó el acceso a los hospitales de la SESPAS que se visitaron; el Instituto Dominicano de Seguridad Social (IDSS) permitió la inclusión en el estudio de 2 de sus hospitales; Sonia Brito, de Conecta, comentó una versión preliminar de este capítulo y compartió información sobre las actividades emprendidas por la SESPAS y Conecta en los últimos 5 años; el Consejo Nacional de Población y Familia (CONAPOFA), Conecta y los miembros de la Delegación de Asociaciones Israelitas-Argentinas (DAIA) proporcionaron comentarios muy útiles durante la elaboración de la propuesta para el estudio finalmente extendemos nuestro agradecimiento a todas las mujeres y prestadores de servicios que compartieron con nosotros sus comentarios y su tiempo.

\section{Referencias}

1. Molinar Achécar M, Ramírez N, Polanco JJ, Ochoa LH, Lerebours G, García B: Encuesta Demográfica y de Salud. ENDESA 2002. Centro de Estudios Sociales y Demográficos (CESDEM), SESPAS, Consejo Presidencial del SIDA (COPRESIDA), USAID, Comisión Ejecutiva para la Reforma del Sector Salud (CERSS), y Measure DHS+/ORC Macro. 2003:509.

2. Miller S, Tejada A, Murgueytio P, et al:: Strategic Assessment of Reproductive Health in the Dominican Republic [Evaluación estratégica de la salud reproductiva en la República Dominicana]. Population Council, febrero 15, 2002.

3. Cáceras Urena F: Mortalidad materna y calidad de servicios. Profamilia, Instituto de Estudios de Población y Desarrollo. Santo Domingo, República Dominicana. 1998.

4. Secretaría de Estado de Salud Pública y Asistencia Social (SESPAS): Tabulado del número de partos normales, cesáreas, número total de nacimientos, número de abortos, y número total de eventos obstétricos en la SESPAS, por región, provincia, municipio y hospital. Enero a diciembre del 2004. 2005.

5. Secretaría de Estado de Salud Pública y Asistencia Social (SESPAS): Normas Nacionales para el Manejo de las Principales Urgencias Obstétricas. En: Serie de Normas Nacionales Núm. 7, Santo Domingo, República Dominicana, 2006.

6. Brito S: Información compartida con los autores de este capítulo por vía electrónica, y basada en los resultados del programa Conecta. 2007.

7. Comisión Especial de Comunidad del Consorcio Atención Posaborto: Elementos Esenciales de la Atención Posaborto: Un Modelo Desarrollado y Actualizado. En: APA en Acción Núm. 2, Suplemento especial, septiembre, 2002. 
Sección

Proveedores y

componentes

||| programáticos 



\section{Función de la enfermera en la atención de mujeres en situación de aborto}

Ma. Dolores Sotelo ${ }^{a}$

La participación del personal de enfermería en los procesos de atención que ofrecen los servicios de salud es fundamental; juega un papel relevante como apoyo al personal médico que brinda los tratamientos y es responsable de los procedimientos específicos que una paciente requiere; de igual modo, tiene a su cargo las actividades de información y educación para el cuidado de la salud.

La función que la enfermera desempeña en la atención de mujeres en situación de aborto es específica y de gran trascendencia, ya que el trato, la comunicación interpersonal y el apoyo técnico que brinde a quien está experimentando un aborto contribuirá a elevar la calidad de la atención y a favorecer la toma de decisiones de la mujer, en beneficio de su salud sexual y reproductiva.

\section{SERVICIOS DE ADMISIÓN O URGENCIAS}

El papel de la enfermera en los servicios de ginecoobstetricia inicia en el servicio de admisión, en donde ella:

- Recibe a la paciente, se presenta y la identifica, le toma signos vitales (pulso, presión arterial, respiración, temperatura), los registra en el expediente clínico y los informa al médico tratante.

- Inicia la asesoría identificando el estado emocional de la paciente a través de preguntas significativas; escucha activamente a la mujer y utiliza sus sentidos para observar su actitud y comportamiento; valora sus necesidades de información.

La consejería es útil para explorar los sentimientos de la paciente que está experimentando un aborto y valorar su capacidad de respuesta ante la situación del momento, así como para disminuir el grado de ansiedad o temor que esto le pueda ocasionar.

\footnotetext{
${ }^{a}$ Consultora de Ipas México, A.C., México, D.F.
} 
Después de la valoración médica, la paciente es trasladada al servicio de observación o de labor.

\section{SERVICIO DE OBSERVACIÓN O SALA DE LABOR}

Aquí, la enfermera recibe a la paciente, se presenta y la identifica llamándole por su nombre. Revisa el expediente clínico y las indicaciones médicas y cumple con ellas.

Continúa con la consejería dirigida a las necesidades específicas de la paciente, como puede ser el manejo del dolor. Le hace saber que toda la información que proporcione será confidencial; le menciona también el riesgo reproductivo que enfrenta, su estado de salud, lo que representa el procedimiento que le van a realizar —aspiración manual endouterina (AMEU) o el legrado uterino instrumental (LUI)-, cuándo se le practicará cualquiera de estos procedimientos, y si tendrá que esperar un tiempo prolongado antes de ser atendida. Mencionará la importancia de usar un método anticonceptivo posteriormente y también que cuenta con servicios y la consejería para cubrir sus necesidades, así como una atención para su control y seguimiento.

\section{UNIDAD TOCOQUIRÚRGICA (SALA DE EXPULSIÓN O QUIRÓFANO)}

En la sala de expulsión o quirófano, la enfermera se presenta, identifica a la paciente y la llama por su nombre; le toma sus signos vitales y los registra. A continuación verifica la disponibilidad del equipo (para AMEU si corresponde a menos de 12 semanas de gestación, o para LUI) y de otro material necesario y asegura su descontaminación, realizando actividades de enfermera circulante. Continúa con la consejería —si es posible de acuerdo con el procedimiento que se vaya a realizar, siempre que se disponga de personal capacitado.

El apoyo emocional a la paciente es fundamental en caso de una anestesia paracervical; se le explica, con palabras sencillas, lo que pudiera ocurrir: ahora es posible que sienta una molestia; o bien: ya casi termina el procedimiento, etc. Un punto relevante es el manejo del dolor estando atenta a cualquier molestia que la paciente mencione.

Si la paciente aceptó un método anticonceptivo, la enfermera verifica que se haya obtenido el consentimiento informado.

\section{SALA DE RECUPERACIÓN O SERVICIO DE HOSPITALIZACIÓN}

En la sala de recuperación o de hospitalización, la enfermera informa a la paciente, al término de la intervención, los riegos y beneficios de su tratamiento, las actividades que podrá realizar o no y cuáles están recomendadas durante su recuperación; del mismo modo, le dará a conocer las complicaciones que pudieran presentarse y lo que debe hacer si llegara a presentar un signo o síntoma de alarma (dolor intenso en el abdomen, fiebre, sangrado abundante, secreciones fétidas y otros). Es importante asegurar que, antes del egreso, la paciente comprenda cabalmente la información que se le proporcionó y lo que requiere para cuidar de manera adecuada su salud.

Si se le suministró un método anticonceptivo, la enfermera informará a la mujer sobre sus efectos secundarios, mecanismos de acción, grado de efectividad, modo de uso, las razones por las que debe acudir al servicio de salud para revisarse y la importancia de cumplir con las citas de control y seguimiento. 


\title{
Consejería en la atención a mujeres en situación de abortoa
}

\author{
Ma. Dolores Sotelo, ${ }^{b}$ Nadine Gasman, ${ }^{c}$ \\ Rubén Ramírez ${ }^{d}$ y Ma. Elena Collado ${ }^{d}$
}

\section{INTRODUCCIÓN}

El embarazo es una etapa importante en la vida de las mujeres en virtud del cambio potencial que representa en sus vidas, e independientemente de que haya sido planeado o no. Cuando un embarazo se interrumpe como consecuencia de un aborto espontáneo o inducido, las mujeres experimentan sentimientos diversos: en algunos casos hay angustia, dolor, desesperación, miedo, impotencia o culpa, que pueden crear un conflicto y llevar a una crisis; en otros, la sensación es de empoderamiento por haber sido capaces de tomar una decisión sobre sus vidas; en otros más, hay un sentimiento de liberación por haber resuelto una situación que en ese momento representaba para ellas un problema.

En términos generales, las mujeres que se enfrentan a situaciones de aborto no expresan sus sentimientos a los prestadores de servicios de salud que las atienden, ya sea porque ellos no les preguntan abiertamente -por el estigma que rodea a este hecho y su temor al juicio que pueda hacerse de ellas-, o bien porque es complicado hablar de una situación que es dolorosa y muchas veces difícil de explicar.

Una parte importante de la atención de calidad a las mujeres en situación de aborto es la consejería, cuyo objetivo es crear un espacio seguro para la comunicación entre el prestador del servicio y la usuaria, que permita a esta última tomar decisiones a partir de la información veraz, objetiva e imparcial que reciba de aquél. Debe enfatizarse que la consejería no es para "dar consejos"; su propósito es, más bien, crear las condiciones para que la usuaria pueda tomar decisiones libres e informadas de acuerdo con sus convicciones y su situación, y así ejercer sus derechos humanos. Se trata de una orientación puntual, especializada y solidaria a las mujeres que viven un aborto.

\footnotetext{
a Publicado en el Boletín de Ipas México ISBN 1-882220-75-7 y reproducido con autorización.

b Consultora de Ipas México, A.C., México, D.F.

${ }^{c}$ Cuando este capitulo fue preparado, Nadine Gasman era Directora de Ipas México, A.C. En la actualidad es Representante del Fondo de Población de las Naciones Unidas (UNFPA) en Guatemala.

${ }^{\mathrm{d}}$ Ipas México, A.C., México, D.F.
} 
La consejería es útil para explorar los sentimientos de la mujer que vive un aborto, valorar su capacidad de respuesta ante la situación que enfrenta, disminuir el grado de ansiedad o temor que esto le pueda ocasionar, e identificar a quien requiere atención especializada por padecer angustia extrema o depresión. A través de la comunicación interpersonal, la o el consejero puede conocer y entender la situación de la mujer y plantearle alternativas entre las cuales pueda elegir la que satisfaga sus necesidades. Los resultados muestran que cuando una mujer recibe apoyo emocional inmediato comprenderá mejor su condición clínica, aceptará con satisfacción el tratamiento requerido y será más receptiva a la información que necesita para tomar decisiones sobre a su estado de salud actual y el futuro de su vida sexual y reproductiva; se ha documentado, igualmente, que en el largo plazo tendrá menos dificultades psicológicas.

La atención en general, y la consejería en particular, deben darse dentro de un marco ético que requiere poner en el centro las necesidades de las mujeres. Se trata de un espacio concreto de respeto a los derechos humanos relacionado con:

- El derecho a la información completa, veraz, imparcial y útil.

- El respeto a la dignidad, privacidad y confidencialidad.

- La libertad de conciencia y expresión.

- El respeto a la voluntad y la elección.

Este texto está dirigido a aquellos prestadores de servicios de salud que atienden a mujeres en situación de aborto y a estudiantes de las carreras de enfermería y medicina, buscando proporcionarles los elementos necesarios para realizar una adecuada consejería.

\section{METODOLOGÍA DE LA CONSEJERÍA}

La consejería posee una metodología propia, que es el camino a recorrer para alcanzar su objetivo: facilitar a la mujer el proceso de toma de decisiones. La o el consjero debe:

- Prestar toda su atención a la mujer.

- Establecer una comunicación abierta y efectiva.

- Ser amable y asegurar a la paciente que toda la información que intercambien será confidencial.

- Evaluar conjuntamente las dudas, necesidades e inquietudes de la paciente en relación con el aborto y la salud reproductiva.

- Proporcionar información veraz, comprensible y necesaria para que la usuaria comprenda su situación, los procedimientos terapéuticos disponibles, riesgos y beneficios.

- Ser solidario con las decisiones que la mujer tome una vez que se ha comprobado que comprende la situación y conoce sus expectativas futuras en relación con su salud sexual y reproductiva.

Las técnicas empleadas en la consejería a mujeres en situación de aborto son:

- Escuchar activamente, lo que comprende la comunicación no verbal; es decir, una actitud y comportamiento corporal empático. 
- Parafrasear, que significa repetir con otras palabras lo que la usuaria ha informado acerca de sus emociones y temores; el consejero deberá demostrar a la mujer que la escucha y comprende.

- Formular preguntas significativas que permitan recabar información importante y estimulen a la usuaria a hablar sobre sí misma.

- Identificar sentimientos al observar y escuchar a la mujer, comprenderla y ayudarla a controlarse en caso de crisis.

- Dar validez a la usuaria, es decir, creer en ella y evitar la influencia de los prejuicios del consejero.

- Informar, que es una parte importante de la consejería, misma que ayuda a la usuaria a tomar una decisión informada.

- Resumir y llegar a un acuerdo, el cual deberá ser expresado por el consejero para verificar la decisión que la usuaria tomó y hacer planes para implementarla.

Las usuarias reaccionan más favorablemente cuando el consejero es abierto y empático, no manifiesta prejuicios y respeta a la paciente sin importar su conducta sexual y reproductiva ni las decisiones que tome.

El consejero que no respeta las decisiones de la mujer, o que actúa con prejuicios en relación con el aborto, tiende a tener actitudes punitivas, lo que es un factor agregado de angustia para la mujer, una falta ética grave y una violación a sus derechos humanos.

El consejero que no tenga la convicción de servir o ayudar puede comunicar su desaprobación a partir de su tono de voz, lenguaje, gestos y actitudes. Si comunica sus creencias personales a la paciente aun sin darse cuenta, no será capaz de proporcionar una orientación de calidad.

\section{PERFIL PROFESIONAL DEL CONSEJERO}

Las características y cualidades que el consejero debe desarrollar son:

- Empatía.

- Dominio del tema.

- Capacidad para el análisis y para establecer una comunicación efectiva.

- Dominio de la comunicación verbal y corporal.

- Reconocimiento de la importancia de la salud sexual y reproductiva.

- Respeto a los derechos reproductivos y a la capacidad de las mujeres para tomar sus propias decisiones.

- Capacidad para identificar sus propios valores y actitudes y separarlos de los intereses de las pacientes.

- Habilidad para mantener la confidencialidad de la información.

- Capacidad para proporcionar atención con calidez.

\section{CONCLUSIÓN}

En América Latina, miles de mujeres viven la experiencia del aborto cada año. En muchos casos se trata de abortos espontáneos; otros son abortos inducidos cuyo número no se conoce con certeza. En ambos casos, la ética obliga a los prestadores de servicios 
a dar el tratamiento que ha demostrado tener el mínimo riesgo, asegurar la calidad de la atención, y proporcionar un trato digno y no discriminatorio. La consejería forma parte integral del modelo de atención que asegura a las usuarias un espacio donde establecer una relación con el consejero para permitir explorar los sentimientos de las mujeres y brindarles el apoyo emocional y la información que les permita tomar decisiones sobre su situación actual y sus opciones futuras, acordes con sus expectativas reproductivas.

Incorporar la consejería a los programas de educación en ciencias de la salud y en los servicios de atención a mujeres en situación de aborto es una tarea que deben realizar las instituciones educativas, el sector salud y las organizaciones de la sociedad civil en conjunto, utilizando siempre una perspectiva de derechos humanos que permita el ejercicio pleno de los derechos sexuales y reproductivos. 


\section{Observación de pares como una técnica de capacitación a proveedores en complicaciones hemorrágicas de la primera mitad del embarazo}

Patricia Riveros, ${ }^{a}$ Orlando Hernández, ${ }^{b}$

Ricardo Vernon, ${ }^{c}$ José del Barco y ${ }^{b}$ Franz Calani ${ }^{d}$

\section{INTRODUCCIÓN}

En 1998, el Ministerio de Salud Pública (MSP) de Bolivia estableció el acceso a servicios de atención posaborto (APA) e dentro del Seguro Básico de Salud (SBS), como una manera de contribuir a la reducción de la mortalidad materna. A partir de este cambio de política, la demanda de APA aumentó de forma notable, especialmente cuando el SBS evolucionó a Seguro Universal Materno Infantil (SUMI) y los servicios de APA se empezaron a ofrecer.

Tradicionalmente, el tratamiento de las complicaciones de la hemorragia de la primera mitad del embarazo (HPME) dentro de los hospitales del MSP se había centrado en la atención a la urgencia médica utilizando el legrado uterino instrumental (LUI) como método de evacuación endouterina. La aspiración manual endouterina (AMEU) era poco utilizada, y en la mayor parte de los hospitales el modelo de atención no incluía la orientación a la paciente o la provisión de otros servicios de salud reproductiva, ni siquiera de métodos anticonceptivos. Ante este panorama, en 1999 la Agencia de los Estados Unidos para el Desarrollo Internacional (USAID) Bolivia otorgó fondos a Pathfinder International, organización que llevaba ya varios años realizando pequeños proyectos para introducir un modelo integral de APA, a fin de incorporar este servicio en la mitad de los hospitales del país. ${ }^{f}$

Al igual que en los años anteriores, Pathfinder utilizó una metodología en talleres. La capacitación inicial en APA se dio en cascada. Al principio, en cada hospital se for-

\footnotetext{
a Fronteras de la Salud Reproductiva, Population Council, La Paz, Bolivia.

b Consorcio Catalyst, Bolivia.

c Fronteras de la Salud Reproductiva, Population Council, México, D.F.

d Consultor independiente.

e Conocidos en Bolivia como "atención a las complicaciones hemorrágicas de la primera mitad del embarazo".

${ }^{\mathrm{f}}$ Ipas está (o ha estado) a cargo de capacitar a la otra mitad de los establecimientos en el país.
} 
maron cuatro capacitadores; más tarde este equipo replicó el entrenamiento con todo el personal de ginecoobstetricia de cada hospital. Los talleres duraron 40 horas, en las que se estudiaron diez temas: aborto inseguro como problema de salud pública; orientación, trato y comunicación entre la mujer y el proveedor de servicios; prevención de infecciones; procedimientos y técnicas para el manejo ambulatorio; evaluación de la mujer; manejo del dolor; procedimientos clínicos en el tratamiento de las complicaciones hemorrágicas de la primera mitad del embarazo; manejo de los problemas y las complicaciones de la AMEU y el LUI en las hemorragias de la primera mitad del embarazo; anticoncepción posaborto y la organización y administración de los servicios. Sin embargo, Pathfinder observó que quienes acudían a los talleres a menudo requerían un apoyo complementario para sentir confianza en sus propias destrezas y a fin de mejorar su desempeño; por ello, se inició la búsqueda de una estrategia que permitiera mejorar los resultados a un costo bajo. La alternativa seleccionada fue la técnica de observación o revisión de pares.

Según Jacques, ${ }^{1}$ la revisión de pares es un proceso durante el cual un colega evalúa el trabajo de otro. Se diferencia de una supervisión tradicional en que los individuos que participan no tienen vínculos administrativos. De esa forma, el miedo de represalias no existe, los colegas pueden ser más abiertos y la evaluación resultar más constructiva, pues el observador retroalimenta al observado y señala las acciones que pueden corregir el desempeño.

Tal y como se usó en este estudio, la observación de pares permite que los proveedores puedan descubrir sus debilidades comparándose contra el estándar ideal de un protocolo de atención desglosado en acciones secuenciales concretas, que quedan listadas en un instrumento de observación o lista de verificación. Así, el observador marca las acciones que el observado realiza o no, y lo retroalimenta sobre los errores u omisiones en que haya incurrido. Se asume que esto llevará al observado a corregir su desempeño.

Kim et al. ${ }^{2}$ estudiaron también la permanencia de destrezas 16 semanas después de una capacitación, comparando dos diferentes estrategias de entrenamiento con un grupo control. Estas estrategias consistían en la autoevaluación mediante cuestionarios, y la autoevaluación seguida de una discusión con colegas acerca de los resultados de la misma. El estudio mostró que ambos elementos, presentes también en la revisión de pares, tuvieron efectos positivos, aunque la última estrategia fue más efectiva que la primera en garantizar la permanencia de las habilidades desarrolladas.

Este capítulo presenta la experiencia de la introducción de la observación de pares para reforzar el desempeño de los proveedores de servicios de APA en 8 hospitales del MSP de Bolivia. Se utilizó como técnica de evacuación endouterina la AMEU.

\section{METODOLOGÍA}

El estudio utilizó un diseño no experimental con mediciones antes y después de la intervención. No se usó un grupo control que sirviera como punto de comparación. La intervención consistió en impartir un taller (que se llamará de "refrescamiento") entre los 12 y 18 meses después de que se impartiera el taller de capacitación de 40 horas, que tomaron todos los prestadores de servicios de ginecoobstetricia en su propio hospial. En el taller de refrescamiento se revisaron los procedimientos seguidos durante la APA y se explicó la técnica de revisión de pares para mejorar el desempeño de los proveedores de 
servicios. Como parte de los talleres de refrescamiento, los prestadores de servicios aprendieron a usar la lista de verificación que se utilizaría para observar el desempeño de los pares, se hicieron ejercicios de juego de funciones, y cuando las circunstancias lo permitieron, los capacitados practicaron el uso de la lista de verificación observando a un colega durante un procedimiento de APA en el hospital. Por último, se solicitó que se observaran cuando menos tres procedimientos de APA de cada prestador de servicios utilizando las guías de verificación. Las observaciones las debería realizar un colega que hubiera recibido también la capacitación previa y prestara servicios de APA en el hospital.

El instrumento de observación utilizado en este estudio (que sirvió también como instrumento de medición) fue una lista de verificación desarrollada por Pathfinder International, que desglosa el protocolo recomendado de APA en 42 acciones observables, de las cuales diez deben efectuarse antes del procedimiento; 26 son acciones que se llevan a cabo durante el procedimiento de evacuación endouterina y seis se realizan después del procedimiento. Para cada acción se incluye un espacio donde el observador marca si el prestador de servicios aplicó la acción o no. La lista de verificación empleada se presenta como Anexo a este capítulo.

El estudio se llevó a cabo en ocho hospitales públicos de Bolivia, con la participación de 38 médicos y 14 enfermeras. Los médicos observaron a médicos (sin hacer distinción del grado de especialización) y las enfermeras observaron a otras enfermeras. Aunque se recomendó que los dos miembros de cada par se observaran uno al otro cuando menos una vez, esto no siempre fue posible en razón de los diferentes turnos y funciones del personal; por ello, las observaciones se hicieron con los colegas que estaban disponibles cuando los casos de APA se presentaron, hasta completar cada prestador las tres observaciones de su desempeño en un periodo máximo de cuatro meses. Todos los médicos realizaron los procedimientos de evacuación endouterina, aunque con frecuencia no orientaron a la paciente antes y después de la atención clínica. En estos casos, la observación incluyó la atención clínica. En contraste, las enfermeras observaron mutuamente su desempeño en la atención pre y posprocedimiento, es decir, básicamente en el proceso de consejería a la paciente.

Para medir los efectos de la intervención, cada participante fue observado por un capacitador experto durante o inmediatamente después del taller de refrescamiento (es decir, antes de la primera observación de un par), y una segunda vez alrededor de cuatro meses después de este taller, ya que se habían hecho las observaciones de pares. El capacitador observó el desempeño de los proveedores usando la misma lista de verificación que los proveedores durante sus ejercicios de observación de pares. La variable dependiente fue el grado de apego de los proveedores a las normas de APA desglosadas en 42 conductas. De este modo, se midió el efecto de la observación de pares en el desempeño de los proveedores comparando las observaciones final e inicial del experto. Cada tema en la lista de competencia fue calificada con cero puntos cuando el proveedor observado no realizó la actividad específica, con un punto cuando realizó la actividad con asistencia del experto, y con dos cuando realizó la actividad sin asistencia alguna. Los puntos totales por proveedor se obtuvieron a partir de la suma de los individuales de cada actividad. Los puntos máximos de desempeño que podían alcanzarse eran 20 para el preprocedimiento, 52 para el procedimiento y 12 para el posprocedimiento, con un total de 84 para los médicos y 32 para las enfermeras (que no realizan evacuaciones endouterinas).

Para calcular la significancia estadística de las diferencias entre las observaciones pre y posintervención, se utilizó la $t$ de Student. Se compararon promedios en muestras 


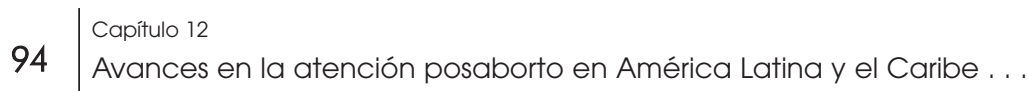

pareadas; es decir, se parearon los puntajes pre y posintervención para cada participante. Se utilizó el programa SPSS para hacer el análisis estadístico y se consideró una probabilidad menor a 5\% para determinar la significancia de los resultados.

\section{RESULTADOS}

El promedio de edad de los 52 proveedores (38 médicos y 14 enfermeras) que participaron en la observación de pares fue de 36 años; la persona más joven tenía 25 años y la mayor 79. La mayoría de los participantes tenían 33 años. De los médicos (generales o especialistas), 61\% era mujer, y todas las enfermeras también eran mujeres. La mayoría de los proveedores eran casados (60\%) y en su mayor parte (73\%) trabajaba exclusivamente en el hospital participante. El cuadro 12-1 detalla los porcentajes de apego al protocolo antes, durante y después de la intervención por tipo de proveedor de servicios. Se observan mejoras estadísticamente significativas (nivel de confianza estadística de $95 \%$ ) en la atención clínica de los médicos y en las actividades pre y posprocedimiento

\section{CUADRO 12-1.}

Porcentaje de apego a los temas del protocolo antes y después de la intervención, por tipo de proveedor y fase de la atención

\begin{tabular}{|c|c|c|c|c|}
\hline Fase & $\begin{array}{l}\text { Tipo de } \\
\text { proveedor }\end{array}$ & $\begin{array}{c}\text { Pre- } \\
\text { intervención } \\
\text { (porcentaje } \\
\text { promedio) }\end{array}$ & $\begin{array}{c}\text { Pos- } \\
\text { intervención } \\
\text { (porcentaje } \\
\text { promedio) }\end{array}$ & Significancia \\
\hline \multirow{3}{*}{ Preprocedimiento } & $\begin{array}{l}\text { Médicos } \\
(\mathrm{N}=38)\end{array}$ & $82 \%$ & $83 \%$ & 0.666 \\
\hline & $\begin{array}{l}\text { Enfermeras } \\
(\mathrm{N}=14)\end{array}$ & $68 \%$ & $95 \%$ & 0.002 \\
\hline & $\begin{array}{l}\text { Médicos y } \\
\text { enfermeras }\end{array}$ & $78 \%$ & $86 \%$ & 0.018 \\
\hline Procedimiento & $\begin{array}{l}\text { Médicos } \\
(\mathrm{N}=38)\end{array}$ & $84 \%$ & $92 \%$ & 0.001 \\
\hline \multirow{3}{*}{ Posprocedimiento } & $\begin{array}{l}\text { Médicos } \\
(\mathrm{N}=38)\end{array}$ & $72 \%$ & $79 \%$ & 0.198 \\
\hline & $\begin{array}{l}\text { Enfermeras } \\
(\mathrm{N}=14)\end{array}$ & $60 \%$ & $96 \%$ & 0.003 \\
\hline & $\begin{array}{l}\text { Médicos y } \\
\text { enfermeras }\end{array}$ & $69 \%$ & $83 \%$ & 0.005 \\
\hline \multirow{3}{*}{$\begin{array}{l}\text { Total } \\
\text { (Preprocedimiento + } \\
\text { procedimiento + } \\
\text { posprocedimiento) }\end{array}$} & $\begin{array}{l}\text { Médicos } \\
(\mathrm{N}=38)\end{array}$ & $82 \%$ & $88 \%$ & 0.021 \\
\hline & $\begin{array}{l}\text { Enfermeras } \\
(\mathrm{N}=14)\end{array}$ & $65 \%$ & $95 \%$ & 0.001 \\
\hline & $\begin{array}{l}\text { Médicos y } \\
\text { enfermeras }\end{array}$ & $80 \%$ & $89 \%$ & 0.166 \\
\hline
\end{tabular}


llevadas a cabo por las enfermeras, etapas donde el desempeño de los médicos no sufrió cambios. La mediana de puntaje preintervención para los médicos fue de 71 puntos y para las enfermeras de 24.5 puntos

Otra medida utilizada para observar el grado de mejoramiento en la prestación de servicios de APA se presenta en el cuadro 12-2, donde se muestra la distribución de proveedores de cada tipo, dependiendo de si su calificación de apego a los rubros del protocolo en la lista de verificación fue mayor o menor al promedio observado en la primera medición del experto. Como puede verse, en esta primera medición y como consecuencia del método usado, los médicos y enfermeras están repartidos en mitades aproximadas por encima y por debajo del promedio de apego al protocolo. En contraste, en la medición ocurrida después de la observación de pares, cerca de $63 \%$ de los médicos y $93 \%$ de las enfermeras obtienen calificaciones superiores al promedio de las que se observaron en la línea basal. Sin embargo, estos cambios no fueron estadísticamente significativos.

Se analizó también si la antigüedad en el cargo que ocupan los proveedores de servicios en el hospital, edad, sexo y estado civil explicaban en alguna medida su desempeño con la técnica de la observación por pares. Se hizo una comparación entre la preintervención y la postintervención de cada uno de los cuatro aspectos mencionados. Ninguna de las comparaciones mostraron resultados que demuestren tendencias diferentes de desempeño ya sea por antigüedad, edad, sexo o estado civil.

\section{CONCLUSIONES}

Los resultados de este estudio sugieren que los programas de atención posaborto pueden mejorar el desempeño de los prestadores de servicios utilizando la observación de pares como técnica para complementar su capacitación. Esta técnica parece tener un mayor efecto en la capacitación de enfermeras en la atención pre y posprocedimiento, pero también los médicos parecieron mejorar su desempeño clínico. Sin embargo, debido a

CUADRO 12-2.

Porcentaje de proveedores de servicios que tuvieron un apego mayor y un apego menor a los de la línea basal antes y después de la observación de pares, por tipo de proveedor

\begin{tabular}{|c|c|c|c|c|}
\hline \multirow{2}{*}{$\begin{array}{c}\text { Nivel } \\
\text { comparativo } \\
\text { de } \\
\text { apego }\end{array}$} & \multicolumn{2}{|c|}{ Antes } & \multicolumn{2}{|c|}{ Después } \\
\hline & Número & Porcentaje & Número & Porcentaje \\
\hline Médicos & \multicolumn{2}{|c|}{$N=38$} & \multicolumn{2}{|c|}{$N=38$} \\
\hline Mayor & 18 & $47.4 \%$ & 24 & $63.2 \%$ \\
\hline Menor & 20 & $52.6 \%$ & 14 & $36.8 \%$ \\
\hline Enfermeras & \multicolumn{2}{|c|}{$N-14$} & \multicolumn{2}{|c|}{$\mathrm{N}-14$} \\
\hline Mayor & 7 & $50.0 \%$ & 13 & $92.9 \%$ \\
\hline Menor & 7 & $50.0 \%$ & 1 & $7.1 \%$ \\
\hline
\end{tabular}


que este estudio utilizó un diseño no experimental y a los tamaños pequeños de muestra que se utilizaron, los resultados deben tomarse únicamente como ilustrativos y como una invitación a seguir investigando los efectos de esta técnica, pues parecería ser de fácil uso y permitir la capacitación continua de los prestadores.

La intervención estuvo acompañada de otros resultados positivos que no se habían contemplado. Entre ellos pueden citarse los siguientes:

- El programa de APA se socializó entre el personal que no participó de la investigación y promovió una mayor motivación para implementar las acciones adicionales que implica incorporar el modelo de atención integral de APA en los hospitales.

- Se mejoró la distribución de trabajo de APA, especialmente en el pre y posprocedimiento, pues los médicos, que consideraban sólo la parte clínica como su responsabilidad, empezaron también a hacer labores de sensibilización y orientación a pacientes.

- Los prestadores de servicios se sensibilizaron en cuanto a la importancia de dar orientación sobre métodos anticonceptivos a las mujeres y de mejorar las relaciones interpersonales entre el personal de salud y las pacientes, lo que se tradujo en una atención más cálida e integral.

El principal obstáculo que se encontró durante la intervención, fue el poco personal en las salas de ginecoobstetricia y el elevado número de pacientes. Esto implica que a menudo no hay un colega que pueda hacer la observación, o que se establezcan diferentes condiciones a las que podrían aumentar el impacto de la técnica. Por ejemplo, en la propuesta original se pensó en hacer la revisión de pares de acuerdo con la clasificación de desempeño inicial (proveedor con alto desempeño observado por un proveedor con bajo desempeño). También se pensó que las observaciones se harían siempre entre colegas del mismo rango y de la misma profesión. Sin embargo, esto no fue posible en todas las ocasiones.

Otro obstáculo fue el rechazo inicial del personal médico a la técnica de observación de pares. Sin embargo, éste disminuyó posteriormente como resultado de la familiarización con el método alcanzada en las prácticas, mismas que se efectuaron gracias a la insistencia de los supervisores.

\section{AGRADECIMIENTOS}

Este estudio se realizó con el apoyo del pueblo estadounidense a través de la Agencia de los Estados Unidos para el Desarrollo Internacional (USAID) bajo los términos del Acuerdo de Cooperación No. HRN-A-00-98-0001200 (Programa Fronteras de la Salud Reproductiva del Population Council). Los contenidos son responsabilidad de los autores y no necesariamente reflejan los puntos de vista de la USAID, del gobierno de los EUA o del Programa Fronteras de la Salud Reproductiva.

\section{Referencias}

1. Jacques A: Rapport de Consultation. Evaluation par les pairs des medecins generalists du secteur prive en planification familiale au Maroc. Projet de Planification Familiale et Sante Maternelles et Infantile. Phase V. John Snow Inc., Aout, 2000.

2. Kim, YM et al.: Training reinforcement improves family planning counseling and may be cost-efective. Operations Research Summary. Quality Assurance Project. 1999. 


\section{ANEXO \\ LISTA DE VERIFICACIÓN \\ Pathfinder International}

Nombre del participante

Hospital donde trabaja

Fecha

\begin{tabular}{|c|c|c|c|c|c|c|c|c|}
\hline Procedimiento & & & Prác & a er & & & & \\
\hline & & Moc & & & ien & & Sì & No \\
\hline PREPROCEDIMIENTO & 1 & 2 & 3 & 4 & 5 & 6 & & \\
\hline $\begin{array}{l}\text { Conversa con orientadora para conocer estado emocional } \\
\text { y decisión en planificación familiar de la paciente }\end{array}$ & & & & & & & & \\
\hline Revisa historia clínica & & & & & & & & \\
\hline Se informa si hubo necesidad de darle sedante & & & & & & & & \\
\hline Saluda a la paciente y se presenta & & & & & & & & \\
\hline Explica a la paciente el procedimiento & & & & & & & & \\
\hline $\begin{array}{l}\text { Se asegura de que el material, medicamentos e instrument } \\
\text { estén disponibles }\end{array}$ & & & & & & & & \\
\hline Pregunta si la paciente evacuó la vejiga & & & & & & & & \\
\hline Se lava las manos & & & & & & & & \\
\hline $\begin{array}{l}\text { Se pone guantes estériles y/o dedil sometidos a desinfecció } \\
\text { de alto nivel }\end{array}$ & & & & & & & & \\
\hline $\begin{array}{l}\text { Realiza examen pélvico y determina tamaño, consistencia } \\
\text { y posición uterina }\end{array}$ & & & & & & & & \\
\hline PROCEDIMIENTO & & & & & & & & \\
\hline $\begin{array}{l}\text { Usa guantes estériles o sometidos a desinfección de alto } \\
\text { nivel }\end{array}$ & & & & & & & & \\
\hline Prepara el momento metálico adecuadamente & & & & & & & & \\
\hline $\begin{array}{l}\text { Carga la jeringa de } 10 \mathrm{~mL} \text { con } 5 \mathrm{~mL} \text { de xilocaína y } 5 \mathrm{~mL} \\
\text { de agua destilada }\end{array}$ & & & & & & & & \\
\hline Coloca espéculo con delicadeza & & & & & & & & \\
\hline $\begin{array}{l}\text { Limpia el cérvix y la vagina con solución antiséptica las } \\
\text { veces que sea necesario }\end{array}$ & & & & & & & & \\
\hline Pinza el cuello uterino con tenáculo a horas 11 y 1 & & & & & & & & \\
\hline $\begin{array}{l}\text { Realiza el bloqueo paracervical a horas } 5 \text { y } 7 \text { en el } \\
\text { pliegue cervicovaginal penetrándolo } 1 \mathrm{~cm}\end{array}$ & & & & & & & & \\
\hline $\begin{array}{l}\text { Prepara el momento plástico a modo de esperar } 3 \text { a } 5 \text { min } \\
\text { para iniciar el procedimiento }\end{array}$ & & & & & & & & \\
\hline Prepara la jeringa y comprueba el vacío & & & & & & & & \\
\hline
\end{tabular}




\begin{tabular}{|c|c|c|c|c|c|c|c|c|}
\hline \multirow[b]{3}{*}{ PREPROCEDIMIENTO } & \multicolumn{6}{|c|}{ Práctica en: } & \multicolumn{2}{|c|}{ Competente } \\
\hline & \multicolumn{3}{|c|}{ Modelo } & \multicolumn{3}{|c|}{ Paciente } & \multirow[t]{2}{*}{ Si } & \multirow[t]{2}{*}{ No } \\
\hline & 1 & 2 & 3 & 4 & 5 & 6 & & \\
\hline $\begin{array}{l}\text { Selecciona la cánula a ser utilizada de acuerdo con la edad } \\
\text { gestacional y tamaño uterino }\end{array}$ & & & & & & & & \\
\hline $\begin{array}{l}\text { Dilata el cuello uterino delicada y firmemente hasta un número } \\
\text { superior a la cánula seleccionada }\end{array}$ & & & & & & & & \\
\hline Introduce la cánula seleccionada con la técnica de "no tocar" & & & & & & & & \\
\hline Mide la cavidad uterina & & & & & & & & \\
\hline Conecta la cánula a la jeringa preparada & & & & & & & & \\
\hline Suelta la válvula de seguridad & & & & & & & & \\
\hline $\begin{array}{l}\text { Realiza la aspiración del contenido delicadamente y con } \\
\text { movimientos giratorios, abarcando el fondo y cuerpo uterino }\end{array}$ & & & & & & & & \\
\hline Durante el proceso dialoga con la paciente & & & & & & & & \\
\hline $\begin{array}{l}\text { Indica analgésico en caso de quejas de dolor por la paciente } \\
\text { o a sugerencia de la orientadora }\end{array}$ & & & & & & & & \\
\hline $\begin{array}{l}\text { Termina el proceso cuando se observa: burbujas en la cánula, } \\
\text { sensación de aspereza, y/o si la cánula es apretada por el útero }\end{array}$ & & & & & & & & \\
\hline Realiza la revisión de la cavidad con la cánula № 6 & & & & & & & & \\
\hline Desconecta la jeringa de la cánula y retira el instrumental & & & & & & & & \\
\hline $\begin{array}{l}\text { Realiza compresión hemostática en caso de sangrado por } \\
\text { el pinzamiento del cuello uterino }\end{array}$ & & & & & & & & \\
\hline Coloca todo el material en solución de cloro al $0.5 \%$ & & & & & & & & \\
\hline Llena la jeringa con la solución de cloro al $0.5 \%$ & & & & & & & & \\
\hline Inspecciona los restos extraídos & & & & & & & & \\
\hline $\begin{array}{l}\text { Descontamina los guantes en la solución de cloro. En caso } \\
\text { de ser reutilizables se dejan en la solución de cloro. Si son } \\
\text { desechables se tiran después de descontaminarlos }\end{array}$ & & & & & & & & \\
\hline POSPROCEDIMIENTO & & & & & & & & \\
\hline Controla y evalúa signos vitales posprocedimiento & & & & & & & & \\
\hline Indicaciones posprocedimiento a la paciente & & & & & & & & \\
\hline Informa de las señales de peligro & & & & & & & & \\
\hline Informa de la normalización de la fertilidad & & & & & & & & \\
\hline $\begin{array}{l}\text { Se marca la fecha de control o referencia a otro servicio antes } \\
\text { del alta }\end{array}$ & & & & & & & & \\
\hline La paciente recibe método anticonceptivo antes del alta & & & & & & & & \\
\hline
\end{tabular}

Observaciones:

Nombre del capacitador

Firma del capacitado 
Sección

Atención clínica con tecnologías diversas 



\section{Métodos de evacuación endouterina en la atención posaborto ${ }^{a}$}

Jeanine Herrick, ${ }^{b}$ Catherine Turner,
Teresa McInerney
y Laura Castleman

\section{INTRODUCCIÓN}

La evacuación endouterina es la extracción del contenido del útero. Los métodos para efectuarla en el primer trimestre son varios, como la aspiración endouterina, métodos quirúrgicos y farmacológicos, técnicas que pueden utilizarse dependiendo de las habilidades y la formación del personal de salud, y del equipo y los agentes médicos disponibles. El estado clínico de la paciente, altura uterina, edad gestacional y preferencias personales, también son factores clave que deben considerarse al determinar el método más adecuado.

La aspiración endouterina (AEU) utiliza succión eléctrica o manual para desocupar el útero. El legrado uterino instrumental (LUI), conocido también como dilatación y legrado (o curetaje), es un método quirúrgico de evacuación endouterina. Los métodos que implican la administración de medicamentos o agentes farmacológicos interfieren en la continuación del embarazo y causan contracciones uterinas que expulsan los restos ovulares (RO).

Para la Organización Mundial de la Salud (OMS), la AEU es el método preferido, siendo la aspiración manual endouterina (AMEU) de las variedades más accesibles para tratar complicaciones del aborto. ${ }^{1}$ A pesar de que la OMS recomienda el LUI sólo en los casos en que no es posible practicar la AMEU, muchos establecimientos de salud aún lo utilizan.

Cuando la evacuación endouterina está indicada para eliminar los RO, suele ser un componente vital de la atención posaborto (APA) y debe practicarse rápido. Entre los casos clínicos que requieren una evacuación endouterina están el aborto inevitable, incompleto, séptico, diferido (huevo muerto y retenido) y el embarazo molar. En los

\footnotetext{
${ }^{a}$ Reproducido y adaptado con autorización de: Woman-centered postabortion care: Reference manual. Chapel Hill, NC, Ipas, 2004.

${ }^{\mathrm{b}}$ Ipas, Chapel Hill, N.C., E.U.A.
} 


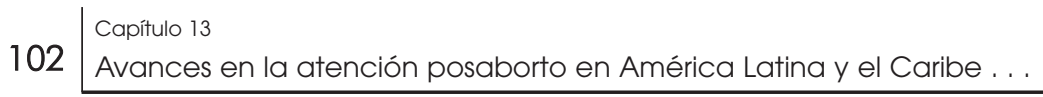

casos de huevo muerto y retenido, no hay necesidad de evacuar el útero de inmediato; el procedimiento puede programarse para una fecha posterior.

Los prestadores de servicios de salud encargados de tratar las complicaciones posaborto deben poseer los conocimientos clínicos para efectuar una evacuación endouterina. Diversas categorías de trabajadores sanitarios pueden practicar esta evacuación o servir de asistentes durante ésta. La capacitación antes del servicio o en el servicio, permite a los profesionales adquirir la aptitud clínica necesaria y dominar esta técnica que tantas vidas salva.

En este capítulo se resumen los métodos de evacuación endouterina usados en los servicios de APA. Para cada método, se expone información (cuando está disponible) sobre su seguridad y eficacia clínica, costo, grado de aceptación por parte de las pacientes, riesgos y efectos secundarios.

\section{ASPIRACIÓN ENDOUTERINA (AEU)}

Muchas autoridades nacionales e internacionales consideran la tecnología de AEU como un servicio esencial. Por ejemplo, en 1997, la OMS y la Federación Internacional de Ginecología y Obstetricia (FIGO) emitieron la siguiente declaración conjunta: Los hospitales que están equipados adecuadamente deben... adoptar el método de aspiración [de evacuación endouterina], y seleccionar la aspiración manual y/o eléctrica según la experiencia y el conocimiento del personal de salud. ${ }^{2}$

\section{Descripción}

La AEU, conocida también como legrado por aspiración, es un método de evacuación del contenido uterino por medio de una cánula plástica o metálica conectada a una fuente de vacío. La principal diferencia entre las opciones de AEU es la fuente de vacío. La AMEU utiliza un aspirador manual portátil. La aspiración eléctrica endouterina (AEEU) utiliza una bomba eléctrica. A pesar de que todas estas técnicas proporcionan un vacío equivalente al iniciarse el procedimiento, el vacío sostenido a lo largo de él es variable. El nivel de vacío por el aspirador de AMEU disminuye a medida que el cilindro va llenándose de sangre y tejido, descendiendo la necesidad del vacío. La bomba de AEEU proporciona un nivel de succión continuo y constante. La bomba manual o de pedal requiere un esfuerzo humano continuo para mantener el vacío.

El procedimiento de AEU requiere la dilatación del cérvix; introducción de la cánula en la cavidad uterina; conexión a la fuente de vacío y aspiración de los $\mathrm{RO}$, la cual dura entre tres y diez minutos, según la altura uterina y la cantidad de RO.

\section{Dilatación cervical}

En los casos de aborto inevitable o incompleto, el cérvix puede estar lo suficientemente abierto como para permitir la evacuación endouterina sin que sea necesario realizar una dilatación complementaria o sólo mediante una dilatación mínima. En los casos de aborto diferido se requiere, por lo general, una dilatación del cérvix. Para ello se puede utilizar un dilatador metálico o plástico, o un medicamento como el misoprostol. 
Evaluación de la altura uterina para determinar el método adecuado de evacuación endouterina

En casos de aborto incompleto, aborto diferido o embarazo ectópico, la altura uterina establecida durante el examen bimanual puede ser inferior a la gestación determinada a partir de la fecha de la última menstruación (FUM) debido a la expulsión de los restos ovulares, a muerte fetal o al hecho de que el embarazo sea extrauterino. Los cálculos de la altura uterina pueden variar también si existe un error en la determinación de la FUM. Por tanto, la elección de la técnica de AEU para diversos diagnósticos de APA debe basarse en un conjunto de parámetros clínicos.

\section{Seguridad y eficacia clínica}

La AEU tiene una tasa de eficacia de entre 95 y 100\%. Para el tratamiento de abortos incompletos, dicha tasa suele sobrepasar el 98\%. La AEU tiene pocas complicaciones, especialmente si se practica antes de la semana 12 de gestación, calculada a partir de la FUM. En comparación con el legrado uterino instrumental, la aspiración endouterina permite disminuir considerablemente los riesgos de infección, lesión cervical y perforación uterina; además, con la AEU la necesidad de dilatar el cérvix es menor, el sangrado no es tan abundante, la estancia hospitalaria es más corta y la necesidad de administrar medicamentos anestésicos es menor.

Costo

La AEU puede resultar muy rentable cuando se practica en un ámbito de pacientes externas en clínicas o servicios ambulatorios, lo cual requiere que se usen menos recursos del establecimiento de salud, como personal, anestesia general, camas hospitalarias y quirófanos. Los ahorros que resultan del uso de la AEU pueden transmitirse del establecimiento de salud a las pacientes.

\section{Aceptación por las pacientes}

La AEU es bien aceptada por las mujeres. En la mayor parte de los casos requiere bajos niveles de manejo del dolor. Por lo general, basta con aplicar anestesia local (bloqueo paracervical) y administrar analgésicos por vía oral. Además, se pueden usar palabras reconfortantes y, si es necesario, una sedación leve o superficial, lo cual permite que la paciente permanezca despierta y consciente de lo que sucede durante el procedimiento. Dado que requiere niveles más bajos de medicamentos para el dolor, el tratamiento de APA con la AEU se puede proporcionar de modo ambulatorio y las mujeres suelen preferir esta opción a una estancia hospitalaria.

\section{ASPIRACIÓN MANUAL ENDOUTERINA (AMEU)}

En la APA, la AMEU se utiliza principalmente para la evacuación endouterina en el primer trimestre. Para practicar la AMEU, se introduce en el útero una cánula del tamaño 
correspondiente (según la altura uterina); a continuación, un aspirador manual de plástico de $60 \mathrm{~cm}^{3}$, que está cargado con el vacío, se conecta a la cánula. El vacío se libera al oprimir los botones en el aspirador; la cánula se gira delicada y lentamente mientras se desplaza hacia adelante y hacia atrás en el útero. El aspirador sirve como fuente del vacío para aspirar los restos ovulares a través de la cánula hacia el interior del cilindro del aspirador.

La AMEU, recomendada por la OMS como el método preferido para tratar las complicaciones del aborto, es segura y eficaz. Dado que no requiere electricidad, puede utilizarse en zonas de bajos recursos con un suministro de electricidad intermitente, y por ende, aumentando el acceso de las mujeres a la atención médica. Como sucede con la AEU en general, los servicios de AMEU pueden prestarse en una clínica o en un servicio de pacientes externas que requieren menos recursos y disminuyen el costo del tratamiento. En lugares donde se puede reutilizar el instrumental, el costo por cada procedimiento puede ser relativamente bajo. El aumento en la disponibilidad local de la atención médica y la disminución del tiempo de espera para recibir tratamiento hacen de la AMEU un método aceptado por muchas mujeres. El procedimiento de evacuación endouterina no produce mucho ruido, lo que algunas mujeres encuentran más aceptable al compararlo con el que produce la AEEU.

\section{ASPIRACIÓN ELÉCTRICA ENDOUTERINA (AEEU)}

\section{Descripción}

La AEEU puede emplearse en el tratamiento de APA en el primero y segundo trimestres de la gestación por parte de personal clínico adecuadamente capacitado. En la AEEU se introduce en el útero una cánula (por lo general con un diámetro de siete a $12 \mathrm{~mm}$ ) que se conecta mediante un tubo a una bomba eléctrica o máquina de succión. A continuación, la válvula se cierra de la manguera con el dedo pulgar, se enciende la máquina y se gira la cánula deslizándola hacia adelante y hacia atrás, hasta que todos los $\mathrm{RO}$ son aspirados hacia el interior de un recipiente de cristal que se encuentra al final de la manguera.

Como el costo inicial de los equipos de AEEU es elevado, casi siempre se les utiliza en lugares centralizados que atienden gran número de casos. La AEEU es menos apropiada para lugares donde el suministro de electricidad es intermitente. Además, la mayoría de las mujeres la acepta, aunque a algunas les causa temor el zumbido o retumbo de la bomba eléctrica.

Riesgos y efectos secundarios de los métodos de evacuación endouterina

Los posibles efectos secundarios de los procedimientos de evacuación endouterina comprenden cólicos abdominales, náuseas leves a moderadas, vómito, dolor y sangrado similar al de una menstruación.

Aunque ocurren rara vez, las posibles complicaciones de los procedimientos de AEU y LUI son: evacuación incompleta; reacción vagal; lesión cervical o uterina, como perforación y laceración; infección pélvica; complicaciones de la anestesia; sepsis; hemorragia y hematómetra aguda. Algunas de estas afecciones pueden causar infertilidad secundaria, lesiones graves y, en algunos casos, la muerte. El riesgo de complicaciones graves es más elevado en los procedimientos de evacuación endouterina del segundo tri- 
mestre en comparación con los que se practican en el primero, aunque el tratamiento es muy seguro cuando lo efectúan profesionales de la salud capacitados y calificados.

\section{Precauciones}

Antes de practicar el procedimiento de aspiración endouterina, debe tratarse de inmediato todo trastorno que amenace la vida de la paciente, como por ejemplo choque, hemorragia, infección cervical o pélvica, sepsis, perforación y lesión abdominal, que pueden presentarse en los casos de aborto incompleto o clandestino. En estos casos, la aspiración y evacuación endouterina suele ser un componente importante del manejo definitivo, y una vez estabilizada la paciente, dicho procedimiento no debe postergarse. Al proporcionar atención médica a la paciente, debe tenerse en cuenta sus antecedentes de discrasias sanguíneas.

Dilatación y evacuación para tratar complicaciones del aborto en el segundo trimestre

En los casos de tratamientos de APA suministrados en gestaciones mayores de 12 semanas a partir de la FUM, es posible que los RO ya hayan sido expulsados parcialmente o que aún se encuentren dentro del útero. En general, la dilatación requiere:

- Más dilatación que la necesaria para los procedimientos practicados en las etapas iniciales del embarazo, usando dilatadores mecánicos, medicamentos como el misoprostol o una combinación de ambos. Por lo general, lo mejor es preparar primero el cérvix, si es que aún no está abierto.

- Prestadores de servicios con capacitación y habilidades especiales. Una vez que el cérvix se encuentra preparado y se han administrado los medicamentos para el manejo del dolor, los prestadores de servicios de salud adiestrados pueden efectuar un procedimiento de dilatación y legrado en aproximadamente diez a 30 minutos. La paciente se recupera dentro de la primera hora o un poco más, y es dada de alta.

- Manejo farmacológico del dolor, como la sedación leve, y en ocasiones, anestesia general.

- Sólo establecimientos ambulatorios, lo cual permite que las mujeres no sean sometidas a largas estancias hospitalarias; disminuye también los costos.

\section{LEGRADO UTERINO INSTRUMENTAL (LUI)}

\section{Descripción}

El legrado uterino instrumental, conocido también como dilatación y legrado, consiste en dilatar el cérvix y utilizar después una cureta metálica afilada para raspar las paredes uterinas. Durante el procedimiento, la paciente suele recibir anestesia general o regional, o una sedación que puede variar de superficial a profunda. En el tratamiento de las complicaciones del aborto, el LUI se utiliza tanto en el primer trimestre como en el segundo. Debido a que este método conlleva más riesgos, la OMS lo recomienda sólo 
$106 \mid$\begin{tabular}{l|l} 
Capítulo 13 \\
Avances en la atención posaborto en América Latina y el Caribe . . .
\end{tabular}

cuando no se disponga de AEU. La misma OMS insta a los administradores de salud a hacer todo lo posible por sustituir el LUI por la AEU.

Seguridad y eficacia clínica

Por lo general, la práctica del legrado uterino instrumental implica mayores tasas de complicaciones que la $\mathrm{AEU}$, como hemorragia, infección pélvica, lesión cervical o perforación uterina.

\section{Costo}

El LUI suele practicarse en un quirófano, bajo anestesia general y con estancia hospitalaria. Por tanto, resulta más costoso que la AEU. Si la sala de operaciones está parcialmente disponible para practicar los procedimientos de evacuación endouterina, los retrasos en el tratamiento de APA pueden implicar una atención médica costosa, como la administración de antibióticos por vía intravenosa y una estancia hospitalaria prolongada. Los costos del tratamiento de un aborto incompleto son considerablemente más elevados cuando el hospital opta por emplear el LUI.

\section{Aceptación por las pacientes}

La técnica del LUI requiere dosis medicamentosas más elevadas para el manejo del dolor, como anestesia general, que suelen implicar estancias hospitalarias o clínicas más largas, un hecho que podría representar un inconveniente para las mujeres. Además, los riesgos de complicaciones del método lo hacen menos aceptado por las pacientes.

Comparación entre la AEU y el LUI

\begin{tabular}{|c|c|}
\hline $\begin{array}{l}\text { Aspiración endouterina } \\
\text { - Uso de succión para aspirar el contenido del útero, } \\
\text { disminuyendo el riesgo de perforación uterina } \\
\text { - Dilatación cervical mínima } \\
\text { - Se puede utilizar analgesia, palabras reconfortan- } \\
\text { tes, sedación superficial y/o anestesia local } \\
\text { - Puede ser efectuada por ginecólogos, médicos } \\
\text { generales, una obstetriz/partera u otro profesional } \\
\text { de la salud capacitado } \\
\text { - Procedimiento ambulatorio, lo cual disminuye la } \\
\text { necesidad de estancia hospitalaria }\end{array}$ & $\begin{array}{l}\text { Legrado uterino instrumental } \\
\text { - Raspado con una cureta metálica grande y afilada } \\
\text { que aumenta el riesgo de perforación uterina } \\
\text { - Dilatación mecánica, requerida a menudo para } \\
\text { permitir el paso de la cureta } \\
\text { - Con frecuencia, se utiliza sedación profunda, } \\
\text { analgesia y/o anestesia general } \\
\text { - En general, lo realizan exclusivamente los ginecólo- } \\
\text { gos o los médicos generales capacitados en la } \\
\text { técnica } \\
\text { - Procedimiento practicado en quirófano con } \\
\text { hospitalización frecuente }\end{array}$ \\
\hline
\end{tabular}




\section{MÉTODOS FARMACOLÓGICOSC}

\section{Descripción}

Creado para el tratamiento de enfermedades del tracto gastrointestinal, el misoprostol es el análogo sintético de una prostaglandina que tiene también el efecto de ablandar o madurar el cérvix y estimular contracciones uterinas. Se le utiliza a menudo para inducir el trabajo de parto y es reconocido por su uso, junto con la mifepristona, para inducir un aborto. En la actualidad, el misoprostol es objeto de estudios para usarse en diversas indicaciones terapéuticas, tanto en obstetricia como en ginecología, incluyendo la APA; puede administrarse por vía oral, vaginal o rectal. El producto es estable a temperatura ambiente y tiene una larga durabilidad. Estos factores lo vuelven, potencialmente, un agente muy útil en la prestación de servicios de APA.

Hoy en día, el misoprostol está registrado en más de 80 países para problemas gastrointestinales. Aunque se supone que está disponible en todos esos países hasta un cierto grado, hay una gran disparidad regional relacionada con su disponibilidad, con un acceso relativamente limitado en muchas partes de África y Asia meridional.

\section{Seguridad y eficacia clínica}

Hasta la fecha, se ha mostrado que el misoprostol es eficaz para el tratamiento del aborto diferido. Se estudia su seguridad y eficacia clínica para el tratamiento del aborto incompleto; los resultados preliminares son positivos. Sin embargo, como muchos de los estudios realizados hasta ahora han sido pequeños, sus resultados son difíciles de comparar; se han centrado en mujeres saludables y clínicamente estables, en lugares donde ha sido posible vigilarlas de cerca con ecografía y otra tecnología. El uso del misoprostol no se aconseja cuando un retraso en el procedimiento de evacuación endouterina podría añadir considerable riesgo a la vida o salud de la mujer. En dichos casos, la AEU es el método de tratamiento preferido.

En la actualidad se estudian los efectos secundarios y riesgos específicos del tratamiento de las complicaciones del aborto con misoprostol; entre los primeros figuran vómito, náuseas, diarrea, dolor abdominal, escalofríos, temblores y fiebre. Estos efectos varían según la dosis y vía de administración. Es importante recalcar que mientras más elevada es la edad gestacional, mejor responde el útero a la acción del misoprostol.

Los prestadores de servicios de salud deben estar conscientes de que en algunos lugares las mujeres usan el misoprostol sin supervisión médica para interrumpir un embarazo no deseado. Las dosis excesivas tomadas en gestaciones avanzadas pueden causar ruptura uterina. De igual modo, si el embarazo continúa después de que la mujer ha intentado inducir un aborto con este medicamento, el feto puede desarrollar el síndrome de Mobius, defectos en las extremidades u otras malformaciones congénitas.

\footnotetext{
c Véase también "Tratamiento del aborto incompleto con misoprostol”, más adelante en esta obra.
} 
Costo

No se ha determinado aún el costo de este método para el tratamiento de las complicaciones derivadas del aborto. A pesar de que el medicamento en sí no es caro, el costo lo determina el esquema clínico específico usado, la tecnología que se utilice para vigilar y confirmar la evacuación completa, y el costo de repetir la evacuación del útero, de ser necesario. El lapso que la mujer debe permanecer en el establecimiento de salud para ser vigilada a fin de confirmar la obtención de una evacuación endouterina completa, puede dar lugar a costos adicionales.

\section{Manejo expectante}

Un aborto espontáneo puede llevar a una expulsión parcial de los restos ovulares, o aborto incompleto. No obstante, el aborto espontáneo suele resolverse por sí solo y, con el tiempo, la expulsión finaliza de manera natural, sin necesidad de una intervención. El hecho de permitir que este proceso siga un curso natural con vigilancia de cerca para garantizar la expulsión completa de todos los restos ovulares se conoce como "manejo expectante". La paciente debe tener acceso a servicios de urgencias en caso de que surjan complicaciones durante este periodo.

El manejo expectante debe considerarse sólo en casos de aborto espontáneo sin complicaciones, en lugares donde se dispone de recursos como ecografía y de un laboratorio para medir la gonadotropina coriónica humana (HCG, por sus siglas en inglés).

\section{Aceptación por las pacientes}

No hay suficientes datos que puedan llevar a conclusiones sólidas respecto a la aceptación del misoprostol para la APA. Sin embargo, los resultados preliminares de estudios recientes indican que las mujeres están satisfechas con el método. Como con cualquier otro asunto de salud reproductiva, mientras más amplia es la gama de métodos a escoger, mayor es la aceptación de la intervención.

\section{ALIANZAS ENTRE LA COMUNIDAD Y LOS PRESTADORES DE SERVICIOS}

- Los profesionales de la salud pueden movilizar a las mujeres y a los grupos comunitarios para que aboguen a fin de que los establecimientos de salud ofrezcan servicios de APA en su comunidad y, donde sean posibles, distintas opciones de tratamiento.

- Los profesionales de la salud pueden educar a los miembros de la comunidad, farmacéuticos y a otras personas que utilizan o preparan medicamentos acerca de las dosis recomendadas y las dosis peligrosas de misoprostol.

\section{Referencias}

1. Organización Mundial de la Salud (OMS): Integrated management of pregnancy and childbirth (IMPAC). Managing compications in pregnancy and childbirth: A guide for midwives and doctors. Ginebra, OMS, 2000. 
2. FIGO/WHO Task Force, Cemicamp: Abortion: A professional responsibility for obstetricians and gynecologists. Campinas, Brasil: Informe final del taller, marzo, 1997.

Nota. las personas interesadas en la bibliografía recomendada en este capítulo y en un cuadro comparativo de la efectividad y costo de las técnicas, pueden consultar el manual completo, disponible en http://www.ipas.org/publications/es

\section{Compra del instrumental de Ipas}

El instrumental de Ipas, que incluye el aspirador Ipas AMEU Plus y las cánulas Ipas EasyGrip, se distribuye en numerosos paises por medio de distribuidores comerciales, programas de capacitación y organizaciones de salud reproductiva. Para recibir información sobre los distribuidores del instrumental para la AMEU en su pais, favor de dirigirse al Servicio de Atención al Cliente de lpas: POBox 5026, Chapel Hill, N.C. 27514 U.S.A., teléfono 800-334-8446 (sin costo en llamadas desde EUA), o (919) 960-6453 o (919) 9677052, fax (919) 929-7687, correo-e: customerservice@ipas.org. Sitio en Internet: www.ipas.org 



\section{Manejo del dolor en la atención posaborto}

Daniel Grossman $^{a}$ y Claudia Díaz Olavarrieta ${ }^{b}$

A pesar de los múltiples avances en la calidad de los servicios de atención posaborto (APA) en el mundo, el manejo del dolor todavía es un reto y un aspecto de la APA que requiere atención. Los estudios que documentan el manejo deficiente del dolor en mujeres que acceden a los servicios de APA señalan la ausencia de tratamiento o uso rutinario de anestesia general. Investigadores y diseñadores de políticas han buscado diseñar lineamientos que enfaticen la importancia del manejo del dolor en la APA. Sin embargo, queda mucho por hacer en este campo.

En una revisión del tema, Julie Solo cita cuatro razones principales para el manejo inadecuado del dolor en la APA: la creencia de que las mujeres que experimentan un aborto inducido deben ser castigadas, la idea de que los medicamentos para controlar el dolor no son necesarios, la falta de acceso a tales medicamentos y el entrenamiento inadecuado de los profesionales de la salud a cargo de este tipo de atención, tema, este último, sobre el cual versará este capítulo.

\section{LINEAMIENTOS SOBRE MANEJO DEL DOLOR}

\section{Componentes del dolor}

La percepción del dolor es una sensación compleja que incluye elementos físicos y psicosociales; por ello, es posible que el tratamiento farmacológico sea insuficiente para remediar totalmente los síntomas de una paciente. El dolor asociado al cuidado posaborto, a menudo no recibe la atención que amerita antes, durante y después de la aspiración.

\footnotetext{
a Al momento de elaborar este texto, el coautor trabajaba en el Population Council en México, D.F. En la actualidad se desempeña en Ibis Reproductive Health en San Francisco, Ca., EUA.

b Cuando este capítulo se elaboró, la coautora trabajaba en el Population Council en México, D.F. En la actualidad se desempeña en el Centro de Investigación en Evaluación y Encuestas, Instituto Nacional de Salud Pública, México, D.F.
} 
La inervación sensorial del útero afecta varios tipos de nervios. El cérvix y el segmento uterino inferior están inervados por fibras parasimpáticas (S2 a S4) que conforman el ganglio lateral del cérvix que ingresa acompañado de los vasos sanguíneos uterinos. El fondo uterino está inervado por fibras simpáticas (T10 a L1) a través del nervio hipogástrico inferior, el cual se introduce al útero a nivel de los ligamentos uterosacrales, así como que a través de los plexos ováricos que entran en la cornua. Que la inervación sensorial del útero se derive de dos fuentes implica que el bloqueo paracervical (el cual anestesia los nervios del plexo ubicados junto al cérvix) sólo disminuirá el dolor asociado con la dilatación cervical y la manipulación. Este bloqueo tiene un efecto mínimo en los cólicos asociados con el vaciado del útero.

Mas allá del componente físico del dolor, hay aspectos psicológicos y sociales que influyen en su percepción, como la personalidad de la paciente, su experiencia previa y actual de dolor, y su estado de ánimo. Las mujeres que se han sometido a un aborto en países donde éste es legal, han demostrado que las jóvenes y quienes están más temerosas del procedimiento reportan más dolor. Otros factores asociados con un incremento del dolor durante la aspiración incluyen escolaridad baja, menor tolerancia reportada al dolor, "problemas morales", un útero en retroversión y antecedentes de dismenorrea. Un estudio mostró que las mujeres con niveles de depresión y ansiedad de moderados a severos antes del procedimiento, reportaban grados mayores de dolor. Está demostrado que un parto vaginal previo está asociado con una percepción disminuida de dolor.

La situación de una mujer al solicitar servicios de APA es física y emocionalmente estresante. Si ella busca los servicios por un aborto espontáneo o por una terminación de embarazo realizada de forma deficiente, muy probablemente tendrá efectos psicológicos que modularán la percepción del dolor físico que experimentará. La literatura ha descrito situaciones en donde el personal de salud y los médicos adoptan actitudes prejuiciadas contra la mujer, expresando que la condición por la que atraviesa es su culpa, que ella debería experimentar algún sufrimiento y negándole medicamentos para el dolor como forma de castigo por sus acciones. Esta falta de apoyo puede empeorar su percepción del dolor.

\section{Métodos de control de dolor}

Existen diversos métodos para controlar el dolor que son útiles en el contexto de la APA; incluyen analgésicos orales, parenterales, locales con o sin sedación y anestesia general. La elección de analgésicos o anestesia dependerá de la etapa de la APA y de la preferencia de la paciente, la elección del médico, los recursos de la institución y las indicaciones médicas. Algunas mujeres prefieren analgésicos no narcóticos y anestesia local para evitar los efectos del estado alterado de conciencia que producen los narcóticos o los sedantes; otras pueden preferir estar totalmente "dormidas". La sedación intravenosa y la anestesia general requieren medicamentos y equipo de vigilancia que no siempre están disponibles en los hospitales.

A falta de una prueba o índice fisiológico para medir el dolor, los médicos deben confiar en los informes verbales de las pacientes. Preguntar a la mujer si está experimentando dolor no es suficiente cuando existe una variedad de intervenciones para aliviarlo. Tratar de juzgar el nivel de dolor observando las reacciones a la situación tampoco es suficiente, pues las personas pueden reaccionar de manera diferente a estímulos dolorosos similares. Una escala de dolor (figura 14-1) es una técnica útil de medición que valora también la respuesta a la intervención. Se puede usar una escala verbal cuantitativa 


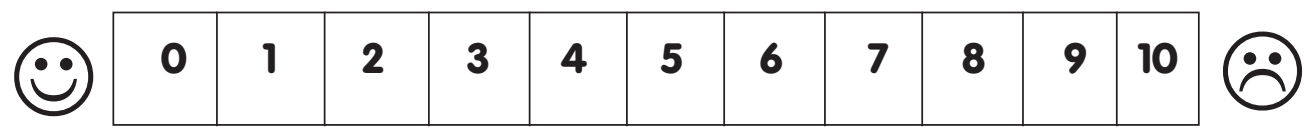

Ausencia de dolor

Mucho dolor

Figura 14-1. Escala de nivel del dolor.

o una escala visual análoga para cuantificar los niveles de dolor de una paciente. Es importante enseñar a la mujer a que describa con la mayor precisión posible su dolor, en una escala de cero a diez, en donde cero es la ausencia de dolor y diez un dolor muy intenso. De este modo, es posible vigilar el efecto de los medicamentos y de otras técnicas de intervención, y documentar con más exactitud el manejo del dolor en el expediente clínico.

\section{Analgésicos}

Los analgésicos orales y parenterales (intravenosos o intramusculares) son muy útiles antes y después de la aspiración uterina. Los antiinflamatorios no esteroideos (AINE) y los narcóticos son los analgésicos más utilizados; los opioides se unen a receptores específicos en la médula espinal y el cerebro, modificando la percepción del dolor. Los AINE inhiben la producción de prostaglandinas y tienen un efecto antiinflamatorio. A veces se combinan con medicamentos ansiolíticos (benzodiazepinas) que se pueden administrar también por vía oral o intravenosa. El cuadro 14-1 muestra algunos analgésicos orales de uso común y sus dosis. La analgesia suele abordarse de forma escalonada, dependiendo del nivel de dolor de la paciente. Los medicamentos más inocuos o las dosis más bajas se utilizan primero, seguidas de ajustes o dosis repetidas según la respuesta de la paciente.

Algunos proveedores de salud se han mostrado reticentes a usar los AINE en la APA por el riesgo teórico de producir una pérdida de sangre mayor. Si bien estos medicamentos pueden causar un decremento en la agregación plaquetaria, no existen datos o evidencias que muestren que su uso en el corto plazo puede traer consigo complicaciones. El ácido acetilsalicílico tiene un efecto más importante en la función plaquetaria y

CUADRO 14-1.

Analgésicos orales

\begin{tabular}{l|l|l}
\multicolumn{1}{c|}{ Medicamento } & \multicolumn{1}{|c}{ Dosis más frecuente } & \multicolumn{1}{c}{$\begin{array}{c}\text { Efectos secundarios } \\
\text { más comunes }\end{array}$} \\
\hline Acetominofén & 325 a $650 \mathrm{mg}$ cada 4 a $6 \mathrm{~h}$ & Mínimos \\
\hline lbuprofeno & 400 a $600 \mathrm{mg}$ cada 4 a $6 \mathrm{~h}$ & Gastritis \\
\hline Acetominofén con codeína (Tylex) & 1 a 2 tabletas cada 4 a $6 \mathrm{~h}$ & Náuseas, vómito \\
\hline
\end{tabular}




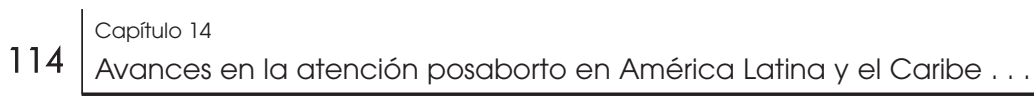

probablemente no debería administrarse. Las mujeres a quienes se les prescriben narcóticos intramusculares, intravenosos o ansiolíticos, deben manejarse como si hubieran recibido sedación.

\section{Sedación}

La sedación consciente implica un nivel de depresión mínima en el estado de conciencia que mantiene la capacidad de la paciente de mantener las vías áreas libres y de responder a instrucciones verbales. Este nivel es ideal para procedimientos cuya duración y dolor son moderados y que no suelen practicarse en la sala de operaciones; también puede ser útil antes o durante la aspiración uterina. Mientras se realiza la aspiración, la sedación consciente puede ser un accesorio a la anestesia local. La sedación profunda es un estado de conciencia deprimida; en él, no es fácil que la paciente se muestre alerta. Se acompaña de una pérdida parcial o total de reflejos de protección, incluyendo la capacidad de mantener viables las vías aéreas. Este nivel, así como la anestesia general, no deben utilizarse si no existe el apoyo de reanimación completo (medicamentos, equipo y personal entrenado).

Los narcóticos y los opioides se utilizan por sus propiedades analgésicas; los medicamentos intravenosos e intramusculares más utilizados y sus dosis se listan en el cuadro 14-2. Cualquier unidad médica que administre narcóticos debe contar también con su antagonista naloxona (Narcanti). Todos los narcóticos pueden producir depresión respiratoria, y las pacientes que los reciben deben estar vigiladas estrechamente.

Cuando sucede un retraso importante en el proceso de aspiración en mujeres con dolor moderado a severo, se puede recurrir a la morfina, especialmente antes del procedimiento. La duración de acción de la morfina es variable, pero casi siempre su rango se encuentra entre las tres y cuatro horas. La meperidina (Demerol) es útil, igualmente, en la etapa previa a la aspiración uterina, ya que su vida media de eliminación es similar a la de la morfina, y tiene utilidad limitada durante el procedimiento. Algunos centros pueden contar con una disponibilidad limitada de narcóticos, y el bajo costo de la meperidina puede tornarla una opción disponible y viable. La morfina y la meperidina pueden

CUADRO 14-2.

Narcóticos parenterales

\begin{tabular}{l|l|l}
\multicolumn{1}{c|}{ Medicamento } & \multicolumn{1}{|c}{ Dosis más frecuente } & \multicolumn{1}{|c}{ Efectos secundarios más comunes } \\
\hline Morfina & $10 \mathrm{mg} \mathrm{IV} \mathrm{o} \mathrm{IM} \mathrm{cada} 3$ a $5 \mathrm{~h}$ & $\begin{array}{l}\text { Posible hipotensión (especialmente en pacien- } \\
\text { tes hipovolémicas), comezón ly posible broncos- } \\
\text { pasmo en pacientes asmáticas) debido a libe- } \\
\text { ración de histamina, náuseas, vómito }\end{array}$ \\
\hline Meperidina (Petidina) & 75 a $125 \mathrm{mg}$ IV o IM cada 2 a $3 \mathrm{~h}$ & $\begin{array}{l}\text { Toxicidad del sistema nervioso central (ansiedad, } \\
\text { crisis convulsivas, desorientación, psicosis), } \\
\text { náuseas, vómito, comezón }\end{array}$ \\
\hline Fentanil & 0.1 a $0.2 \mathrm{mg}$ IV cada 1 a $2 \mathrm{~h}$ & Rigidez muscular con dosis altas o repetidas \\
\hline
\end{tabular}


producir náuseas y vómito, así como depresión respiratoria cuando se utilizan en dosis más elevadas. La meperidina está contraindicada en pacientes bajo tratamiento con inhibidores de la monoaminaoxidasa.

El fentanil es un narcótico de corta duración que puede ser muy útil para una sedación consciente durante la aspiración; a dosis bajas, puede tener un inicio rápido (generalmente menos de cinco minutos) y un curso de acción breve. Es mucho más potente que la meperidina o la morfina, produce menos náuseas o vómito y su efecto de depresión respiratoria es más breve que el de otros narcóticos. El fentanil no libera histamina y por ello no produce broncospasmo o comezón.

Las benzodiazepinas son una familia de medicamentos con propiedades ansioliticas, sedantes y amnésicas que suelen utilizarse combinadas con narcóticos para lograr una sedación consciente. El diazepam (Valium), lorazepam (Ativan) y el midazolam (Dormidium) son los más utilizados. Si está disponible, el midazolam es preferible al diazepam por ser soluble en agua y por ser menos doloroso al inyectarse que el diazepam. La eliminación más breve del midazolam produce una recuperación más rápida. Ambos medicamentos tienen un inicio súbito en sus efectos, observable en pocos minutos. El lorazepam ( 1 a $2 \mathrm{mg}$ ) o el diazepam (5 a $10 \mathrm{mg}$ ) pueden ser útiles en casos de ansiedad leve a moderada; se administrarán por vía oral al menos 30 minutos antes de la aspiración; pueden ayudar a disminuir la ansiedad de la paciente durante el procedimiento y su percepción del dolor

Administradas en combinación con narcóticos, las benzodiazepinas pueden producir una depresión respiratoria más acentuada. Por tanto, se debe vigilar con extremo cuidado el estado respiratorio de la paciente. Quienes consumen alcohol con regularidad tienen una tolerancia incrementada a las benzodiazepinas. Los proveedores de salud deben estar conscientes de la posibilidad de que una paciente puede haber ingerido un narcótico antes de acudir a los servicios médicos. El flumazenil es una benzodiazepina con efectos antagonistas que puede administrarse a pacientes en las que existe incertidumbre sobre sus efectos depresores, que se cree se deben al efecto de las benzodiazepinas. El flumazenil se puede administrar a dosis de 0.1 a $0.2 \mathrm{mg}$ por vía intravenosa, repitiendo cada uno a dos minutos, hasta lograr una dosis máxima de $3 \mathrm{mg}$. Si está disponible, el flumazenil debe almacenarse junto con las benzodiazepinas.

\section{Anestesia local}

El bloqueo paracervical controla eficazmente el dolor durante la aspiración uterina, y en algunos casos antes de la aspiración. Para aliviar el dolor durante la evacuación, el bloqueo local se puede combinar con analgésicos orales y/o ansiolíticos, y con sedación consciente. El bloqueo paracervical comprende la infiltración de un anestésico local en el área que rodea los ganglios laterales al cérvix. Mientras que los anestésicos locales actúan bloqueando la entrada de los iones de sodio a través de la membrana de las células nerviosas, existe evidencia de que el bloqueo paracervical disminuye también el dolor al aplicar presión física al tejido que contiene las fibras nerviosas.

Existen dos clases de anestésicos locales: los aminoésteres y las aminoamidas. Los aminoesteres se metabolizan rápidamente por las colinesterasas plasmáticas, mientras que las amidas atraviesan el metabolismo hepático. La lidocaína, una aminoamida, es el anestésico local más utilizado para bloqueo paracervical; es muy seguro cuando se administra de manera correcta, aunque se han reportado efectos secundarios graves y muertes, con 
frecuencia a causa de una sobredosis o una inyección intravascular. Los efectos sistémicos tóxicos de la lidocaína están relacionados con la dosis administrada: a dosis relativamente bajas, la paciente puede padecer vértigo o mareo, tinnitus (zumbido en los oídos), cosquilleo peribucal y un sabor metálico bucal. A concentraciones más elevadas en la sangre, se pueden presentar fasciculaciones musculares, pérdida de conciencia y crisis convulsivas. Los efectos cardiovasculares, incluyendo hipertensión, bradicardia, insuficiencia cardiaca y muerte, se manifiestan con valores plasmáticos muy elevados. Las reacciones alérgicas - al anestésico o a los conservadores en la solución-, son una complicación poco frecuente del bloqueo paracervical; se inician, en general, con eritema que puede progresar hacia urticaria, broncoespasmo, anafilaxia y muerte.

El manejo de las reacciones tóxicas abarca el tratamiento estándar para alergia; incluye pseudoefedrina y posiblemente adrenalina y/o los esteroides. Los síntomas neurológicos o el colapso cardiovascular se tratan con manejo de vías aéreas, administración de oxígeno y reanimación cardiopulmonar estándar. Las crisis convulsivas se controlan con benzodiazepinas.

Para evitar reacciones tóxicas, se recomienda como dosis máxima de lidocaína 4.5 $\mathrm{mL} / \mathrm{kg}$ peso con una dosis total de hasta $200 \mathrm{mg}$, que se debe administrar inyectando $20 \mathrm{~mL}$ de $1 \%$ lidocaína $(20 \mathrm{~mL} \times 10 \mathrm{mg} / \mathrm{mL}=200 \mathrm{mg})$. La absorción sistémica de la lidocaína se reduce agregando vasoconstrictores a la solución anestésica. También se ha mostrado que dosis bajas de vasopresina reducen el sangrado uterino durante la aspiración.

Las técnicas de inyección para bloqueo paracervical son muy variadas; se ha demostrado que la inyección a profundidad es más efectiva que la superficial. Una aguja de calibre 23 de $38 \mathrm{~mm}$ de ancho $(3.75 \mathrm{~cm})$ suele ser suficiente para lograr la profundidad que se requiere. La técnica inicia con una inyección de 1 a $2 \mathrm{~mL}$ en la parte superior del cérvix, donde se colocará el instrumento para estabilizarla. En lugar de utilizar pinzas con dientes, la mayor parte de los casos de aspiración se pueden llevar a cabo colocando pinzas atraumáticas Allis o Bierer para estabilizar el cérvix. Después, se administran $5 \mathrm{~mL}$ de 0.5 o $1 \%$ de lidocaína en cada sitio, aproximadamente a la mitad entre la os cervical y la periferia del cérvix a una profundidad de 18 a $25 \mathrm{~mm}$. El anestésico se puede inyectar a medida que la aguja se retira. Es importante retirar el émbolo de la aguja antes de la inyección para evitar una aplicación intravascular de lidocaína. Si se aspira sangre, se debe retirar la aguja hasta la superficie mucosa y redirigirla. En ocasiones se puede presentar sangrado en los sitios de la inyección del bloqueo paracervical, especialmente cuando se utiliza una aguja mayor al calibre 23. El sangrado por lo general se detiene aplicando una presión suave con una gasa.

\section{Aspectos no farmacológicos de manejo del dolor}

El manejo exitoso del dolor requiere una comunicación óptima entre la paciente y el equipo de salud, que debe reconocer los aspectos emocionales de la circunstancia en la que la paciente se encuentra, y que pueden afectar su percepción del dolor. Es importante ayudar a la paciente a distinguir entre el dolor físico y el emocional. Una mujer que accede a la APA se encuentra bajo un estrés emocional importante; de ahí la relevancia de establecer comunicación y apoyo entre ella y el proveedor.

Varios métodos no farmacológicos de control del dolor han demostrado su eficacia. La "sugestión positiva" es una técnica que brinda información a la paciente para enfatizar los significados positivos de la situación que está viviendo. Por ejemplo, si la paciente 
sufre cólicos durante la aspiración, se le puede decir que la sensación significa que la cirugía está por concluir, que su cuerpo está sano y haciendo lo que requiere para prevenir mayor sangrado. Un enfoque similar, el de "atención estructurada", intenta que la paciente se concentre en su dolor y describa sus sensaciones, considerando lo que podría hacer para aliviarlas. La "relajación" es otra técnica; en ella, el proveedor de servicios instruye a la paciente para que contraiga los músculos de la pelvis y los glúteos y luego los relaje, pidiéndole experimentar la sensación de relajamiento cada vez que sienta malestar durante el procedimiento. Una técnica más compleja incluye dirigirse a la paciente con voz suave y pedirle que se concentre en relajarse desde los pies hasta la cabeza.

Otra técnica es la de "imágenes guiadas" o "visualización de imágenes sensoriales". Antes de llevar a cabo el proceso de aspiración, se pide a la mujer describir un sitio o actividad favorita en donde ella se imaginará a sí misma durante el procedimiento brindando claves detalladas para mejorar su nivel de dolor.

Marie Stopes International (MSI) ha promovido el uso de técnicas no farmacológicas de manejo del dolor que combinan varios de los métodos ya descritos. La anestesia "local oral" se inicia tratando de lograr que la paciente se sienta cómoda desde el contacto inicial con el proveedor, haciendo del consultorio un sitio agradable en donde la interacción con la paciente ocurre de manera cálida y relajada. La técnica se centra en distraer a la mujer del procedimiento haciéndole preguntas de formato abierto. Luego se procede con los ejercicios de respiración, las técnicas de relajación y la atención estructurada. MSI ha reportado éxitos con este método durante la AMEU, generalmente sin recurrir al bloqueo paracervical.

Cabe mencionar que las técnicas no farmacológicas de manejo del dolor ya descritas son más efectivas cuando un miembro del equipo de salud ha establecido una relación cercana con la paciente y mantiene una comunicación continua con ella durante el procedimiento. Muchas veces, sin embargo, los recursos no permiten que un miembro del personal esté disponible, en cuyo caso la enfermera o el proveedor mismo pueden llevar a cabo el procedimiento y fungir como el anestesiólogo "no farmacológico".

\section{MANEJO DEL DOLOR EN LAS DIFERENTES ETAPAS DEL CUIDADO POSABORTO}

\section{Dolor previo a la aspiración}

Las mujeres que acuden a los servicios de APA a menudo experimentan dolor; pero los proveedores de salud no siempre les ofrecen tratamiento adecuado para calmarlo. Un aborto incompleto con cólico uterino es claramente un proceso doloroso, y una mujer que se ha sometido a un procedimiento quirúrgico inseguro para interrumpir su embarazo quizá experimentará más malestar. La situación de cada mujer puede tornar la experiencia aún más dolorosa. Por ejemplo, pacientes que experimentan un aborto espontáneo de un embarazo muy deseado, o quienes se han sometido a un aborto inseguro y riesgoso, podrán estar temerosas o ansiosas, y estos sentimientos pueden intensificar su dolor físico.

Mostrar sensibilidad a la circunstancia de cada paciente es crucial para ofrecer una APA de calidad que puede contribuir a aliviar su dolor. Son inaceptables los comentarios despectivos sobre las circunstancias del aborto o culpar a la mujer, pues ello puede 
asustarla y empeorar su percepción del dolor asociado a la aspiración. Además, los proveedores de salud, con acciones como ignorar la privacidad de la paciente, también pueden hacer sentir a la mujer incómoda y temerosa. Incluir a la paciente en su manejo del dolor puede ayudarla a sentir que tiene poder y control de la situación, lo que a su vez puede disminuir su miedo y ansiedad. Esto se puede lograr si se le explica de forma clara la naturaleza y severidad de su problema, aunque también es cierto que durante el proceso de aspiración algunas mujeres prefieren no recibir explicaciones detalladas de lo que está ocurriendo.

El manejo del dolor durante esta fase de la APA depende del nivel que la mujer experimente. Por desgracia, en muchos hospitales públicos con sobrecarga de trabajo, el tiempo de espera previo a la aspiración uterina suele ser prolongado. Además de intentar reducir este factor, los proveedores de salud deben estar conscientes de que las pacientes que esperan un proceso de aspiración pueden experimentar fluctuaciones en sus niveles de dolor, sobre todo una exacerbación a medida que los efectos del medicamento se desvanecen. Algunas pueden experimentar cólico y sangrado leves, y otras presentar dolor intenso. El dolor leve o moderado suele aliviarse con analgésicos orales (cuadro 14-1) u otros narcóticos más potentes. Si estos medicamentos fallan o la paciente reporta dolor más severo, los narcóticos intramusculares o intravenosos se tornan necesarios. Se requiere vigilancia apropiada de signos vitales, incluyendo signos de depresión respiratoria cuando se administran estos medicamentos, especialmente si se combinan benzodiazepinas con narcóticos. Como el bloqueo paracervical alivia el dolor asociado con dilatación cervical y manipulación, así como con la acción de un anestésico de corta duración, los anestésicos locales no juegan un papel prominente en el manejo del dolor preaspiración.

\section{Dolor durante el proceso de aspiración}

Siempre que sea posible, se recomienda el bloqueo paracervical con o sin sedación consciente para manejar el dolor durante la aspiración, sobre todo si se lleva a cabo con AMEU o con aspiración eléctrica. Esta técnica suele ofrecer un alivio del dolor durante el procedimiento; no obstante, su acción es suficientemente breve para que las pacientes se recuperen pronto de los efectos anestésicos. Con personal bien entrenado y con equipo de reanimación, esta técnica se puede realizar de manera segura fuera de la sala de operaciones, reduciendo también los costos.

La anestesia local, con o sin sedación, puede y debe combinarse con métodos no farmacológicos de manejo del dolor, incluyendo relajación, sugestión positiva e imágenes guiadas. La falta de experiencia de los proveedores de salud al interactuar con una paciente durante un proceso quirúrgico puede contribuir a la sobreutilización de la anestesia general. Por este motivo, es importante educar a los médicos, enfermeras y otros miembros del personal para que reconforten y acompañen a una paciente que permanece despierta durante el procedimiento. Por ejemplo, el personal de salud acostumbrado a trabajar en una sala de operaciones debe adaptar su conducta al estar en presencia de una paciente que puede ver y oír lo que sucede a su alrededor.

En muchos países, la anestesia general se utiliza para aliviar el dolor durante la evacuación uterina, en especial si se recurre al legrado. Existen casos donde esta técnica (o la sedación profunda) puede ser útil, incluyendo el aborto de segundo trimestre, o cuando una paciente tiene un umbral muy bajo de tolerancia al dolor que no puede contro- 
larse por otras vías. Para la mayoría de las pacientes, sin embargo, la anestesia general no es necesaria y añade riesgo al procedimiento. Algunos estudios han mostrado una asociación entre anestesia general y un riesgo incrementado de perforación uterina y hemorragia. Además, la anestesia general requiere que la paciente sea manejada por un anestesiólogo en una sala de operaciones, incrementando así el costo y tiempo de espera. Dependiendo de los medicamentos que se utilicen, la anestesia general suele requerir periodos de recuperación más prolongados, lo que retrasa el egreso de la mujer de la unidad de atención. Un estudio hecho en la India, introduciendo la anestesia local en una práctica clínica en donde sólo se ofrecía anestesia general durante la aspiración, reportó que $40 \%$ de las mujeres eligieron la anestesia local.

\section{Dolor posterior al proceso de aspiración}

Este dolor, causado por los cólicos uterinos normales, casi siempre es leve, pero en casos más severos el proveedor de salud debe considerar otras causas que puedan producirlo, incluyendo la perforación uterina, hematómetra ("síndrome posaborto") o infección. El dolor posterior al proceso de aspiración casi siempre se controla con analgésicos orales; pero en ocasiones puede requerir narcóticos intramusculares o intravenosos.

Como las pacientes pueden no recordar todo lo que se les ha dicho durante el procedimiento, sobre todo si estaban sedadas, los proveedores de salud les deben explicar, una vez más, lo que sucedió después de la aspiración. El simple hecho de informar a la paciente que el procedimiento concluyó y que se encuentra fuera de peligro, puede ayudar a mitigar sus miedos y disminuir su percepción del dolor.

La recuperación de la anestesia posaspiración varía según la técnica empleada. Las mujeres cuyo procedimiento se hizo bajo anestesia local pueden recuperarse muy rápido. En estos casos se requiere poca vigilancia. Quienes recibieron sedación o anestesia general pueden requerir vigilancia después del procedimiento, más prolongada e intensiva y que, en general, está estandarizada en los hospitales; pero éste puede no ser el caso de la sedación cuando se realiza fuera de la sala de operaciones. Si así ocurre, es importante que el personal esté entrenado para observar con cuidado a la paciente. Las mujeres en esta circunstancia deben estar acompañadas hasta recuperarse por completo, pues existe riesgo de un cambio en el estado de conciencia o de vómito súbito. Los lineamientos para dar de alta a una paciente del área de recuperación incluyen signos vitales normales, control del sangrado, ausencia de confusión y capacidad para tolerar líquidos, ambular sin mareos y orinar. Si la mujer va a ser dada de alta, es importante que esté acompañada por un adulto responsable. A estas pacientes se les debe sugerir que no manejen ni realicen actividades complejas hasta el día siguiente al procedimiento.

Los proveedores de servicios deben ofrecer a la mujer analgésicos orales (medicamento o receta) una vez que se dan de alta. Los AINE, como el ibuprofeno, casi siempre son suficientes; sin embargo, algunas pueden requerir un narcótico como el acetaminofén con codeína (Tylex) u otros más potentes. Contar con estos medicamentos de antemano no sólo mejorará el dolor de la paciente, sino que disminuye la probabilidad de que acuda al médico o se presente en la sala de urgencias del hospital por un dolor que no fue debidamente controlado. La mujer debe recibir información sobre signos de alarma y las características del dolor que puede experimentar después de la aspiración. Es importante que comprenda las circunstancias en las que puede ser necesaria ayuda adicional para controlar su dolor. 


\section{Referencias}

Castleman L, Mann C: Manual vacuum aspiration (MVA) for uterine evacuation: Pain management. Chapel Hill (NC): IPAS, 2002.

Clark S, Krishna U, Kallenbach L et al.: Women's preferences for general or local anesthesia for pain during first trimester surgical abortion in India. En: Contraception. 66(4), 2002::275279.

Darney PD, Horbach NS, Korn AP: Pain relief for office surgery. En: Protocols for office gynecologic surgery. Cambridge (MA): Blackwell Science; 1996:23-42.

Langer A, García-Barrios C, Heimburger A, et al.: Improving post-abortion care in a public hospital in Oaxaca, Mexico. En: Reproductive Health Matters. 9, 1997:20-28.

Maltzer DS, Maltzer MC, Wiebe ER, et al.: Pain management. En: Paul M, Lichtenberg ES, Borgatta L, Grimes DA, Stubblefield PG (Eds): A clinician's guide to medical and surgical abortion. Philadelphia (PA): Churchill Livingstone; 1999:73-89.

Paris PM, Yealy DM: Pain management. En: Marx JA, Hockenberger RS, Walls RM, Adams J, Barkin RM, Barsan WG, Danzl DF, Gausche-Hill M, Hamilton GC, Ling LJ, Newton E, (Eds). Rosen's emergency medicine: Concepts and clinical practice, $5^{\text {th }}$ ed. St. Louis (MO): Mosby; 2002:2556-2577.

Reves JG, Glass PSA, Lubarsky DA: Nonbarbiturate intravenous anesthetics. En: Miller RD, (Ed): Anesthesia, $5^{\text {th }}$ ed. Philadelphia (PA): Churchill Livingstone; 2000:228-272.

Solo J: Easing the pain: Pain management in the treatment of incomplete abortion. En: Reproductive Health Matters. 8(15), 2000:45-51. 


\section{Misoprostol en el tratamiento de aborto incompleto ${ }^{a}$}

Ricardo G. Rizzi ${ }^{b}$

\section{INTRODUCCIÓN Y DEFINICIÓN}

Se llama aborto a la separación del producto de la concepción antes de un nivel de maduración, sin la cual no puede ser viable. Este tiempo corresponde a las 22 semanas completas (154 días completos), o cuando el feto no supera los 500 g de peso. ${ }^{1}$

El aborto puede ser espontáneo o provocado. Se estima que el aborto espontáneo ocurre en 15 a $20 \%$ de todos los embarazos humanos. ${ }^{2}$ Tanto el aborto espontáneo como el provocado pueden ser completos o incompletos. Es completo cuando la evacuación del contenido uterino es total, es incompleto si la evacuación es parcial; es decir, cuando quedan en el interior del útero restos ovulares o membranas.

El diagnóstico clínico del aborto incompleto se establece cuando, después de la expulsión de material ovular, se observa la persistencia de metrorragia, canal cervical permeable y dolor. ${ }^{3} \mathrm{El}$ examen ecográfico permite confirmar el diagnóstico.

El aborto incompleto es una grave preocupación de salud pública, y la falta de tratamiento adecuado puede provocar alta morbilidad e incluso la muerte. El principal peligro del aborto incompleto no infectado es el choque hipovolémico seguido por muerte en casos de hemorragias profusas. En algunos países menos desarrollados, las muertes atribuibles al aborto pueden llegar a constituir entre 22 y $56 \%$ de todas las muertes maternas directas. ${ }^{4,5}$

El tratamiento del aborto incompleto recomendado por la mejor evidencia científica hasta la fecha es la evacuación uterina por medio de aspiración manual endouterina (AMEU) o por vacío eléctrico; de no estar disponibles, o en caso de no contar con profesionales entrenados en su uso, se puede utilizar también el legrado, que se realiza con cureta bajo anestesia. ${ }^{6}$ En algunos casos, es preciso reponer el volumen de sangre, cuando la pérdida sanguínea haya provocado una anemia aguda.

\footnotetext{
a Publicado en: Faúndes, Anibal (Ed). Uso de misoprostol en la obstetricia y ginecología. Managua, Nicaragua: Federación Latinoamericana de Ginecología y Obstetricia (FLASOG). 2a ed. 2007

b Facultad de Ciencias Médicas - Universidad Nacional de Córdoba, Argentina.
} 
El legrado tiene como complicaciones la perforación uterina y lesiones posoperatorias cervicales, ${ }^{6}$ así como la posibilidad de sinequias uterinas o síndrome de Asherman, sobre todo si se debe repetir por evacuación insuficiente. ${ }^{7}$ La AMEU como tratamiento del aborto incompleto es un procedimiento rápido y menos doloroso, tanto que la analgesia y sedación no siempre son necesarias, y las complicaciones son menores que las que ocurren con el legrado con cureta. ${ }^{8}$

El manejo quirúrgico de la evacuación uterina después de un aborto incompleto, especialmente con legrado y anestesia general, no está exento de complicaciones y fracasos; además, consume importantes insumos hospitalarios con un alto costo económico para el sector público.

Se hace necesario, por tanto, que los servicios busquen formas de ofrecer mayores opciones de tratamiento, con menores riesgos y costos reducidos, manteniendo la misma eficacia y dando mayor comodidad a la mujer ${ }^{9}$ en un contexto de servicios de calidad. El atractivo de los métodos clínicos para la evacuación del aborto incompleto es que ofrecen la posibilidad de cumplir con estos requisitos. ${ }^{10}$ Se estima que el costo del manejo quirúrgico con legrado y anestesia general es más del doble que cuando se usa misoprostol, sin contar el costo indirecto, social, familiar y laboral para las pacientes. ${ }^{9,11}$

En antiguos libros de obstetricia ya se hablaba de un tratamiento clínico para el aborto incompleto. Iffy y Kaminetzky postulaban que la infusión intravenosa de sustancias oxitócicas facilitaba la evacuación espontánea del contenido uterino, en franca discrepancia con Williams, quien refiere que rara vez la oxitocina es eficaz en el tratamiento del aborto incompleto. ${ }^{12}$ Se sabe, además, que con una conducta expectante muchos de estos casos se resolverían sin ninguna intervención médica. ${ }^{13-16}$

El misoprostol se está usando cada vez más en el tratamiento de aborto incompleto debido a su facilidad de uso y bajo costo. La amplia disponibilidad actual del misoprostol, que actúa sobre el miometrio en cualquier edad gestacional, ofrece la posibilidad de conseguir la evacuación del aborto incompleto mediante un tratamiento exclusivamente farmacológico.

El misoprostol facilita el acceso al tratamiento, y puede ser un alivio para los servicios terciarios, hoy sobrecargados con la atención de numerosos casos de aborto incompleto que podrían tratarse con misoprostol en los servicios básicos de salud. De esta forma, sería posible reducir enormemente los costos para los servicios y permitir que la mujer no se separe de su familia, además de evitar las complicaciones que se observan con el tratamiento quirúrgico.

Desde el primer estudio publicado acerca del uso del misoprostrol en el tratamiento del aborto incompleto, en 1993, ${ }^{17}$ se han publicado varias investigaciones que usaron diversas, vías de administración y periodos de espera para definir el éxito del tratamiento. ${ }^{18,19}$ Las investigaciones más recientes permiten concluir que una dosis de $600 \mathrm{mg}$ de misoprostol por vía oral tiene resultados casi tan eficientes como una aspiración uterina manual con esta misma indicación. ${ }^{20-22}$

Aunque a largo plazo (ocho semanas) la conducta expectante muestra resultados parecidos al uso del misoprostol, el sangrado es más breve y el periodo de espera más corto con el tratamiento farmacológico. ${ }^{4,23}$

\section{INDICACIONES}

El misoprostol para el tratamiento del aborto incompleto se recomienda en pacientes:

- Cuyo tamaño uterino corresponda a una gestación menor o igual a 12 semanas. Puede utilizarse con precaución en pacientes con un tamaño uterino mayor, pero 
con una edad gestacional confirmada igual o menor a 12 semanas (p. ej., con aumento del tamaño uterino por miomas).

- Sin infección.

- En buen estado general y hemodinámicamente compensadas.

- Que acepten voluntariamente utilizar esta opción, otorguen su consentimiento informado y entiendan que la evacuación quirúrgica pudiera ser necesaria ante el fracaso de este tratamiento.

- Con posibilidades de regresar de inmediato al centro asistencial en caso de presentarse cualquier complicación.

\section{CONTRAINDICACIONES}

- Sangrado abundante.

- Síntomas o signos de infección genital y/o sepsis.

- Mal estado general, síntomas de inestabilidad hemodinámica o choque.

- Alergia a prostaglandinas.

- Sospecha de embarazo ectópico.

- Antecedentes de trastornos de la coagulación, o que estén tomando anticoagulantes.

\section{PROCEDIMIENTOS PARA EL TRATAMIENTO MÉDICO DEL ABORTO INCOMPLETO}

Se recomienda lo siguiente.

1. El protocolo de tratamiento es simple y requiere sólo una consulta externa. En esa consulta se debe realizar un examen físico general y ginecológico para precisar el diagnóstico de aborto incompleto y que el tamaño del útero no sea mayor al correspondiente a 12 semanas de edad gestacional. En donde exista la posibilidad, debe realizarse una ecografía abdominal o transvaginal para asegurar el diagnóstico. Aunque la ecografía es conveniente, no es condición necesaria para usar misoprostol.

2. Se recomienda dar información sobre la vía de administración del misoprostol, los posibles efectos secundarios o el pequeño riesgo de que queden restos, en cuyo caso será necesario realizar aspiración al vacío o legrado uterino. Es importante explicar que la expulsión de los restos puede ocurrir en las horas o días subsiguientes, y que puede sangrar más que una menstruación normal por tres o cuatro días, y continuar con un manchado por dos semanas o más.

3. Se recomienda programar una visita de control una semana después de la administración de misoprostol para confirmar el éxito o no del tratamiento.

4. Se recomienda garantizar que la mujer será atendida de inmediato si presenta cualquier ugencia o tiene cualquier duda durante el periodo entre el tratamiento y la consulta de control. 
$124 \mid \begin{aligned} & \text { Capítulo } 15 \\ & \text { Avances en la atención posaborto en América Latina y el Caribe . . . }\end{aligned}$

\section{VIIAS Y DOSIS RECOMENDADAS}

La conclusión de un grupo de expertos convocados por la OMS fue que una dosis única de $600 \mu \mathrm{g}$ de misoprostol VO está indicada para el tratamiento del aborto incompleto en mujeres con tamaño uterino igual o menor al correspondiente a 12 semanas de embarazo. Esta propuesta se basa en una cuidadosa revisión de la literatura, que indica que esta dosis oral consigue completar la evacuación del útero con seguridad y eficacia.

Ese mismo grupo de expertos propuso que una alternativa posible es usar dosis únicas de $400 \mu \mathrm{g}$ por vía sublingual, aunque las evidencias hasta ahora son más débiles que las que permiten recomendar la vía oral. Además, la vía oral tiene la ventaja de una mejor aceptación que la vía vaginal, ${ }^{24}$ aunque parece que los efectos secundarios son menores cuando se usa esta última. ${ }^{25-27}$

\section{TIEMPO HASTA CONSEGUIR EL EFECTO}

Como se puede verificar en el cuadro 15-1, la tasa de éxito, definida como el vaciamiento uterino completo sin que sea necesario realizar legrado o aspiración, parece depender más del tiempo de espera para obtener el efecto que de la dosis o vía de administración.

Las tasas de éxito aumentan cuando el tiempo de espera es de entre siete y diez días, y parecen no mejorar aunque se continúe esperando por 14 o 15 días. Por tanto, se recomienda una espera de siete a diez días antes de evaluar el éxito del tratamiento médico y considerar la opción de la evacuación quirúrgica, si todavía se encontraran restos de aborto. 38,39

Los autores con mayor experiencia en el uso del misoprostol para el aborto incompleto, sugieren que la tasa de éxito aumenta cuando el equipo de salud tiene confianza y experiencia de uso con esta indicación, entiende el mecanismo de acción y orienta adecuadamente a sus pacientes. ${ }^{27}$

\section{COMPLICACIONES Y EFECTOS SECUNDARIOS}

La principal complicación, aunque poco frecuente, es la hemorragia grave durante el tratamiento. Si se selecciona bien a las mujeres que cumplen con los requisitos para optar por el tratamiento farmacológico del aborto incompleto, esta complicación es muy poco frecuente. Sin embargo, los estudios han encontrado que la pérdida total de sangre parece ser un poco mayor con el tratamiento médico que cuando se practica la evacuación inmediata del útero. ${ }^{16,18}$ En compensación, se elimina la posibilidad de lesiones traumáticas y anestésicas propias de los métodos quirúrgicos, sobre todo el legrado. El total de complicaciones parece ser menor con misoprostol que con el tratamiento quirúrgico. ${ }^{38,41}$

Una complicación rara, pero ya descrita, es la hipertermia severa con o sin escalofríos. ${ }^{43}$ Autores con experiencia han advertido sobre este riesgo cuando se usa la vía oral o sublingual en dosis excesivas o a intervalos muy cortos. ${ }^{43}$

Los efectos indeseados más comunes son náuseas, vómito y diarrea. Con menos frecuencia, el misoprostol puede provocar hipotensión, fiebre, escalofríos y temblor. En ausencia de estudios comparativos aleatorios, no es posible afirmar si la aparición de 
CUADRO 15-1.

Eficacia del misoprostol para el tratamiento del aborto incompleto, según vía de administración, dosis y tiempo de espera

\begin{tabular}{|c|c|c|c|c|c|c|}
\hline Autor & Vía & Dosis & Veces & $\begin{array}{c}\text { Tiempo de } \\
\text { observación }\end{array}$ & Éxito & $\begin{array}{l}\text { Número de } \\
\text { casos }\end{array}$ \\
\hline de Jonge $1995^{28}$ & Oral & 400 & 1 & $12 \mathrm{~h}$ & $13 \%$ & 50 \\
\hline Chung $1999^{29}$ & Oral & 400 & 4 & $24 \mathrm{~h}$ & $51 \%$ & 635 \\
\hline \multirow[t]{2}{*}{ Pang $2001^{30}$} & Oral & 800 & 2 & $24 \mathrm{~h}$ & $64 \%$ & 95 \\
\hline & Vaginal & 800 & 2 & $24 \mathrm{~h}$ & $61 \%$ & 113 \\
\hline Demetrioulis $2001^{25}$ & Vaginal & 800 & 1 & 8 a $10 h$ & $93 \%$ & 80 \\
\hline Blohm 2005 & Vaginal & 400 & 1 & 7 días & $81 \%$ & 126 \\
\hline Gronlund $2002^{32}$ & Vaginal & 400 & 1 & 8 días & $90 \%$ & 78 \\
\hline Bagratee $2004^{23}$ & Vaginal & 600 & 2 & 7 dias & $100 \%$ & 104 \\
\hline Moodliar $2005^{33}$ & Vaginal & 600 & 1 & 7 días & $91.5 \%$ & 94 \\
\hline Zhang $2005^{21}$ & Vaginal & 800 & 2 & 8 días & $84 \%$ & 491 \\
\hline Tang $2003^{34}$ & Sublingual & 600 & 1 & 7 dias & $85.7 \%$ & 80 \\
\hline Tang $2006^{27}$ & Sublingual & 600 & 3 & 7 días & $92 \%$ & 180 \\
\hline Ngoc $2005^{26}$ & Oral & 600 & 1 & 7 dias & $94.6 \%$ & 300 \\
\hline Phupong $2004^{35}$ & Oral & 600 & 1 & 7 días & $86 \%$ & 100 \\
\hline Ngoc $2004^{36}$ & Oral & 800 & 2 & 10 días & $94.6 \%$ & 300 \\
\hline \multirow[t]{2}{*}{ Blanchard $2004^{37}$} & Vaginal & 600 & 1 & 14 días & $66 \%$ & \multirow[t]{2}{*}{169} \\
\hline & Vaginal & 600 & 2 & 14 días & $70 \%$ & \\
\hline Shelley $2005^{14}$ & Vaginal & 400 & 1 & 14 días & $80 \%$ & 40 \\
\hline Ngai $2001^{19}$ & Vaginal & 400 & 3 & 15 días & $100 \%$ & 59 \\
\hline Weeks $2005^{20}$ & Oral & 600 & 1 & 14 días & $93 \%$ & 317 \\
\hline
\end{tabular}

estos síntomas ocurre con más frecuencia cuando se utiliza la vía sublingual que cuando se usa la vía oral o vaginal, como podría sugerirse a partir de los datos del cuadro 15-2. 19, 20, 23, 25, 26, 27, 34, 44

La mayoría de las mujeres que fueron asistidas con esta modalidad de tratamiento consideran los efectos secundarios como tolerables, aun en los casos en que recibieron dosis altas de misoprostol. ${ }^{26}$ La mayoría refiere también que lo elegiría nuevamente, en caso de necesitarlo, y que lo recomendaría a una amiga. ${ }^{26,34}$

\section{PRECAUCIONES}

Es importante mencionar que, hasta ahora, el uso de misoprostol para el tratamiento del aborto incompleto no está aprobado en ningún país. Las evidencias existentes son suficientes, sin embargo, para recomendar su uso en los casos apropiados. 


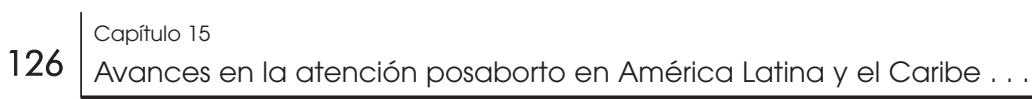

CUADRO 15-2.

Efectos secundarios del tratamiento con misoprostol del aborto incompleto, según vía de administración, dosis y tiempo de espera

\begin{tabular}{|c|c|c|c|c|c|c|c|c|}
\hline Autor & Vía & $\begin{array}{l}\text { Dosis } \\
\text { unitaria }\end{array}$ & $\begin{array}{l}\text { Dosis } \\
\text { en } 24 \mathrm{~h}\end{array}$ & $\begin{array}{c}\text { Náuseas } \\
\%\end{array}$ & $\begin{array}{c}\text { Vómito } \\
\%\end{array}$ & $\begin{array}{c}\text { Diarrea } \\
\%\end{array}$ & $\begin{array}{c}\text { Fiebre } \\
\%\end{array}$ & $\begin{array}{c}\text { Hemorragia } \\
\%\end{array}$ \\
\hline Ngai $2001^{19}$ & Vaginal & 400 & 400 & 45,5 & 23,3 & 13,3 & & 3,3 \\
\hline Bagratee $2004^{23}$ & Vaginal & 600 & 600 & 34,6 & 15,4 & 21,2 & - & - \\
\hline Demetroulis $2001^{25}$ & Vaginal & 800 & 800 & 15,0 & 7,5 & - & - & 10 \\
\hline Crenin $1997^{44}$ & Vaginal & 800 & 800 & - & 13 & 38 & & - \\
\hline Tang $2003^{34}$ & Vaginal & 600 & 1800 & 50 & 22,5 & 27,5 & 47,5 & - \\
\hline Crenin $1997^{44}$ & Oral & 400 & 400 & - & 30 & 50 & - & - \\
\hline Weeks $2005^{20}$ & Oral & 600 & 600 & - & - & 3 & 3,8 & 3,1 \\
\hline Ngoc $2005^{26}$ & Oral & 600 & 600 & 22,1 & 12,8 & 34,3 & 10,1 & - \\
\hline Ngoc $2005^{26}$ & Oral & 600 & 1200 & 13,1 & 11,7 & 46,7 & 8,3 & - \\
\hline Tang $2003^{34}$ & Sublingual & 600 & 1800 & 60 & 17,5 & 70 & 57,5 & - \\
\hline Tang $2006^{27}$ & Sublingual & 600 & 1800 & 50 & 15 & 68 & 60 & - \\
\hline
\end{tabular}

Como ante cualquier otro procedimiento médico, la elección del misoprostol para tratar el aborto incompleto requiere una asesoría adecuada, consentimiento informado y una toma de decisión basada en la elegibilidad clínica y el deseo de cada una de las pacientes tratadas.

Como parece haber mayor pérdida de sangre que cuando se realiza la evacuación inmediata, debe verificarse que la mujer no presente anemia y ofrecerse la posibilidad de esa evacuación, por AMEU o legrado, en cualquier momento que la paciente lo precise o lo solicite.

Se recomienda establecer localmente criterios para aceptar el fracaso del tratamiento dentro de un plazo prudente después de su inicio (no menor de siete días). Debe recurrirse también al tratamiento quirúrgico en cualquier momento si el tratamiento se complica con una hemorragia importante o infección, cuando se valora que la medicación no ha logrado el resultado esperado, o cuando la paciente así lo decide.

\section{SEGUIMIENTO}

Se deben respetar los parámetros clínicos que han guiado a través del tiempo el resultado de la evacuación uterina con los métodos convencionales: desaparición de la hemorragia, ausencia de signos de infección, disipación del dolor. En los lugares donde esté disponible, realizar una ecografía siete a 14 días después del inicio del tratamiento permitirá 
la comprobación fehaciente de la total evacuación del contenido uterino. Sin embargo, hay evidencia creciente que sugiere que la ecografía no es indispensable. ${ }^{45}, 46$

Pregunta: ¿Se puede usar el misoprostol en casos de feto muerto retenido y en casos de huevo anembrionado del primer trimestre?

Respuesta: La mayor parte de las publicaciones colocan juntos el aborto incompleto y el aborto retenido del primer trimestre, incluyendo "huevo anembrionado". Cuando los trabajos separan los dos grupos, la diferencia en los resultados es pequeña, así que por ahora se puede decir que lo que está en este capítulo se aplicaría también al aborto retenido del primer trimestre, sólo que la dosis recomendada es mayor. Se recomienda utilizar $800 \mu \mathrm{g}$ por vía vaginal en única dosis, con lo cual se obtiene una tasa de éxito razonable. ${ }^{21,35,48}$

\section{Referencias}

1. Organización Mundial de la Salud: (2003). Glossary of Terms. Disponible en: http://www.who.int/ reproductive-health/publications/interagency_manual_on_RH_in_refugee_situations/a3.pdf

2. Blumenthal PD: Abortion: Epidemiology, safety and technique. En: Curr Opin Obstet Gynecol 4(4), 1992:506-512.

3. Otaño L: Aborto espontáneo y muerte fetal. En: Gadow E, Fiorillo A (Eds.): Obstetricia en esquemas. Buenos Aires: El Ateneo. Primera edición, p. 206.

4. Rees H, Katzenellenbogen J, Shabodien R, Jewkes R, Fawcus S, McIntyre J, Lombard C, Truter H: The epidemiology of incomplete abortion in South Africa. National Incomplete Abortion Reference Group. En: S Afr Med J 87(4), 1997:432-437.

5. Briozzo L, Rodríguez F, León I, Vidiella G, Ferreiro G, Pons JE: Unsafe abortion in Uruguay. En: Int J Gynaecol Obstet 85(1), 2004:70-73.

6. Forna F, Gulmezoglu AM: Surgical procedures to evacuate incomplete abortion. En: Cochrane Database Syst Rev (1), 2005:CD001993.

7. Westendorp IC, Ankum WM, Mol BW, Vonk J: Prevalence of Asherman's syndrome after secondary removal of placental remnants or a repeat curettage for incomplete abortion. En: Hum Reprod 13(12), 1998:3347-3350.

8. Organización Mundial de la Salud: El aborto sin riesgos: Guía técnica y de políticas para sistemas de salud. 2003. Disponible en: http://www.who.int/reproductive-health/publications/es/ safe_abortion/text_es.pdf

9. Kay BJ, Katzenellenbogen J, Fawcus S, Abdool Karim S: An analysis of the cost of incomplete abortion to the public health sector in South Africa-1994. En: S Afr Med J 87(4); 1997:442-447.

10. Coughlin LB, Roberts D, Haddad NG, Long A: Medical management of first trimester incomplete miscarriage using misoprostol. En: J Obstet Gynaecol 24(1), 2004:67-68.

11. You J, Chung T: Expectant, medical or surgical treatment for spontaneous abortion in first trimester of pregnancy: a cost analysis. En: Hum Reprod 20(10), 2004:2873-2878.

12. Iffy L, Kaminetzky HA: Obstetricia y Perinatología. Principios y práctica. Buenos Aires: Editorial Médica Panamericana. 1985:595.

13. Ballagh SA, Harris HA, Demasio K: Is curettage needed for uncomplicated incomplete spontaneous abortion? En: Am J Obstet Gynecol 179(5), 1998:1279-1282.

14. Shelley JM, Healy D, Grover S: A randomized trial of surgical, medical and expectant management of first trimester spontaneous miscarriage. En: Aust N Z J Obstet Gynaecol 45(2), 2005:122-127. 
$128 \begin{aligned} & \text { Capítulo } 15 \\ & \text { Avances en la atención posaborto en América Latina y el Caribe . . . }\end{aligned}$

15. Griebel CP, Halvorensen J, Golemon T, Day AA: Management of spontaneous abortion. En: Am Fam Physician 72(7), 2005:1243-1249.

16. Sotiriadis A, Makrydimas G, Papatheodorou S, Ioannidis JPA: Expectant, medical, or surgical management of first trimester miscarriage: A meta-analysis. En: Obstet Gynecol 105, 2005:1104-1113.

17. Henshaw RC, Cooper K, el-Refaey H, Smith NC, Templeton AA: Medical management of miscarriage: Non-surgical uterine evacuation of incomplete and inevitable spontaneous abortion. En: BMJ 306(6882), 1993:894-895.

18. Chung TK, Cheung LP, Lau WC, Haines CJ, Chang AM: Spontaneous abortion: A medical approach to management. En: Aust N Z J Obstet Gynaecol 34(4), 1994:432-436.

19. Ngai SW, Chan YM, Tang OS, Ho PC: Vaginal misoprostol as medical treatment for first trimester spontaneous miscarriage. En: Hum Reprod 16(7), 2001:1493-1496.

20. Weeks A, Alia G, Blum J, Winikoff B, Ekwaru P, Durocher J, Mirembe F: A randomized trial of misoprostol compared with manual vacuum aspiration for incomplete abortion. En: Obstet Gynecol 106(3), 2005:540-547.

21. Zhang J, Gilles J, Barnhart K, Creinin M, Westhoff C, Frederick M: A comparison of medical management with misoprostol and surgical management for early pregnancy failure. En: N Engl J Med 353(8), 2005:761-769.

22. Trinder J, Brocklehurst P, Porter R, Read M, Vyas S, Smith L: Management of miscarriage: Expectant, medical, or surgical? Results of randomised controlled trial (miscarriage treatment (MIST) trial). En: BMJ 332 (7552), 2006:1235-1240.

23. Bagratee JS, Khullar V, Regan L, Moodley J, Kagoro H. A randomized controlled trial comparing medical and expectant management of first trimester miscarriage. En: Hum Reprod 19(2), 2004:266-271.

24. Arvidsson C, Hellborg M, Gemzell-Danielsson K:. Preference and acceptability of oral versus vaginal administration of misoprostol in medical abortion with mifepristone. En: Eur J Obstet Gynecol Reprod Biol 123(1), 2005:87-91.

25. Demetroulis C, Saridogan E, Kunde D, Naftalin AA: A prospective randomized control trial comparing medical and surgical treatment for early pregnancy failure. En: Hum Reprod 16(2), 2001:365-369.

26. Ngoc NT, Blum J, Durocher J, Quan TT, Winikoff B: A randomized controlled study comparing 600 versus $1200 \mathrm{mg}$ oral misoprostol for medical management of incomplete abortion. En: Contraception 72(6), 2005:438-442.

27. Tang O, Ong C, Yu Tse K, Ng E, Lee S, Ho PC: A randomized trial to compare the use of sublingual misoprostol with or without an additional 1 week course for the management of first trimester silent miscarriage. En: Human Reprod 21(1), 2006:189-192.

28. de Jonge ET, Makin JD, Manefeldt E, De Wet GH, Pattinson RC: Randomized clinical trial of medical evacuation and surgical curettage for incomplete miscarriage. En: BMJ 311(7006), 1995:662.

29. Chung TK, Lee DT, Cheung LP, Haines CJ, Chang AM: Spontaneous abortion: A randomized, controlled trial comparing surgical evacuation with conservative management using misoprostol. En: Fertil Steril 71(6), 1999:1054-1059.

30. Pang MW, Lee TS, Chung TK: Incomplete miscarriage: A randomized controlled trial comparing oral with vaginal misoprostol for medical evacuation. En: Hum Reprod 16(11), 2001:2283-2287.

31. Blohm F, Friden BE, Milsom I, Platz-Christensen JJ, Nielsen S: A randomised double blind trial comparing misoprostol or placebo in the management of early miscarriage. En: BJOG 112(8), 2005:1090-1095.

32. Gronlund A, Gronlund L, Clevin L, Andersen B, Palmgren N, Lidegaard O: Management of missed abortion: Comparison of medical treatment with either mifepristone + misoprostol or misoprostol alone with surgical evacuation. A multi-center trial in Copenhagen county, Denmark. En: Acta Obstet Gynecol Scand 81(11):1060-1065. 
33. Moodliar S, Bagratee JS, Moodley J: Medical vs. surgical evacuation of first-trimester spontaneous abortion. En: Int J Gynaecol Obstet 91(1), 2005:21-26.

34. Tang OS, Lau WNT, Ng EH, Lee SW, Ho PC: A prospective randomized study to compare the use of repeated doses of vaginal and sublingual misoprostol in the management of first trimester silent miscarriages. En: Hum Reprod 18(1), 2004:176-181.

35. Phupong V, Taneepanichskul S, Kriengsinyot R, Sriyirojana N, Blanchard K, Winikoff B: Comparative study between single dose 600 microg and repeated dose of oral misoprostol for treatment of incomplete abortion. En: Contraception 70(4), :307-311.

36. Ngoc NT, Blum J, Westheimer E, Quan TT, Winikoff B: Medical treatment of missed abortion using misoprostol. En: Int J Gynaecol Obstet 87(2), 2004:138-142.

37. Blanchard K, Tancepanichskul S, Kiriwat O, Sirimai K, Svirirojana N, Mavimbela N, Winikoff B: Two regimens of misoprostol for treatment of incomplete abortion. En: Obstet Gynecol 103(5), 2004:860-865.

38. Declaración de Consenso: instrucciones para empleo - Misoprostol para el tratamiento de abortos incompletos y espontáneos. Reunión de expertos sobre misoprostol apoyada por Reproductive Health Technologies Project y Gynuity Health Projects. Junio 9, 2004. Nueva York, NY. Disponible en: http://www.gynuity.org/documents/ifu_txincom_sp.pdf

39. Ipas: Tratamiento con misoprostol en el primer trimestre para el huevo muerto y retenido o aborto diferido. Notas para la práctica clínica. 2004. Disponible en: http://www.ipas.org/ publications/es/Medical_Abortion/miso_first_tri_missed_es.pdf

40. Graziosi GC, Mol BW, Ankum WM, Bruinse HW: Management of early pregnancy loss. En: Int J Gynaecol Obstet 86(3), 2004:337-346.

41. Stubblefield PG, Carr-Ellis S, Borgatta L: Methods for induced abortion. En: Obstet Gynecol 104(1):174-185.

42. Chong YS, Chua S, Arulkumaran S: Severe hyperthermia following oral misoprostol in the immediate postpartum period. En: Obstet Gynecol 90(4), 1997:703-704.

43. Chong YS, Chua S, Arulkumaran S: Sublingual misoprostol for first trimester termination of pregnancy: Safety concerns. En: Hum Reprod 17(10), 2002:2777.

44. Creinin MD, Moyer R, Guido R: Misoprostol for medical evacuation of early pregnancy failure. En: Obstet Gynecol 89(5), 1997:768-772.

45. Fielding SL, Schaff EA, Nam N: Clinicians' perception of sonogram indication for mifepristone abortion up to 63 days. En: Contraception 66(1), 2002:27-31.

46. Markovitch O, Tepper R, Klein Z, Fishman A, Aviram R: Sonographic appearance of the uterine cavity following administration of mifepristone and misoprostol for termination of pregnancy. En: J Clin Ultrasound 34(6), 2006:278-282.

47. Neilson JP, Hickey M, Vazquez J: Medical treatment for early fetal death (less than 24 weeks). En: Cochrane Database Syst Rev (3), 2006:CD002253. 

Sección

Hombres, juventud

y comunidad

V 



\section{Participación de la pareja masculina en el proceso de atención posabortoa}

\section{Deborah L. Billings ${ }^{b}$ y Eliana del Pozo ${ }^{c}$}

Las mujeres que buscan servicios de atención por complicaciones del aborto en los hospitales públicos de Bolivia, acuden a veces acompañadas por sus parejas masculinas. ${ }^{\mathrm{d}}$ Reconociendo la importancia del papel que la pareja puede jugar en la salud de la mujer, este texto explora las posibilidades de incorporarla en un proceso de información, asesoría y orientación sobre el estado de salud de la mujer, sus necesidades durante el proceso de recuperación y el uso de métodos anticonceptivos. Se presentan resultados de entrevistas realizadas con parejas de mujeres internadas en hospitales públicos por complicaciones derivadas de un aborto, para poder entender mejor su realidad y desarrollar estrategias que respondan a las necesidades expresadas por ambos. ${ }^{\mathrm{e}}$

Pocos programas de atención posaborto (APA) en el mundo han tratado de incorporar a las parejas y evaluar el impacto de la estrategia. Uno de los ejemplos más importantes es el de Egipto, en donde se dio información, consejería y orientación sobre la salud de la mujer y los métodos anticonceptivos a los hombres después de que sus parejas autorizaran esta actividad. Los resultados mostraron un impacto positivo en la recuperación de la mujer, en términos emocionales y físicos, y en el uso o intención de utilizar un método anticonceptivo después de su salida del hospital., 3

a Publicado en APA en Acción, Boletín Núm. 2, diciembre de 2000. Reproducido con autorización.

b Ipas México, A.C. México, D.F.

${ }^{\mathrm{c}}$ Ipas Bolivia. La Paz, Bolivia.

d El término "pareja masculina" se emplea aquí para referirse al esposo, novio, compañero habitual o pareja sexual. ${ }^{1}$

${ }^{\text {e }}$ Las entrevistas se realizaron como parte de una investigación más amplia sobre la APA en Bolivia: Testing a Model for the Delivery of Emergency Obstetric Care and Family Planning Services in the Bolivian Public Health System disponible en: http://www.popcouncil.org/pdfs/frontiers/FR_FinalReports/Bolivia_Ipas_PAC.pdf 
$134 \mid \begin{aligned} & \text { Capítulo } 16 \\ & \text { Avances en la atención posaborto en América Latina y el Caribe . . . }\end{aligned}$

\section{LA MUESTRA}

Entre noviembre de 1999 y febrero de 2000, y entre septiembre y diciembre de 2000, 394 mujeres y 156 de sus parejas fueron entrevistadas antes de su egreso del Hospital "Jaime Sánchez Porcel", en la ciudad de Sucre. Antes de realizar la entrevista con los hombres y después de informar a la paciente sobre su razón y contenidos, las investigadoras obtuvieron el consentimiento informado de la paciente. Enseguida, obtuvieron el consentimiento informado de la pareja masculina; ninguna se negó a ser entrevistada, con lo que se aseguró que la pareja no obtuviera información sobre el estado de salud de la mujer sin el acuerdo explícito de ella.

De las mujeres, 49\% no iba acompañada por su pareja, y 19\% de las que acudieron acompañadas negaron su consentimiento para que él fuera entrevistado, expresando razones como: temor a ser acusada de provocarse el aborto; miedo a una reacción violenta de la pareja; haberse embarazado de otro hombre o como producto de una violación; la relación ya había terminado; posible abandono de su pareja (especialmente las más jóvenes); vergüenza de haber estado embarazada y sufrido un aborto, y no desear que su pareja se enterara. De las mujeres que consintieron en la entrevista con su pareja, $51 \%$ era casada, 34\% vivía en unión libre y 15\% era soltera.

\section{RESULTADOS}

El análisis de las secciones siguientes se basa en la muestra de 156 parejas masculinas y sus parejas femeninas atendidas por complicaciones derivadas de un aborto. Los resultados muestran que pocas mujeres y sus parejas reciben información sobre el estado de salud de la mujer y sobre los métodos anticonceptivos que podrían utilizar.

\section{INFORMACIÓN RECIBIDA SOBRE EL ESTADO DE SALUD DE LA MUJER}

De las 156 mujeres atendidas por complicaciones de aborto y cuyas parejas fueron entrevistadas, a 85\% el médico que las revisó a su llegada al hospital les explicó en qué consistía su problema de salud. En cambio, sólo 29\% de las mujeres recibió información sobre su estado de salud después del procedimiento de evacuación uterina. En general, $38 \%$ de las parejas masculinas recibieron información sobre la condición de la salud de la mujer, la mayoría (97\%) acerca del procedimiento. De los 96 hombres que no recibieron ninguna información, $60 \%$ expresó que le habría gustado recibirla, en especial sobre el procedimiento, los cuidados que la mujer requeriría al regresar a la casa, las posibles causas del problema de salud, cómo evitar el mismo problema en el futuro y sobre métodos anticonceptivos.

De la muestra masculina, $80 \%$ se quedó con preguntas por hacer; las más comunes fueron sobre la salud de la mujer después de su atención, la causa del problema, el "raspaje" o procedimiento en sí y sus consecuencias, y si ella podía volver a embarazarse. 


\section{MÉTODOS ANTICONCEPTIVOS}

Según los hombres, 24\% de ellos y/o las mujeres usaban un método al momento de ocurrir el embarazo; en la mayor parte de los casos (58\%) se trataba del método del ritmo o calendario.

Tres de las 156 mujeres atendidas por complicaciones del aborto recibieron un método anticonceptivo antes de su salida del hospital; 80\% expresó no haber recibido ninguna explicación sobre los métodos disponibles, y sólo 12\% fue cuestionada si deseaba un método; en contraste, a 79\% le habría gustado recibir alguno.

En cuanto a los hombres, sólo cinco de los 156 entrevistados recibieron información sobre métodos anticonceptivos durante la estancia de su pareja en el hospital; 99\% expresó que le hubiera gustado recibir tal información para saber cómo planificar o conocer mejor los métodos. Casi todos (99\%) expresaron que les hubiera gustado recibir la información junto con la mujer; $56 \%$ mencionó que él o su pareja utilizaría un método anticonceptivo tras salir del hospital; sin embargo, 38\% respondió que no sabía cuál (40\% prefería el dispositivo intrauterino o DIU).

\section{APOYO A LAS MUJERES EN CASA}

Al final de la entrevista, se preguntó a las parejas masculinas qué tipo de apoyo brindarían a las mujeres cuando volvieran a casa. Todos los hombres mencionaron que tomarían una acción cuando menos, entre ellas: colaborar en las labores de la casa; asegurarse de que ella no hiciera mucho esfuerzo o que estuviera en reposo; apoyarla en todo; ver que se alimentara bien; darle apoyo espiritual y psicológico; preocuparse por su salud; darle apoyo económico, y ayudarla a cuidar a los niños. Todos estos apoyos podrían dirigirse mejor a atender las necesidades de la mujer si el hombre recibiera información adecuada sobre su condición de salud.

\section{CONCLUSIONES}

Los resultados presentados no son representativos sólo de los hombres entrevistados en el Hospital "Jaime Sánchez Porcel” de Sucre, sino de la situación de los hospitales públicos en Bolivia. Demuestran que las mujeres y sus parejas quieren y precisan información sobre el estado de salud de ella y sobre los métodos anticonceptivos que pueden utilizar después del egreso hospitalario.

Dar información, consejería y orientación a las mujeres atendidas por hemorragias de la primera mitad del embarazo es un elemento clave del modelo de atención integral posaborto. Los resultados de este estudio demuestran que es importante también incorporar a las parejas masculinas en tales procesos, aplicando siempre los aspectos éticos pertinentes, especialmente conseguir el consentimiento de la mujer antes de involucrar a su pareja y no sustituir la orientación y consejería directamente a la mujer con la orientación y consejería a la pareja masculina. 
$136 \mid \begin{aligned} & \text { Capítulo } 16 \\ & \text { Avances en la atención posaborto en América Latina y el Caribe . . . }\end{aligned}$

\section{Referencias}

1. Abdel-Tawab N, Huntington D, Hassan EO, Youseff H, Nawar L: Effects of husband involvement on postabortion patients' recovery and use of contraception in Egypt. En: Huntington D, Piet-Pelon NJ (eds.): Postabortion Care: Lessons from Operations Research. Nueva York: Population Council. 1999:16-37.

2. Wegner N, Landry E, Wilkinson D, Tzanis J: Men as partners in reproductive health: From issues to action. Int Fam Plan Perspec 24(1), 1998:38-42.

3. Schehl M, Green C: Men as Partners initiative: Summary report of literature review and case studies. Nueva York: AVSC International, 1997. 


\section{Guía técnica sobre APA amigable a la juventuda, b}

\section{7}

Consorcio Atención Postaborto

Este documento presenta las recomendaciones que el grupo de trabajo sobre juventud del Consorcio Atención Postaborto ${ }^{\mathrm{C}}$ (APA) hizo para que los servicios de APA sean más agradable para los jóvenes. Ofrece también indicadores para que los gerentes y el personal de los programas puedan vigilar y evaluar el grado en que sus programas satisfacen las diversas necesidades de la juventud.

\section{¿POR QUÉ ENFOCARNOS EN LOS ADOLESCENTES DENTRO DE LOS PROGRAMAS DE APA?}

La adolescencia es definida por la Organización Mundial de la Salud (OMS) como la etapa del desarrollo que ocurre entre los diez y 19 años. Aunque las prácticas difieren según la región y la cultura, el número de jóvenes que tienen
Distintas clases de adolescentes

Los adolescentes no son un grupo homogéneo; abarca a mujeres y varones que:

- Transitan por diferentes etapas de desarrollo físico y psicosocial.

- Estudian o no

- Están casados o solteros.

- Son seropositivos, seronegativos o desconocen su condición respecto al VIH

- Pertenecen a minorías étnicas.

- Tienen orientaciones sexuales diferentes (heterosexuales, homosexuales y bisexuales).

- Pueden ser trabajadores del sexo comercial o vivir en la calle.

- Son pobres o ricos.

- Pueden ser huérfanos o jóvenes vulnerables.

\footnotetext{
a Reproducido y adaptado con autorización del Consorcio de Atención Postaborto. Traducción de Guillermina Herrera.

b Los adolescentes son el grupo de edad entre 10 y 19 años, mientras que el término "juventud" se refiere a quienes tienen entre 15 y 24 años; la "gente joven" abarca tanto a la juventud como a los adolescentes. En este documento, se usarán indistintamente los términos "juventud", "gente joven" y "adolescentes".

c Las organizaciones que participaron en el Grupo de Trabajo sobre APA Amigable a la Juventud del Consorcio APA fueron Pathfinder International, Ipas, Family Health International, el Consorcio CATALYST, IPPF y JHPIEGO.
} 
relaciones sexuales premaritales es cada vez mayor. Este hecho se vincula con la tendencia, tanto masculina como femenina, a contraer matrimonio a una edad mayor, lo que resulta en un tiempo más prolongado para que la actividad sexual y el embarazo puedan ocurrir fuera del matrimonio. Estas tendencias seguramente continuarán en la medida en que los cambios sociales que influyen sobre esos comportamientos avanzan de manera creciente en todo el mundo. Tales cambios incluyen el acceso a los medios de comunicación masiva y a nuevas ideas, urbanización, migración, cambios en los canales de comunicación tradicionales mediante los cuales los adultos solían transmitir información y guía a los jóvenes, mejores oportunidades de educación para niñas y mujeres, y oportunidades de los hombres y mujeres para interactuar social y profesionalmente. ${ }^{1}$

Las jóvenes son, a menudo, más vulnerables al embarazo no deseado y al aborto inseguro dado su desarrollo psicosocial, las inequidades de poder frente a los adultos, su pobreza, el abuso sexual y la coerción, y también en razón de los valores tradicionales y culturales que impiden o limitan su acceso a la información y los servicios de salud sexual y reproductiva (SSR). Entre la población joven más pobre, menos de $5 \%$ usa métodos anticonceptivos modernos, mientras que una tercera parte de las mujeres de los países en desarrollo tiene hijos antes de cumplir 20 años 2,3.

En virtud de la sensibilidad que rodea al aborto, es difícil determinar su incidencia. Se estima, sin embargo, que 4.5 millones de adolescentes buscan cada año un aborto. ${ }^{4-7} \mathrm{De}$ ese número, $40 \%$ se realiza en condiciones de riesgo, mientras $95 \%$ de todos los abortos inseguros ocurren en países en desarrollo, en donde está legalmente restringido o es muy inaccesible. ${ }^{8}$ Un análisis de datos sobre aborto inseguro por edad señala que el patrón de edad difiere marcadamente de una región a otra. En Africa, por ejemplo, la proporción de mujeres de 15 a 19 años que han experimentado un aborto inseguro es mayor que en cualquier otra región del mundo, y casi $60 \%$ de los abortos inseguros los experimentan mujeres menores de 25 años. Lo anterior contrasta con Asia, América Latina y el Caribe, donde, respectivamente, 30 y $42 \%$ de los abortos inseguros ocurren entre mujeres menores de 25 años. ${ }^{9}$

Las mujeres jóvenes son más proclives que las mayores a retrasar la búsqueda de un aborto, y como suelen recurrir a proveedores más baratos e inseguros, su riesgo de sufrir complicaciones se incrementa; de igual modo, suelen retrasar la búsqueda de atención a las complicaciones derivadas de un aborto una vez que ello sucede. De lo anterior resulta que, al compararse con otros grupos, el de las adolescentes tiene mayores probabilidades de sufrir complicaciones severas derivadas de abortos inseguros. Además, las tasas más altas de abortos espontáneos ocurren entre adolescentes muy jóvenes.

\section{BARRERAS EN LOS SERVICIOS Y DEFINICIÓN DE LOS SERVICIOS AMIGABLES A LA JUVENTUD}

Las adolescentes están menos dispuestas y tienen menor capacidad para buscar servicios de planificación familiar a fin de prevenir embarazos no deseados y abortos inseguros, al igual que servicios de APA en casos de abortos inseguros, debido a las razones siguientes:

- Las leyes y políticas nacionales restringen el acceso a los servicios con base en la edad o el estado civil.

- Los horarios de funcionamiento no son convenientes. 
- El transporte es escaso.

- Los servicios tienen un costo elevado.

- La comprensión que tienen de su cuerpo y de la concepción es escasa.

- El conocimiento de los servicios disponibles y su ubicación es limitado.

- La creencia de que los servicios no están destinados para ellas.

- La preocupación de que el personal será hostil o crítico, y que los servicios carecen de privacidad y confidencialidad;

- El temor a los procedimientos médicos y a los métodos anticonceptivos, incluyendo los efectos secundarios.

- La turbación por necesitar o desear los servicios.

- El temor de que sus padres puedan enterarse de su visita.

- La vergüenza, especialmente si la visita ocurre a raíz de un abuso o coerción sexual.

Para abordar estas barreras en la atención a las adolescentes, el Consorcio APA busca mejorar la calidad de los servicios de APA a fin de que satisfagan mejor las necesidades únicas de las adolescentes y, al mismo tiempo, que su acceso a estos servicios se incremente. El "acceso" se refiere a servicios integrales asequibles que se ubiquen en sitios de fácil acceso para las adolescentes; que el lenguaje que se use para atender a las jóvenes sea comprensible y significativo para ellas, y que existan políticas para eliminar las barreras en los servicios que se les presten.

El concepto de "servicios amigables para la juventud" aborda aspectos de calidad e igualmente de acceso. Y aunque existen variaciones en cuanto a la definición de servicios amigables para la juventud, en términos generales se trata de servicios atractivos que satisfacen de forma adecuada y cómoda las necesidades de salud de las y los adolescentes y que logran retenerlos. Los servicios de APA amigables para la juventud tienen las siguientes características:

- Ofrecen privacidad y confidencialidad.

- Tienen a proveedores de la salud especialmente capacitados que suministran los servicios sin mostrarse críticos, y que al comunicarse con las jóvenes en temas sensibles se sienten cómodos.

- Son asequibles o gratuitos para las adolescentes.

\section{ELEMENTOS ESENCIALES DE LA APA}

La definición que el Consorcio APA hace de los servicios de APA integrales consta de cinco elementos de atención:

- Alianzas entre la comunidad y los proveedores de servicios para prevenir embarazos no deseados y abortos inseguros, movilizar recursos (para ayudar a que las mujeres reciban atención apropiada y oportuna a complicaciones derivadas de abortos), y asegurar que los servicios de salud reflejen y satisfagan las expectativas y necesidades comunitarias.

- Asesoría para identificar y responder a las necesidades emocionales y de salud física de las mujeres, pero también a otras preocupaciones.

- Tratamiento del aborto incompleto e inseguro y de las complicaciones que potencialmente amenazan la vida. 
$140 \begin{aligned} & \text { Capítulo } 17 \\ & \text { Avances en la atención posaborto en América Latina y el Caribe . . . }\end{aligned}$

- Servicios anticonceptivos y de planificación familiar para ayudar a las mujeres a prevenir embarazos no deseados o a practicar el espaciamiento entre nacimientos.

- Salud reproductiva y otros servicios de salud que, de preferencia, se suministran en el sitio o mediante referencias a otras instalaciones accesibles que forman parte de las redes de los proveedores.

Las necesidades específicas de las adolescentes y las acciones recomendadas en su relación con cada uno de los elementos esenciales, se exploran más profundamente a continuación.

\section{ALIANZAS ENTRE LA COMUNIDAD Y LOS PROVEEDORES DE SERVICIOS}

Las alianzas entre los miembros de la comunidad (jóvenes, padres, lideres comunitarios y religiosos, hombres y mujeres) y los proveedores de servicios (adultos y jóvenes trabajadores de la salud laicos, curanderos tradicionales y proveedores de servicios formalmente capacitados), pueden jugar un papel vital para prevenir embarazos no deseados y abortos inseguros e incrementar el acceso de los jóvenes a servicios de APA sostenibles y de alta calidad. Estas alianzas pueden facilitar el diálogo comunitario sobre temas sensibles (como la actividad sexual de los adolescentes y el embarazo no deseado), y crear un ambiente propicio para apoyar la información y servicios de SSR para los jóvenes. Este tipo de alianzas ofrece también una oportunidad para que la comunidad contribuya a organizar mejor y a elevar la calidad de los servicios de APA para las adolescentes. Al ubicar a la APA en un contexto más amplio, como el de la maternidad sin riesgos o el de la SSR de los adolescentes, se puede fomentar una mayor participación comunitaria.

Aunque la participación comunitaria es un ingrediente necesario para los servicios integrales y sostenibles de APA, en algunos casos puede entorpecer la prestación de tales servicios, especialmente en las comunidades donde sus miembros y los lideres influyentes tienen perspectivas muy conservadoras sobre la sexualidad de los adolescentes, el embarazo fuera del matrimonio y el aborto; por esto, es importante que los gerentes de programas y los proveedores de servicios tengan una visión realista de hasta qué punto pueden involucrar a la comunidad; en ocasiones podría ser preferible trabajar con grupos dispuestos de mujeres o con parteras tradicionales. En el trabajo comunitario es importante tomar pasos que incrementen y desarrollen alianzas sólidas.

La creación de alianzas entre grupos de interés requiere de una variedad de estrategias innovadoras donde las jóvenes deben jugar un papel activo y progresivo. Es posible que, inicialmente, los programas tengan que trabajar con adolescentes para ayudarles a construir habilidades a fin de que puedan participar como iguales. Además, pudiera ser necesario sensibilizar a los socios adultos para que respeten y alienten la participación y perspectivas de las jóvenes. Las estrategias para crear alianzas entre la comunidad y los proveedores incluyen:

- Realizar reuniones comunitarias e integrar grupos de discusión con la participación de una variedad de grupos de interés, incluyendo diferentes cohortes de jóvenes. Facilitar hábilmente estas reuniones es esencial para asegurar que ningún grupo o perspectiva prevalezca en la discusión. En algunos contextos culturales, puede llegar a ser necesario trabajar en forma separada con hombres y mujeres. 
El propósito de tales actividades debería ser desarrollar estrategias para el cambio positivo, que incluyan maneras para apoyar a las jóvenes que experimentan un embarazo no deseado y un aborto en condiciones de riesgo y que requieren servicios de APA.

- Desarrollar espacios en donde grupos de interés que comparten perspectivas se reúnan para diseñar propuestas a fin de mejorar la información y los servicios disponibles para los jóvenes. Las propuestas desarrolladas por la juventud son especialmente importantes para fomentar el cambio.

- Llevar a cabo talleres informativos y para la construcción de habilidades que ayuden a las personas a comprender los temas del embarazo, aborto y atención posaborto, y que ofrezcan oportunidades para construir alianzas entre los jóvenes y los adultos para permitir el abordaje de estos temas de una manera no crítica.

- Conducir campañas de comunicación que atraigan los talentos de los jóvenes y que contribuyan a divulgar mensajes en toda la comunidad sobre temas de sexualidad y salud reproductiva, vinculándolos con experiencias relevantes para la juventud, incluyendo la pobreza, inequidad, el acceso desigual al poder y la toma de decisiones y la violencia de género.

- Capitalizar sobre los programas para jóvenes y las intervenciones que ya existen para fortalecer los vínculos entre la comunidad y los proveedores. Las intervenciones comunitarias - del tipo de la educación de pares-, tienen un gran potencial para ayudar a prevenir embarazos no deseados y abortos en condiciones de riesgo al brindar información sobre la SSR y los métodos anticonceptivos no clínicos. Del mismo modo, pueden referir a las jóvenes que requieren servicios de APA.

Las alianzas que propicien la participación juvenil en todas las etapas de la prestación de servicios, incluyendo la formación, comunicación, implementación y vigilancia, pueden resultar en estrategias innovadoras para satisfacer sus necesidades de servicios.

En las siguientes secciones se perfilan los componentes básicos y específicos para la juventud que deberían incluirse en los otros cuatro elementos de la APA, aunque algunos de los componentes aplican a toda la visita de APA; éstos se describen abajo.

\section{ASISTENCIA A LOS SERVICIOS DE APA}

Es importante revisar las normas sanitarias, lineamientos y leyes para aclarar si se requiere el consentimiento de los padres o la pareja, o la notificación, antes de brindar los servicios de APA. Si no existen requisitos legales, se deberá preguntar a la adolescente a quién desea involucrar en su atención (su pareja, un amigo, sus padres). El proveedor debe entonces incluirlos de tal modo que representen un apoyo para la paciente adolescente durante el procedimiento y en el proceso de recuperación.

Con todas las pacientes, pero particularmente con las adolescentes (que enfrentan el estigma adicional de su edad y de no estar casadas en muchos casos), debe enfatizarse la privacidad y confidencialidad de la atención. Cuando sea posible, la disponibilidad de una sala de espera separada para las pacientes jóvenes puede ofrecerles un sentido de privacidad y aliviar sus temores de ser vistas por adultos de la comunidad.

Una barrera común en la búsqueda de servicios de APA es el temor a las actitudes negativas de los proveedores de servicios. De ahí que éstos deban ser sensibilizados, mediante capacitación y supervisión, en el sentido de que todas las pacientes en APA 
$142 \begin{aligned} & \text { Capítulo } 17 \\ & \text { Avances en la atención posaborto en América Latina y el Caribe . . . }\end{aligned}$

merecen y tienen derecho al mismo trato y estándar de atención, sin importar que su aborto sea inducido o espontáneo. Del mismo modo, los proveedores deben estar conscientes de que la violencia o la coerción sexual, comunes entre las adolescentes, puede ser la causa de un embarazo no deseado y de un aborto subsiguiente.

Al brindar los servicios, las clínicas y los proveedores deben ser extremadamente sensibles al tiempo de estancia de las adolescentes en la unidad. A menudo, las jóvenes son supervisadas por sus padres o sus escuelas, y es posible que no puedan alejarse mucho tiempo sin dar una explicación, lo cual puede representar una barrera para la búsqueda de los servicios. Si las adolescentes están conscientes de que recibirán servicios de APA discretos y oportunos, las probabilidades de que busquen tales servicios se incrementan.

\section{CONSEJERÍA}

Para algunas adolescentes, la asistencia a los servicios de APA puede representar su primer contacto con un centro de salud para solicitar servicios de salud reproductiva. Puede ocurrir que muchas de las jóvenes no tengan conocimientos adecuados sobre la anticoncepción o acerca de la prevención de embarazos no deseados a futuro, y pudieran tener preguntas sobre otros temas de salud reproductiva. El proveedor debe aprovechar al máximo la visita para identificar las necesidades de SSR de la paciente y ofrecer información sobre: a) qué esperar durante el tratamiento o los procedimientos, b) cualquier medicamento o droga, c) complicaciones y cuándo regresar al centro de salud, d) anticoncepción, e) prevención de infecciones de transmisión sexual, incluyendo el $\mathrm{VIH}$, (f) toma de decisiones sobre SSR y (g) negociación del condón.

$\mathrm{Al}$ proporcionar consejería a pacientes adolescentes, es importante recordar que:

- La asesoría debe adecuarse a las necesidades y características especiales de cada joven, considerando que "los adolescentes/la juventud" no son un grupo homogéneo. Las diferencias en cuanto a edad, etapa del desarrollo, nivel de educación/ alfabetización y estado civil, afectan el contenido de la sesión de consejería, incluyendo el tipo de información que debe brindarse y cómo comunicarla de manera efectiva.

- Las adolescentes pueden sentirse más temerosas y es menos probable que sus familiares o pareja las apoyen, en comparación con otras pacientes en APA.

- Las personas jóvenes suelen estar menos informadas y confían en lo que sus parejas les transmiten; esta información puede ser inexacta, de donde pudiera ser necesario abordar mitos y rumores.

- Las adolescentes pudieran evitar mencionar su problema o preocupación real al comenzar la sesión de consejería. Los proveedores de servicios deben procurar mayor tiempo para brindar consejería a las adolescentes y tenerles paciencia.

- Puede ser un medio importante para el manejo del dolor ofrecer apoyo verbal y explicar qué está ocurriendo conforme el procedimiento se realiza, cuando las mujeres están conscientes en el transcurso de dicho procedimiento.

- Se puede ofrecer apoyo adicional a través de la consejería de parejas o de programas laicos de consejería. Véase después la sección "Referencia a otros servicios de salud reproductiva". 
Durante la consejería, el proveedor de servicios debe:

- Brindar información clara y sencilla sobre qué esperar durante el examen físico, el tratamiento y cualquier otro procedimiento. Describir a la adolescente el dolor y/o la incomodidad que pudiera llegar a sentir durante la evacuación uterina y ofrecerle opciones para el manejo del dolor, incluyendo el apoyo que puede significar la compañía de una amiga o del compañero, si la paciente lo desea.

- Animar a la adolescente a expresar sus sentimientos en relación con la pérdida de su embarazo. Ayudar a que la joven aclare lo que siente en relación con el embarazo actual y el aborto incompleto. Comentar con ella cuándo puede volver a quedar embarazada y sus planes para embarazarse.

- Revisar en la paciente la posible existencia de abuso sexual y violencia de género (VG). En caso de que el proveedor tenga que reportar a la autoridad legal los casos de abuso sexual o violencia de género, comentar con la adolescente cómo se manejará este hecho. Los proveedores deben estar capacitados sobre este particular, y debe estar vigente un protocolo para revisarla. Se debe asegurar que los proveedores analizarán el tema de manera confidencial y empática, y sabrán responder adecuadamente cuando se revele la violencia de género.

- Revisar la posible presencia de las ETS/VIH y ayudar a la paciente a evaluar su riesgo de contraer infecciones. Debe subrayarse la protección dual para prevenir embarazos no deseados y ETS/VIH.

- Ofrecer instrucciones claras en relación con el seguimiento de la atención, que incluye cualquier tipo de medicamento que sea necesario, y explicar las señales de peligro que requerirían reingresar a la clínica. Dar a la paciente el nombre de una persona —el médico que la atiende o la enfermera que está a cargo_ a quien pudiera dirigirse en caso de que necesitara volver a la clínica.

\section{TRATAMIENTO DE LAS COMPLICACIONES}

Aunque el tratamiento de las complicaciones derivadas de un aborto es similar para las mujeres adultas y para las adolescentes, existen aspectos adicionales que deben considerarse en el tratamiento de las jóvenes.

- Para ellas, los aspectos técnicos incluyen el uso de un espéculo más pequeño durante el examen y el procedimiento, junto con misoprostol para facilitar la dilatación y madurez cervical.

- Dada la importancia del tiempo para estas pacientes, no se les debería requerir que permanecieran en la unidad 24 horas después del procedimiento, como otras pacientes de APA. Para facilitar el egreso oportuno, es preferible considerar una aspiración manual endouterina (AMEU) como paciente ambulatoria, o una aspiración eléctrica cuando tal cosa sea clínicamente posible.

- A menudo, las adolescentes esperan más tiempo antes de buscar un aborto inseguro; este hecho tiene implicaciones sobre la gravedad de las complicaciones y puede influir en el tipo de proveedor capaz de suministrar el tratamiento y en el tipo de tecnología a ser usada (p. ej., AMEU, aspiración eléctrica, dilatación y legrado y legrado uterino instrumental (LUI) y/o misoprostol).

- Además del beneficio de la AMEU o de la aspiración eléctrica, en términos del tiempo de estancia, la OMS recomienda, en el caso de las adolescentes, preferir 
$144 \begin{aligned} & \text { Capítulo } 17 \\ & \text { Avances en la atención posaborto en América Latina y el Caribe . . . }\end{aligned}$

la AMEU o la aspiración eléctrica sobre el LUI, en virtud de que las complicaciones severas son menos probables.

- Los procedimientos clínicos de la AMEU, la aspiración eléctrica, el LUI o el misoprostol, son los mismos para una paciente que para una adulta. Sin embargo, no saber qué esperar, junto con el limitado apoyo emocional de la familia, pueden llevar a una ansiedad mayor y también a mayor dolor. El apoyo que se brinde a la paciente joven durante el procedimiento y atención para el manejo del dolor puede mejorar su experiencia con la APA.

- Durante el tratamiento, los proveedores deben tomar nota de cualquier otro problema de salud reproductiva (p. ej., ETS) que se detecte y asegurarse de que la paciente reciba atención adecuada o sea referida.

\section{ANTICONCEPCIÓN POSABORTO Y SERVICIOS DE PLANIFICACIÓN FAMILIAR}

Como se comentó antes, la APA puede ser la primera ocasión en que una adolescente acceda a servicios de salud reproductiva; por ello, es imperativo que reciba consejería y servicios de anticoncepción posaborto. Considerando que las jóvenes suelen no regresar a la clínica para atención de seguimiento, es importante que existan métodos anticonceptivos (por lo menos condones) para las adolescentes antes de su egreso.

Durante la prestación de servicios anticonceptivos posaborto, el proveedor de servicios debe:

- Aclarar desde un principio las intenciones reproductivas de la cliente; enfatizar la necesidad de esperar seis meses antes de embarazarse de nuevo, ${ }^{12}$ y evaluar y analizar si la disposición física y emocional es adecuada para embarazarse una vez más (p. ej., si tiene anemia severa o está deprimida).

- Recordar que la edad no es una contraindicación para usar cualquier método anticonceptivo; de ahí que a las adolescentes se les deban ofrecer diversos. Con todo, el DIU no es recomendable si la paciente presenta una infección; en cuanto a la esterilización, normalmente no es apropiada a esa edad.

- Analizar la protección dual contra un embarazo no deseado y las ETS/VIH de forma integral. Demostrar el uso apropiado del condón (femenino y también el masculino), y solicitar a la paciente que repita la demostración.

- Ayudar a que la paciente aprenda a pedir el uso del condón a su pareja. A menudo, las jóvenes carecen de las habilidades de comunicación y de la experiencia requeridas para tratar este tema con su pareja.

- Recordar que las jóvenes pueden necesitar ayuda e información adicionales para usar el método que elijan (p. ej., vincular su actividad diaria con la ingesta del anticonceptivo), y que pueden tener preocupaciones distintas a las de las pacientes adultas (p. ej., recuperar peso o padecer acné). Además, es posible que las jóvenes no dispongan de lugares seguros para guardar el método (p. ej., la caja o paquete de pastillas), de modo que algunos métodos, como los inyectables, pudieran ser más aceptables para ellas.

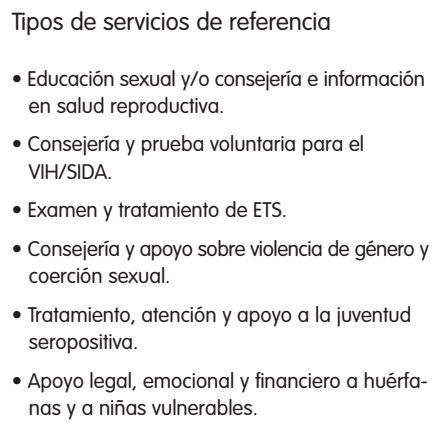

Tipos de servicios de referencia

- Educación sexual y/o consejería e información en salud reproductiva.

- Consejería y prueba voluntaria para el $\mathrm{VIH} / \mathrm{SIDA}$.

- Examen y tratamiento de ETS.

- Consejería y apoyo sobre violencia de género y coerción sexual.

- Tratamiento, atención y apoyo a la juventud seropositiva.

- Apoyo legal, emocional y financiero a huérfanas y a niñas vulnerables. 
- Acudir a lugares donde se proporcione ayuda visual y material de información, educación y comunicación dirigido a la juventud para reforzar los mensajes de planificación familiar.

- Dar información sobre el uso de las pastillas anticonceptivas de emergencia (PAE) en caso de falla de otro método anticonceptivo o por no haber usado uno. Si se requiere una receta para obtener las PAE, suministrarla para que la paciente tenga el método a la mano si llega a tener actividad sexual no protegida.

- Involucrar al compañero varón en la consejería anticonceptiva, si ello es posible y la paciente lo desea.

\section{REFERENCIA A OTROS SERVICIOS DE SALUD REPRODUCTIVA}

Se debe brindar la mayor cantidad posible de servicios, tanto de salud reproductiva como otros de salud en la clínica en que se prestó el servicio de APA, pues las adolescentes a menudo no regresan a citas posteriores en la clínica o no acuden a la unidad a la que se les refiere. Sin embargo, si la referencia es absolutamente necesaria, se deben considerar los siguientes puntos:

- Cuando sea posible, referir a la adolescente a las clínicas que ofrezcan servicios a la juventud, o a instalaciones que sean receptivas a las pacientes adolescentes.

- Los proveedores deben destinar tiempo para explicar con claridad a las adolescentes el propósito e importancia de la referencia. En general, las adolescentes están menos familiarizadas y tienen una experiencia limitada con los diferentes servicios, procedimientos médicos y sus propósitos.

- En las tarjetas o fichas de referencia se debe anotar el tipo de servicio y consejería que la adolescente requiere; estas tarjetas o fichas pueden formar parte del registro entre el lugar al que la joven acudió en primera instancia y aquél al que fue referida. La tarjeta puede destacar también el hecho de que la paciente es una adolescente que requiere atención especial y servicios o tratamientos más oportunos.

- En la medida de lo posible, ofrecer a las pacientes materiales de fácil lectura y comprensión que:

- Expliquen los servicios que se obtendrán en el lugar al que fueron referidas.

- Describan sus derechos como pacientes para recibir servicios de salud confidenciales.

- Ofrezcan información general sobre salud reproductiva.

- Los proveedores de servicios deben estar al tanto de los servicios de salud reproductiva que existan en la comunidad (p. ej., de promotores juveniles voluntarios, promotores institucionales, puestos de distribución de condones y otros anticonceptivos, farmacias para jóvenes), y estar dispuestos a referir a estos servicios comunitarios cuando tal cosa sea apropiada; por ejemplo, si una adolescente en APA necesitara apoyo emocional o condones para ejercer su decisión de evitar embarazos y ETS/VIH. Pudiera ser que un apoyo de este tipo estuviera disponible más fácilmente a través de redes de proveedores pares y de otros programas juveniles.

- En algunos países existen líneas telefónicas sobre salud reproductiva para jóvenes o sitios en internet; en esos casos, se pueden dar a las adolescentes los números de teléfono o las direcciones electrónicas de los sitios respectivos para que puedan allegarse más información. 
Seguimiento y evaluación

$\frac{\text { Objetivos }}{\text { 1. Alianzas entre la comunidad y los prestadores }}$
de servicios que involucren a las adolescentes para definir necesidades de servicios de APA amigables a la juventud reciben servicios de APA
Proceso e indicadores de resultados

- Participación para desarrollar alianzas y definir los temas importantes que esas alianzas abordarán (número de adolescentes, descripción de las funciones que realizan, número de reuniones/diálogos comunitarios con jóvenes y adultos; descripción del impacto de la participación juvenil en el proceso y la toma de decisiones)

- Los acuerdos para las alianzas formales explicitan las necesidades de, y los servicios que se brindan a las adolescentes

- Porcentaje de mujeres adolescentes que reciben consejería sobre sus necesidades y preocupaciones de salud

- Porcentaje de adolescentes entrevistadas que señalan que sus necesidades de salud y preocupaciones fueron abordadas por el personal

- Porcentaje de mujeres adolescentes que recibieron consejería de manera privada y confidencial lotros no podían verlas $\mathrm{u}$ oirlas, con o sin sus padres $\mathrm{u}$ otra persona a su cargo, conforme al deseo de las adolescentes)

- De las que quisieron que su pareja masculina participara, porcentaje que recibió la asesoría con él (cuando él está disponible)

3. Dar tratamiento clínico a todas las adolescentes que experimentan complicaciones derivadas de un aborto inseguro

- Porcentaje de adolescentes tratadas por tipo de procedimiento médico (AMEU, AE, LUI, misoprostol o AMEU y legrado uterino con misoprostol)

- Porcentaje de adolescentes tratadas que dieron su consentimiento informado verbal o escrito para realizar el procedimiento

4a. Informar a las adolescentes ly a sus compañeros cuando las jóvenes lo desean) sobre la diversidad de anticonceptivos disponibles

$4 b$. Suministrar a las adolescentes los métodos anticonceptivos elegidos

4a.

- Porcentaje de mujeres adolescentes que recibieron información sobre anticonceptivos

- Porcentaje de mujeres adolescentes que recibieron información sobre anticonceptivos sin el consentimiento previo de sus padres o guardianes

- De las adolescentes que desean que su pareja masculina participe en la consejería, porcentaje que recibió la información con él (cuando él está disponible)

$4 b$.

- De las adolescentes que desean métodos, porcentaje que recibe cualquier método antes de salir del centro de salud

- De las adolescentes que desean anticonceptivos, porcentaje que recibe el método deseado antes del alta, por tipo de método

- De las adolescentes que solicitaron un método, porcentaje que lo recibió sin el consentimiento de los padres o personas a su cargo

- Porcentaje de mujeres adolescentes que egresaron de la unidad con: a) un condón masculino, b) un condón femenino (ya sea como método único o además de un método)

5. Brindar a las adolescentes otros servicios de salud reproductiva que requieran después de la APA
- Porcentaje de adolescentes en las que se exploró la presencia de violencia de género, especialmente violencia sexual (en sus vidas en general y como causa del embarazo que terminó en un aborto inseguro)

- Porcentaje de adolescentes en las que se identificaron otras necesidades de SSR durante la APA (por tipo de necesidad identificada)

- De las adolescentes con otras necesidades de SSR, porcentaje que recibe atención directa en el mismo centro de salud

- De las adolescentes con otras necesidades de SSR, porcentaje referido para atención a otros servicios 
Los esfuerzos para que los servicios de APA sean más amigables para la juventud pueden incrementar el acceso a la APA y salvar más vidas; pueden, asimismo, reducir en el futuro el número de embarazos no deseados y ayudar a que los jóvenes pongan en práctica comportamientos sanos de salud reproductiva. Los servicios de APA amigables para la juventud no deben verse como una intervención adicional, sino como una manera de mejorar la calidad de los servicios al satisfacer las necesidades de todas las pacientes, incluyendo las de las adolescentes. Aunque el enfoque principal de este capítulo son las adolescentes, la discusión y las recomendaciones son pertinentes, de igual modo, para muchas jóvenes que tienen entre 20 y 24 años. El Consorcio APA confía en que esta guía técnica será útil y relevante para quienes proveen servicios de APA en los diferentes países en donde se trabaja. Si el lector tiene sugerencias, favor hacerlas llegar a: info@pac-consortium.org. Para información adicional sobre la APA y los adolescentes, visitar el sitio en Internet: www.pac-consortium.org

\section{Referencias}

1. Senderowitz J, Hainsworth G y Solter C: A Rapid Assessment of Youth Friendly Reproductive Health Services. Technical Guidance Series, Núm. 4. Watertown, MA, Pathfinder International, 2003.

2. Ibid.

3. de Bruyn, M y S Packer: Adolescents, Unwanted Pregnancy and Abortion: Policies, Counseling and Clinical Care. Chapel Hill, NC: IPAS, 2004.

4. Treffers, P: Issues in Adolescent Health and Development: Adolescent Pregnancy. WHO/FCH/ CAH/02.08 \& WHO/RHR/02.14. Ginebra, WHO, 2003.

5. United Nations General Assembly. Report of the Round Table on Adolescent Sexual and Reproductive Health and Rights: Key Future Actions. Disponible en el sitio: http://www.unfpa.org/ icpd/round\%26meetings/ny_adolescent/reportrtl.htm

6. Alan Guttmacher Institute (AGI): Into a New World. Young Women's Sexual and Reproductive Lives, Nueva York: AGI, 1998.

7. Pathfinder International: Insight from Adolescent Project Experience. Watertown, MA: Pathfinder, 1998

8. World Health Organization: Unsafe abortion: Global and regional estimates of incidence of mortality due to unsafe abortion with a listing of available country data. 3a. edición. Ginebra. Doc. Núm. WHO/RHT/MSM/97.16, 1997. Disponible en el sitio: http://www.who.int/reproductivehealth/publications/MSM_97_16/MSM_97_16_table_of_contents_en.html

9. World Health Organization: Unsafe abortion, Fourth edition. Global and regional estimates of the incidente of unsafe abortion and associated mortality in 2000. Ginebra, WHO, 2004.

10. Raufu A: Unsafe Abortions Cause 20,000 Deaths a Year in Nigeria. British Medical Journal. 200, 325:988.

11. WHO: Safe abortion: Technical and policy guidance for health systems. Ginebra, WHO, 2003.

12. Conde-Agudelo A et al.: Effect of the interpregnancy interval after an abortion on maternal and perinatal health in Latin America. En: Int'l Journal of Gynecology and Obstetrics. 89, S34S40, 2005. 



\section{Adolescentes pacientes de atención posaborto en República Dominicana:}

\section{sus necesidades y experiencias ${ }^{a}$}

Brígida García Romero ${ }^{b}$ Inés Escandón ${ }^{c}$ y José Figueroa ${ }^{d}$

En el año 2002, EngenderHealth emprendió una investigación cualitativa en República Dominicana a fin de conocer más acerca de las necesidades de las adolescentes pacientes de atención posaborto (APA). El estudio, financiado por USAID, se llevó a cabo en colaboración con el Centro de Estudios Sociales y Demográficos (CESDEM), una institución de investigación local; 40 pacientes de APA entre los 13 y 19 años de edad, y 21 médicos, enfermeras, médicos residentes y trabajadoras sociales fueron interrogados en dos hospitales para maternidad de Santo Domingo sobre las razones por las cuales las adolescentes buscan servicios de APA; las barreras que encuentran al buscar, llegar y obtener la atención; y las necesidades de información y servicios de las adolescentes.

La mayoría de las pacientes entrevistadas (87.5\%) no había pasado del octavo grado escolar; aproximadamente $60 \%$ no iba a la escuela; la mitad vivía en unión libre, y $37.5 \%$ tenía por lo menos un hijo. Aunque la mayoría dijo que no pensaba embarazarse en ese momento, tampoco estaba tomando medidas para evitarlo.

Los resultados mostraron que muchas pacientes aplazaron la obtención de la APA por carencias de equipo en los establecimientos de salud o por la falta de dinero para pagar los servicios. En cuanto a las deficiencias de la atención médica, las adolescentes identificaron control inadecuado del dolor, mala orientación y actitudes punitivas de los prestadores de servicios. Estos últimos señalaron deficiencias en la prevención de infecciones y en la orientación, así como carencia del equipo para la AMEU, y falta de espacio adecuado, medicamentos y analgésicos. Casi todas las pacientes se expresaron muy bien

\footnotetext{
${ }^{\text {a }}$ Presentado en la reunión del Consorcio de APA realizada en Washington, D.C., el 5 de mayo de 2005. El resumen en inglés de los resultados de este estudio está disponible en: http://www.engenderhealth.org/res/offc/ pac/adolescent/index.html El presente resumen en español, preparado para el Boletíndel Consorcio APA, fue elaborado a partir del documento: "Los servicios postaborto en las adolescentes de la República Dominicana", de Engenderhealth y el Centro de Estudios Sociales y Demográficos, Santo Domingo, República Dominicana, 2002. Reproducido con autorización.

b Centro de Estudios Sociales y Demográficos, Santo Domingo, República Dominicana.

c Engenderhealth, Nueva York, N.Y., E.U.A.

${ }^{d}$ Consultor, República Dominicana.
} 
$150 \begin{aligned} & \text { Capítulo } 18 \\ & \text { Avances en la atención posaborto en América Latina y el Caribe . . . }\end{aligned}$

de la planificación familiar, aunque no percibían de manera positiva todos los métodos; muchas expresaron inquietudes sobre los efectos secundarios de los anticonceptivos.

A raíz de este estudio, se hicieron las siguientes recomendaciones para establecer programas en los dos hospitales:

- Mejorar la capacitación de los prestadores de servicios de salud para ayudarlos a entender mejor las complejidades psicológicas de las pacientes adolescentes y ayudar a cambiar sus actitudes negativas, lo que fomentaría un trato más humano.

- Crear lineamientos para la prestación de servicios de APA para las adolescentes.

- Ampliar las intervenciones más allá de las escuelas para llegar a las pacientes adolescentes que corren un riesgo más elevado antes de que queden embarazadas.

El estudio aportó también lecciones valiosas sobre cómo realizar investigaciones con las pacientes adolescentes en APA:

- Avanzar el trabajo previo y consultar con colegas que tengan más experiencia de trabajo con las adolescentes.

- Determinar cuál es el grupo etario culturalmente apropiado para la investigación con base en los registros y no en la tradición de la investigación. En este estudio se seleccionó al grupo de 13 a 19 años de edad después de consultar los libros de registro del establecimiento; si se hubieran utilizado los grupos usados en otras investigaciones (de 16 a 20 ó de 19 a 23 años de edad) hubieran llevado a excluir a una proporción importante de las adolescentes atendidas en los servicios de APA.

- Asegurar que los investigadores reciban capacitación y sensibilización suficiente respecto a la APA y el trabajo con adolescentes.

- Contar con suficiente tiempo para llevar a cabo el estudio. Las consultas con otras instituciones, procesar la revisión ética del protocolo y capacitar y sensibilizar al personal del estudio, son actividades que llevan mucho tiempo, pero son esenciales.

Para fomentar la aplicación de los resultados del estudio, EngenderHealth llevó a cabo una reunión de difusión en Santo Domingo y sesiones para planificar acciones en los dos establecimientos donde la investigación se realizó. Del mismo modo, EngenderHealth acudió a las experiencias y lecciones aprendidas para diseñar un estudio similar en Malawi. Además, compartió los resultados de su estudio con otras organizaciones, como Family Health International, que ha utilizado los resultados en su propio programa. 


\title{
Percepciones comunitarias del aborto y de la atención a sus complicaciones
}

\author{
Fernando González, Ricardo Vernon, \\ Claudia de la Quintana, Cecilia Cossio y José del Barco ${ }^{a}$
}

\section{INTRODUCCIÓN}

¿Importa lo que piensen y sepan los miembros de una comunidad sobre el aborto y sus consecuencias para diseñar servicios y estrategias de atención posaborto? Esta pregunta parecería ser meramente retórica, ya que casi cualquier profesional de la salud respondería que las percepciones de los habitantes de la comunidad importan, desde luego; y sin embargo, es raro encontrar estudios sobre este tema, y más raro aún ubicar ejemplos de instituciones que de forma expresa hayan utilizado resultados de este tipo de estudios para diseñar los modelos de atención que dan respuesta a los problemas de los miembros de una comunidad determinada.

Solter ${ }^{1}$ sostiene que para responder de manera adecuada a una mujer que sufre una complicación derivada de un aborto, es importante que los miembros de la comunidad, incluyendo la mujer afectada: a) reconozcan los síntomas de la urgencia posaborto; b) conozcan las consecuencias de la misma; c) exista apoyo comunitario para poder movilizar los recursos que permitan atender la urgencia, especialmente en el caso de grupos marginales; y d) haya acceso a servicios de salud y confianza en su calidad. Si cualquiera de estas condiciones no se da, entonces es probable que la atención a una mujer con un aborto complicado se demore o no ocurra, y muera o su salud sufra graves consecuencias. $^{2}$

Pathfinder International había participado en Bolivia en la sensibilización, información, capacitación y redacción de normas técnicas relacionadas con la atención de las

\footnotetext{
a Cuando se hizo este trabajo, Fernando Gonzáles era Oficial Nacional de Programas y Ricardo Vernon era Director Regional, ambos en el Programa Fronteras de la Salud Reproductiva del Population Council; Claudia de la Quintana y Cecilia Cossio eran consultoras independientes en La Paz, Bolivia; José del Barco era el Director Médico de Pathfinder en Bolivia.
} 
complicaciones de la primera mitad del embarazo desde 1988. En 1999, b USAID Bolivia proporcionó fondos a Pathfinder para implantar servicios de APA en los hospitales públicos de cinco departamentos del país (Beni, Cochabamba, La Paz, Oruro y Santa Cruz). ${ }^{c}$ Como parte de ese mismo programa, Pathfinder capacitó a personal en el manejo clínico de las urgencias, orientación a usuarias y derivación a otros servicios de salud reproductiva. En el 2004, Pathfinder agregó al modelo integral de APA un cuarto componente, el comunitario, atendiendo a las recomendaciones expedidas por el Consorcio de APA. ${ }^{3}$ El estudio que aquí se presenta fue implementado por Pathfinder, el Proyecto CATALYST y el Proyecto Fronteras de la Salud Reproductiva del Population Council, para retroalimentar el proceso de introducción de un cuarto componente al modelo de tres que se estaba utilizando en la APA.

\section{METODOLOGÍA}

El estudio tuvo como objetivo describir los conocimientos, actitudes y prácticas relacionadas con la sexualidad y la anticoncepción, aborto espontáneo y aborto inducido, y con los servicios para atender urgencias por un aborto en curso o complicado de los habitantes del área de influencia de los hospitales que recibían la asistencia técnica de Pathfinder.

La metodología utilizada fue la de grupos focales, que son conversaciones que un moderador tiene con un grupo de personas representativas del público objetivo de un programa determinado. Para discutir a fondo los temas, el moderador usa una guía de entrevista, dirige la conversación hacia los temas de interés y deja que los miembros del grupo interactúen libremente y hablen sobre esos temas. Las conversaciones son grabadas y transcritas, y los investigadores analizan tales transcripciones, incluyendo las oraciones y párrafos, en categorías con significados conceptuales similares.

Los grupos focales se condujeron en las ciudades de Beni, Cochabamba, La Paz, Oruro y Santa Cruz. En cada ciudad se integraron diez grupos focales, dos grupos con cada uno de los siguientes cinco segmentos de la población: a) mujeres entre los 15 y los 17 años de edad, y b) de 18 a 21 años, en ambos casos solteras y sin pareja estable; c) mujeres entre los 22 y 30 años, y d) entre 31 y 40 años de edad, en ambos casos con pareja estable, casadas o en unión libre; y e) hombres entre los 22 y 40 años de edad, con pareja estable, casados o en unión libre. En total, hubo 426 participantes, 357 mujeres y 69 varones. El tamaño promedio de los grupos fue de 8.5 participantes, y el rango fue de seis a 11. Todos los participantes residian en áreas marginales y eran los usuarios potenciales de los servicios del Ministerio de Salud (MS). Los participantes firmaron hojas de consentimiento informado antes de su participación.

Los grupos fueron moderados por dos consultoras con amplia experiencia en su conducción. Los participantes fueron reclutados por personal comunitario de CARE, Save the Children, Food for Hunger International, Population Services International, el

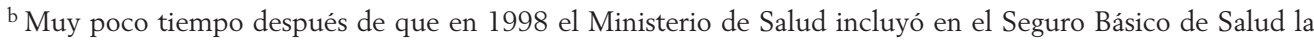
atención gratuita a mujeres con "hemorragias en la primera mitad del embarazo".

c Ipas Bolivia fue la otra organización que proporcionaría el apoyo para expandir los servicios de APA en el resto del país; había trabajado también, muy extensamente, en la introducción de servicios integrales de atención posaborto.
} 
Fondo de Inversión Social y el Consejo Rural Andino. Se seleccionaron de comunidades urbanas y rurales en el área de cobertura de los hospitales donde se estaban introduciendo los servicios de APA. Además de la moderadora, en cada grupo una persona previamente capacitada tomó notas para poder elaborar los informes preliminares. Adicionalmente, todas las conversaciones en los grupos fueron grabadas y transcritas, y los textos fueron analizados por los primeros dos autores de este artículo para buscar diferencias y coincidencias entre los diferentes grupos. A continuación se resumen los resultados de los diferentes grupos. En todos los casos, las citas se refieren a lo dicho por las participantes en los grupos descritos en cada inciso.

\section{RESULTADOS}

\section{Sexualidad y métodos anticonceptivos}

En relación con la sexualidad y métodos anticonceptivos, se distinguen situaciones muy diferentes entre las mujeres jóvenes que todavía no están unidas y las mujeres ya unidas. Las primeras, especialmente las menores de 18 años, tienden a hablar con sus amigas sobre los hombres como parejas amorosas, sobre sus cuerpos, la manifestación de la sexualidad y el sexo.

Hablamos entre amigas de cositas. Se puede decir que cuando hablamos de los cambios del cuerpo y alguien no conocía las partes del hombre con sus nombres exactos.......Ah, se sonrojan.

Cuando necesitan información concreta sobre métodos anticonceptivos, la solicitan de una amiga, una hermana mayor o alguna persona en la que tengan plena confianza, de preferencia casada, aunque no sea experta en el tema. Prefieren no acudir a los padres o aun a los prestadores de servicios, pues temen que haya repercusiones negativas o les da vergüenza preguntar. En cambio, consideran que para los hombres es más fácil, porque tienen amigos que saben y conocen.

Piensan que eres muy joven para estar preguntando esas cosas.

Si, es verdad, no se puede decir a la mamá todo, porque a veces se enojan.

En las conversaciones de las mujeres de 18 a 22 años de edad, también predominan los temas románticos, pero las pláticas son mucho más explícitas e informadas; no temen introducir temas relacionados con la anticoncepción y se sienten más seguras de pedir y recibir información en centros de salud, clínicas y centros juveniles. Sin embargo, su conocimiento de los anticonceptivos no es muy profundo y perciben una preparación deficiente del personal de los centros de salud.

...Vas a un centro y pides que te orienten y lo hacen. Es muy sencillo.

Hay otras enfermeras que no tienen conocimiento. Les preguntamos cosas que queremos saber y responden no sé, habla con el doctor... Te cambian las palabras y no tienen conocimiento. 
Las mujeres solteras que no tienen relaciones están conscientes de que ellas mismas son quienes deben "cuidarse" (prevenir un embarazo) en caso necesario; pero, en general, persiste entre ellas la idea del recato y la vergüenza de ejercer la sexualidad fuera del matrimonio, por lo que la ven como una situación poco probable en el futuro. Para ellas, la mejor opción es decir "no". En cambio, las que tienen relaciones con sus parejas, suelen tenerlas sólo en ocasiones y muchas utilizan el condón, el cual por lo general consigue el hombre. Muy pocas mencionan usar la píldora o algún otro método.

La situación de las mujeres con pareja estable contrasta con la de mujeres solteras de menor edad. Cuando hablan de temas relacionados con la sexualidad, el que predomina es el de métodos anticonceptivos, pero prevalecen la desinformación y las creencias erróneas. Las amigas también son la primera fuente de información, seguidas por la pareja, grupos organizados (como bancos comunales, club de madres y otros) y prestadores de servicios en hospitales, centros de salud, farmacias y durante las campañas de salud. Estas mujeres ya no tienen ninguna dificultad en conseguir información sobre los métodos. Es un tema que dejó de ser tabú, aprueban que se hable abiertamente de él y respaldan la educación sexual en los colegios. Reconocen el esfuerzo que hacen las instituciones públicas para dar información, pero piensan que en la consulta privada la información es más rápida y accesible, porque el lenguaje es claro y asimilable. Dicen que el problema en los servicios públicos es la cantidad de gente que tienen que atender, el lenguaje complicado que usan para explicar y el uso de jovencitas sin experiencia y no casadas para dar la información y los métodos. Prácticamente todas las mujeres pueden mencionar más de una fuente donde podrían obtener un método anticonceptivo si lo quisieran.

La mayoría de las mujeres unidas usa métodos anticonceptivos modernos, aunque todavía una proporción importante utiliza métodos naturales, especialmente las mayores de 30 años, debido a la desconfianza que tienen a los efectos de los métodos modernos. Es frecuente escuchar a alguna participante decir que algún método es "peligroso", otras tienen preguntas qué les preocupan y otras más desconfían de la sinceridad de los médicos y enfermeras para darles la información verídica, pues distinguen un interés especial del personal de salud en promover los métodos anticonceptivos. Cuando se les pregunta qué les gustaría saber de los métodos, mencionan características específicas de cada método y mayor conocimiento sobre lo que fisiológicamente pasa en el cuerpo de las mujeres cuando usan un método, y en especial, todo lo relacionado con la sangre: a dónde se va cuando no hay menstruación, por qué aumenta el flujo con algunos métodos, etc.

\begin{abstract}
Cuando yo tenía a mi hijo, me salía leche celeste y por eso no le daba, y me quedé embarazada antes del año. Luego, mi cuñada me hizo colocar la T de cobre, pero me daba hemorragia cuando alzaba pesado... A los dos años me hice sacar y he tenido fracaso; he vuelto con el médico para que me pongan la T de cobre... Me han puesto $y$ sigue la hemorragia, y me dijeron que ya iba a pasar.
\end{abstract}

En cuanto a quién debe tomar la decisión de usar un método, casi todas las mujeres dicen que es la mujer, y aunque opinan que la decisión debería ser compartida con la pareja, la mayor parte no cuenta con el apoyo efectivo de su compañero.

Contrariamente a lo que mencionan las mujeres, la mayoría de los hombres están de acuerdo con que sus parejas usen los métodos anticonceptivos, saben dónde conseguirlos y sienten que hoy en día es muy fácil usarlos. Aunque efectivamente la mayoría 
confía en que su pareja sea la que acuda a los servicios por un método, sus comentarios hacen pensar que más que una evasión de la responsabilidad, su poca participación en la toma conjunta de la decisión se debe a que no tienen claro que es lo qué podrían hacer para participar más activamente.

\section{PERCEPCIONES SOBRE EL ABORTO ESPONTÁNEO}

El aborto espontáneo se mencionó casi exclusivamente en los grupos de mujeres casadas y en el contexto de una pareja unida. Las mujeres más jóvenes se refirieron al aborto espontáneo como un acontecimiento externo y lejano: algunas participantes contaron experiencias de su propia familia, pero no sintieron que fuera un tema del que debían preocuparse. En términos generales, la mayoría de las mujeres identificaba como causas del aborto espontáneo cietos factores orgánicos (como matriz débil o infantil, anemia y edad avanzada) y causas sociales y laborales (como la violencia de la pareja o por cargar cosas pesadas). Prácticamente todas las mujeres identifican como síntomas del aborto espontáneo la hemorragia y el dolor.

Cuando se preguntó cuál era la conducta típica de una mujer que tenía un aborto, la mayoría dijo que se aguantaban el dolor hasta donde pudiera, con la esperanza de que cesaran el sangrado y el dolor con el tiempo. Algunas hablarían con familiares y con amigas íntimas, pero casi siempre después de varios días. Aunque las mujeres perciben apoyo y solidaridad de la comunidad con las mujeres que tienen un aborto espontáneo, pocas hablarían con los vecinos, pues éstos pueden malinterpretar y sacar conclusiones equivocadas. Sólo cuando ya no pueden más con el dolor y la situación se percibe como una urgencia de mucho peligro solicitan a sus familiares y amigos que las lleven al servicio de salud. De hecho, es mucho más frecuente que la mujer vaya al servicio de salud debido a la insistencia de la amiga, el familiar o la pareja, que por iniciativa propia. Esto, más que ser una muestra de pasividad, parece reflejar una baja autoestima, temor a los costos del procedimiento (lo que muestra que no saben bien que el servicio de APA es gratuito por estar cubierto por el Seguro Básico del MS, o que se refieren a cobros por medicamentos o insumos no cubiertos por el seguro), y temor al trato que reciben cuando acuden a los servicios de salud, ya que la atención con frecuencia choca con sus ideas de cómo debe ser el trato:

A mi amiga le dio dolor de espalda. Luego la seña de desembarazo, cristalina con un poquito de sangre, pero ella por no ir, porque le habian dicho que tenia que hacerse poner unas inyecciones caras y no tenía dinero, se ha quedado esperando hasta que le vino un hemorragia fuerte.

En cambio, los hombres tienen claro que ante esta situación deben llevar a sus parejas a los servicios de salud estatales para recibir tratamiento.

\section{PERCEPCIONES SOBRE EL ABORTO INDUCIDO}

Al igual que con los demás temas, existen amplias diferencias entre las mujeres jóvenes sin pareja estable y las mujeres en unión libre de más de 22 años de edad. Para las primeras, el aborto inducido es prácticamente la única salida posible ante la catástrofe de 


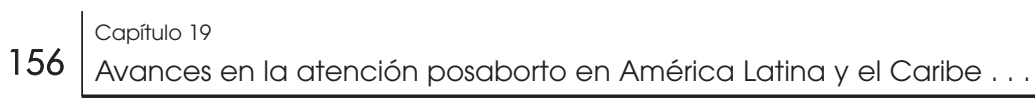

un embarazo no deseado, que comprometería su posición y pertenencia familiar y comunitaria (pues el embarazo fuera del matrimonio provocaría rechazo, vergüenza, desilusión, discriminación y estigmatización de la familia y la comunidad). El embarazo pondría punto final también a su desarrollo individual, pues se tendrían que dejar de lado objetivos de vida como continuar estudiando, trabajar y ahorrar antes de casarse, o cualquier otro.

Ella se ve sola sin apoyo de su familia, de su enamorado. Yo creo que la única solución es el aborto.

Ante un embarazo no deseado, las jóvenes solteras dicen que hablarían con sus amigas íntimas y algunas con el hombre que provocó el embarazo, pues podría ser una persona clave para resolver la situación, ya sea casándose o ayudando a encontrar y pagar por los servicios de aborto. Sin embargo, una parte importante dice que no hablaría con la pareja, pues están conscientes de que una reacción muy común del hombre es evadir su responsabilidad.

Ese hijo no es mio... Con cuantos te habrás acostado después que te acostaste conmigo.

En los casos en los que la pareja no responde, las solteras describen la secuencia de conductas y estados de ánimo por los que atraviesa una mujer. La primera etapa es de depresión, a veces acompañada de ideas de suicidio y consumo de drogas y alcohol; algunas piensan en abandonar la casa y otras lo llegan a hacer. En una segunda etapa, las jóvenes intentan provocarse un aborto tomando mates, hierbas, pastillas o inyecciones que pudieron haber recomendado diferentes personas, como amigas, parteras, curanderos, hierberos y dependientes de farmacias; o cargando cosas pesadas o saltando; haciendo ejercicios extenuantes y, en general, haciendo todas las cosas que se advierten a las embarazadas que no hagan. Cuando esto no funciona, entonces consideran la posibilidad de tener al niño y criarlo, entregarlo en adopción o abandonarlo. Si toman esta decisión, es cuando hablan con sus padres. En esta etapa, la decisión alternativa es tener un aborto inducido. Las mujeres están conscientes del riesgo que corren al experimentar un aborto inseguro, pero piensan que las consecuencias de hacer público el embarazo y de ser madres solteras son peores.

La mayoría tiene la certeza de que los servicios de aborto inducido están disponibles en algún lugar cercano y que quien lo quiera podrá tenerlo. Sin embargo, casi ninguna de las entrevistadas conocía a alguien que prestara este servicio; hablaban más bien de proveedores de servicios no efectivos, como los listados arriba, lo que hace suponer que hay una exploración y un peregrinar antes de llegar al proveedor indicado, en caso de que finalmente lo encuentren. Las posibles informantes son amigas que ya han tenido un aborto, enfermeras, estudiantes de medicina y dependientes de farmacias. En la mente de las mujeres existe una relación directa entre el costo de la intervención y la seguridad del procedimiento. Como la mayoría no tiene dinero, están conscientes de que en su caso el riesgo sería más elevado que para alguien que dispone de él.

En contraste con las solteras, las mujeres casadas consideran que el aborto es consecuencia de una situación socioeconómica que no les permitiría mantener otro hijo. También son justificación suficiente para un aborto la fatiga del cuerpo y los problemas 
con la pareja. Finalmente, se mencionó el fatalismo que les impide usar métodos anticonceptivos:

\begin{abstract}
O sea, desde el primer bebé, mi mamá me ha dicho al menos, ya no más, ya no más... Y me embaracé... Ha nacido mi segundo hijo y he dicho me voy a cuidar: voy a ir, estaba yendo y no voy: ya ha nacido el tercero y no voy; desde hace seis meses que no voy al Centro pero no sé qué pasa y no puedo... Quiero tomar las pastillas, pero digo no, porque no soy constante. Parece que con la T de cobre... Pero no hay cuando vaya.
\end{abstract}

Aunque las mujeres casadas, especialmente las de mayor edad, ven más factible que los miembros de su familia les den apoyo para hacerse un aborto, o que cuando menos se desentiendan de la situación y no sean críticos o negativos, están conscientes de que la actitud de la comunidad hacia el aborto es muy negativa y que, de enterarse, evaluarán el hecho desde una óptica religiosa. De hecho, ellos comparten la evaluación negativa del aborto, aun cuando ya lo hayan practicado:

Si hacemos eso, Dios se va a enojar.

Yo vivo pensando cómo iba ser su carita... Yo creo que me muero: voy a pensar que podría haberle criado.

El aborto es un crimen, es malo hacer.

La mayoría considera que la pareja tampoco estaría de acuerdo con la decisión y preferiría no decirle nada. Las que tienen confianza en la respuesta del marido ante esa situación hablarian sólo con él; entre ambos se encargarían del problema.

Las soluciones que toman las mujeres casadas en caso de un embarazo no deseado son las mismas que las mujeres solteras. Sin embargo, estas mujeres mencionan también la posibilidad de introducirse una sonda, de acudir con alguien para que les haga un legrado o una aspiración (identificando los procedimientos por nombre) y aun tomar Cytotec, un medicamento que de haber estado disponible en Bolivia cuando se hizo este estudio, lo estaba en forma muy escasa. Aunque las mujeres mayores no conocen los sitios donde se hacen los abortos, están seguras de que habrá médicos, enfermeras, personas particulares y algunas farmacias que les sabrán informar. Están conscientes de que algunos lugares pueden ser higiénicos y contar con instrumental especializado, y otros ser antihigiénicos y con instrumental insuficiente. Manifiestan, incluso, que en Cochabamba hay centros "legales" atendidos por médicos. Están conscientes, igualmente, que entre más pronto se practica un aborto es mejor desde el punto de vista de la salud y del costo del procedimiento. Los precios mencionados oscilaban entre el equivalente de 50 y 150 dólares (EUA).

Por último, los hombres parecen estar conscientes de que su pareja puede elegir informarles o no sobre un aborto en curso o complicado. En caso de que les informen, ellos asumen una posición solidaria, pero no se les ocurre qué hacer más allá de llevar a la mujer con un médico y darle apoyo moral. En términos generales, los varones ven a la mujer como la persona que controla la anticoncepción y también quien asume la responsabilidad de tomar las decisiones sobre qué hacer en caso de ocurrir un embarazo no deseado. Las respuestas posibles que perciben son acoger al producto en el seno familiar; deshacerse de la criatura; o interrumpir el embarazo mediante diversos métodos, 
incluyendo sondas, Cytotec, aspiración, legrado o los remedios caseros, acciones con las que los hombres, en general, no están de acuerdo. De hecho, muchos se imaginan reacciones violentas ante ese hecho, o consideran la posibilidad de abandonar a la mujer o incluso denunciarla ante las autoridades. En lugares como La Paz y Oruro, los maridos parecen tener actitudes más solidarias con sus mujeres.

\title{
SERVICIOS DE ATENCIÓN POSABORTO
}

El último tema sobre el que se indagó en los grupos focales fue si las mujeres y hombres reconocían que ante un aborto en curso o complicado debían ser atendidas por personal médico. Se encontró que la percepción generalizada es que ante cualquier complicación de salud es mejor acudir con el personal sanitario; sin embargo, suelen tener el temor a ser mal atendidas o maltratadas, por lo que se demoran en acudir. Quienes habían pasado por un trance similar hablaron de la mala atención:

\begin{abstract}
...Llegué al hospital y mi novio fue a sacar ficha para que me atendieran. Me dijo que esperara en la sala, y yo le dije al doctor: Apúrese, me duele, me siento mal... El doctor seguía conversando y me dijo: Enseguida... y no me quiso atender... Estaba con hemorragia, toda bañada en sangre, y aun así él no quiso atender; pedí ayuda y nadie me quiso mover. Pasaban las enfermeras como si nada.
\end{abstract}

Casi todas asumen que frente a un problema grave como puede ser un aborto complicado, acudirían al servicio de emergencias ${ }^{\mathrm{d}}$ del hospital público. Sin embargo, otras mujeres refieren también que acudirían a centros de salud o clínicas privadas, lo que en su caso demoraría la atención; ello es muestra, igualmente, de la necesidad de informar a la comunidad acerca de los servicios existentes. Una mujer refirió el caso de una amiga:

\begin{abstract}
Una señora por sólo levantar una piedra tuvo un fracaso... Entonces hemos ido a todas partes y nada... Hemos llevado a un centro de salud, hemos llegado cargando en una cama... Tampoco, porque esos casos no atendía; llevamos a los Andes tampoco... A una clínica particular, aqui en la avenida Antofagasta, y ahi nos atendieron.
\end{abstract}

Algunas mujeres solteras dijeron que a los servicios públicos se podría acudir en el caso de abortos espontáneos, pero no en el caso de complicaciones derivadas de abortos inducidos, que deberían atenderse en el lugar donde se hizo el aborto o en sitios privados. Otras razones para no acudir a atenderse las complicaciones derivadas de abortos inducidos es que se cree que habría mala atención, y además cobrarían por el servicio, cosa que no ocurriría con un aborto espontáneo. Lo anterior muestra la necesidad de llevar a cabo labores de educación comunitaria, pues los habitantes no distinguen la mejoría en el trato que han mostrado los abortos como consecuencia de la introducción del programa de APA.

Ante la pregunta de cómo debería ser el servicio, las mujeres mencionaron la atención inmediata, respetuosa y cordial, de preferencia brindada por mujeres y con apoyo

$\overline{\mathrm{d} \text { Llamado servicio de urgencias en }}$ otros países. 
psicológico profesional, pues las pacientes necesitan fortalecerse anímicamente. Las casadas hablaron de servicios rápidos y seguros, en donde no hicieran muchas preguntas y no hubiera necesidad de llenar demasiados formularios.

Cuando una está con la moral baja, debe haber un personal que le escuche, que le dé
mayor confianza.

Tener un lugar donde atiendan doctoras.

Que haya un lugar exclusivo donde no hagan preguntas... Porque una chica está agonizando y le hacen miles de preguntas en vez de ponerle en una camilla...

Así como nosotros recibimos charlas, por qué no dan charlas a las enfermeras, incluso a los médicos, y comentarles todo lo que decimos las señoras...

Tener un lugar donde nos pueden explicar lo que tenemos; que tengan todos los medicamentos... Que nos traten con cariño... Lo importante es el buen trato que debemos recibir... Cariño y no gritos.

En términos generales, las opiniones de los hombres no fueron muy diferentes de las de las mujeres.

\section{CONCLUSIONES}

Este estudio cualitativo muestra que la principal barrera para que las y los jóvenes accedan a la anticoncepción es la percepción de que el sexo fuera del matrimonio es fuertemente rechazado por los padres y los prestadores de servicios, por lo que es previsible que en caso de necesitarla, las mujeres dudarían mucho para acercarse a solicitar los métodos, y que aun si los consiguieran a través de amigas, sería probable que los utilizaran mal. A pesar de lo mucho que se ha avanzado en este tema, se debe continuar la capacitación a los prestadores de servicios en hospitales, centros y puestos de salud, así como a los dependientes de farmacias, para que siempre que sea posible aprovechen la interacción con los adolescentes para darles información científica y confiable sobre los métodos anticonceptivos, y para que cuando acudan a solicitar estos servicios, los entreguen de manera atenta, profesional y sin hacer juicios morales.

Por otro lado, el conocimiento deficiente de los métodos anticonceptivos por parte de las mujeres mayores y casadas habla de la importancia de continuar educando a la población en las comunidades y durante sus visitas a los centros de salud.

En términos de las condiciones que Solter menciona para poder responder de forma apropiada a una complicación por aborto, se puede decir que prácticamente todos identifican las hemorragias y al dolor como consecuencias de un aborto complicado, y que todos reconocen la importancia de acudir a un médico por considerar estos síntomas como graves. Sin embargo, casi nadie percibe la existencia del apoyo comunitario para atender una urgencia de este tipo; la percepción casi universal es más bien la de un clima hostil y un fuerte rechazo al aborto inducido. De hecho, aun en el caso de abortos espontáneos, las mujeres preferirían no involucrar a sus vecinos, quienes podrían de manera equivocada hacer surgir rumores, juzgar y condenar, sin siquiera ayudar a resolver la 
situación. La respuesta de la pareja misma, por otro lado, se percibe como incierta, no confiable, quizás violenta y amenazante. Ante esta situación, las mujeres quedan prácticamente desvalidas, orilladas a esperar a que el sangrado y el dolor desaparezcan por sí mismos con el tiempo, o en su caso, a contar con la ayuda de sus amigas. Respecto a la otra condición que Solter plantea - sobre el acceso a servicios y la confianza en su calidad- el estudio muestra que todos entienden la importancia de acudir al servicio de urgencias (aunque no necesariamente al hospital; muchos perderían tiempo acudiendo a centros de salud sin capacidad resolutiva); pero que existe la convicción de que en el caso de un aborto inducido complicado, la mujer sería maltratada, le cobrarían por los servicios, la atenderían mal y, quizás peor, la acusarían ante las autoridades. (En la práctica, a raíz de la introducción del programa de APA, los servicios no distinguen en la atención de complicaciones por aborto espontáneo o inducido, ni tampoco hay casos de mujeres encarceladas por este motivo). Fuera del mal trato, casi en todos los casos las mujeres dudan de la calidad de la información que se les otorga y de la competencia técnica y pericia de los prestadores de los servicios para manejar la situación. Así pues, estas percepciones podrían incrementar la mortalidad materna al obstaculizar el uso de los servicios estatales de salud.

En resumen, se puede concluir que cuando menos dos de las cuatro condiciones que Solter considera necesarias para poder responder a las necesidades de una mujer con complicaciones por aborto no se cumplen: el apoyo comunitario y la confianza en la calidad de los servicios. A pesar de que las evaluaciones muestran un cambio en las condiciones objetivas a raíz de la introducción del modelo integral de la APA, las comunidades no distinguen aún que estos cambios hayan ocurrido. Es por ello que se recomienda al MS emprender acciones de información y sensibilización comunitaria mediante las cuales se reconozca que el aborto es un problema de salud en las comunidades, que se fomente una actitud más solidaria y una respuesta organizada para enfrentar las urgencias que se presenten, y que se resalten los cambios positivos en los servicios de APA. Por último, se recomienda a los programas de otros países incluir a la comunidad en sus programas de APA, junto con el modelo de atención integral propuesto por el Consorcio APA. ${ }^{3}$

\section{AGRADECIMIENTOS}

Este estudio se realizó con el apoyo del pueblo estadounidense a través de la Agencia para el Desarrollo Internacional de Estados Unidos (USAID) bajo los términos del Acuerdo de Cooperación No. HRN-A-00-98-0001200 (Programa Fronteras de la Salud Reproductiva del Population Council). Los contenidos son responsabilidad de los autores y no necesariamente reflejan los puntos de vista de USAID, del gobierno de EUA o del Programa Fronteras de la Salud Reproductiva.

\section{Referencias}

1. Solter, C: Expanded PAC model: Community involvement. Ponencia presentada en la reunion de IBP, Cairo, Egipto, Febrero 9-13. Pathfinder. 2002

2. Thaddeus S, Maine D: Too far to walk: Maternal mortality in context. En: Soc Sci Med; Apr; 38(8), 1994:1091-1110.

3. Comisión Especial de Comunidad del Consorcio APA: Elementos esenciales de la atención posaborto: un modelo ampliado y actualizado. PAC in Action, Número 2, suplemento 2, septiembre 2002. (Presentado como capítulo 1 en esta misma obra). 


\title{
Empoderamiento de la comunidad para mejorar la salud sexual y reproductiva y la atención posaborto en Bolivia
}

\author{
Carmen Monasterios $\mathrm{O},{ }^{a}$ Rocio Lara Palma, ${ }^{b}$ y \\ Carolyn Curtis $^{c}$
}

\section{INTRODUCCIÓN}

En Bolivia, la razón de mortalidad materna para el periodo 1998-2003, estimada por la Encuesta Nacional de Demografía y Salud de 2003, fue de 229 defunciones maternas por cada 100000 nacimientos. ${ }^{1}$ Según la información del Ministerio de Salud y Deportes (MSD), entre 27 y 35\% de las muertes maternas son causadas por complicaciones derivadas del aborto, tanto espontáneo como incompleto. Sin embargo, dado el subregistro de casos, es difícil conocer con precisión la contribución de las complicaciones de los abortos a la mortalidad materna.

Las políticas y programas en salud sexual y reproductiva del gobierno boliviano se basan en el acceso a la información, consejería y servicios para que las mujeres y parejas puedan ejercer su derecho a decidir de manera libre y responsable el número y espaciamiento de sus hijos y, por tanto, puedan prevenir los embarazos no planeados y el aborto inducido. Más allá de esta orientación general, en 1999, con asistencia técnica y financiera de la Agencia de los Estados Unidos para el Desarrollo Internacional (USAID), Pathfinder International e Ipas, el MSD inició un programa para incorporar en sus hospitales un modelo de atención posaborto (APA). ${ }^{\mathrm{d}}$ Posteriormente, con la asistencia de USAID y Prosalud-Socios para el Desarrollo, el MSD inició un programa para vincular los servicios de APA con las comunidades y movilizar recursos comunitarios a fin de contribuir para que las mujeres recibieran la atención apropiada y el tratamiento oportuno para las complicaciones derivadas del aborto.

\footnotetext{
a Programa APA Comunitario, La Paz, Bolivia.

b USAID/Bolivia, La Paz, Bolivia.

c USAID, Washington, D.C., EUA.

d Véanse en esta misma obra: Comisión Especial de Comunidad del Consorcio APA. "Elementos esenciales de la atención posaborto: un modelo ampliado y actualizado". PAC in Action, Número 2, suplemento 2, septiembre 2002; y del Pozo, Eliana; M. Morales, J. del Barco y C. Cornejo. 2007. "La experiencia en Bolivia de la atención posaborto".
} 
En este documento se presentan las experiencias que se obtuvieron en la creación de alianzas entre prestadores de servicios y las comunidades en cinco redes de salud de tres ciudades del país (las redes de Los Andes y Corea, en El Alto; las redes Norte y Este, en Santa Cruz; y la red Cercado Sur en Cochabamba).

\section{METODOLOGÍA}

El modelo de creación de alianzas comunitarias que se observó constó de las siguientes etapas:

1) Organización de la comunidad, en la cual el personal de los centros de salud identificó a mujeres y hombres —adultos y adolescentes-, dispuestos a participar en las actividades de movilización. Las personas identificadas seleccionaron a sus propios líderes, quienes recibieron capacitación para convertirse en facilitadores comunitarios.

2) Autodiagnóstico, en el cual los miembros de la comunidad identificaron sus necesidades y asignaron prioridades a los problemas que experimentan en torno a las complicaciones de las hemorragias en la primera mitad del embarazo (HPME), y a los tres atrasos (reconocer, decidir y resolver) que suelen poner en riesgo la vida de las mujeres. Como parte de estas actividades, se utilizaron diferentes metodologías, como las historias de vida, caminos recorridos, sociodramas, mapeo y puente de posibilidades, con el propósito de iniciar una reflexión sobre los problemas y complicaciones asociados a las HPME y a los embarazos no planeados. Entre los temas más abordados se encontraron la demanda de información sobre salud sexual y reproductiva, violencia doméstica, calidad de los servicios de salud, comunicación de pareja y de padres con hijos, y el desconocimiento de las organizaciones de base de la comunidad.

3) Elaboración del plan de acción, basado en los resultados del autodiagnóstico. Los grupos trabajaron en un plan de acción para resolver los problemas identificados, enfatizando en soluciones reales, alcanzables y medibles a través de indicadores que la misma comunidad definía. Los planes de acción de cada grupo se consolidaron en un plan de acción del centro de salud que comprende los de todos los grupos que se ubican en su área de influencia. En esta etapa se logró que los grupos de la comunidad tuvieran una nueva relación con el centro de salud, que trascendió la crítica de la calidad de los servicios para contribuir a su mejoramiento considerando la realidad de los mismos.

4) Implementación y seguimiento, etapa en la cual los líderes de los grupos dieron seguimiento a las actividades programadas. Los líderes se reunieron cuando menos tres veces con los miembros de sus grupos para analizar el grado de avance de las soluciones propuestas para cada problema. En esta etapa, los líderes sirvieron como puentes entre la comunidad y los prestadores de servicios de salud en un proceso sinérgico.

5) Evaluación participativa, durante la cual se llevaron a cabo reuniones entre los líderes, representantes de los grupos, personal del centro de salud y de otras instituciones que brindaron apoyos, y los dirigentes de organizaciones de base, todo ello con el propósito de analizar los resultados de las acciones e iniciar la planeación del nuevo ciclo. 
La metodología utilizada propone realizar tres ciclos de este ejercicio abarcando las cinco etapas anteriores; se anticipa que cada ciclo tenga una duración aproximada de ocho meses. La expectativa es que al término de los tres ciclos la comunidad se apropie de la metodología y continúe implementándola. Para facilitar esta apropiación, en el primer ciclo se proporciona a la comunidad toda la asistencia técnica, que incluye a los facilitadores, materiales y refrigerios. A partir del segundo ciclo, este apoyo disminuye de forma paulatina para que al terminar el tercer ciclo la comunidad asuma la responsabilidad por la aplicación de la metodología.

\section{RESULTADOS}

El cuadro 20-1 presenta los resultados de la aplicación del modelo de formación de alianzas en las cinco redes de salud que participaron en la primera experiencia.

Como puede verse, en el ejercicio participaron 33 centros de salud con 82 grupos formados y 149 líderes capacitados. De los 1520 participantes, 90\% fueron mujeres; $85 \%$ tenía entre 15 y 44 años de edad, 68\% era casado/a, y 60\% había cursado sólo la educación primaria.

Todas las redes completaron exitosamente el primer ciclo de acción comunitaria; en el segundo ciclo sólo una red no pudo completar 20\% de las soluciones propuestas. Cuando este capítulo fue preparado, dos redes habían logrado terminar el tercer ciclo y dos más llevaban terminadas $70 \%$ de las acciones programadas, sin que hubiera información sobre la red faltante.

CUADRO 20-1.

Resumen de resultados de los ciclos de participación comunitaria

\begin{tabular}{l|c|c|c|c|c|c|c|c}
\hline Regional & $\begin{array}{c}\text { Redes } \\
\text { de Salud }\end{array}$ & $\begin{array}{c}\text { No. de } \\
\text { Centros } \\
\text { de Salud }\end{array}$ & $\begin{array}{c}\text { No. de } \\
\text { grupos }\end{array}$ & $\begin{array}{c}\text { No. de } \\
\text { líderes }\end{array}$ & $\begin{array}{c}\text { Total de } \\
\text { partici- } \\
\text { pantes }\end{array}$ & $\begin{array}{c}\text { ler ciclo } \\
\text { de acción } \\
\text { comunitaria }\end{array}$ & $\begin{array}{c}\text { 2do ciclo } \\
\text { de acción } \\
\text { comuni- } \\
\text { taria }\end{array}$ & $\begin{array}{c}\text { 3er ciclo } \\
\text { de acción } \\
\text { comuni- } \\
\text { taria }\end{array}$ \\
\hline EL ALTO & Los Andes & 4 & 17 & 34 & 405 & $\checkmark$ & $\checkmark$ & $\checkmark$ \\
Corea & 4 & 15 & 30 & 235 & $\checkmark$ & $\checkmark$ & $\checkmark 70 \%$ \\
\hline SANTA CRUZ & Norte & 7 & 15 & 25 & 234 & $\checkmark$ & $\checkmark$ & $\checkmark$ \\
COCHABAMBA & Cercado Sur & 8 & 20 & 40 & 400 & $\checkmark$ & $\checkmark 80 \%$ & $\checkmark 70 \%$ \\
\hline TOTAL & & 33 & 82 & 149 & 1520 & 5 & 4,8 & 3,4 \\
\hline
\end{tabular}


La capacitación inicial de los líderes incluyó los temas de salud sexual y reproductiva, abogacía y gestiones para mejorar la calidad de la atención en los servicios de salud, así como la función de los comités populares de salud. La capacitación permitió a los líderes organizar grupos de manera eficaz, realizar gestiones ante las autoridades locales e idear formas para mantener motivados a los miembros de los grupos, por ejemplo, dando premios a sus participantes. Al principio, los líderes tuvieron problemas para definir un número manejable de prioridades, pues era común ver en el primer ciclo grupos con 15 prioridades establecidas; sin embargo, al alcanzarse el tercer ciclo, y con la práctica y habilidades adquiridas, los grupos definieron un promedio de tres prioridades para cada una de las demoras. La capacidad adquirida se pudo demostrar, igualmente, con el hecho de que varios centros de salud incorporaron en sus programas operativos anuales algunas de las actividades incluidas en el plan de acción comunitario.

Las necesidades y problemas identificados y priorizados se trasladaron a planes de acción, uno para cada una de las siguientes categorías: centros de salud, capacitación, Seguro Universal Materno Infantil (SUMI) y comunidad. Cada plan de acción identificaba la necesidad, el problema y el indicador que se tomaría en cuenta para determinar el problema identificado y los resultados del seguimiento que se hacía tres meses después. Así, por ejemplo, el segundo plan de acción de una red de salud de la ciudad de Santa Cruz mostraba entre los problemas de los centros de salud la falta de equipos e insumos médicos y la falta de una ambulancia para atender urgencias; el indicador para medir el éxito era la existencia de tales elementos; y los resultados del seguimiento mostraron, en el primer caso, que las gestiones con funcionarios, autoridades y representantes de la comunidad habían derivado en la asignación de presupuesto para la compra del equipo y la ampliación del personal, mientras que en el segundo caso se había establecido un acuerdo mediante el cual el hospital se comprometía a atender las necesidades de transportación de urgencias en el área de cobertura del centro de salud, en tanto que el centro de salud se comprometía a atender un mayor número de partos y otros eventos que permitirían descongestionar el uso de la ambulancia y las instalaciones del hospital; el plan de acción referente al SUMI identificaba la falta de medicamentos que el SUMI proporcionaba a los menores de cinco años en dos centros de salud, y el seguimiento narraba que las gestiones propuestas con las autoridades pertinentes habían logrado reducir el desabasto en 50\%; el plan de acción de la comunidad identificaba la falta de comités populares de salud en algunas comunidades y la falta de participación de la comunidad en la preparación del plan operativo anual (POA) de los centros de salud, mientras que los resultados del seguimiento indicaban la creación de los comités y la inclusión de propuestas específicas de la comunidad en los POA de cinco centros de salud.

Para evaluar el impacto de las actividades sobre los conocimientos, actitudes y prácticas relacionadas con la salud reproductiva de los habitantes de las comunidades, se llevaron a cabo encuestas antes y después de implementar las acciones del programa. Los resultados mostraron un aumento en el conocimiento y uso de métodos anticonceptivos, formas de prevención del SIDA y cómo responder a los casos de violencia doméstica. Mostraron también que quienes habían asistido a los centros de salud percibían una mejora en la calidad de atención, en términos de las explicaciones que recibían sobre sus problemas de salud, aclaración de dudas, respeto mostrado y el resultado de la atención, aunque el tiempo de espera continuó siendo un problema que había que resolver todavía. 
El empoderamiento de los líderes y de los participantes se reflejó igualmente en el ámbito privado, al interior del hogar, donde las relaciones de poder de género tienen raíces fuertes y los cambios suelen ocurrir de manera lenta y difícil, según lo mencionaron participantes en grupos focales:

... antes, con mi marido, boca a boca discutíamos; ahora le hago comprender,... ya no me hace callar... Me hago respetar, la comunicación ha mejorado y también con mis hijos. (Integrante del grupo focal en El Alto).

Mi esposo es machista, me decía que en estos cursos se perdía el tiempo, yo le contaba lo que llevábamos y hacíamos... ahora él me recuerda de las reuniones y se queda con mis niños. (Integrante del grupo focal en Santa Cruz).

En total, alrededor de 4000 personas participaron en las sesiones educativas organizadas por los grupos en cada ciudad. La comunidad fue asumiendo algunos gastos de contraparte, como los refrigerios y los ambientes o espacios para las sesiones. Esto se tradujo también en una mayor asistencia a los centros de salud:

Lo positivo es que los grupos organizados, mujeres en particular, se han empoderado en la parte de conocer sobre la salud,... lo otro es de que con todos los temas de educación que han solicitado las señoras en salud se ha visto que ha ido aumentando la afluencia de pacientes, en particular en el Papanicolaou, y en otros programas donde en realidad estábamos con coberturas bajas ... pero esto es un proceso, todavia hay que ver cómo va adelante, ¿no?, pero sí, lo que nos ha gustado más es el empoderamiento de las señoras en el aspecto de conocer sus derechos de salud. (Director del Centro de Salud de El Alto).

Finalmente, el proceso permitió que se entablara un diálogo y se estableciera coordinación entre los líderes y las autoridades (subalcaldes, supervisores de centros de salud, responsables del Programa de Salud Sexual y Reproductiva, gerentes de los servicios departamentales de salud y demás), para encontrar soluciones a las necesidades identificadas y planificar actividades en otras instancias como las de los Comités de Análisis de Información (CAI) y las ferias de salud.

\section{LECCIONES APRENDIDAS}

\section{En cuanto a los grupos comunitarios}

- El proceso mostró que organizar a los grupos comunitarios es difícil y que se requieren equipos técnicos comprometidos y dispuestos a superar todas las barreras.

- Es importante identificar primero a los grupos ya organizados y seleccionar en ellos al líder del grupo.

- La mayor motivación para la participación en los grupos fue la metodología participativa aplicada y la posibilidad de tener relaciones horizontales con los servicios de salud. 
- Es importante plantear la necesidad de recursos comunitarios para sostener el trabajo en la comunidad desde el momento en que inicia la implementación de la metodología.

En cuanto a los líderes

- Al inicio del proceso, los líderes no estaban conscientes de que al cabo del tiempo ellos mismos tendrían que facilitarlo. La etapa de seguimiento de las actividades del plan de acción fue el salto que los motivó a buscar los resultados que se planificaron.

- Tomar en cuenta a los líderes reconocidos en las comunidades facilita poner en marcha la metodología.

- El fortalecimiento y el seguimiento continuos de los líderes propicia su empoderamiento.

En cuanto al personal de salud

- Es fundamental buscar el apoyo y asegurar el compromiso de las gerencias de las diferentes redes de salud que trabajan en la comunidad respectiva para obtener buenos resultados.

- El "Plan de acción comunitario" es una actividad reveladora para muchos prestadores de salud, pues hace evidente la importancia de la vinculación de los centros de salud y la comunidad, permite visualizar las demandas comunitarias y demuestra que este espacio puede ser un canal de comunicación efectivo.

En cuanto a la metodología

- Se confirmó que la metodología es efectiva porque permite que los miembros de la comunidad superen el miedo a relacionarse con otras personas y adquieran conocimientos útiles para superar problemas reales.

- Es importante mantener reuniones periódicas con las diferentes instancias para planificar y realizar las actividades optimizando recursos.

- Para favorecer el cumplimiento de compromisos se debe mantener un cuaderno de actas en el que se registren los acuerdos y compromisos.

\section{Referencias}

1. Instituto Nacional de Estadística. Encuesta Nacional de Demografía y Salud. Bolivia, 2003. 


\section{ANEXO}

Organizaciones con trabajo en el tema de atención posaborto

- Alan Guttmacher Institute http://www.guttmacher.org

- Alianza por el Derecho a Decidir (Andar) http://www.andar.org. $m x$

- Centro de Investigación en Salud de Comitán http://www.cisc.org.mx

- Centro de Investigación Epidemiológica en Salud Sexual y Reproductiva http://www.ciesar.org.gt

- Consorcio APA

http://www.pac-consortium.org

- Engenderhealth

http://www.engenderhealth.org

- Equidad de Género, Ciudadanía, Trabajo y Familia, A.C. http://www.equidad.org.mx

- Family Care International

http://www.familycareintl.org

- Fundación Esar (Educación para la Salud Reproductiva)

http://www.fundacionesar.org 
168 Anexo 2 Avances en la atención posaborto en América Latina y el Caribe . . .

- Grupo de Información en Reproducción Elegida (GIRE)

http://www.gire.org.mx

- Instituto Chileno de Medicina Reproductiva (Icmer)

http://www.icmer.org

- International Planned Parenthood Federation/Western Hemisphere Region http://www.ippfwhr/org

- Ipas

http://www.ipas.org

- Johns Hopkins School of Public Health http://www.jhsph.edu

- JHPIEGO

http://www.jhpiego.org

- Marie Stopes International http://www.mariestopes.org.uk

- Organización Mundial de la Salud (OMS)

http://www.who.int y http://www.who.int/es/index.html

- Pathfinder International

http://www.pathfind.org

- Population Council

http://www.popcouncil.org y

http://www.popcouncil.org/frontiers/frontiers.html

- Population Reference Bureau

http://www.prb.org

- Planetwire

http://www.planetwire.org

- Red Latinaomericana de Católicas por el Derecho a Decidir http://www.catolicasporelderechoadecidir.org 


\title{
COMPAC
}

\author{
Información, tratamiento, calidad y análisis. \\ Herramientas sencillas para vigilar \\ y evaluar la calidad \\ de los servicios de atención posaborto
}

\section{COMPAC facilita la creación, vigilancia y mejoramiento de los servicios de atención de calidad a mujeres en situación de aborto.}

Constituye un instrumento completo de evaluación formado por dos herramientas ampliamente relacionadas, que fueron diseñadas para registrar, vigilar y evaluar la calidad de la atención de mujeres en situación de aborto. Para ambos instrumentos, la recolección de datos es una tarea simple, rápida y de muy bajo costo. En los dos casos, los reportes finales son muy completos, sencillos y autogenerados, de modo que el usuario que interprete este análisis podrá modificar y mejorar, con acciones ajustadas a las necesidades, la atención de mujeres en situación de aborto en su servicio, hospital, sistema de salud, estado/provincia, país o subregión en el continente. Los formatos pueden ser completados en papel inicialmente y luego cargarse en el programa a nivel central o de otro establecimiento.

COMPAC-INFO es un sistema de vigilancia de los servicios que usa la información clínica registrada en el cuidado de las pacientes, produciendo reportes sencillos que permiten a los jefes de servicio, administradores y especialistas en salud pública conocer "en tiempo real" la información sobre los servicios de APA. Permite tomar decisiones informadas y dirigir los recursos de capacitación y económicos hacia donde son más operativos y útiles, a fin de brindar un servicio de mayor calidad y menor costo.

COMPAC-EVAL es una herramienta que incorpora la mayoría de los contenidos de EvalAPA, el programa original, con métodos mejorados para evaluar calidad de atención. Monitorea la calidad de atención postaborto a nivel de unidades de salud. Usa una lista de cotejo para recabar información sobre diferentes aspectos de la calidad de atención y genera reportes gráficos sobre las áreas más problemáticas en donde la calidad necesita ser mejorada.

Para mayor información dirijase a:

Dr. Rodolfo Gómez Ponce de León, Asesor Superior de Sistemas de Salud, Unidad de TSDI, Tel: 1-919-9605573 y Maribel Mañibo, Coordinadora Técnica, Unidad R \& E Tel: 1-919-9605717 o a la dirección electrónica: compac@ipas.org_

Ipas, Chapel Hill, NC, EUA 



\section{Índice}

NOTA: Los números de página en negritas indican cuadros y en cursivas corresponden a figuras

A

Aborto(s), 42

aspectos técnicos, 143

atención,

a sus complicaciones, 151

de mujeres en situación de, 85

capacitación del personal hospitalario, 16

clandestino, 7, 41, 65

completos, 121

complicaciones, 49

complicado, 43

consejería en la atención, 87

costos de oportunidad, 17

de alto riesgo, 4, 5

de embarazo muy deseado, 117

diferido, 101, 107

duración promedio de estancia, 17

electivos, 21

en adolescentes, 138

en condiciones de inseguridad y clandestinidad, 41

en curso, 58

en el segundo trimestre, 105

en México, 48

espontáneo, 8, 41, 66, 87, 108, 121, 152,155 incompleto, 5, 101, 121

AMEU para, 67

ingresos hospitalarios por, 35

misoprostol en el tratamiento del, 121

procedimientos para el tratamiento médico, 123

tratamiento, 3

inducido, 41, 48, 66, 73, 87, 152, 155

inevitable, 101

inseguro, 7, 41, 73, 92, 156

interacciones paciente-proveedor, 16

legal, 21, 48, 65

legalmente restringido, 12

legislación del, 65

lucha contra el, 27

manejo expectante, 108

morbilidad, 7

mortalidad, 7

mujeres en situación de, 87, 169

óptica religiosa del, 157

orientación psicológica en, 79

percepciones comunitarias, 151

periodo posintervención, 14

prevención de infecciones, 92

procedimientos y técnicas para manejo

ambulatorio, 92

proveedor de servicios, 92 
provocado, 41, 121

sentimientos de la mujer, 88

séptico, 101

servicios de admisión o urgencias, 85

tratamiento de las complicaciones, 143

Abuso sexual, 143

Acetominofén, 113

con codeína, 113

Actividad sexual, 138

Adrenalina, 116

AEEU (aspiración eléctrica endouterina), 102,104

AEU (aspiración endouterina), 101, 102

AINE (antiinflamatorios no esteroideos), 113

Alergia, 116

Alianzas comunitarias, 162

elaboración del plan de acción, 162

evaluación participativa, 162

implementación y seguimiento, 162

organización, 162

Altura uterina, 101

AMEU (aspiración manual endouterina), $5,8,11,28,36,42,47,58,67,75$, $76,86,91,101,103,121,143$

Aminoamida, 115

Anafilaxia, 116

Analgésicos

intramusculares, 113

intravenosos, 113

locales, 112

orales, 112,113

parenterales, 112, 113

Anestesia, 112

general, 13, 105, 112

local, 103, 112, 115

oral, 117

paracervical, 86

posaspiración, 119

regional, 105

Anestesiólogo, 31

no farmacológico, 117

Angustia, 87

Ansiedad, 14, 112

Antagonista naloxona, 114

Anticoncepción, 3, 20, 142

de emergencia, 5

de urgencia, 21 en Nicaragua, 57

posaborto, 32, 38, 44, 49, 92, 144

asesoria, 52

información, 52

posevento obstétrico, 44

Anticonceptivos, 4

en mujeres casadas, 65

inyectables, 60,70

orales, 60,70

posaborto, 12, 14

Antiinflamatorios no esteroideos, 113

APA (Atención posaborto), 3, 8, 35, 47, 57, $75,91,101,111,133,137,149,161$

Apoyo emocional, 86, 90

inmediato, 88

Asesoría anticonceptiva, 73

Aspiración

dolor posterior al proceso de, 119

eléctrica endouterina, 13, 102 riesgos y efectos secundarios, 104

endouterina, 101

por succión eléctrica, 101

por succión manual, 101

precauciones, 105

manual endouterina, 5, 42, 58, 67, 75, $76,86,91$

costo, 104

en cuanto a instituciones, 31

infraestructura y equipamiento, 31

procedimiento, 104

recursos humanos, 31

usuarias y comunidad, 31

Aspirador manual de plástico, 104

Atención

de mujeres en situación de aborto, 85

ginecoobstétrica, 13

materna, 62

materna-neonatal, 45

obstétrica, 62, 76

en República Dominicana, 75

posevento obstétrico, 42

Atención posaborto, 3, 65, 75

alianzas entre comunidad, 3

y proveedores de servicios, 139

amigable a la juventud, 137

apoyo,

a las mujeres en casa, 135

emocional durante, 4 
asistencia a los servicios de, 141

barreras en los servicios, 138

calidad,

de la consejería durante, 75

de los servicios de, 35, 169

consejería en el, 142

construcción de consensos, 11

costos, 53

de urgencia, 29

elementos esenciales, 3, 139

en adolescentes, 149

en América Latina, 7

en Bolivia, 161

en el primer nivel de atención, 44

en Guatemala, 35

en Honduras, 41

en México, 49

en las instituciones, 49

estudios sobre, 51

en Nicaragua, 57

en Perú, 65

calidad y acceso a la, 65

contexto, 65

en República Dominicana, 75

contexto, 76

en adolescentes, 149

recomendaciones, 80

en un escenario rural, 68,72

en un hospital urbano, 67,69

estudio de la situación, 58

estudios de, 10

experiencia de México, 47

experiencia en Bolivia, 27

herramientas sencillas para vigilar, 169

información, tratamiento, calidad y análisis, 169

intervenciones de base hospitalaria, 9

investigación operativa, 7

manejo del dolor, 111

material y métodos, 36

mejoramiento de los servicios, 47

metodología, 77

métodos de evacuación endouterina en, 101

métodos y hallazgos en, 10

modelo ampliado y actualizado, 3

muestreo,

conglomerado, 37

estratificado, 37 orientación y consejería, 3,4

participación de la pareja, 133

prevención secundaria, 20

procedimiento de, 93

proveedor de servicios, 143

razón fundamental de cada elemento esencial, 4

recomendaciones para políticas, 7

reorganización física de servicios, 11

servicios amigables a la juventud, 138

talleres para gerentes, 11

tiempos de estancia, 53

tratamiento clínico de pacientes en, 67

Autodiagnóstico, 162

\section{B}

Benzodiazepinas, 113, 115

Bloqueo paracervical, 13, 103, 112, 115

Broncoespasmo, 116

Centros de estudios sociales y demográficos, 149

Centros de Salud con médico, 45 rurales, 45

Cérvix, inervación sensorial del, 112

Cesárea, 42

CESDEM (Centro de estudios sociales y demográficos), 149

Choque hipovolémico, 121

CIPD (Conferencia Internacional sobre la población y desarrollo), 4, 8, 27, 47

Citología vaginal, 41

Clínica de ginecoobstetricia, 62 de planificación familiar, 62

Cólicos, 117 uterinos normales, 119

Comisión especial de comunidad del consorcio APA, 29

COMPAC, 169

COMPAC-EVAL, 169

COMPAC-INFO, 169

Complicaciones posaborto, 77

Conciencia deprimida, 114 
Condón, 60, 142

femenino, 144

masculino, 144

Consejería, 88

anticonceptiva, 145

trato digno y no discriminatorio, 90

Consejero

abierto, 89

características y cualidades, 89

dar validez a la usuaria, 89

empático, 89

escuchar activamente, 88

formular preguntas significativas, 89

identificar sentimientos, 89

parafrasear, 89

perfil profesional, 89

resumir y llegar a un acuerdo, 89

Consentimiento informado, 86

Consorcio atención postaborto, 78, 137, 152

Contracciones uterinas, 101

Crisis, 87

Cuidado

de la salud, 85

obstétrico de emergencia, 76

Culpa, 87

Curetaje, 101

\section{D}

Declaración de principios sobre población y desarrollo sostenible, 27

Depresión, 112, 156

Derechos de salud, 165

Desesperación, 87

Diazepam, 115

Dilatación cervical, 101, 102 complementaria, 102

Dilatador cervical metálico, 102 plástico, 102

Dismenorrea, 112

Dispositivo intrauterino, 52, 59, 135 posaborto, 43 posparto, 43

DIU (dispositivo intrauterino), 52, 59, 135

Dolor, 87 agudo, 17 asociado al cuidado posaborto, 111 ausencia de, 113

componentes del, 111

control de, 112

del cuidado posaborto, 117

durante el proceso de aspiración, 118

elementos,

físicos, 111

psicosociales, 111

escala de nivel del, 113

leve, 118

lineamientos sobre manejo del, 111

manejo del, 111

aspectos no farmacológicos de, 116

métodos de control de, 112

moderado, 118

muy intenso, 113

percepción del, 116

posterior al proceso de aspiración, 119

preaspiración, 118

previo a la aspiración, 117

Edad

gestacional, 101

reproductiva, 65

Educación sexual, 154

y/o consejería, 144

EHP (estancia hospitalaria promedio), 18 Embarazo, 87, 138

complicaciones hemorrágicas de la primera mitad de, 91

ectópico, 103

extrauterino, 103

hemorragias de la primera mitad del, 27

molar, 101

no deseado, 73

no planeado, 7,78

prevenir un, 154

Enfermedades

de transmisión sexual, 5, 41, 78

del tracto gastrointestinal, 107

Enfermera, 85

en servicios de ginecoobstetricia, 85 funciones, 85

Enfermería, 31 
Escala

de dolor, 112

de nivel del dolor, 113

Estancia hospitalaria promedio, 18

Esterilización femenina, 60

Esteroides, 116

ETS (enfermedades de transmisión sexual), 5,143

Evacuación endouterina, 101

aceptación por las pacientes, 103

costo, 103

efectos secundarios, 104

eficacia clínica, 103

método adecuado de, 103

precauciones, 38

riesgos, 104

seguridad, 103

señales de peligro, 38

servicio, 37

tratamiento, 37

Evacuación uterina, 11, 14, 69

Evento obstétrico, 42

Examen

bimanual, 103

ecográfico, 121

F

Farmacias Institucionales Municipales, 31

Fecundidad, 14, 78

Federación Internacional de ginecología y obstetricia, 50

Fentanil, 114, 115

Fertilidad, 60

Fibras

parasimpáticas, 112

simpáticas, 112

FIGO (Federación Internacional de ginecología y obstetricia), 50

FIM (Farmacias Institucionales Municipales), 31

Flumazenil, 115

Fondo

de población de las Naciones Unidas, 76

uterino, inervación sensorial del, 112

FUM (fecha de la última menstruación), 103

\section{G}

Ginecología, 31, 50

Ginecoobstetras, 31, 49, 68

Gonadotropina coriónica humana, 108

Guía técnica sobre APA, 137

\section{H}

Hematómetra, 119

Hemorragias de la primera mitad del embarazo, 27, 91 obstétricas, 49, 53

Hipertermia severa, 124

Histamina, 115

Hospital del Ministerio de Salud, 57

Materno Infantil de Tegucigalpa, 42 urbano, 72

Hospitalización, 86

HPME (hemorragia de la primera mitad del embarazo), 27, 91, 162

Huevo anembrionado, 127

Ibuprofeno, 113, 119

Ideas de suicidio, 156

Infección

de transmisión sexual, 142

pélvica, 104

Infertilidad, 41

Inventario nacional de APA, 68

de servicios posaborto, 66

Inyecciones hormonales, 59

$\mathbf{L}$

Legrado, 101 uterino instrumental, 11, 28, 51, 58, $67,86,91,101,105$

aceptación por las pacientes, 106 costo, 106 seguridad y eficacia clínica, 106

Lesión

cervical, 104

uterina, 104 
Líderes, 166

Lidocaína, 115

Ligamentos uterosacrales, 112

Lorazepam, 115

Lucha contra el aborto, 27

LUI (legrado uterino instrumental), 11 , $28,51,58,67,86,91,101,105,143$

\section{M}

Madres solteras, 156

Malformaciones congénitas, 48, 107 genéticas, 48

Manejo expectante del aborto, 108

Manual de normas, reglas, protocolos para HPME, 32

Marie Stopes International, 117

Maternidad, 62

Matriz débil, 155 infantil, 155

Matronas, 14

Medicamentos ansiolíticos, 113

Medicina, 31

Médicos generales, 31

Meperidina, 114

Metodología de la consejería, 88

Métodos anticonceptivos, 5, 8, 32, 42, 67, 77, 78, $133,135,153$

a mujeres en el posaborto, 59

del calendario, 135

del ritmo, 135

efectivos, 39

modernos, 58, 138, 154

naturales, 154

no clínicos, 141

peligrosos, 154

posaborto, 68

de control de dolor, 112

de evacuación endouterina, 101

de planificación familiar posaborto, 70

farmacológicos,

aceptación por las pacientes, 108

costo, 108

eficacia clínica, 107

seguridad, 107
Metrotexato, 13

Midazolam, 115

Miedo, 87

Mifepristona, 13, 107

Minilaparotomía, 50

Ministerio de Salud, 28, 152

Pública, 91

Pública y Asistencia Social de Guatemala, 35

Miomas, 123

Misoprostol, 13, 102, 107, 121, 122

complicaciones, 124

contraindicaciones, 123

dosis recomendadas, 124

efectos secundarios, 124

del tratamiento con, 126

indicaciones, 122

precauciones, 125

tiempo hasta conseguir el efecto, 124 vías, 124

Modelo

de atención a las HPME, 30

integral de calidad, 28

Morfina, 114

Mortalidad infantil, 28

materna, 28, 66, 161

en México, 49

MS (Ministerio de Salud), 152

MSI (Marie Stopes International), 117

MSP (Ministerio de Salud Pública), 91

Muerte materna, 35

Mujeres

en situación de aborto, 87

fértiles, 60

\section{N}

Narcóticos, 113 ansiolíticos, 114 intramusculares, 114 intravenosos, 114 parenterales, 114

Nervio hipogástrico, 112

Norma nacional de atención materna-neonatal, 45 
0

Observación de pares, 91, 94

protocolo, antes de la intervención, 94 después de la intervención, 94

Obstetrices, 14

Obstetricia, 31

OMS (Organización Mundial de la Salud), 7,101

Opioides, 113

OPS (Organización Panamericana de la Salud), 76

Organización Mundial de la Salud, 7, 101, 108, 137

Organización Panamericana de la Salud, 76

Orientación psicológica, 79

Ovulación posaborto, 38

$\mathbf{P}$

Pacientes posaborto, 15, 17

ambulatorias, 17, 19

apoyo emocional, 86

estado emocional, 85

hospitalizadas, 17

PAE (pastillas anticonceptivas de emergencia), 145

Papanicolaou, 165

Parto, 42

Pastillas anticonceptivas de emergencia, 145

Pathfinder, 91, 152

International, 28, 97

Personal

de enfermería, 85

de salud, 166

hospitalario, 16

Plan

de acción comunitario, 166

operativo anual, 164

vida, 28

Planificación familiar, 4, 66, 144

normas de, 60

posaborto, $15,29,70$

Plexos ováricos, 112

POA (Plan operativo anual), 164
Población indígena, 51

Population Council, 42

Procedimiento de evacuación uterina, 17, 93

Programa

de planificación familiar, 81

IMSS Oportunidades, 51

Prostaglandinas, 113

Proyecto

CATALYST, 152

de Salud Reproductiva del Population

Council, 152

Pseudoefedrina, 116

Psicólogos, 31

Q

Quirófano, 86

\section{$\mathbf{R}$}

Refrescamiento, 92

Relaciones sexuales, 17 premaritales, 138

Relajación, 117

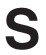

Sala

de expulsión, 86

de labor, 86

de recuperación, 86

Salud

de la mujer, 134

emocional posaborto, 80

física posaborto, 80

reproductiva, 3, 4, 41, 50, 66, 138, 140, 144

del Population Council, 43

en Bolivia, 161

sexual, 4, 138

en Bolivia, 161

Sangrado, 17

SBS (Seguro Básico de Salud), 91

Secretaría de Salud, 42, 47, 49,

Sedación, 114

consciente, 115

fuerte, 13

intravenosa, 112 
leve, 103

ligera, 13, 14

profunda, 114

superficial, 103

Seguro

Básico de Salud, 28, 91

Nacional de Maternidad y Niñez, 28

Universal Materno Infantil, 91, 164

Servicios

anticonceptivos, 140

clandestinos de aborto inducido, 73

de anticoncepción, 5 posaborto, 14

de atención posaborto, 158

de planificación familiar, 5, 140, 144

de salud reproductiva, 5, 41, 145, 152

ginecoobstétricos, 71

posaborto del sector público, 66

Sexo, 153

Sexualidad, 141, 153

SIDA (síndrome de inmunodeficiencia adquirida), 4, 78

SILAIS (Sistema de Atención Integral de Salud), 58

Síndrome de Asherman, 122

de inmunodeficiencia adquirida, 4 de Mobius, 107 posaborto, 119

Sinequias uterinas, 122

Sistema de Atención Integral de Salud, 58

EvalAPA, 68

hospitalario, 44

InfoAPA, 68

Nacional Único de Suministros, 31

Suicidio, 156

SUMI (Seguro Universal Materno Infantil), 91, 164

\section{$\mathbf{T}$}

Talleres de refrescamiento, 93

Tasa de mortalidad materna, 66

Técnica AMEU, 80

Tinnitus, 116

TMM (tasa de mortalidad materna), 66

Tracto gastrointestinal, 107

Tratamiento posaborto, 14, 20

UNFPA (Fondo de Población de las Naciones Unidas), 76

Unidad de urgencias ginecoobstétricas, 71 tocoquirúrgica, 86

Urgencias obstétricas, 4,76 posaborto, 151

Urticaria, 116

USAID (Agencia de los Estados Unidos para el Desarrollo Internacional), 76, 91,161

Útero, inervación sensorial del, 112

V

Vasectomía sin bisturí, 50

Vasopresina, 116

Vértigo, 116

Vida reproductiva, 88 sexual, 88

VIH (virus de inmunodeficiencia humana), 4, 78, 143

Violación, 48

Violencia de género, 143

Virus de inmunodeficiencia humana, 4 

Esta obra se imprimió el

31 de agosto de 2007 en los talleres de

Programas Educativos, S.A. de C.V.,

Calz. Chabacano núm. 65, Local A,

Col. Asturias, 06850

Empresa certificada por el

Instituto Mexicano de Normalización y Certificación, A. C., bajo la Norma ISO-9002:1994/NMX-CC-04:1995, con el número de registro RSC-048,

y bajo la Norma ISO-14001:1996/SAA-1998, con el número de registro RSAA-003, México, D. F. 


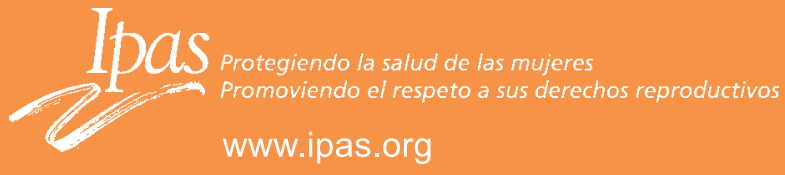

\section{(P Population Council www.popcouncil.org}

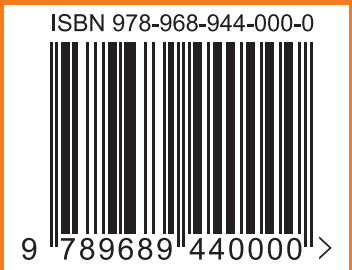

